\title{
A fresh outlook on the smooth-spored species of Inocybe: type studies and 18 new species
}

\author{
Ditte Bandini ${ }^{1} \cdot$ Bernd Oertel $^{2} \cdot$ Ursula Eberhardt $^{3}$ (B) \\ Received: 16 April 2021 / Revised: 21 May 2021 / Accepted: 26 May 2021 \\ (C) The Author(s) 2021
}

\begin{abstract}
On the basis of detailed morphological and molecular investigation, eighteen new species of Inocybe (I. alberichiana, I. beatifica, I. bellidiana, I. clandestina, I. drenthensis, I. dryadiana, I. gaiana, I. ghibliana, I. grusiana, I. knautiana, I. lampetiana, I. oetziana, I. orionis, I. plurabellae, I. rivierana, I. scolopacis, I. sitibunda and I. tiburtina) are described. All of them are smooth-spored, and most of them are pruinose only in the apical part of the stipe. The new species are compared to 40 type specimens, all of which are described here and for several of which (partial) ITS sequences have been generated. For eight species, epi-, lecto- or neotypes were selected, among these are I. geophylla, I. glabripes and I. tigrina. Based on these studies, we suggest twelve synonymies, i.e. that I. clarkii is synonymous with I. sindonia, I. conformata with I. cincinnata, I. elegans with I. griseolilacina, I. fuscidula with I. glabripes, I. griseotarda with I. psammobrunnea, I. obscurella with I. obscuroides, I. obscuromellea with I. semifulva, I. patibilis and I. tigrinella with I. tigrina, I. petroselinolens with I. tenuicystidiata and I. rubidofracta with I. pseudorubens and I. subporospora is synonymized with I. tjallingiorum. All of the new species are supported by phylogenetic analyses. Among the previously described species accepted here, sixteen are represented by types in the phylogenetic analyses and ten by own collections morphologically corresponding to the type. In summary, we here verify or provide morphological concepts associated with molecular data for 44 smooth-spored species of Inocybe.
\end{abstract}

Keywords Agaricales $\cdot$ Inocybaceae $\cdot$ Inocybe $\cdot$ Molecular systematics $\cdot$ Alpha taxonomy

\section{Introduction}

Until recently, the family Inocybaceae consisted of the genera Inocybe (Fr.) Fr., Auritella Matheny \& Bougher and Tubariomyces Esteve-Rav. \& Matheny (see e.g. Latha et al. 2016). The genus Inocybe was divided into the subgenera Mallocybe Kuyper, Inosperma Kühner and Inocybe (Kuyper

This article is part of the Topical collection on Basidiomycote Mycology in honor of Franz Oberwinkler who passed away in March 2018.

Section Editor: Zhu-Liang Yang

Ditte Bandini

ditte.bandini@gmx.de

Ursula Eberhardt

ursula.eberhardt@smns-bw.de

1 Wiesenbach, Germany

2 Alfter, Germany

3 Staatliches Museum für Naturkunde Stuttgart, Rosenstein 1, 70191 Stuttgart, Germany
1986; Stangl 1989; Bon 1997, 1998), or according to Matheny and Kudzma (2019), in the five major clades, Inocybe, Inosperma, Mallocybe, Nothocybe and Pseudosperma. Matheny et al. (2020) raised these five clades to the rank of genera, as Inocybe (Fr.) Fr., Inosperma (Kühner) Matheny \& Esteve-Rav., Mallocybe (Kuyper) Matheny, Vizzini, EsteveRav., Nothocybe Matheny \& K.P.D. Latha and Pseudosperma Matheny \& Esteve-Rav. Thus, following Matheny et al. (2020), the family Inocybaceae now consists of seven genera.

The genus Inocybe, to which the species treated here belong, is by far the most species-rich of the seven genera. Worldwide, the estimated number is 850 species according to Matheny et al. (2020). However, taking into account how many new species were described just in the last few years from all over the world (see for instance Horak et al. 2015; Franchi et al. 2016; Vauras and Larsson 2016a, b; Bizio et al. 2016, 2017; Latha and Manimohan 2017; Matheny and Bougher 2017; Esteve-Raventós et al. 2015, 2016, 2018; Larsson et al. 2018a, b; Cripps et al. 2019b; Matheny and Kudzma 2019; Bandini et al. 2017, Bandini et al. 2019a, b, c, 2020a, b, c), and given the fact that there are many parts of 
the world, as for instance China, where there are no reliable estimates for the actual number of species (see e.g. Fan et al. 2018; Fan and Bau 2010, 2013, 2020), the total number of species will probably exceed the number cited above by far.

Even though the nodulose-spored species of Inocybe are still far from being 'done' and not all taxa have been re-studied yet by morphological and molecular means, in Europe, in the last decade, great progress has been made (see for instance Kokkonen 2011; Esteve-Raventós et al. 2015, EsteveRaventós et al. 2016, Esteve-Raventós et al. 2018; Larsson et al. 2018b; Cripps et al. 2019b; Bandini et al. 2019a, $2020 \mathrm{a}, \mathrm{b})$. Although some studies have been published on smooth-spored species (e.g. Vauras and Larsson 2016a, b; Larsson et al. 2014, 2018a; Bandini et al. 2019a, b, c, 2020a; Dovana et al. 2021; Mešić et al. 2021), these taxa have received less attention, at least in terms of molecular studies. Comprehensive articles by Carteret and Reumaux (e.g. 2012, 2013, 2017), in which mainly or only smooth-spored species are described, or the long chapter about inocybes in Ludwig (2017), are based solely on morphological examinations and were largely done without accompanying type studies.

All species treated here belong to Inocybe ss. str., characterized, e.g. by mostly thick-walled cheilocystidia and the presence of mostly thick-walled pleurocystidia, and they all are smooth-spored. Some of the species have metuloid caulocystidia only near the apex, others form-albeit sparsely - metuloid caulocystidia on the entire length of the stipe. Among the about 470 'morphospecies' of this genus we have encountered in Germany and adjacent countries, ca. 310 are smooth-spored and 140 are nodulose spored. In around 20 of these species, there appears to be no fundamental morphological distinction between nodulose and smooth-spored species (see also Kuyper 1986), e.g. I. ambigua Romagn., I. helobia (Kuyper) Bandini, B. Oertel \& U. Eberh., I. pluppiana Bandini, B. Oertel \& U. Eberh. or I. diabolica Vauras - the spores of which can be called neither smooth nor nodulose. Phylogenetically, there is also no clear distinction between smooth and nodulose-spored species (e.g. Matheny 2009; Ryberg et al. 2010).

One of the challenges with respect to the smooth-spored species is that quite a number of these were synonymized by Kuyper (1986), following a trend of those years to lump species. This led to a simplification of in truth rather complex matters, as we show here. To name only some groups, this concerns not only the smooth-spored species with brown caps, but also those with more reddish-brown caps around the species I. nitidiuscula (Britzelm.) Lapl., and those with lilac or pinkish stipe, or those around I. geophylla (Bull.) P. Kumm. (see Matheny and Swenie 2018), or the Splendentinae (Kropp et al. 2010; Bandini et al. 2019c), all of which comprise several more species than are considered in Kuyper's work.

A further difficulty has been already mentioned above: It is sometimes not at all easy to decide whether a species has an entirely pruinose stipe - a crucial question in the existing keys (e.g. Kuyper 1986; Stangl 1989; Bon 1997, 1998)—or not. There are species where, in many collections, metuloid caulocystidia are only very sparely present in the lower half, while in others they are quite abundant. This is for instance the case in I. furfurea Kühner or I. leochroma Bandini, Vauras \& B. Oertel (Bandini et al. 2019b).

This study is a contribution to the ongoing revision of the smooth-spored species of the genus Inocybe. The selection of species treated here is driven by morphological considerations. We here accept 26 species of which the types have been studied and, if possible, sequenced. In three cases, I. geophylla, I. glabripes and I. tigrina, new types were designated from own material for old and well-known names, in order to be able to unravel the relationships to other, similar taxa. Eighteen species were described as new that emerged as unnamed after having studied all relevant types. As far as possible and permitted, sequence information (ITS, occasionally LSU) was generated from types. For the remaining accepted species, we tried - and succeeded in all cases but two - to find morphologically analysed collections that closely correspond to the types for the generation of 'verified' sequence data, to also give these species a barcode and to be able to place it in phylogenetic analyses.

Species that are described here as new differ from existing species by the combination of at least three independent characters that are constant among representatives of the new species, and the representatives of the new species are monophyletic in phylogenetic ITS (ITS+LSU) analyses. If constant ecological differences between new species and existing species could be recognized, they were also considered meaningful, but we did not describe species based on ecological or ITS differences, without morphological differentiation. Species were synonymized, if the overall impression of the species was very similar, if no constant characters could be found that separated the two species and if neither pronounced ecological preferences nor molecular data (if available) indicated that the two species might be cryptic.

\section{Material and methods}

Fresh material was obtained on a number of forays in Austria, Finland, France, Germany, Netherlands and Switzerland between 2011 and 2020. Type material was loaned from various herbaria. For fresh collections, the relevant macroscopic details, i.e. habit, size and shape of the basidiomata, colour and surface of the pileus, number, colour and edge-type of lamellae, size, colour, surface and base of the stipe, smell and colour of flesh, colour of exsiccata, habitat and surrounding trees, were noted. 
For all collections - if possible in the fresh, otherwise in the dried state - basidia, spores, hymenial cystidia, caulocystidia etc. were examined by D. Bandini with a Leica DM-750 microscope in water and 3\% $\mathrm{KOH}$ solution, at 400 and 1000 magnifications. Photographs of microdetails have been taken with a Zeiss AxioCam ERc5s. The measurements of spores and cystidia were determined using Zeiss Axiovision version 4.8. Cystidia were measured without crystals and basidia without sterigmata. The size of all elements measured is given as length $\times$ width. The $Q$ value equals the ratio of spore length to spore width (calculated for each spore). The number of spores or cystidia measured is included in the description.

Pictures of fresh collections, thus all photographs of basidiomata on the plates, were taken by D. Bandini with a Panasonic Lumix GH2 with a Leica DG Macro-Elmarit 1:2.8/ 45-mm lens. For the determination of the colour temperature, a calibration card was photographed together with the fresh collections at the collection site. The RAW files were developed with Silkypix Developer Studio 4.0.

Colour codes are taken from Munsell (2009, as 'Mu'), terminology follows Vellinga (1988) and Kuyper (1986). Herbarium acronyms are according to Holmgren et al. (1990), the acronym DB refers to the private herbarium of Ditte Bandini.

DNA was extracted from dried material following the protocol described by Cripps et al. (2019a). PCR amplification of the ITS follows Cripps et al. (2019a); for recent collections, the same PCR conditions were used to amplify larger fragments of ITS and nrLSU with standard primers (ITS1F, ITS4, ITS4B, LR0R, LR3, LR5; Vilgalys and Hester 1990; White et al. 1990; LoBuglio et al. 1991; Gardes and Bruns 1993). Bidirectional Sanger sequencing was carried out at LGC Genomics (Berlin, Germany). Sequences were assembled and edited using Sequencher vs. 4.9 (Genecodes). Newly generated sequences were submitted to GenBank with acc. no. MN319692, MW832697, MW 845855-MW845954, MW856425-MW856451, MW856453 and MW856454. Raw data for GenBank accessions MW845951-MW845954 and MW856425-MW856451 were generated by Alvalab.

For obtaining additional information on the habitat and distribution of new species, type sequences were BLASTed Altschul et al. (1990) against GenBank and UNITE (Kõljalg et al. 2005); sequence similarity or identity values were directly copied from BLAST results.

The selection of sequences and species considered in the alignment was driven by taxonomy. For species described here as new, several collections were sequenced for ITS and LSU. Representatives of published sequences putatively belonging to these taxa or very close relative of these taxa (i.e. > 97\% similar in BLAST results) were also included. For species for which we designated epi- or neotypes from our own collections, published sequences carrying the same name were included to illustrate the current use of the name. For species that were synonymized here, we included sequence data, from types (if available) or from material that had been morphologically analysed and considered to represent the same species. Based on the phylogeny presented by Matheny et al. (2020), Inosperma and Pseudosperma spp. where added for rooting.

The final alignment consisted of 303 sequences and 1975 positions. For 160 sequences, information for less than 1200 alignment positions was available, i.e. LSU information was largely missing. Multiple alignments were done online in Mafft using the E-INS-i option (Katoh et al. 2005, 2019). Alignments were viewed and reformatted using AliView 1.26 (Larsson 2014). The entire alignment was treated as a single partition. The alignment was analysed by ML and Bayesian Inference (BI). IQ-Tree vs 1.6 (Nguyen et al. 2015) was used to perform model testing under the Bayesian information (BIC) criterion (Kalyaanamoorthy et al. 2017), ML analysis with the selected model and ultrafast bootstrap (ufb) analysis (Hoang et al. 2018) with 5000 replicates online (Trifinopoulos et al. 2016).

Bayesian inference (BI) was run with MrBayes 3.2.7a (Ronquist et al. 2012) using BEAGLE (Ayres et al. 2012) on CIPRES (Miller et al. 2010). The BI analysis was done in two runs with four chains including one heated chain each, using the GTRINVGAMMA model and a uniform prior and sampling one tree of each run every 1000 generations. The analysis was stopped automatically after 5.466 million generations. The first $25 \%$ of trees were discarded as burn-in. The acceptance rates of chain swaps, the PRSF (potential scale reduction factor) for model parameters and taxon bipartitions indicated that convergence was reached (Ronquist et al. 2011). Trees were visualized using FigTree 1.4.4 Rambaut (2006-2018) and submitted to TreeBASE (accession no. TB2:S28073).

\section{Results}

The Taxonomy section lists new species as well as species type material of which has been re-studied. Species that we consider synonyms of older names are listed under the name accepted by us.

Sequences considered in Fig. 1 are listed in Table 1. In provisional analyses, all ITS and LSU sequences considered by Matheny et al. (2020) when splitting what used to be Inocybe were included in the analyses. These results (not illustrated) showed that the sequences of all taxa discussed here belonged to the genus Inocybe, and (without relevant support) that all are members of the 'smooth-spored temperate boreal clade' ss. Matheny et al. (2020). Members of this clade considered by Matheny et al. (2020) were scattered between clades of taxa considered here, demonstrating - as do the generally low support values close to the backbone of the tree- 


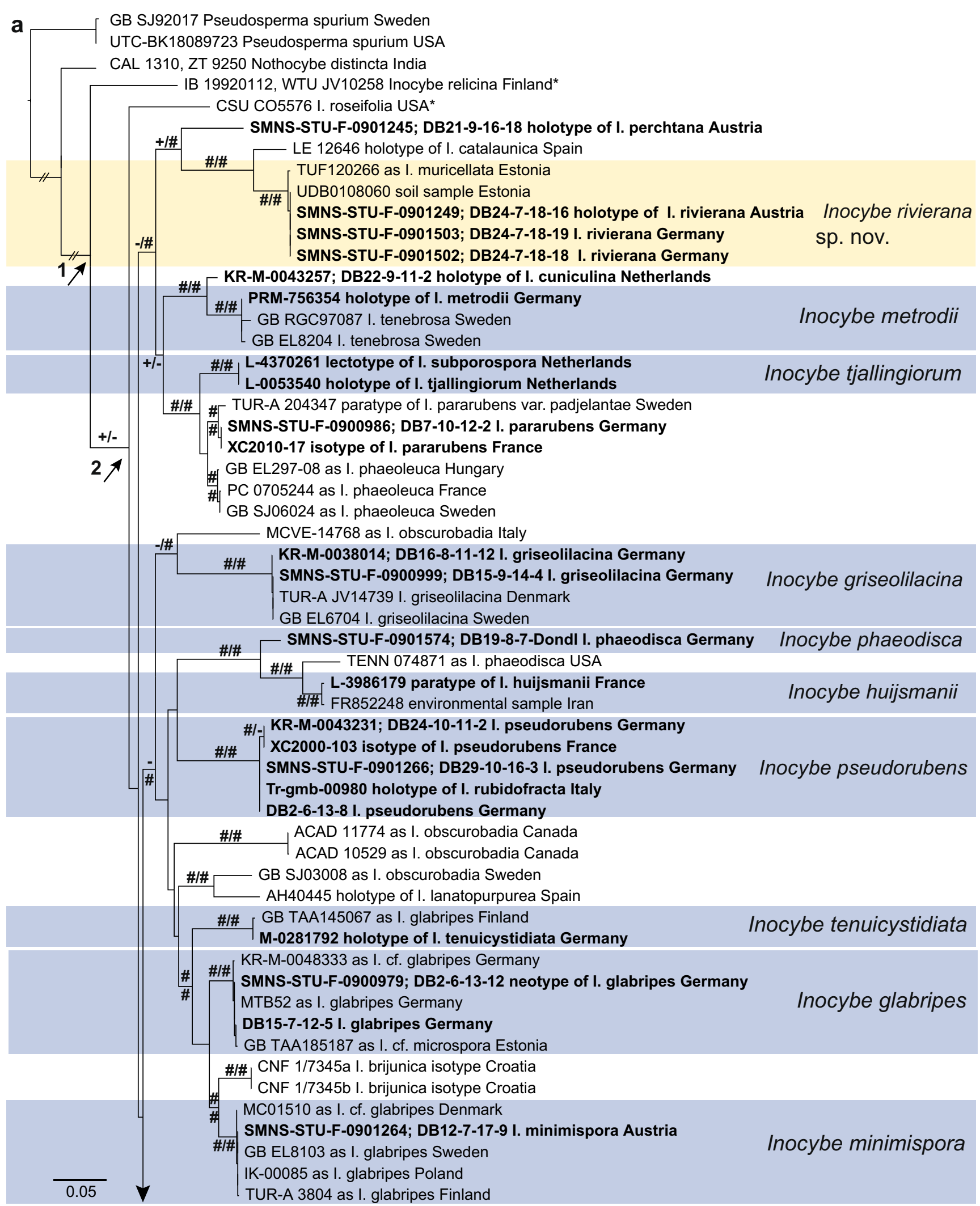

Fig. 1 a-f ML topology ITS and partial LSU sequences of the species of Inocybe treated or discussed here. Nothocybe distincta and Pseudosperma spurium are used for rooting. Clades of species that are described here as new are highlighted in yellow; species clades for which type material is described here are highlighted in blue. Material studied is in bold font. Sequences taken from Matheny et al. (2020) are indicated by*.
Arrow 1: Inocybe (genus); arrow 2: smooth-spored temperate boreal clade (STBC, see Matheny, 2009). Support values from 5000 replicates of ultrafast bootstrap (ufb) and posterior probabilities ( $\mathrm{pp}$ ) from two independent runs are indicated at the branches, \# indicating 100\% ultrafast bootstrap support or posterior probability of $1,+$ indicating values $\geq 98 \%$ ufb or $\geq$ $0.98 \mathrm{pp}$. The ufb value is given first 


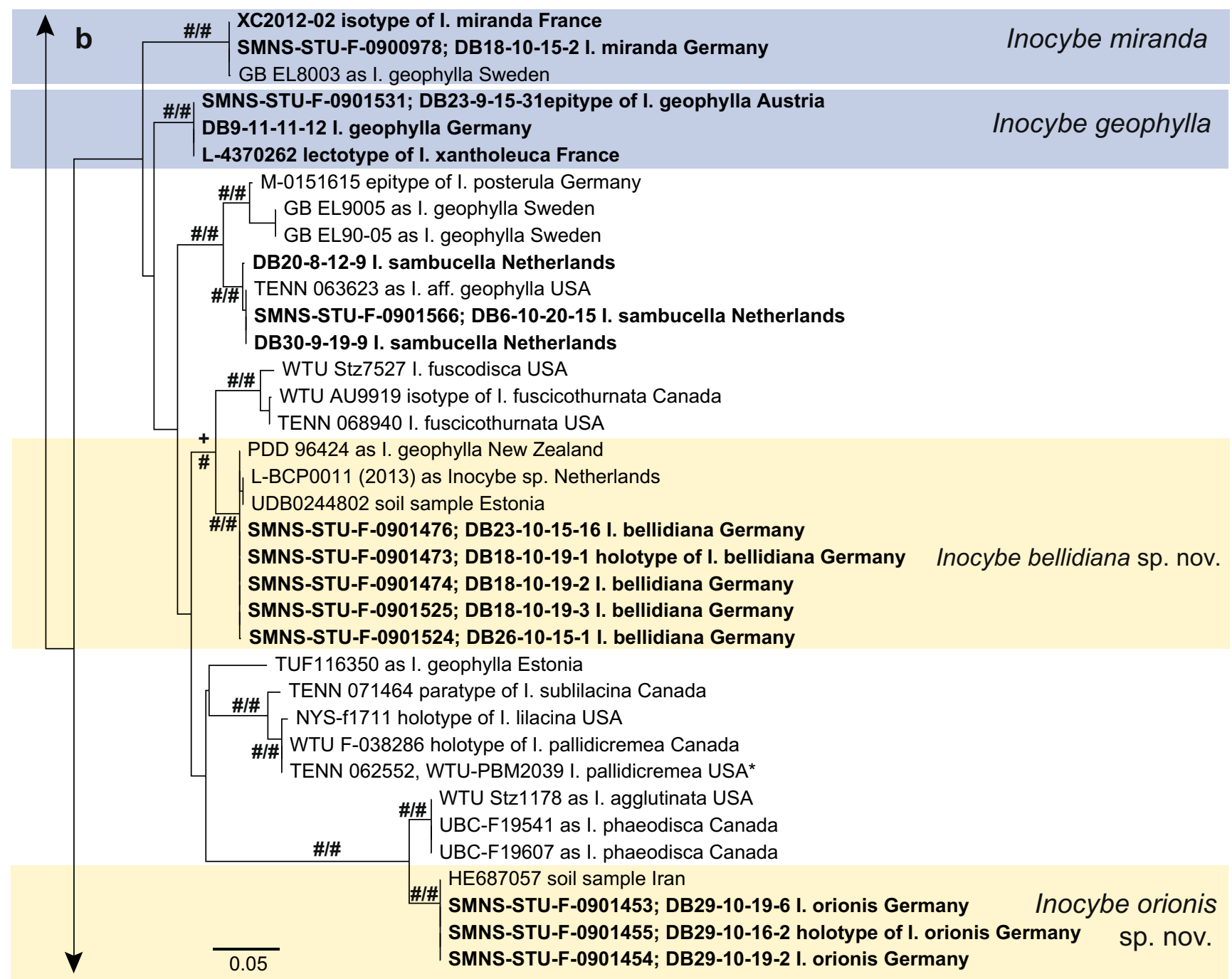

Fig. 1 (continued)

that the relationships between the subclades of Fig. 1 are unresolved.

The ML result was calculated under the GTR+F+R4 model; ultrafast bootstrap was run in 5000 replicates. The topology of the ML tree is shown in Fig. 1. The consensus tree resulting from the BI analysis differed from the depicted ML tree only in some unsupported clades (see TreeBASE submission). Posterior probabilities were based on 8200 trees and given in Fig. 1.

All of the species described here as new were monophyletic in relation to their closest relatives and all but $I$. alberichiana were reciprocally monophyletic in relation to their sister taxa. All species clades of new species apart from the I. grusiana clade were fully supported, i.e. received $100 \%$ ultrafast bootstrap support or a posterior probability of 1 (Fig. 1). The I. grusiana clade still received $96 \%$ ultrafast bootstrap support and a posterior probability of 0.98 . Thus, we consider all of the new species as supported by molecular data. Newly described species are highlighted in yellow in Fig. 1.

For eight species, new types (epi-, lecto- or neotypes) were selected here. In four cases (I. fuscidula, I. pusio, I. subporospora and I. xantholeuca), this was done because the holotype material was mixed; in one case (I. griseovelata), a lectotype was selected among syntypes. In three cases, I. geophylla, I. glabripes and I. tigrina types from own material were selected.

The synonymizations of I. tjallingiorum with I. subporospora, I. pseudorubens with I. rubidofracta and I. geophylla with I. xantholeuca as well as I. psammobrunnea with I. griseotarda, I. tigrina with I. patibilis and I. tigrinella were supported by sequence data of types from both/all three taxa. All are fully supported apart from the last. Inocybe tigrina still received 99\% ultrafast support and a posterior probability of 0.97 .

The 40 species types of which were studied correspond to 28 species. For 16 of these species, type sequence data was newly obtained or previously available (see Table 1). For ten 


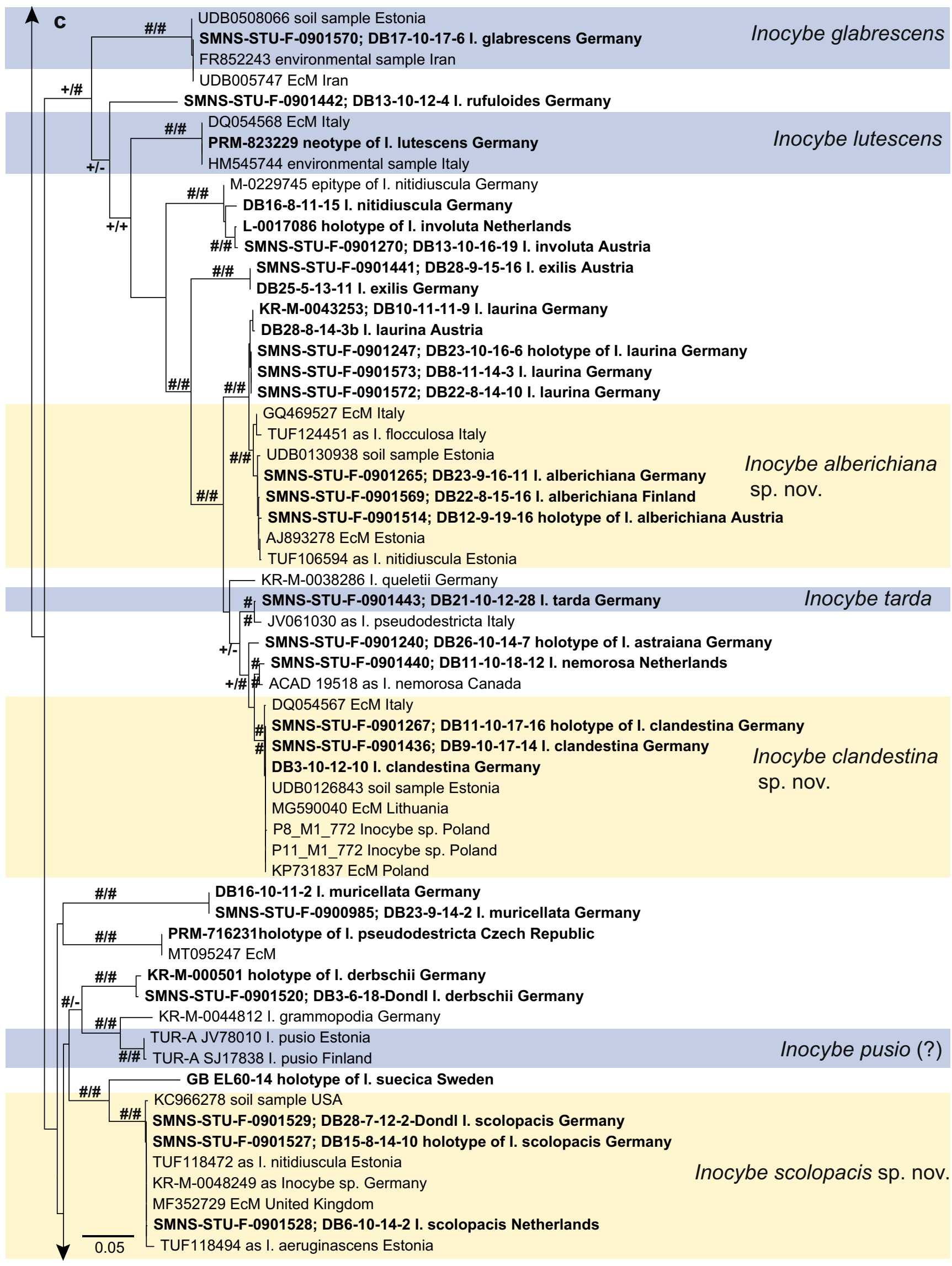

Fig. 1 (continued) 


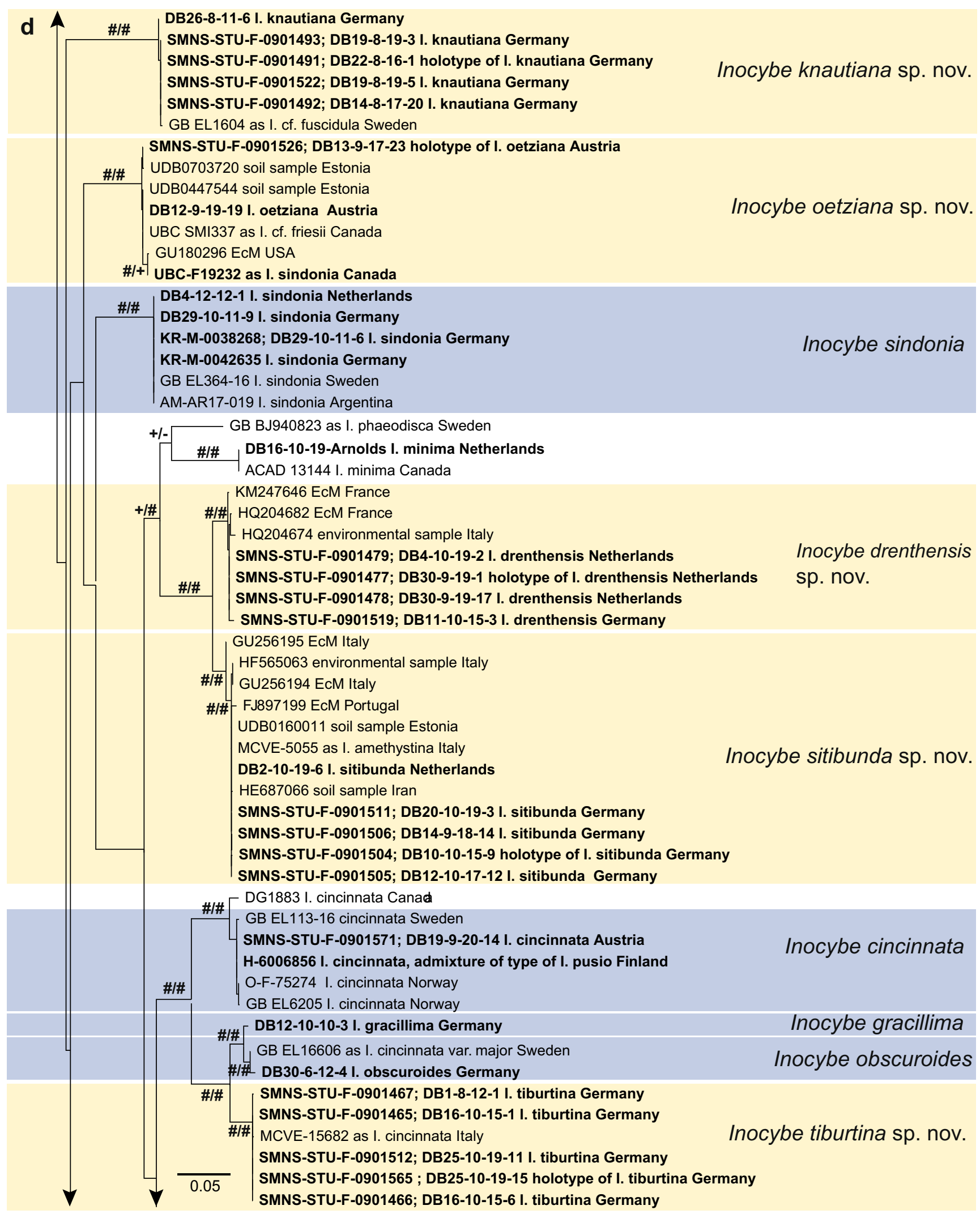

Fig. 1 (continued) 


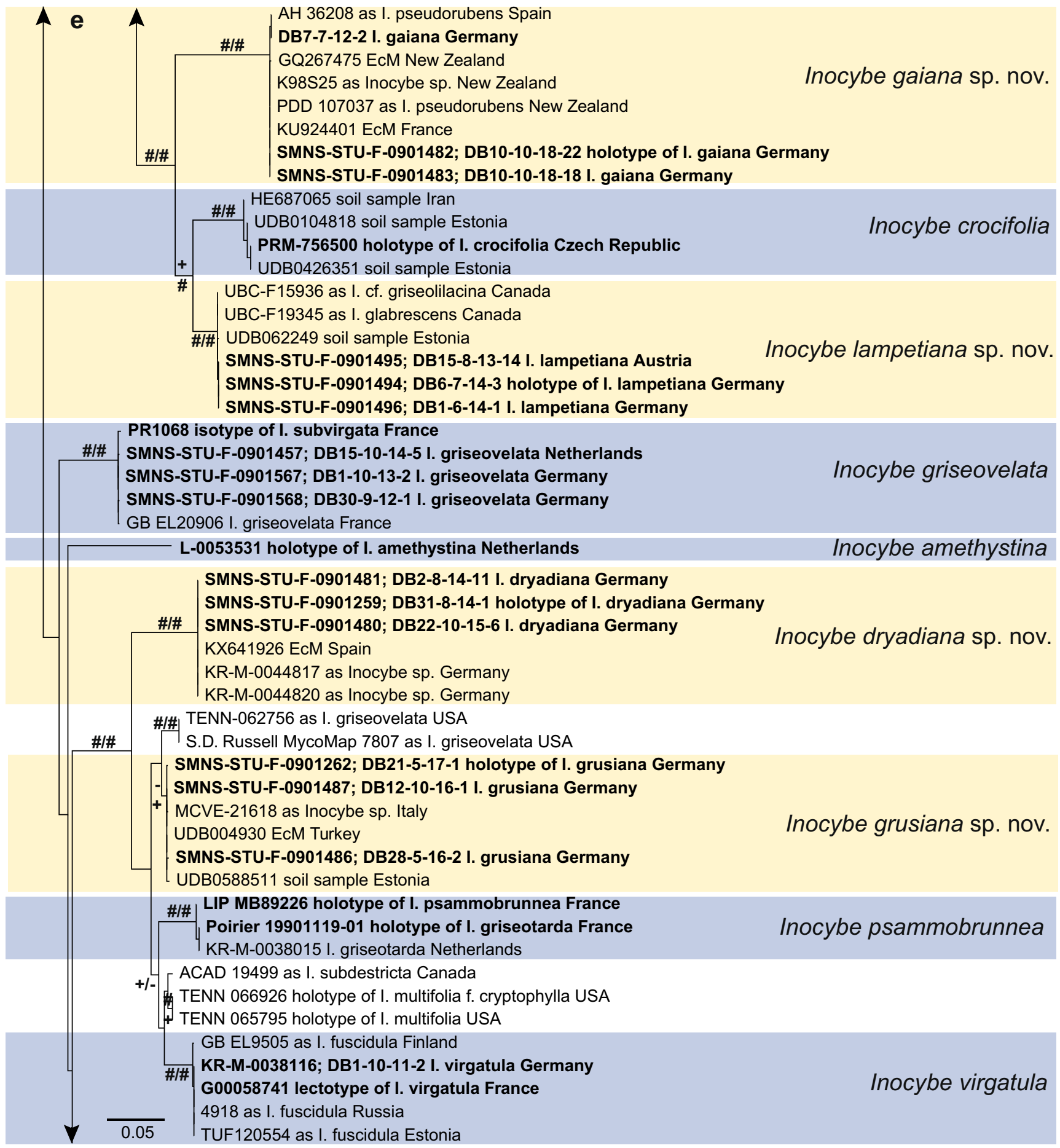

Fig. 1 (continued)

species, own collections were available that morphologically corresponded to types without sequence information. These collections represent the respective species in the phylogenetic analyses. These 26 species are highlighted in Fig. 1 in blue. Five species are represented by a single sequence; the remaining 21 species, with the exception of I. tigrina discussed above, are all fully supported (however, no attempt was made here to establish the full infrageneric variation of these taxa).
For two species, I. obscurobadia and I. pusio, we did not have sequence data from morphologically verified material available. The latter taxon might be represented by two sequences the vouchers of which were not studied here (see Fig. 1 and under I. pusio). Thus, only a single species, I. obsurobadia, remains for which the morphology could not be linked, not even tentatively, to a barcode or species clade. 


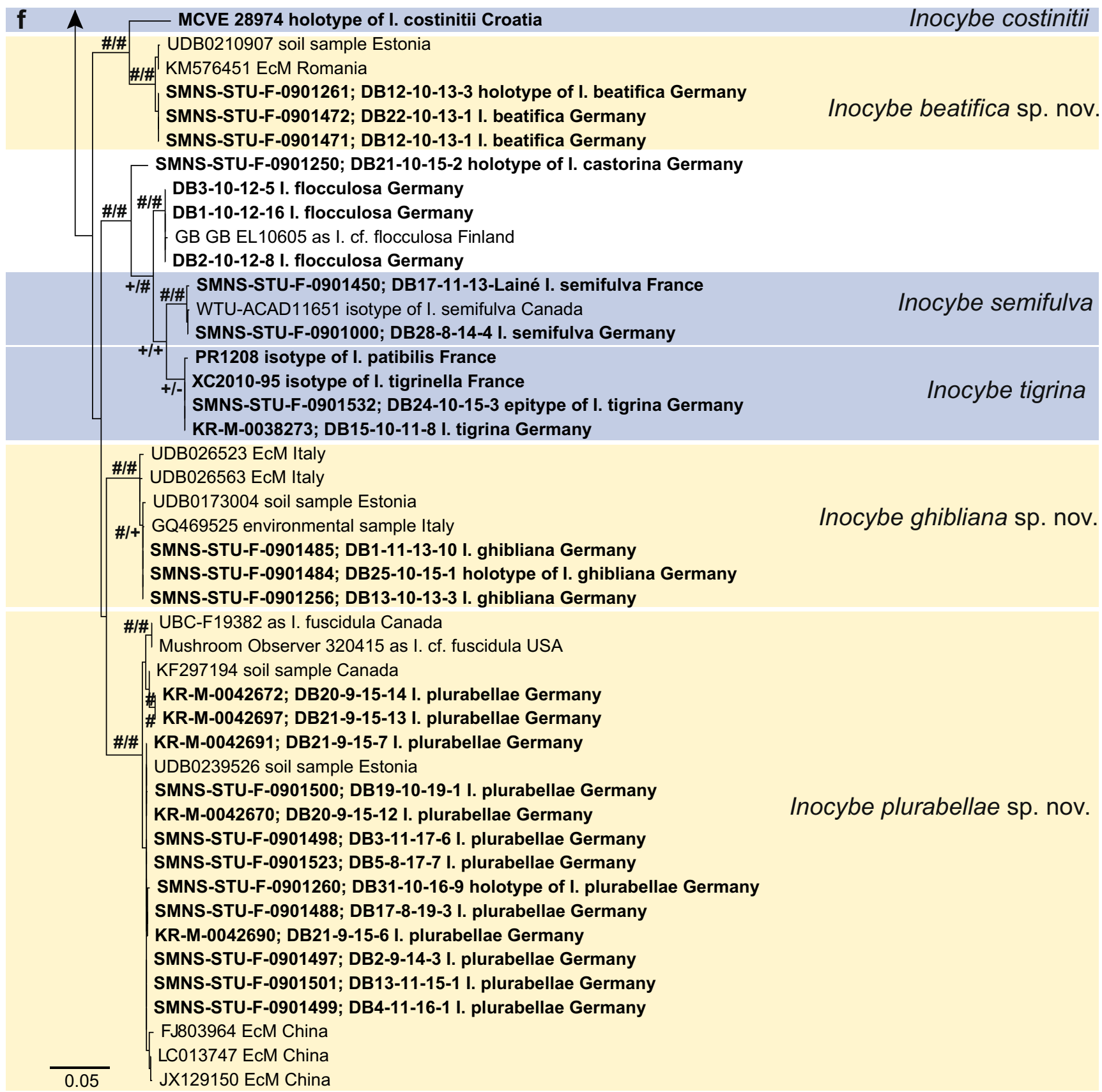

Fig. 1 (continued)

Species groups defined by morphological similarity, like the geophylla complex, the cincinnata-group or other associations of species made based on morphology (Tardae, species with lilac-pinkish stipes, the 'fuscidula-species' etc.) do often not or only in part appear as sister clades in Fig. 1.

\section{Taxonomy}

Species are arranged in alphabetical order.

Inocybe alberichiana Bandini \& B. Oertel sp. nov. Fig. 2
MycoBank number: MB 839151

Etymology: Named 'alberichiana' after the mythic dwarf Alberich, because of the smallness of the basidiomata.

Diagnosis: Inocybe alberichiana is a rather small species with a glabrous to rimulose reddish tinged brown pileus surface, brownish lamellae, becoming intensely ochraceous with age, a stipe which is pruinose only near the apex, smooth spores measuring 8.1-10.8 $\mu \mathrm{m}$ (av. 9.3 $\mu \mathrm{m}) \times 5.0-6.6 \mu \mathrm{m}$ (av. $5.6 \mu \mathrm{m}$ ), subfusiform to (sub)utriform hymenial cystidia, often with rather long and sometimes undate neck and mostly 


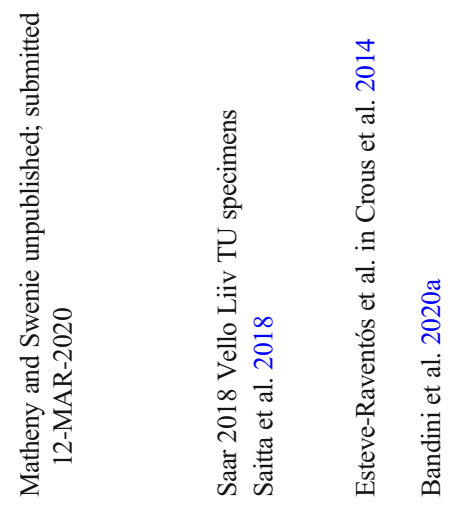

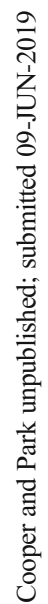

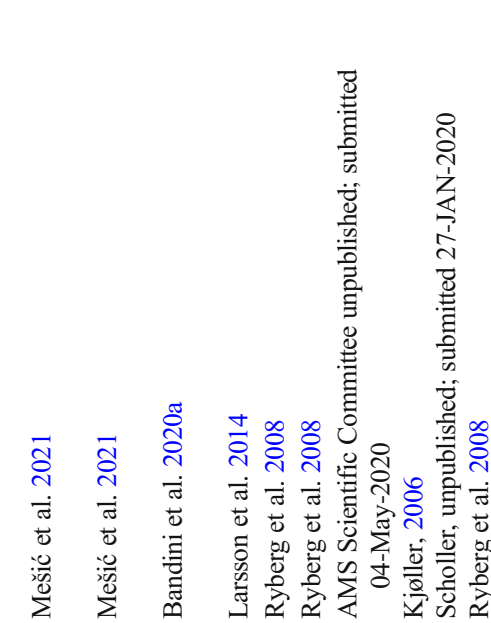

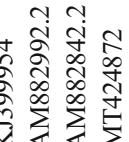

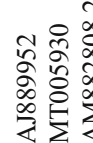

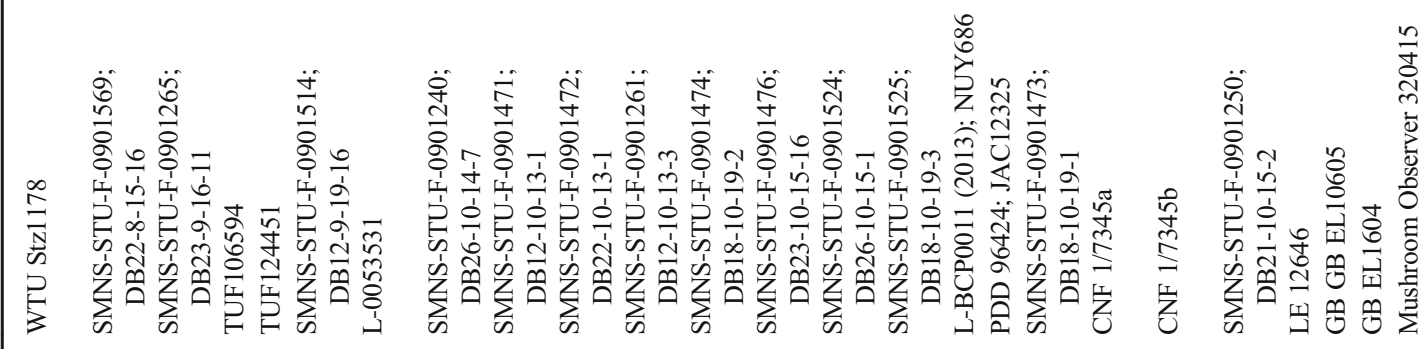

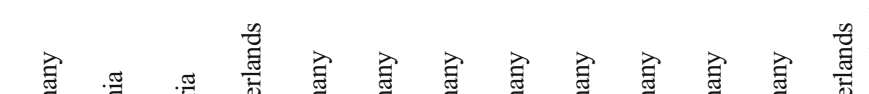
㞼 劳

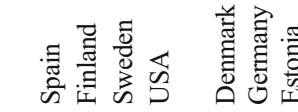
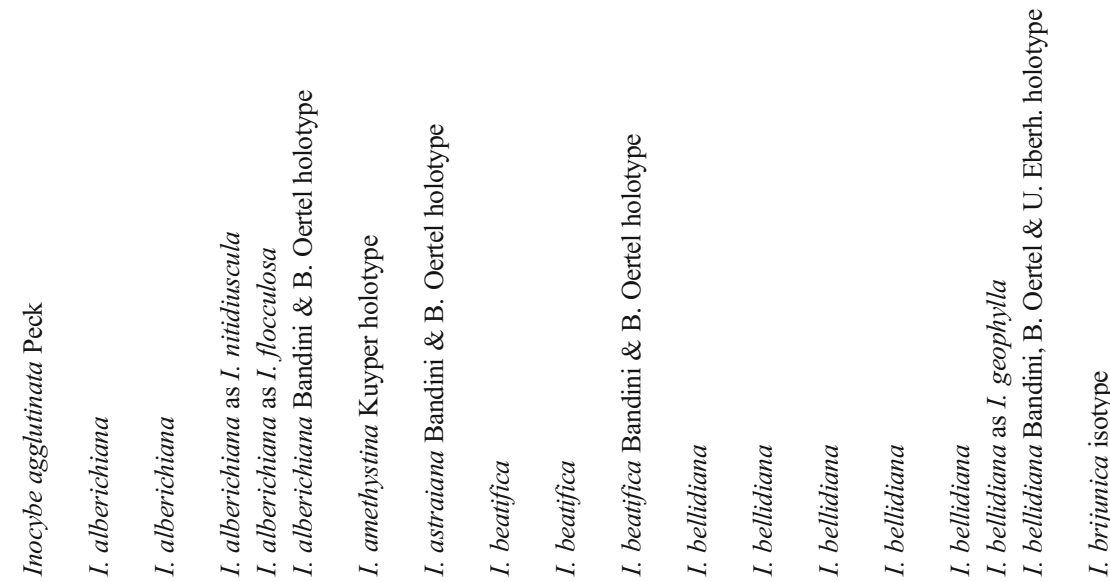


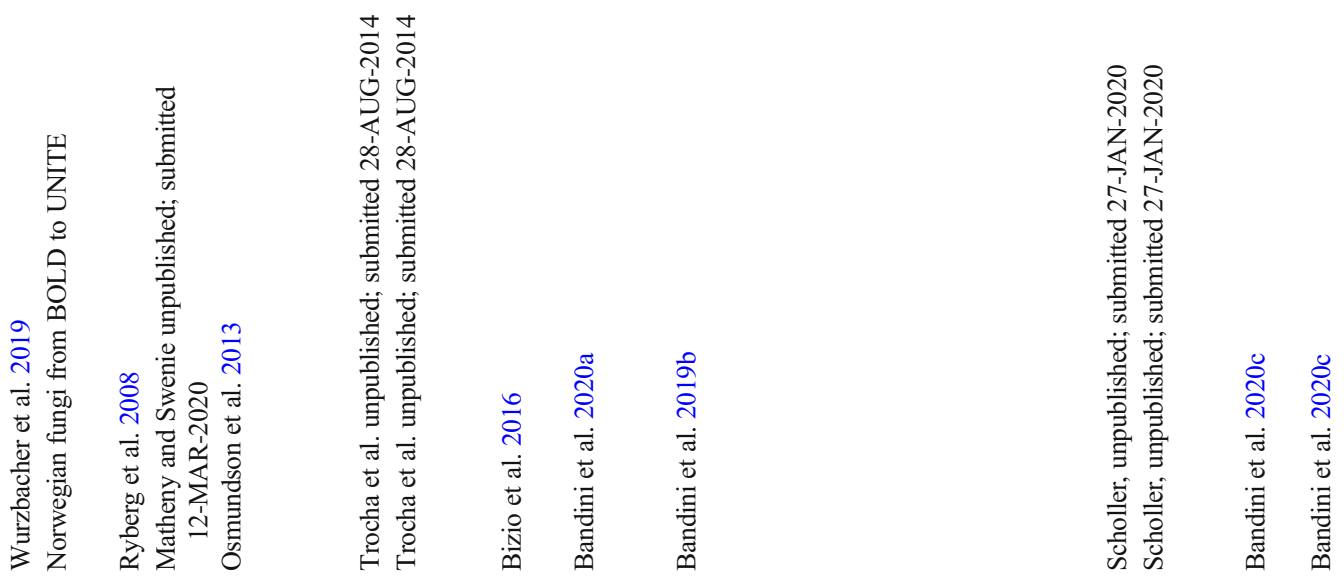

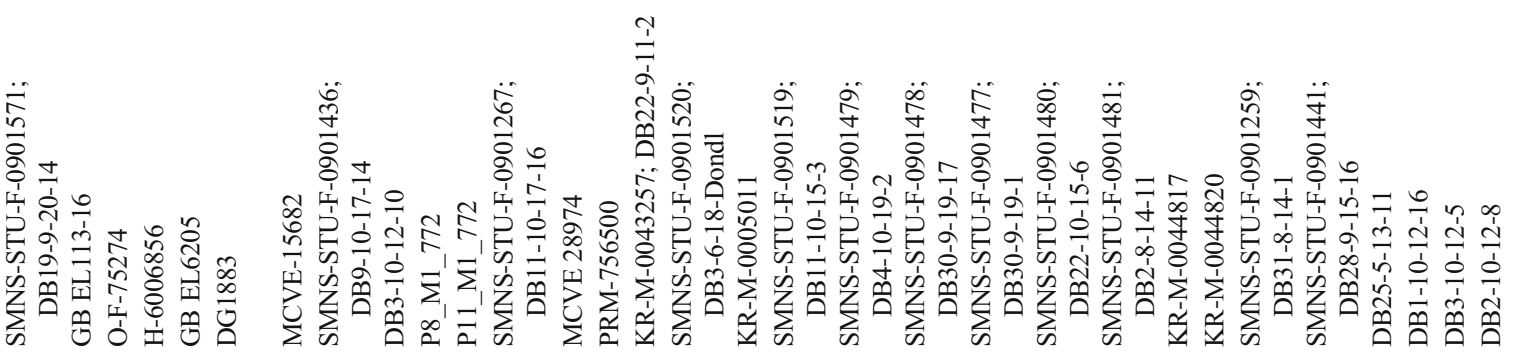

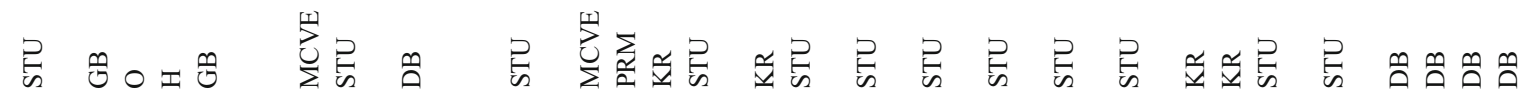

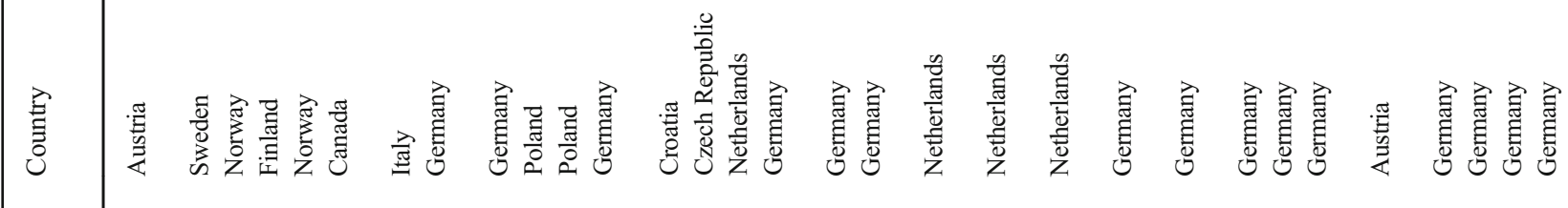
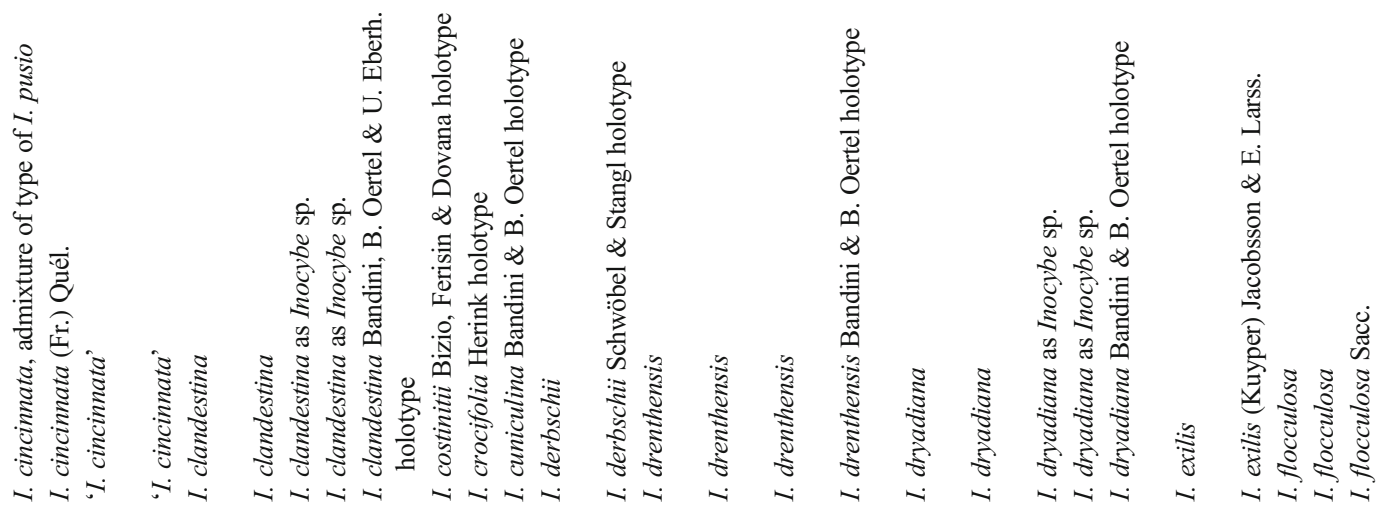


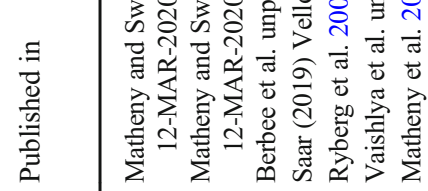
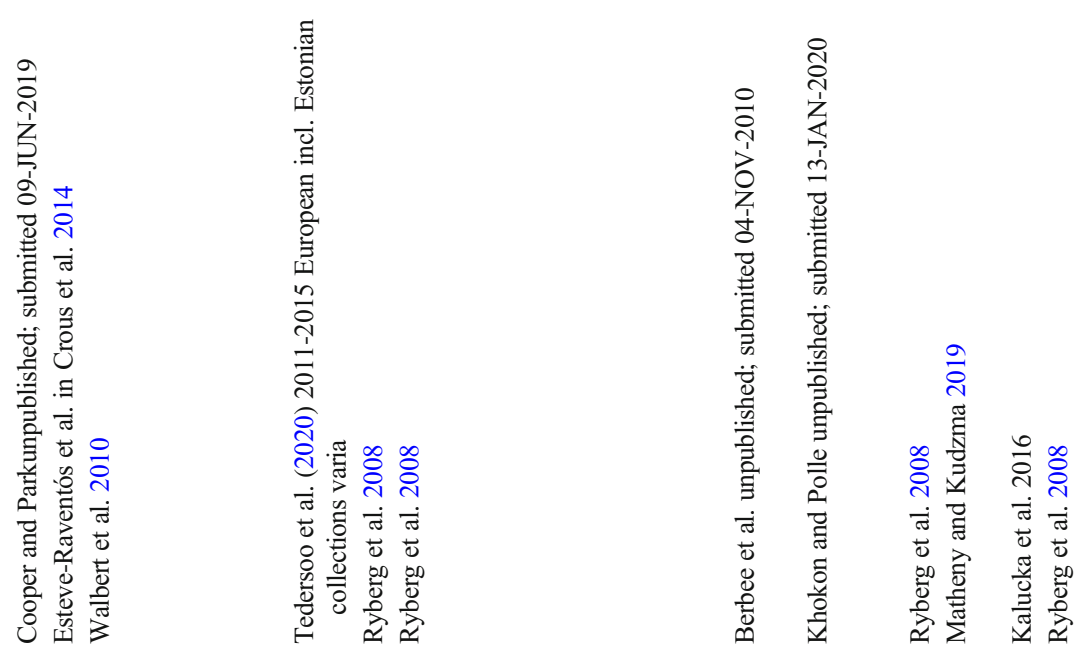

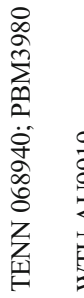

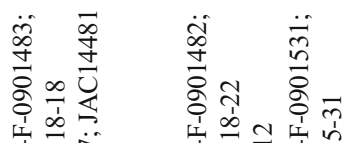

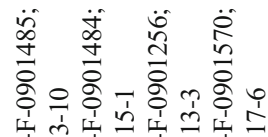

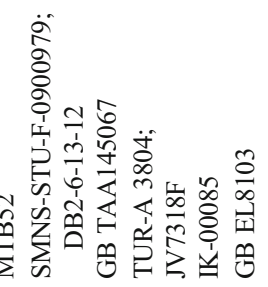

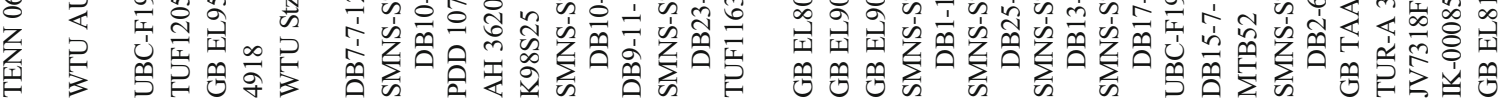

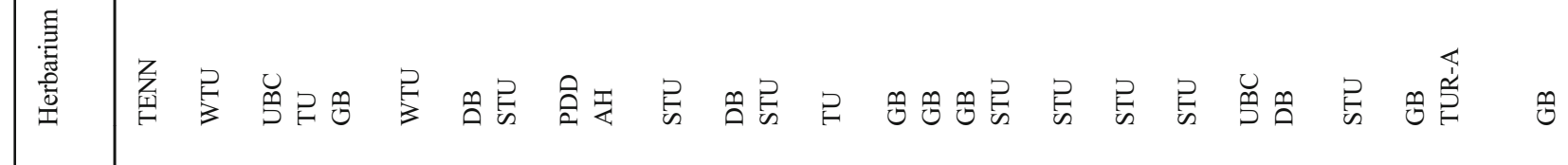

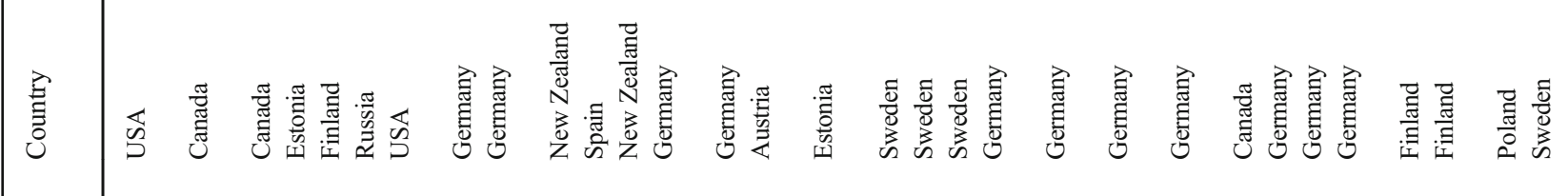
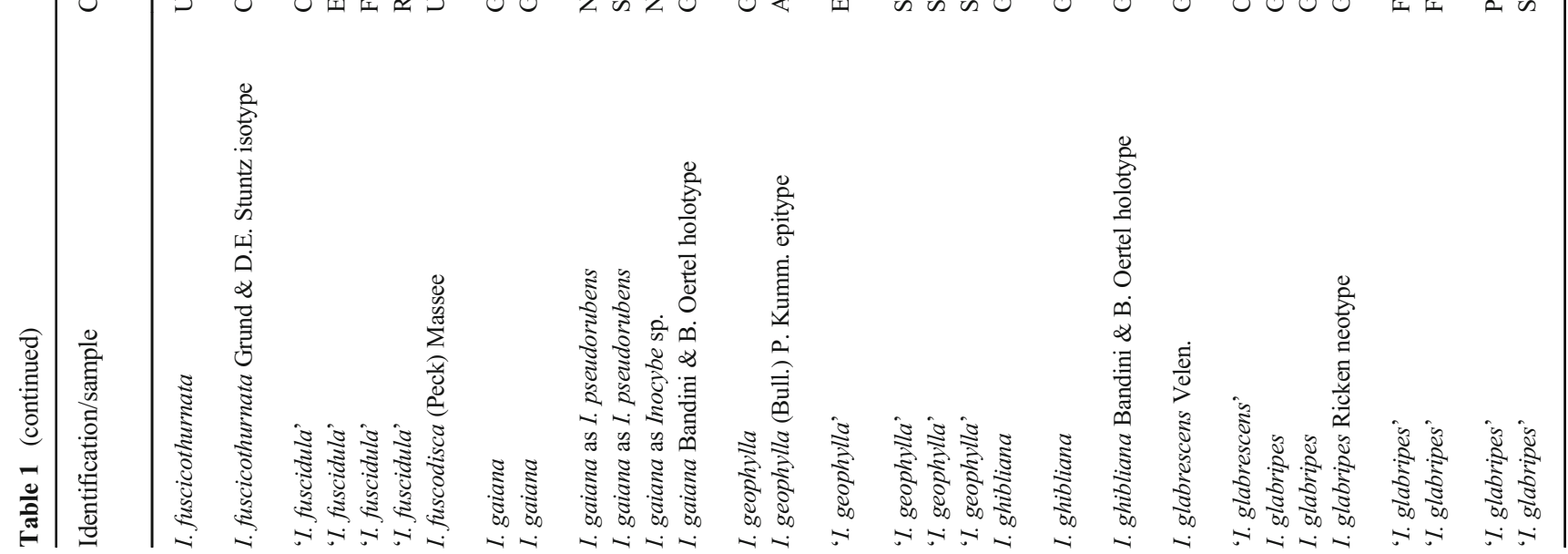


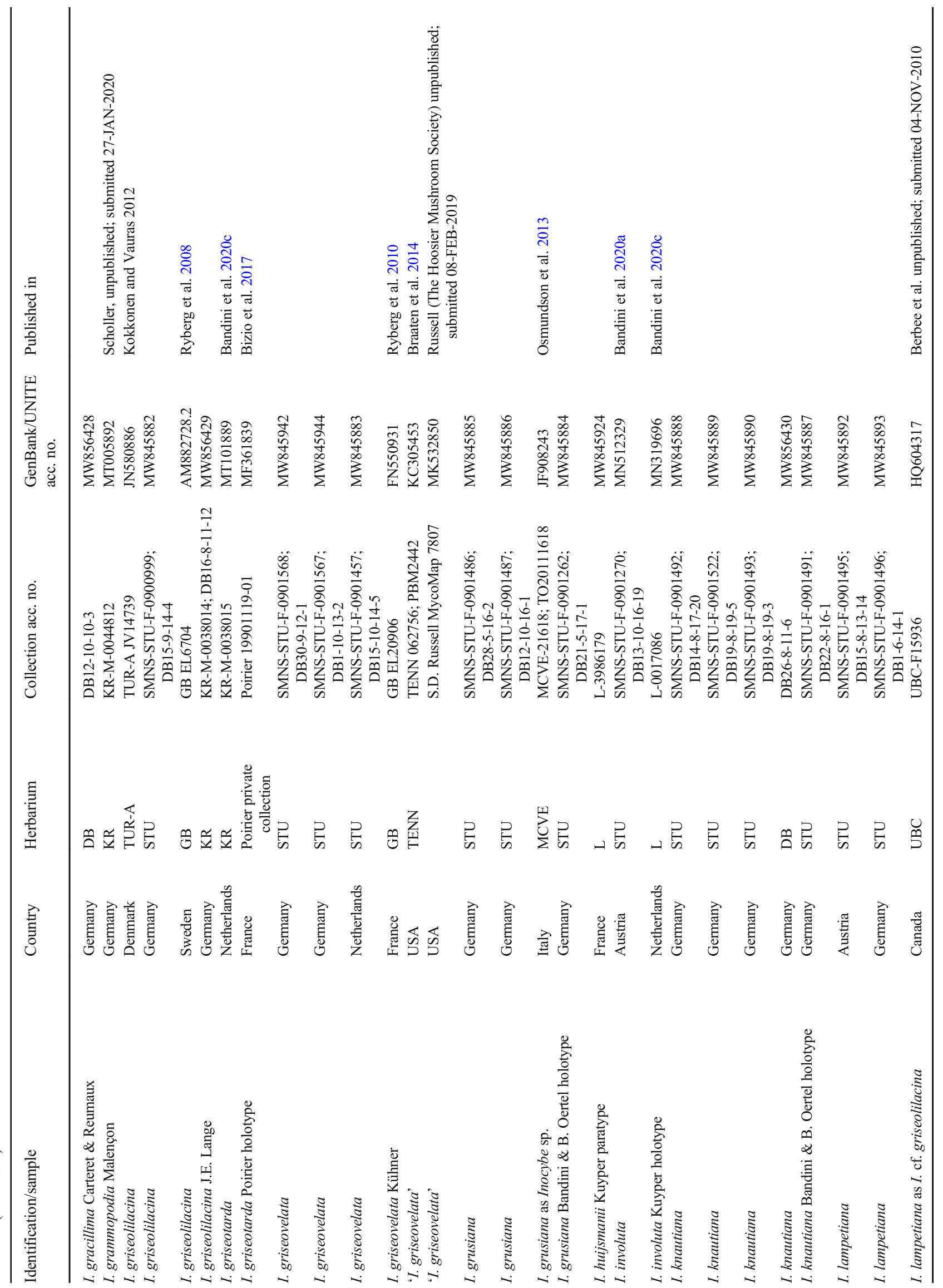




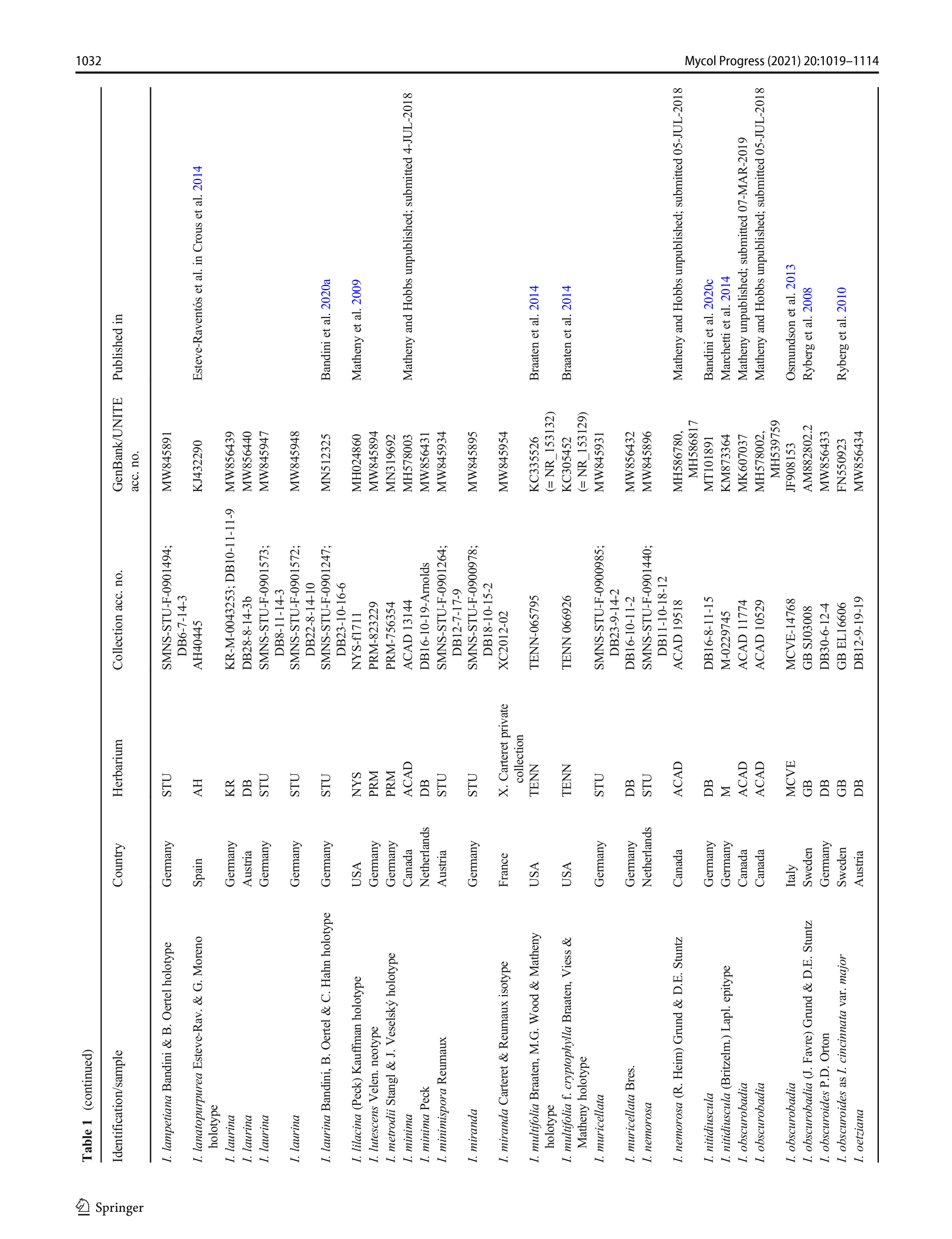




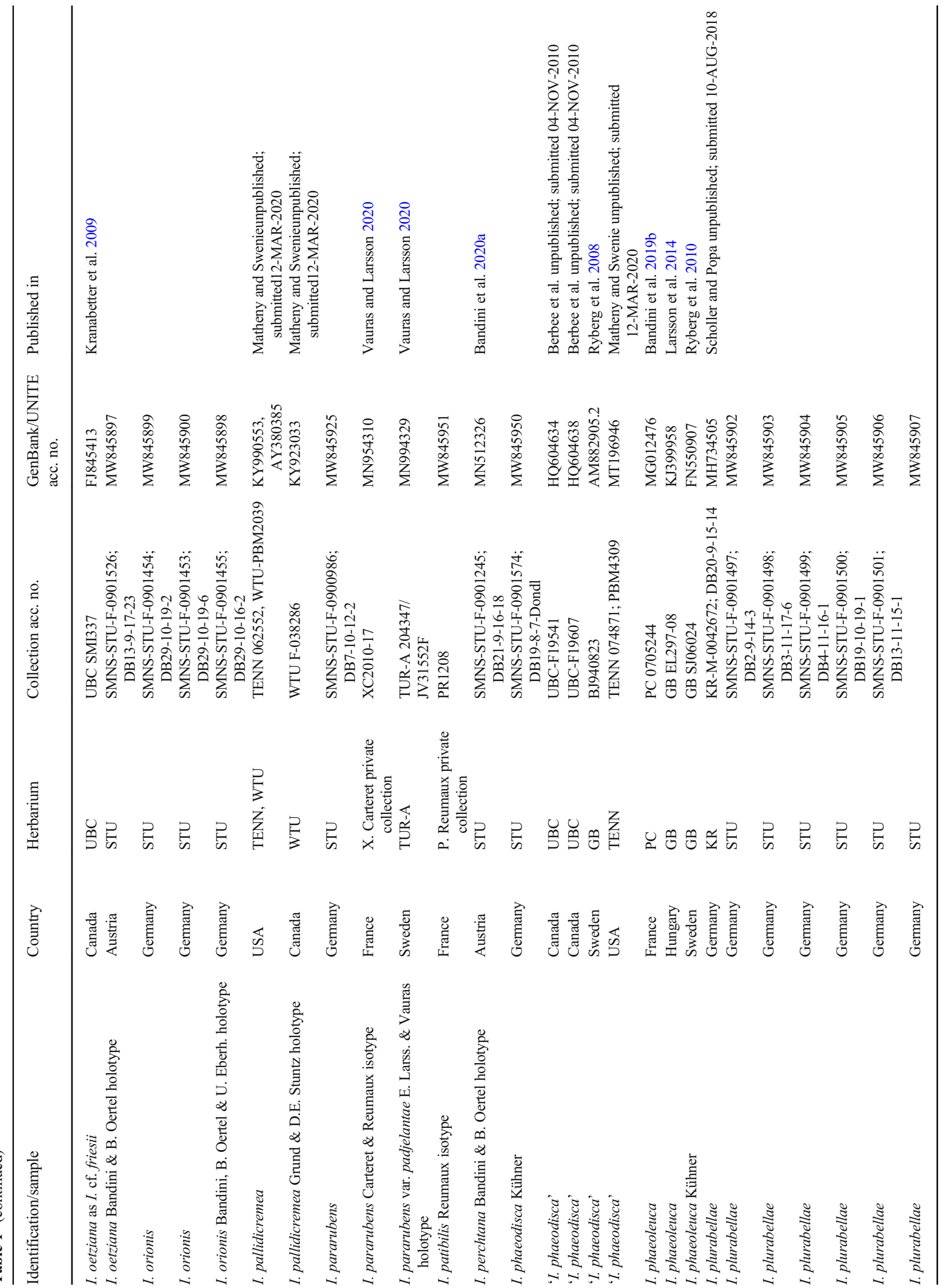


$\stackrel{\infty}{\stackrel{\infty}{\sim}} \stackrel{\infty}{\stackrel{\sim}{\sim}} \stackrel{\infty}{\stackrel{\sim}{*}}$

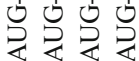

으으응

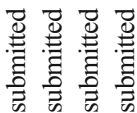

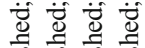

㦴

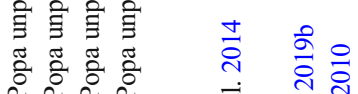

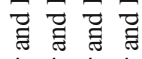

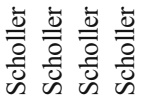
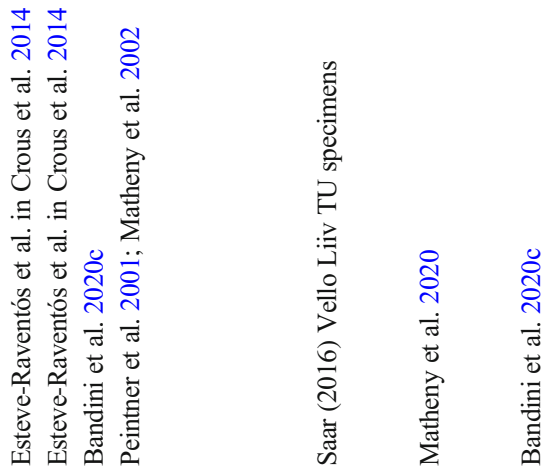

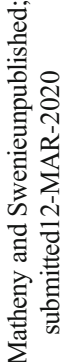

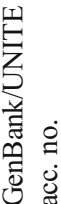

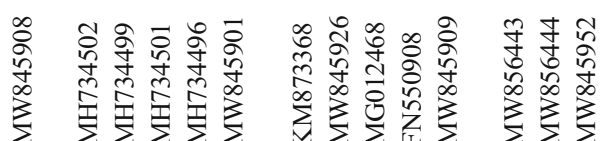

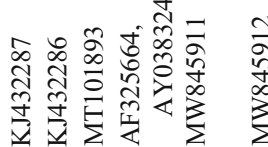

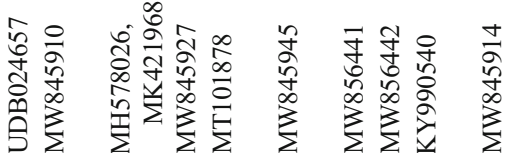
ㄱำ 운 ㄷำ

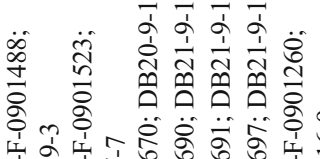

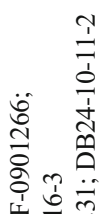

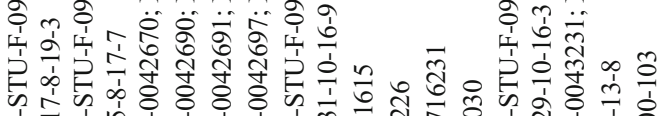

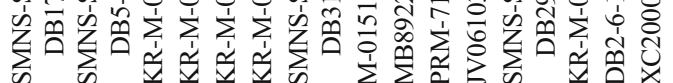

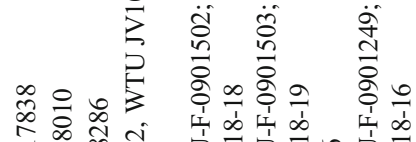

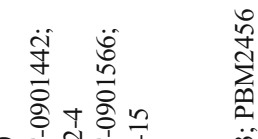

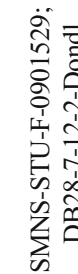

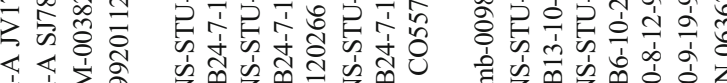

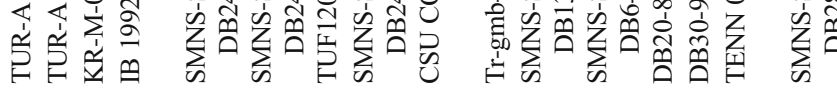
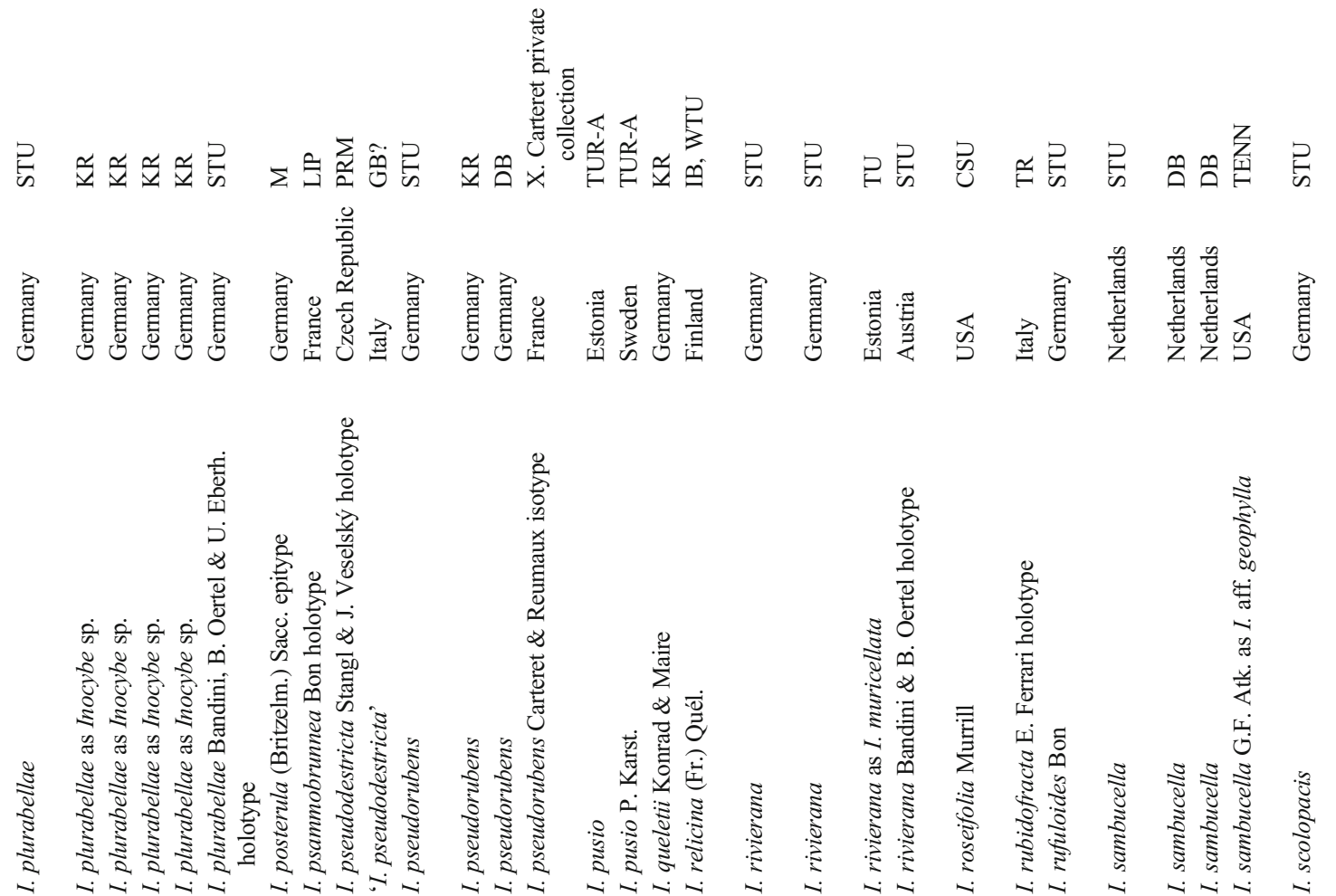

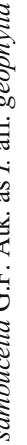

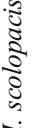




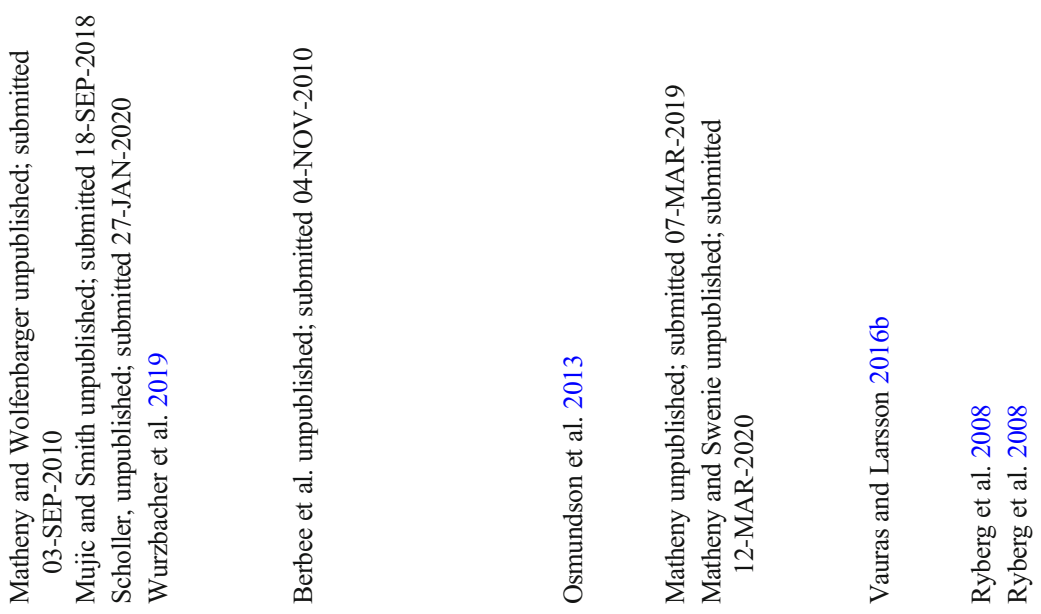

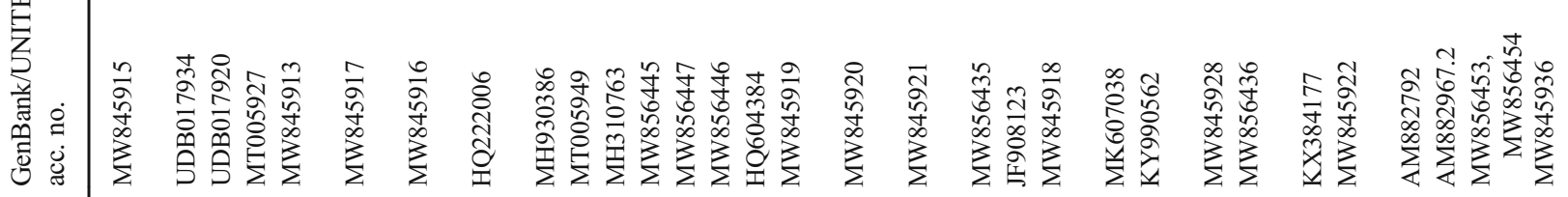

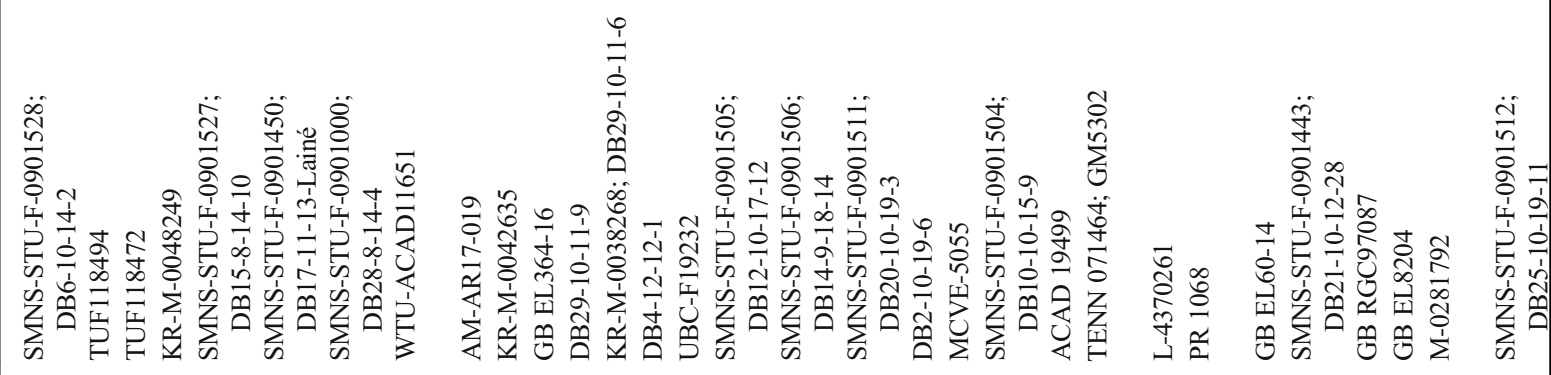

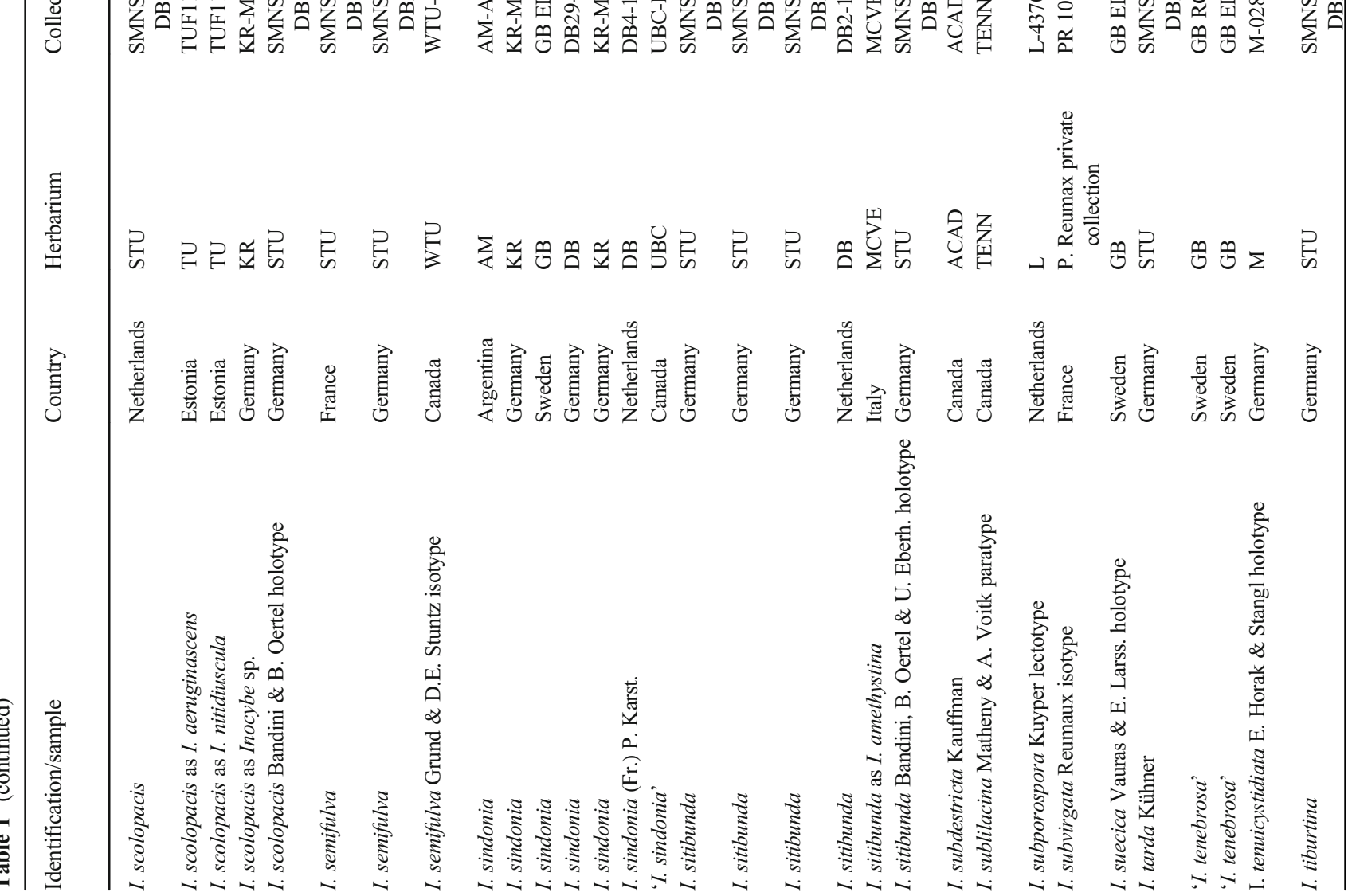




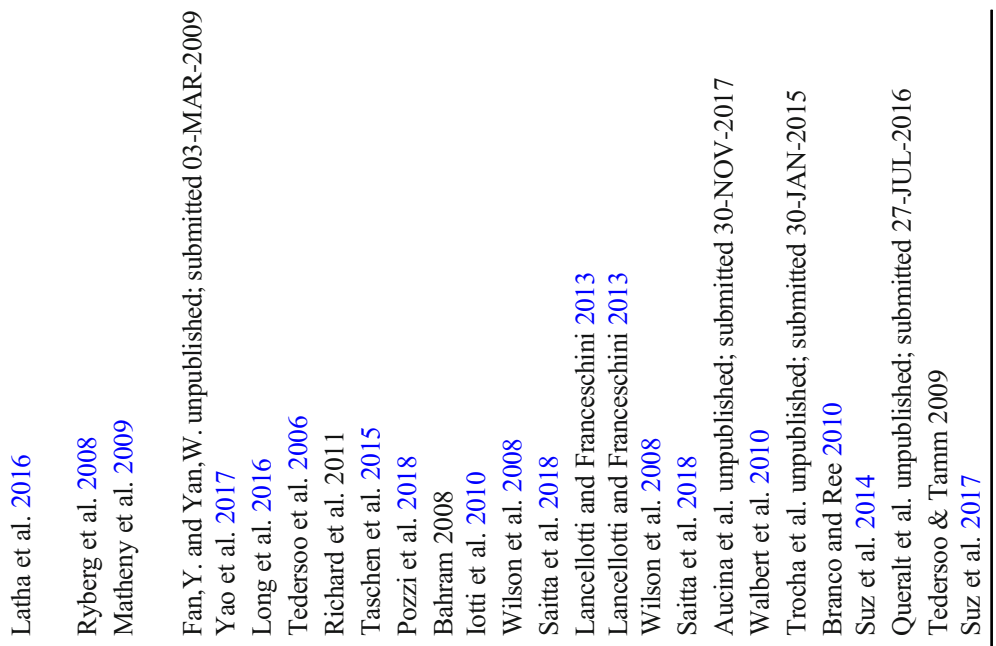

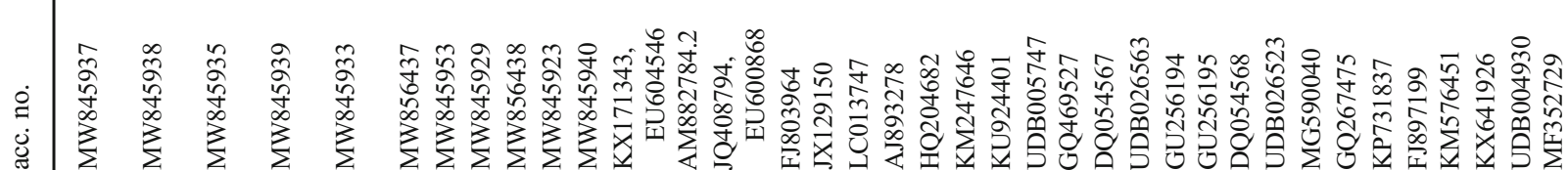

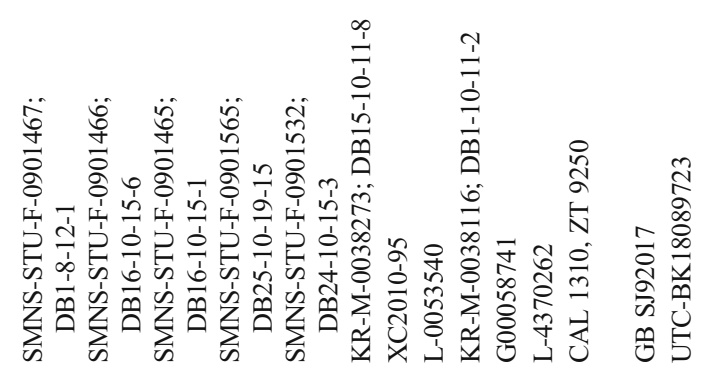

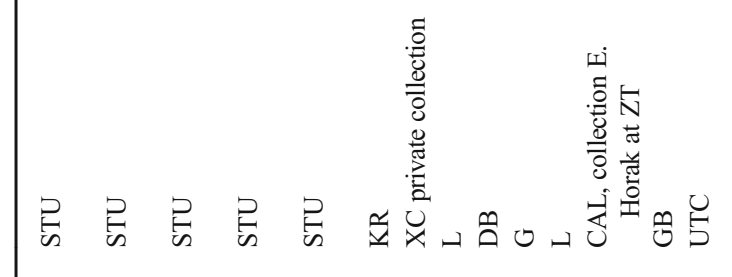

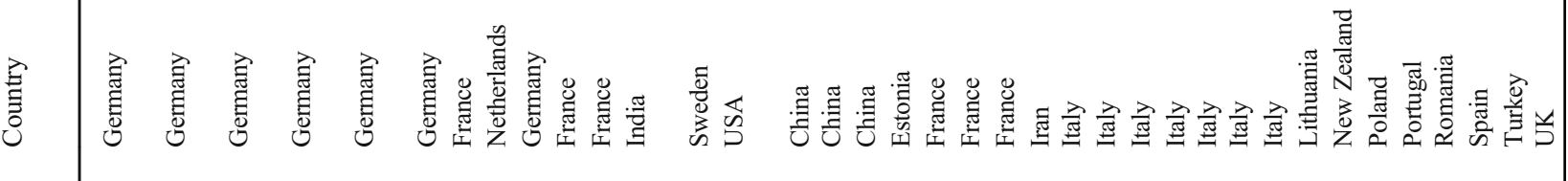

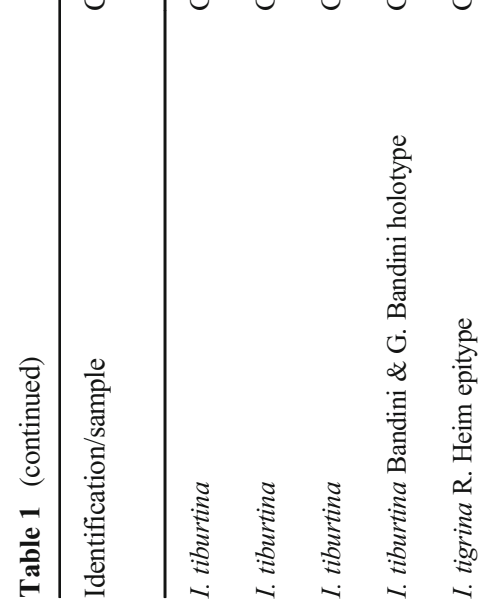

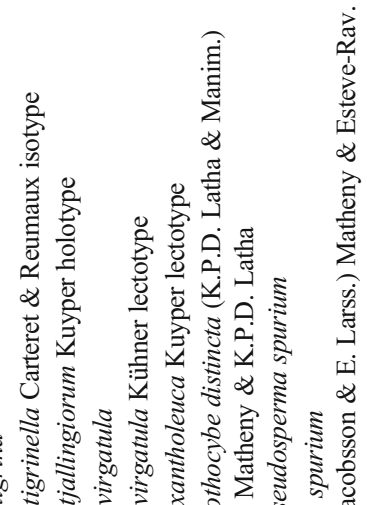

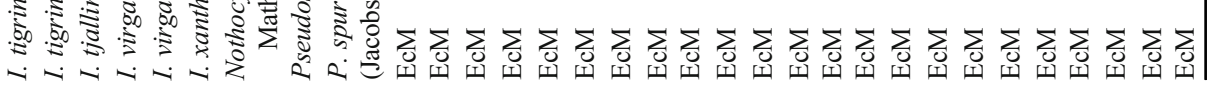



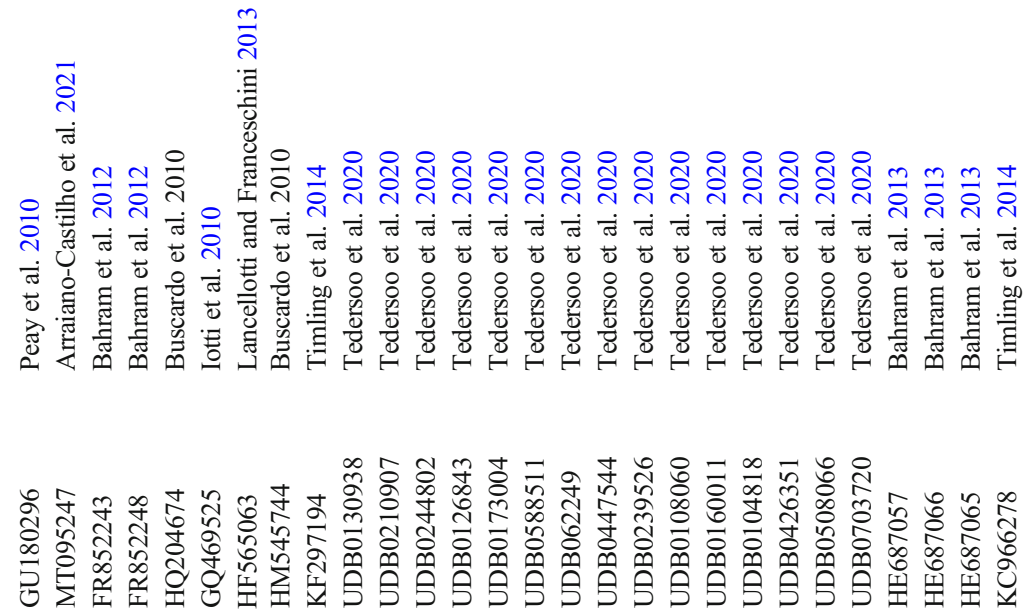

$\dot{g}$

$\frac{0}{3}$

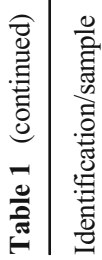

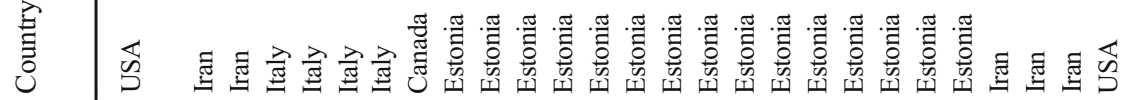

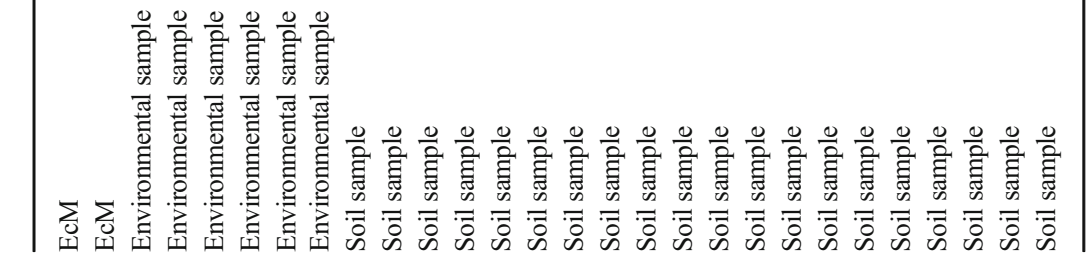



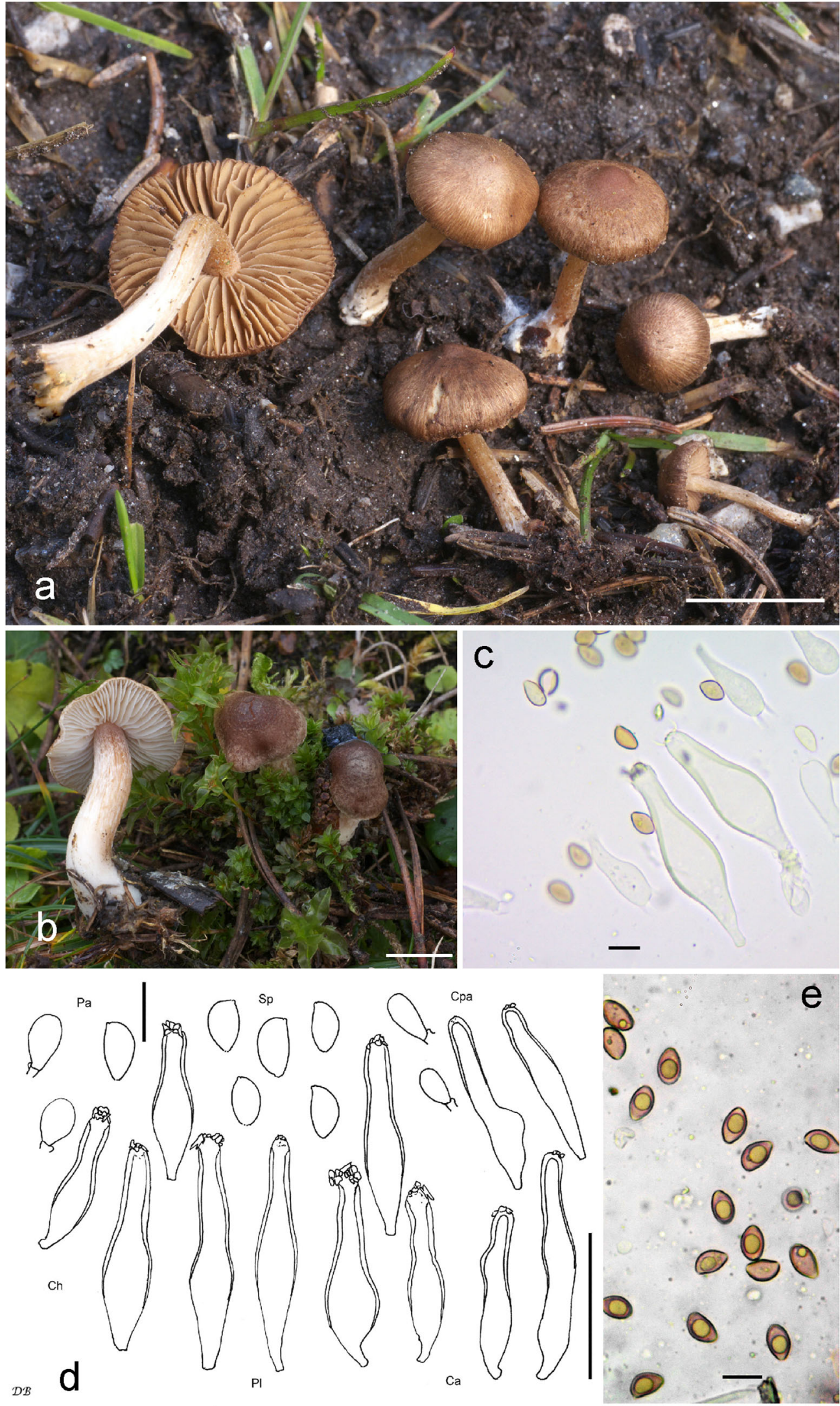

Fig. 2 Inocybe alberichiana, a holotype, scale bar: $1 \mathrm{~cm}$. b Coll. DB239-16-11, scale bar: $1 \mathrm{~cm}$. c Cheilocystidia (coll. DB17-8-12-5), scale bar: $10 \mu \mathrm{m}$. d Microscopical characters (holotype), $\mathrm{Ca}=$ Caulocystidia, $\mathrm{Cpa}=$
Cauloparacystidia, $\mathrm{Ch}=$ Cheilocystidia, $\mathrm{Pa}=$ Paracystidia, $\mathrm{Pl}=$ Pleurocystidia, $\mathrm{Sp}=$ Spores; scale bar spores: $10 \mu \mathrm{m}$, scale bar cystidia: $50 \mu \mathrm{m}$. e Spores (coll. DB13-9-18-11), scale bar: $10 \mu \mathrm{m}$ 
somewhat deformed caulocystidia, pleurocystidia measuring 41-81 $\mu \mathrm{m}$ (av. $62 \mu \mathrm{m}) \times 10-19 \mu \mathrm{m}$ (av. $14 \mu \mathrm{m})$. It appears to associate with Picea abies on calcareous soil. It can be recognized by the combination of the above characters and differs in its ITS sequence from other superficially similar species such as I. nitidiuscula and the phylogenetically related I. laurina.

Holotype: AUSTRIA, Tirol, Imst, near Kühtai, ÖK25V 2221-Ost, alt. ca. 1800 m, Picea abies, 12 Sep 2019, leg. D. Bandini (holotype STU SMNS-STU-F-0901514; isotypes priv. herb. D.B. DB12-9-19-16, TUR-A 209192). GenBank: ITS + partial LSU $=$ MW845855.

Description: Pileus 5-20 (30) $\mathrm{mm}$ wide, at first (sub)campanulate or (sub)conical, later subconical, broadly convex or expanded, when young without, then sometimes with rather low large umbo, margin at first slightly incurved, later decurved, straight or even uplifted, and then pileus depressed around the umbo; young basidiomata with remnants of a fugitive greyish velipellis; colour mostly brown with more or less intense reddish tinge or hue (Mu 7.5YR 4/3-4/ 6; 5YR 4/3-4/6, 3/3-3/4; 2.5YR 3/4-3/6), sometimes darker or greyish at the umbo because of the velipellis, with age sometimes ochraceous brownish because of subhygrophaneity; surface usually glabrous to rimulose or minutely innately fibrillose towards the margin with age, often subhygrophanous towards the margin; young basidiomata with remnants of a whitish cortina. Lamellae subdistant (ca. 30-40, 1 = 1-3), somewhat thickish, adnate, ventricose, at first whitish, but soon yellowish to intensely ochraceous brownish with age; edge irregular fimbriate, whitish to concolorous. Stipe 15-60 (100) $\times 1-5 \mathrm{~mm}$, cylindrical or curved, sometimes a bit widening towards the base, and sometimes very long, when young covered entirely with rather rough whitish tomentum, later reticulate to almost glabrous, at first whitish or pale beige, then pale ochraceous or ochraceous; roughly pruinose only near the apex of the stipe. Context watery whitish in the pileus, whitish in the stipe, sometimes faintly brownish or reddish in the cortex of the stipe. Smell none or subspermatical, at least when cut. Colour of exsiccata: pileus dark brown with faint reddish hue (Mu 7/5YR 4/2-4/4, 3/2-3/ 4), lamellae a little lighter in colour, stipe lighter in colour, no darkening or blackening on drying.

Spores $8.1-10.8 \mu \mathrm{m}$ (av. $9.3 \mu \mathrm{m}$, SD $0.5 \mu \mathrm{m}) \times 5.0$ $6.6 \mu \mathrm{m}$ (av. $5.6 \mu \mathrm{m}$, SD $0.3 \mu \mathrm{m}$ ); $\mathrm{Q}=1.5-2.1$ (av. 1.7, SD 0.1 ) ( $\mathrm{n}=120$ of 3 coll.); smooth, (sub)amygdaloid, without or with only faint suprahilar depression, apex subacute, subobtuse, with indistinct pseudoporus. Basidia 24-32 $\times 7$ $11 \mu \mathrm{m}$, generally 4-spored, but in some collections also 2 spored, and then several mostly deformed spores up to 12.4 $\mu \mathrm{m}$. Lamellae edges sterile, composed of cheilocystidia and numerous colourless, (sub)clavate, thin-walled paracystidia. Pleurocystidia $41-81 \mu \mathrm{m}$ (av. $62 \mu \mathrm{m}$, SD $9 \mu \mathrm{m}) \times 10-19$ $\mu \mathrm{m}$ (av. $14 \mu \mathrm{m}$, SD $2 \mu \mathrm{m}) ; \mathrm{Q}=3.2-7.9$ (av. 4.4, SD 1.0) (n=
45 of 3 coll.), subfusiform to (sub)utriform, often transition between bulge and neck clearly demarcated, often with rather long, somewhat narrowing and sometimes undate neck, at the apex generally wide, usually with rather short pedicel, but sometimes without pedicel and with truncate base, apex usually crystalliferous, walls up to 2.0 (3.0) $\mu \mathrm{m}$ thick at the apex, inner walls often not reaching the apex, yellowish-greenish with $3 \% \mathrm{KOH}$. Cheilocystidia similar in appearance and size. Pileipellis constituted by an epicutis made up of parallel hyphae 3.5-11 $\mu \mathrm{m}$ wide, with encrusting and parietal brownish, brown to dark brown pigment, subcutis with wider and paler to colourless elements. Caulocystidia only near the apex of the stipe, $45-80 \times 10-15 \mu \mathrm{m}$, mostly somewhat deformed subcylindrical with undate walls, apex with or without small crystals, walls up to $1.0(1.5) \mu \mathrm{m}$ thick at the apex, yellowishgreenish with $3 \% \mathrm{KOH}$; intermixed with numerous (sub)clavate to subglobose cauloparacystidia. Clampconnections abundant in all tissues.

Habitat and known distribution: Inocybe alberichiana was collected by us always next to Picea abies, several collections even with no other trees nearby, and all in montane, subalpine or boreal regions on calcareous soil in Austria, Finland and Germany. GenBank resp. UNITE database include sequences from France (as ' $I$. tarda', FN550920) and Estonia (as 'I. nitidiuscula', UDB011885) that are likely to belong to this taxon. Furthermore, there is an EcM sequence in GenBank (AJ893278), and in UNITE there are several sequences of soil samples equally from Estonia, which may belong to I. alberichiana. We found the species from August to September.

Further collections studied: AUSTRIA, Tirol, Reutte, Tannheimer Tal, ÖK25V 2214-Ost, alt. 1180 m, Picea abies, 17 Aug 2012, leg./det. D. Bandini \& B. Oertel (DB17-8-125). Tirol, Reutte, Hahnenkamm, ÖK25V 2214-Ost, alt. 1800 m, Picea abies, Pinus mugo, Salix sp., 18 Sep 2016, leg. D. Bandini; det. D. Bandini \& B. Oertel (DB18-9-16-24). FINLAND, Koillismaa, Kuusamo municipality, Oulanka National Park, Ampumavaara, Picea abies, Pinus sylvestris, Betula sp., 19 Aug 2015, leg. D. Bandini, B. Oertel \& J. Vauras; det. D. Bandini \& B. Oertel (DB19-8-15-7). Ibidem, in some distance from former location, Picea abies, Pinus sylvestris, Betula sp., 22 Aug 2015, leg. D. Bandini, B. Oertel \& J. Vauras; det. D. Bandini \& B. Oertel (STU SMNS-STU-F-0901569; DB22-8-15-16). GERMANY, Bayern, Berchtesgadener Land, Berchtesgaden, TK25 8344/3, alt. ca. 1600 m, Picea abies, 20 Aug 2014, leg. D. Bandini; det. D. Bandini \& B. Oertel (DB20-8-14-12). Bayern, Ostallgäu, Füssen, Buching, TK25 8430/2, alt. 1128 m, Picea abies, 30 Aug 2015, leg. J. Christan \& I. Beer-Lenis Bejarano; det. D. Bandini \& B. Oertel (DB30-8-15-1Christan). Bayern, Garmisch-Partenkirchen, Mittenwald, Wettersteinwald, TK25 8532/4, Picea abies, Fagus sylvatica, 6 Sep 2016, leg. P. Karasch; det. D. Bandini \& B. Oertel 
(DB6-9-16-1-Karasch). Bayern, Ostallgäu, Pfronten, Breitenberg, TK25 8429/3, alt. ca. 1800 m, Picea abies, Pinus mugo, 23 Sep 2016, leg. D. Bandini; det. D. Bandini \& B. Oertel (STU SMNS-STU-F-0901265; DB23-9-16-11). Bayern, Ostallgäu, Pfronten, Achtal, TK25 8429/1, alt. 1050 m, Picea abies, 13 Sep 2018, leg. D. Bandini; det. D. Bandini \& B. Oertel (DB13-9-18-11). Bayern, Ostallgäu, Pfronten, Breitenberg, TK25 8429/3, alt. ca. 1700 m, Picea abies, Pinus mugo, 16 Sep 2018, leg. D. Bandini; det. D. Bandini \& B. Oertel (DB16-9-18-3).

Comments: Inocybe alberichiana is characterized by the rather small size, the reddish tinged brown, smooth to rimulose surface of pileus, with age intensely ochraceous brownish lamellae, spores that on average are shorter than $9.5 \mu \mathrm{m}$ and subfusiform to (sub)utriform hymenial cystidia often with rather long and sometimes undate neck. It can be mistaken for I. nitidiuscula (Britzelmayr 1891; Stangl 1983, 1989; Kuyper 1986; Marchetti et al. 2014). However, the lamellae of this species are not intensely ochraceous brownish with age, the necks of the hymenial cystidia are often narrow near the apex and usually not undate and the spores are, on average, larger. Larger spores also characterize I. tarda Kühner (Kühner 1955) and I. involuta Kuyper (Kuyper 1989; Bandini et al. $2020 \mathrm{a}$, c). Furthermore, the pileus of the former is darker in colour, and the hymenial cystidia are often subcylindrical in shape (see below), while the lamellae of I. involuta often show a striking colour contrast in relation to the reddish stipe. In addition, the spores are on average longer and the caulocystidia rather ventricose (sub)utriform or (sub)lageniform Bandini et al. 2020a; 2020c. Inocybe perchtana Bandini \& B. Oertel can be distinguished by its whitish velipellis, often reddening context in the stipe when bruised and on average smaller spores (Bandini et al. 2020a). Inocybe astraiana Bandini \& B. Oertel grows with Pinus, has a pileus that is strongly discolouring towards the margin with age and its spores, on average, are smaller (Bandini et al. 2020a). Inocybe pseudodestricta Stangl \& J. Veselský differs, e.g. by larger basidiomata, with age innately fibrillose pileus surface and long and narrow caulocystidia (Stangl and Veselský 1973; Bandini et al. 2019b). The lamellae of I. oetziana (see below) are not intensely ochraceous brownish with age, the hymenial cystidia have wider necks and the caulocystidia are usually subutriform. The pileus surface of I. olivaceobrunnea J. Favre ex Kuyper (Favre 1960, and see below) is squamulose around the centre, and the hymenial cystidia are quite different in shape compared to those of I. alberichiana, being plump with rather thin walls. The neotype of I. lutescens Velen. differs, e.g. by larger basidiomata, yellowish hues in the pileus colour, more yellow than ochraceous lamellae, yellowish stipe and on average longer but narrower spores (Stangl and
Veselský 1980, and see below). Inocybe crocifolia Herink differs, e.g. by more warm ferruginous coloured lamellae, 'croceo-aurantiaco' context and longer spores (Herink 1954, and see below). Inocybe laurina Bandini, B. Oertel \& C. Hahn is with $97 \%$ identity in the ITS genetically most closely related to I. alberichiana. It differs from the latter, e.g. by its abundant whitish velipellis, longer and narrower caulocystidia and growth with Pinus (Bandini et al. 2020a).

It seems that I. alberichiana is a fairly common species in mountainous regions, but was up to now mistaken for I. nitidiuscula. Based on ITS, I. alberichiana is very closely related to I. laurina.

Inocybe amethystina Kuyper, Persoonia Supplement 3: 135 (1986) Fig. 23 a

Description of the species: Kuyper 1986.

Studied material (holotype): NETHERLANDS, OostFlevoland, Roggebotzand, with Picea on calcareous sand, 5 Jul 1984, leg. F. Tjallingii \& G. Tjallingii-Beukers (L-0053531). GenBank: ITS = KJ432285, MW845932. Spores $8.4-12.0 \mu \mathrm{m}$ (av. $10.1 \mu \mathrm{m}$, SD $0.7 \mu \mathrm{m}) \times 5.0$ $6.3 \mu \mathrm{m}$ (av. $5.5 \mu \mathrm{m}$, SD $0.3 \mu \mathrm{m}$ ); Q = 1.6-2.1 (av. 1.8, SD $0.1)(n=40)$, smooth, oblong with (sub)conical apex. Basidia 4-spored, but also 2-spored, and then spores up to $>12.0 \mu \mathrm{m}$. Pleurocystidia 53-75 $\mu \mathrm{m}$ (av. $60 \mu \mathrm{m}$, SD $6 \mu \mathrm{m}$ ) $\times 11-16 \mu \mathrm{m}$ (av. $13 \mu \mathrm{m}, \mathrm{SD} 2 \mu \mathrm{m}) ; \mathrm{Q}=3.7-5.7($ av. 4.6, SD 0.6) $(\mathrm{n}=15)$, (sub)utriform, subfusiform, also sublageniform or subcylindrical, apex usually crystalliferous, walls up to $3.0 \mu \mathrm{m}$ thick at the apex, pale yellowish-greenish to yellowish-greenish with $3 \% \mathrm{KOH}$. Cheilocystidia similar in appearance and size. Paracystidia not observed. Caulocystidia only near the apex of the stipe, subutriform, subfusiform with wide neck and short pedicel, in size similar to pleurocystidia.

Comments: The results of the type study agree with the original description. There are several descriptions of I. amethystina in the literature (e.g. Breitenbach and Kränzlin 2000; Ferrari 2010; Ludwig 2017). However, it is doubtful if the descriptions really refer to I. amethystina, since there are notable discrepancies between descriptions and with respect to the original description of the species regarding, e.g. pileus surface, shape of hymenial cystidia and size of spores as well as ecology. The holotype of I. amethystina is in a rather isolated and unresolved position in the tree (Fig. 1).

Inocybe beatifica Bandini \& B. Oertel sp. nov. Fig. 3 MycoBank number: MB 839152

Etymology: From Latin 'beatifica', 'making happy', because several collections were found in the garden of D. Bandini and thus made her happy.

Diagnosis: Inocybe beatifica has a finely textured smooth to rim(ul)ose brown pileus without velipellis, an entirely, but in the lower half only sparely pruinose stipe, smooth oblong 

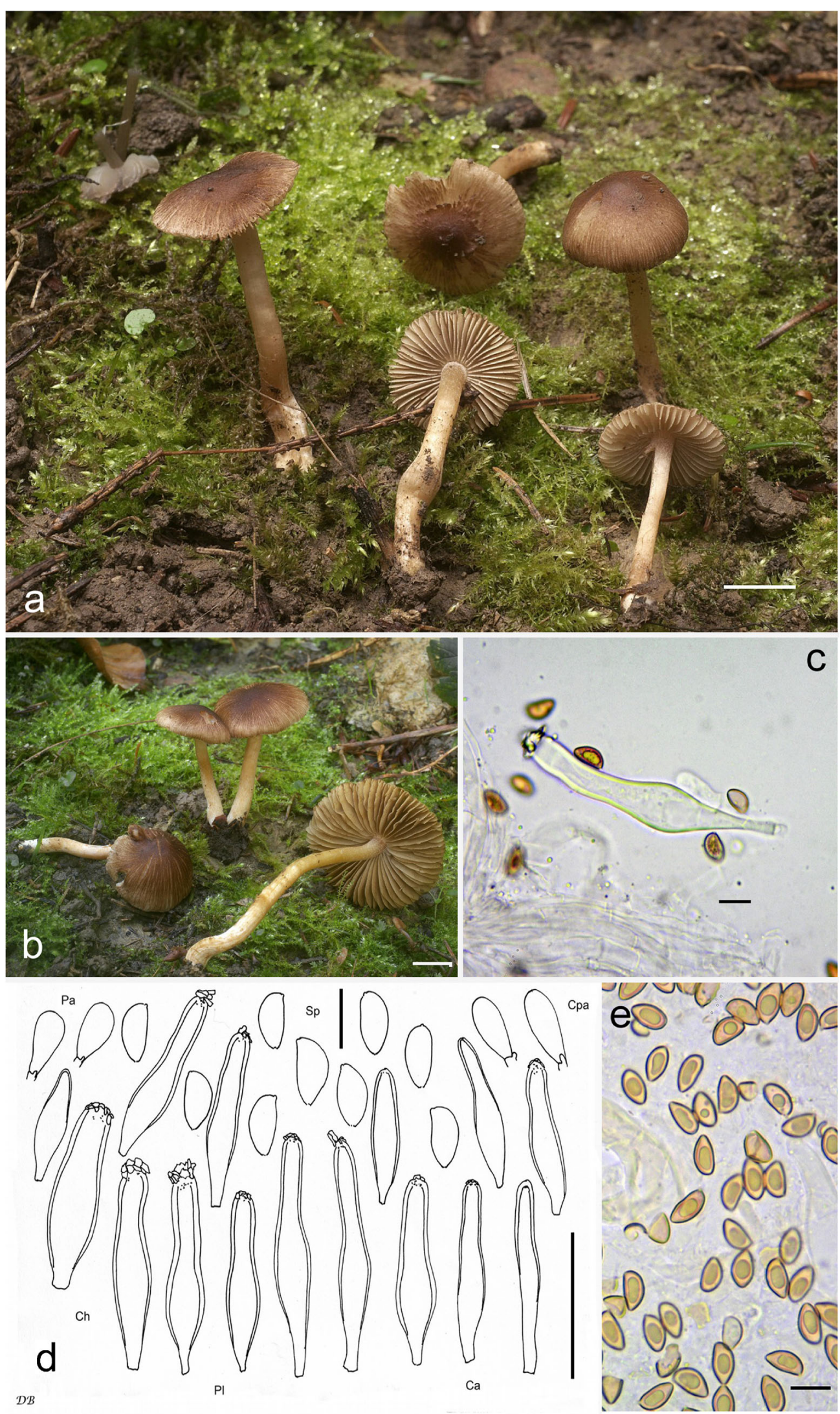

Fig. 3 Inocybe beatifica, a holotype, scale bar: $1 \mathrm{~cm}$. b Coll. DB22-1013-1, scale bar: $1 \mathrm{~cm}$. c Cheilocystide (holotype), scale bar: $10 \mu \mathrm{m}$. d Microscopical characters (holotype), $\mathrm{Ca}=$ Caulocystidia, $\mathrm{Cpa}=$

Cauloparacystidia, $\mathrm{Ch}=$ Cheilocystidia, $\mathrm{Pa}=$ Paracystidia, $\mathrm{Pl}=$ Pleurocystidia, $\mathrm{Sp}=$ Spores; scale bar spores: $10 \mu \mathrm{m}$, scale bar cystidia: $50 \mu \mathrm{m}$. e Spores (coll. 22-10-13-1), scale bar: $10 \mu \mathrm{m}$ 
spores measuring 7.5-12.1 $\mu \mathrm{m}$ (av. 9.8 $\mu \mathrm{m}) \times 4.3-6.7 \mu \mathrm{m}$ (av. $5.4 \mu \mathrm{m}$ ) and hymenial cystidia often with a rather long neck, pleurocystidia measuring $42-96 \mu \mathrm{m}$ (av. $60 \mu \mathrm{m}) \times 8-18$ $\mu \mathrm{m}$ (av. $13 \mu \mathrm{m}$ ). It grows on calcareous soil. This combination of characters and ITS sequence data distinguish Inocybe beatifica from all described species, including other brown species such as I. virgatula or the genetically related I. costinitii.

Holotype: GERMANY Baden-Württemberg, RheinNeckar-Kreis, Wiesenbach, TK25 6618/2, alt. 177 m, bare earth in garden below Picea abies, Juniperus communis, 12 Oct 2013, leg. D. \& G. Bandini (holotype STU SMNS-STUF-0901261; isotype priv. herb. D.B. DB12-10-13-3). GenBank: ITS = MW845857.

Description: Pileus 15-40 mm wide, (sub)glandiform, subconical, subglobose or (sub)campanulate when young, later convex to expanded, with or without more or less prominent umbo, margin incurved when young, later slightly decurved to straight; even with young basidiomata no remnants of a velipellis observed; colour warm nut-brown to chestnutbrown (Mu 7.5YR 4/4-4/6; 5YR 4/3-4/6), sometimes somewhat darker at the umbo; surface at first almost satiny glabrous or smooth, later still glabrous at the umbo, while outwards finely rimulose to rimose with finely textured appressed fibres and with the paler trama visible between the fibres; with age or due to weather conditions sometimes somewhat excoriate around the umbo; young basidiomata with remnants of a whitish cortina. Lamellae moderately crowded to rather distant (ca. 30-50, 1 = 1-3), adnexed to adnate, subventricose, at first almost whitish, then with a tinge of flesh-colour to greyishbrownish, later brownish; edge fimbriate, whitish. Stipe 40$80 \times 3-5 \mathrm{~mm}$, cylindrical or curved, sometimes slightly widening towards the base, at first entirely covered with whitish tomentum, and therefore appearing almost whitish, later longitudinally striate to glabrous, light brown beneath the tissue; losely pruinose on entire length of stipe, but in the lower half only with rather few metuloid cystidia. Context whitish in pileus and stipe. Smell spermatical, at least when cut. Colour of exsiccata: pileus chestnut-brown, dark brown with reddish hue (Mu 5YR 4/3-4/6, 3/3-3/4), lamellae and stipe concolorous or a little lighter in colour, no darkening or blackening on drying.

Spores 7.5-12.1 $\mu \mathrm{m}$ (av. 9.8 $\mu \mathrm{m}$, SD $0.9 \mu \mathrm{m}) \times 4.3-$ $6.7 \mu \mathrm{m}$ (av. $5.4 \mu \mathrm{m}$, SD $0.3 \mu \mathrm{m}$ ); Q $=1.5-2.3$ (av. 1.8, SD $0.2)$ ( $\mathrm{n}=120$ of 3 coll.); smooth, (sub)amygdaloid, mostly oblong, often with more or less explicit suprahilar depression, apex subacute, subobtuse, mostly with indistinct pseudoporus. Basidia 25-36 × 7-10 $\mu \mathrm{m}$, generally 4-spored, but in some collections also 2-spored, and then spores up to $13.0 \mu \mathrm{m}$. Lamella edge sterile, composed of cheilocystidia and numerous colourless, (sub)clavate, subcylindrical or subglobose, thin-walled paracystidia. Pleurocystidia 42-96 $\mu \mathrm{m}$ (av. 60 $\mu \mathrm{m}$, SD $13 \mu \mathrm{m}) \times 8-18 \mu \mathrm{m}($ av. $13 \mu \mathrm{m}$, SD $2 \mu \mathrm{m}) ; \mathrm{Q}=$
2.8-6.6 (av. 4.7, SD 0.9) ( $\mathrm{n}=45$ of 3 coll.), usually rather narrow (sub)utriform to subcylindrical, sometimes also sublageniform, usually with rather long, and sometimes slightly undate neck, at the apex generally wide, with short pedicel, apex usually crystalliferous, walls up to $1.5(2.5) \mu \mathrm{m}$ thick at the apex, but often quite uniformly thick at bulge and apex, pale yellowish-greenish with $3 \% \mathrm{KOH}$. Cheilocystidia similar in appearance and size. Pileipellis constituted by an epicutis made up of parallel hyphae 5-12 $\mu \mathrm{m}$ wide, with coarsely encrusting and parietal brownish pigment, subcutis with wider and paler to colourless elements. Caulocystidia on entire length of the stipe, but quite sparely in the lower half, 40-70 $\times 8-15 \mu \mathrm{m}$, slender (sub)cylindrical, mostly without neck and without or with only short pedicel, apex usually crystalliferous, walls up to $1.0(1.5) \mu \mathrm{m}$ thick at the apex, pale yellowish-greenish with $3 \% \mathrm{KOH}$; intermixed with numerous (sub)clavate to subcylindrical cauloparacystidia. Clampconnections abundant in all tissues.

Habitat and known distribution: Inocybe beatifica is to date only known from collections from Germany, and has only been collected in the vicinity of Picea abies and Quercus. In GenBank is an EcM-sequence from Romania (with Quercus robur, KM576451), and in UNITE there are several sequences from soil samples from Estonia. In Germany, the species was collected in late autumn.

Further collections studied: GERMANY, BadenWürttemberg, Rhein-Neckar-Kreis, Wiesenbach, TK25 $6618 / 2$, in some distance from holotype location, alt. $185 \mathrm{~m}$, bare earth in garden below Picea abies, 12 Oct 2013, leg./det. D. Bandini (DB12-10-13-1). Ibidem, in some distance from former location, alt. $170 \mathrm{~m}$, Picea abies, 12 Oct 2013, leg./det. D. Bandini (DB12-10-13-2). Ibidem, 22 Oct 2013, leg./det. D. Bandini (STU SMNS-STU-F-0901472; DB22-10-13-1). Ibidem, in some distance from former location, alt. $172 \mathrm{~m}$, Picea abies, 15 Sep 2014, leg./det. D. Bandini (DB15-9-142). Baden-Württemberg, Karlsruhe, Stadtgarten, TK 25 7016/1, alt. 120 m, Quercus robur, 8 Oct 2015, leg. A. Schneider; det. D. Bandini \& B. Oertel (KR-M-0044129). Ibidem, 30 Oct 2015, leg. A. Schneider; det. D. Bandini \& B. Oertel (KR-M-0044173, KR-M-0044174). BadenWürttemberg, Rhein-Neckar-Kreis, Wiesenbach, TK25 6618/2, alt. $170 \mathrm{~m}$, Pinus sylvestris, Picea abies, 18 Nov 2017, leg. D. Bandini \& X. Hielscher; det. D. Bandini \& B. Oertel (DB18-11-17-1). Baden-Württemberg, RheinNeckar-Kreis, Lobbach, TK25 6619/1, alt. 176 m, Pinus sylvestris, Picea abies, leg. D. Bandini \& X. Hielscher; det. D. Bandini \& B. Oertel (DB18-11-17-4).

Comments: Inocybe beatifica is characterized by an almost satiny smooth to rim(ul)ose, very finely textured surface of a brown pileus, missing velipellis, an entirely, but in the lower half only sparely pruinose stipe, oblong spores and hymenial cystidia often with rather long necks. Because in the lower half only sparely pruinose stipe, at the first glance, 
it could easily be mistaken for I. virgatula Kühner. This species differs by the presence of a greyish velipellis when young, the often less finely textured surface of pileus and differently shaped, generally wider and (sub)fusiform hymenial cystidia (Kühner 1955, and personal observation). Inocybe derbschii Schwöbel \& Stangl differs, e.g. by a greyish velipellis and short-necked hymenial cystidia (Schwöbel and Stangl 1982; Bandini et al. 2019b) and I. plurabellae (see below) by a less finely textured, usually finely roughened surface of pileus, heterogeneously shaped hymenial cystidia, mostly with short necks, and long and narrow caulocystidia often with curved neck. Inocybe grusiana (see below) differs from I. beatifica, e.g. by ample greyish velipellis and long and narrow (sub)cylindrical caulocystidia, and I. griseovelata Kühner differs, e.g. also by a greyish velipellis, often somewhat reddish apex of stipe, larger spores and often (sub)cylindrical hymenial cystidia (Kühner 1955, and personal observation). Inocybe pseudofuscidula $\mathrm{E}$. Ludw. differs, e.g. by an abundant velipellis and an only near the apex pruinose stipe (Ludwig 2017; Eberhardt et al. in prep.). The stipe of I. scolopacis (see below) is pruinose only near the apex and the surface of pileus is less finely textured. Inocybe semifulva (see below) differs by less finely textured pileus surface, an only near the apex pruinose stipe and whitish-greyish velipellis (Grund and Stuntz 1981; Bandini 2014).

Macroscopically $I$. beatifica might also be mistaken for I. phaeoleuca Kühner or I. pararubens Carteret \& Reumaux. Both species, however, differ, e.g. by ample pruina in the lower half of the stipe, a greyish velipellis and longer spores (Kühner 1955; Kuyper 1986; Carteret and Reumaux 2012; La Rosa et al. 2017; Bandini et al. 2019c; Vauras and Larsson 2020). Inocybe tjallingiorum Kuyper has a more reddish pileus colour, a greyish velipellis and mostly neckless hymenial cystidia (Kuyper 1986; Stangl 1989; personal observation, and see below). Inocybe metrodii Stangl \& Veselský and I. glabrescens Velen., both having an entirely pruinose stipe, differ from I. beatifica, e.g. by smaller spores and shorter hymenial cystidia (Stangl and Veselský 1979; Velenovský 1920-1922; personal observation, and see below). Inocybe costinitii Bizio, Ferisin \& Dovana is with $91 \%$ similarity in the ITS only distinctly related to I. beatifica and differs from the latter, e.g. by a conspicuous whitish velipellis and almost neckless hymenial cystidia. Furthermore, the stipe is pruinose only near the apex (Bizio et al. 2016).

Inocybe bellidiana Bandini, B. Oertel \& U. Eberh. sp. nov. Fig. 4

MycoBank number: MB 839153

Etymology: Named 'bellidiana' after the common daisy (Bellis perennis), because of the small whitish caps with yellowish centre and with age often fibrillose pileus fibres reminiscent flower petals.
Diagnosis: Inocybe bellidiana has a whitish to dingy beige pileus colour with often yellowish centre, smooth to fibrillose surface, smooth spores, measuring 6.8-10.1 $\mu \mathrm{m}$ (av. $8.5 \mu \mathrm{m}$ ) $\times 4.3-6.0 \mu \mathrm{m}$ (av. $4.9 \mu \mathrm{m}$ ) with characteristically bulgy dorsal side and mostly (sub)fusiform or subcylindrical hymenial cystidia, pleurocystidia measuring 44-77 $\mu \mathrm{m}($ av. $58 \mu \mathrm{m}) \times$ 9-19 $\mu \mathrm{m}$ (av. $13 \mu \mathrm{m})$. It grows on calcareous ground with frondose trees. This combination of characters as well as ITS sequence data distinguishes I. bellidiana from all other species of the Inocybe geophylla-group to which it phylogenetically and morphologically belongs.

Holotype: GERMANY, Baden-Württemberg, RheinNeckar-Kreis, Spechbach, TK25 6619/1, alt. 245 m, bare earth with Fagus sylvatica, 18 Oct 2019, leg. D. Bandini (holotype STU SMNS-STU-F-0901473; isotypes priv. herb. D.B. DB18-10-19-1, TUR-A 209193). GenBank: ITS + partial LSU $=$ MW845860.

Description: Pileus 8-25 (35) $\mathrm{mm}$ wide, at first (sub)conical or (sub)campanulate, sometimes also almost subglobose, later broadly convex or expanded, without or with large umbo, margin at first slightly incurved, later decurved to straight or even uplifted, and then pileus depressed around the umbo; young basidiomata with a layer of whitish velipellis; colour whitish, beige, ivory, dingy beige to greyishwhitish (Mu 10YR 8/2-8/6, 7/3-7/6), at the centre often yellowish to pale ochraceous with or without orange tinge; surface at first silky smooth to very finely tomentose, with age innately fibrillose, fibrillose to straggly villose with fine fibres, at the centre often finely diffracted to areolate diffracted; young basidiomata with remnants of a cortina. Lamellae subdistant (ca. 40-50, 1 = 1-3), adnate to broadly adnate, with or without subdecurrent tooth, (sub)ventricose, at first whitish, soon yellowish-greyish or greyish-brownish, with age intensely ochraceous-brownish; edge fimbriate, whitish. Stipe 15-45 $\times 1-3 \mathrm{~mm}$, cylindrical or curved, when young covered with whitish tomentum, later longitudinally striate or glabrous, at first dingy whitish or beige, later pale flesh-coloured or pale wood-coloured; pruinose only near the apex of the stipe. Context whitish in the pileus and the stipe, very brittle. Smell faintly (sub)spermatical, at least when cut. Colour of exsiccata pileus dingy greyish-ivory, at the centre almost nutbrown with orange hue (Mu 7/5YR 6/4-6/8; 10YR 6/3-6/8), lamellae and stipe concolorous or a little lighter in colour, no darkening or blackening on drying.

Spores $6.8-10.1 \mu \mathrm{m}$ (av. $8.5 \mu \mathrm{m}$, SD $0.7 \mu \mathrm{m}) \times 4.3-$ $6.0 \mu \mathrm{m}$ (av. $4.9 \mu \mathrm{m}$, SD 0.3 $\mu \mathrm{m}$ ); Q = 1.4-2.1 (av. 1.7, SD $0.1)(n=120$ of 3 coll.); smooth, (sub)amygdaloid, very often characteristically shaped with bulgy dorsal side, without or with suprahilar depression, apex (sub)acute to subpapillate. Basidia 24-28 $\times 7-9 \mu \mathrm{m}$, generally 4-spored, seldom also 2-spored. Lamellae edges sterile, composed of cheilocystidia and numerous colourless, (sub)cylindrical to subclavate, thinwalled paracystidia. Pleurocystidia 44-77 $\mu \mathrm{m}$ (av. $58 \mu \mathrm{m}$, 

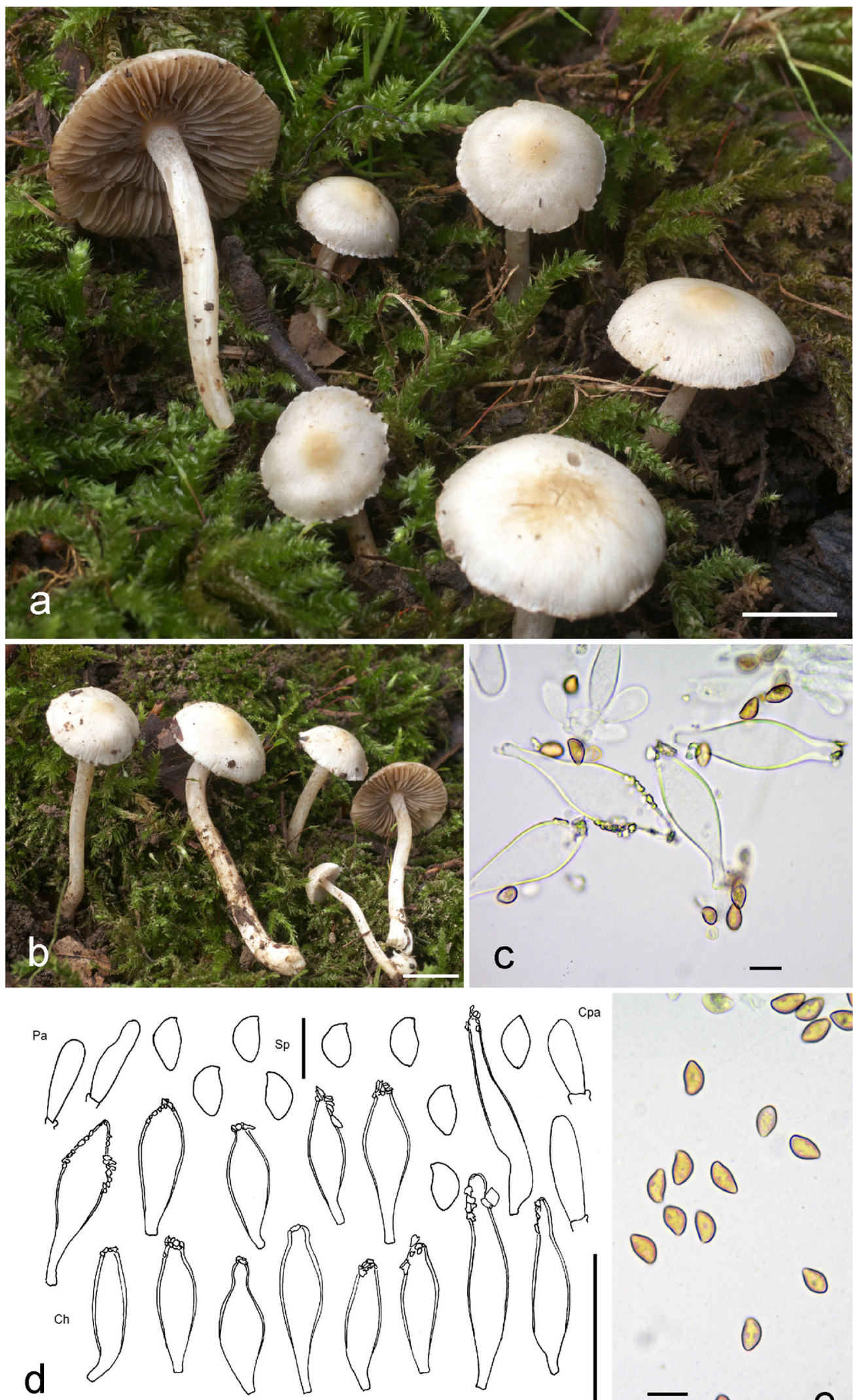

$D^{\prime} B$

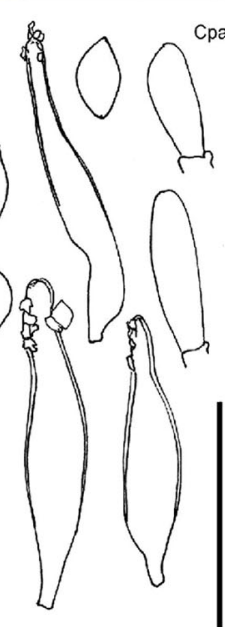

$\mathrm{Ca}$

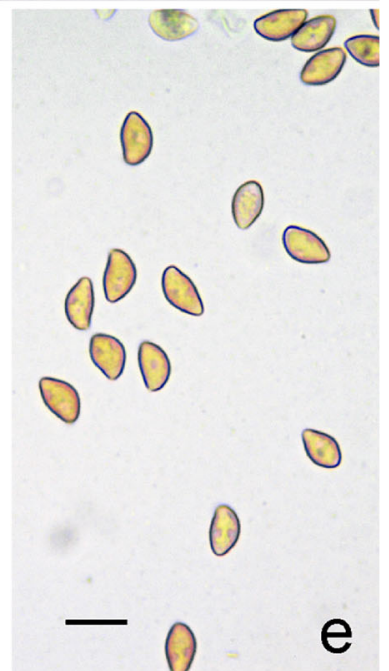

Fig. 4 Inocybe bellidiana, a holotype, scale bar: $1 \mathrm{~cm}$. b Coll. DB18-1019-2, scale bar: $1 \mathrm{~cm}$. c Cheilocystidia (holotype), scale bar: $10 \mu \mathrm{m}$. d Microscopical characters (holotype), $\mathrm{Ca}=$ Caulocystidia, $\mathrm{Cpa}=$
Cauloparacystidia, $\mathrm{Ch}=$ Cheilocystidia, $\mathrm{Pa}=$ Paracystidia, $\mathrm{Pl}=$ Pleurocystidia, $\mathrm{Sp}=$ Spores; scale bar spores: $10 \mu \mathrm{m}$, scale bar cystidia: $50 \mu \mathrm{m}$. e Spores (holotype), scale bar: $10 \mu \mathrm{m}$ 
SD $8 \mu \mathrm{m}) \times 9-19 \mu \mathrm{m}($ av. $13 \mu \mathrm{m}$, SD $3 \mu \mathrm{m}$ ); Q = 2.6-6.6 (av. 4.5 , SD 1.1) ( $\mathrm{n}=45$ of 3 coll.), mostly (sub)fusiform or subcylindrical, sometimes (sub)utriform and occasionally deformed with undate walls, at the apex generally wide and often rounded, without or with only short, often clearly demarcated to subcapitate neck, with short or very long pedicel, apex with or without crystals, walls usually rather thin, up to $1.5 \mu \mathrm{m}$ thick at the apex, yellowish-greenish with $3 \% \mathrm{KOH}$. Cheilocystidia similar in appearance and size. Pileipellis constituted by an epicutis made up of parallel hyphae 3.5-11 $\mu \mathrm{m}$ wide, without or with only very faintly encrusting and parietal yellowish pigment, but mostly colourless, subcutis with wider and paler to colourless elements. Caulocystidia only near the apex of the stipe, 35-70 $\times 8-15 \mu \mathrm{m}$, generally-often somewhat misshaped - subfusiform, with short neck and short pedicel, apex usually crystalliferous, walls up to $1.0 \mu \mathrm{m}$ thick at the apex, yellowish-greenish with $3 \% \mathrm{KOH}$; intermixed with numerous (sub)cylindrical cauloparacystidia. Clampconnections abundant in all tissues.

Habitat and known distribution: Inocybe bellidiana was found by us in Germany on shady pathsides on calcareous soil mostly with frondose trees, preferably with Fagus sylvatica from August to October. Apart from a collection from the Netherlands, examined by us, the species up to now is known only from a sequence in GenBank from New Zealand (as 'I. geophylla', MN047344). From several soil samples (UNITE), it seems that the species is present in Estonia as well.

Further collections studied: GERMANY, BadenWürttemberg, Rhein-Neckar-Kreis, Wiesenbach, TK25 6618/2, alt. 180 m, Pinus sylvestris, Salix sp., 12 Oct 2011, leg. D. Bandini; det. D. Bandini \& B. Oertel (STU SMNSSTU-F-0901475; DB12-10-11-3). Ibidem, in some distance from former location, Fagus sylvatica, Pinus sylvestris, Picea abies, 20 Sep 2013, leg. D. Bandini; det. D. Bandini \& B. Oertel (DB20-9-13-2). Baden-Württemberg, RheinNeckar-Kreis, Wiesenbach, TK25 6619/1, alt. 150 m, Fagus sylvatica, Carpinus betulus, 26 Oct 2015, leg./det. D. Bandini (DB26-10-15-1). Baden-Württemberg, Rhein-Neckar-Kreis, Spechbach, TK25 6619/1, alt. 290 m, Fagus sylvatica, 24 Aug 2019, leg./det. D. Bandini (DB24-8-19-1). BadenWürttemberg, Rhein-Neckar-Kreis, near Waldwimmersbach, TK25 6619/1, alt. 185 m, Fagus sylvatica, 18 Oct 2019, leg./ det. D. Bandini (STU SMNS-STU-F-0901474; DB18-10-192). Baden-Württemberg, Rhein-Neckar-Kreis, Lobbach, TK25 6619/1, alt. 200 m, Fagus sylvatica, 18 Oct 2019, leg./det. D. Bandini (STU SMNS-STU-F-0901525; DB1810-19-3). Baden-Württemberg, Rhein-Neckar-Kreis, Epfenbach, TK25 6619/4, alt. 250 m, Fagus sylvatica, 24 Oct 2020, leg./det. D. Bandini (DB24-10-20-5). Bayern, Neuburg-Schrobenhausen, Nature Reserve 'Kreut', near Neuburg a.d. Donau, TK25 7232/4, alt. 411 m, calcareous soil with Carpinus betulus, Quercus robur, 4 Oct 2020, leg. M.
Wallesch \& L. Krieglsteiner; det. D. Bandini (DB4-10-20Krieglsteiner). Rheinland-Pfalz, Bad Kreuznach, Eckweiler near Rehbach, cemetery, TK25 6111/2, alt. 395 m, Carpinus betulus, Pinus nigra, 23 Oct 2015, leg./det D. Bandini \& B. Oertel (SMNS-STU-F-0901476, DB23-10-15-16). NETHERLANDS, Utrecht, Leersum, Zuilenstein, mixed wood on calcareous soil, 12 Oct 2013, leg. B.J. van den Berg; det. D. Bandini \& B. Oertel (L - BCP0011 (2013)my686).

Comments: Inocybe bellidiana is characterized by rather small brittle basidiomata, whitish to dingy beige pileus colour, mostly becoming at least yellowish at the centre with age, when young smooth, later characteristically finely fibrillose surface with diffracted centre and rather small spores with unusually bulgy dorsal side. Inocybe geophylla (Bulliard 1788-1792), as well as I. miranda Carteret \& Reumaux (Carteret and Reumaux 2013) or I. posterula (Britzelm.) Sacc. (Saccardo 1887; Kühner 1955; Stangl 1985) usually are uniformly whitish to dingy whitish in colour without yellowish diffracted centre, and the spores do not show the typical bulgy dorsal side (see for instance the iconoplate in Bulliard, 1788-1792; Kuyper 1986; Stangl 1989; Carteret and Reumaux 2013, and the epitype of I. geophylla below). Most similar to I. bellidiana in its macroscopic aspect is I. huijsmanii Kuyper. However, the pileus surface of the latter species becomes finely lanose, while the centre is more orange or even greenish in colour with age and not diffracted. Furthermore, the spores are larger on average and less bulgy in shape (Kuyper 1986; Stangl 1989; personal observation, and see below). The pileus of I. bolbitioides Carteret \& Reumaux is (dingy) whitish with darker centre, but the colour of the centre is more brownish. Furthermore, the spores are much longer (Carteret and Reumaux 2013; personal observation and see below comments to I. bolbitioides). The surface of pileus of I. orionis (see below) remains smooth, and the centre is more orange-brownish, while the hymenial cystidia are much shorter and the spores are less bulgy. Inocybe sambucella G.F. Atk. often is entirely yellow(ish) and often has an areolate diffracted centre of pileus (Atkinson 1918, and personal observation). Inocybe sindonia (Fr.) P. Karst differs by often larger basidiomata, not yellowish pileus centre, on average longer spores and longer hymenial cystidia (see Karsten 1879; Kuyper 1986; Stangl 1989).

Based on current knowledge, I. bellidiana is ITSmolecularly rather isolated. Its closest relatives, I. fuscicothurnata Grund \& D.E. Stuntz (see Matheny and Swenie 2018) and the sequence from a collection identified as I. fuscodisca (Peck) Massée (WTU Stz7527), are with 90\% identity in the ITS only distinctly genetically related. The pileus of the former species is more fuscous, the stipe is purplish at the apex and the spores are longer and less bulgy (see Grund and Stuntz 1975). The pileus of the latter species is 'covered 
with blackish brown fibrils' (Peck 1875), and it smells like chestnut flowers.

Inocybe bellidiana seems to be not a very common species. However, it is quite possible that it has sometimes been mistaken for one of the other species of the I. geophylla-group.

Inocybe bolbitioides Carteret \& Reumaux, Cahiers de la FMBDS 2: 45 (2013) Fig. 23 b

$=$ ? Inocybe gypsea Carteret \& Reumaux, Cahiers de la FMBDS 2: 43 (2013)

Description of the species: Carteret and Reumaux 2013.

Studied material (isotype): FRANCE, bois de Voncq (Ardennes), wood with frondose trees, Aug 1982, leg. P. Reumaux (XC2012-72). Spores 9.2-12.4 $\mu \mathrm{m}$ (av. $10.8 \mu \mathrm{m}$, SD $0.7 \mu \mathrm{m}) \times 4.6-6.1 \mu \mathrm{m}($ av. $5.4 \mu \mathrm{m}$, SD $0.3 \mu \mathrm{m}) ; \mathrm{Q}=1.8-$ 2.5 (av. 2.0, SD 0.1) $(\mathrm{n}=40)$, smooth, oblong and narrow, sometimes slightly constricted, with (sub)acute to subobtuse apex. Basidia generally 4-spored, but some also 2-spored. Pleurocystidia 53-73 $\mu \mathrm{m}$ (av. $58 \mu \mathrm{m}$, SD $6 \mu \mathrm{m}) \times 7-14$ $\mu \mathrm{m}$ (av. $10 \mu \mathrm{m}, \mathrm{SD} 2 \mu \mathrm{m}$ ); Q = 4.0-9.1 (av. 5.9, SD 1.3) (n $=15$ ), mostly (sub)cylindrical to (sub)fusiform, without or with only short neck, with short or longer pedicel, apex usually crystalliferous, walls up to $1.0(1.5) \mu \mathrm{m}$ thick, colourless with $3 \% \mathrm{KOH}$. Cheilocystidia not observed, because only a very small bit of a lamellae and no edge of a lamellae was obtained. Paracystidia not observed. Caulocystidia not studied, because stipe not present.

Comments: The type of I. bolbitioides is rather similar to that of $I$. gypsea and the species are possibly synonymous. Because of lingering doubt, we prefer to keep them separate for the time being. Molecular data is not available for either I. bolbitioides or I. gypsea. As both species were published simultaneously, none of the names has priority by default. No sequence information has been published for either of these two taxa. It is further possible that I. phaeodisca var. geophylloides (Kühner 1955; Kuyper 1986) corresponds to I. bolbitioides and/or I. gypsea. It furthermore cannot entirely be excluded that I. bolbitioides (and perhaps also I. gypsea if the two species are synonymous) in fact is synonymous to I. huijsmanii, and the differences in spore size are due to the 2-spored basidia.

Inocybe cincinnata (Fr.) Quél., Mém. Soc. Émul. Montbéliard, Sér. 2 5: 179 (1872) Fig. 23 c

$=$ Inocybe conformata $\mathrm{P}$. Karst., Bidr. Känn. Finl. Nat. Folk 48: 465 (1889)

Description of the species: Karsten 1889, and see below.

Studied material (neotype of I. cincinnata, designated by Kuyper 1989): Sweden, Småland, Femsjö, Löjenäs, meadow with short grass, 18 Sep 1980, leg./det. M. Moser \& R. Pöder (IB-19800323; duplicate STU SMNS-STU-F-0901517). Spores 7.0-8.9 $\mu \mathrm{m}$ (av. 8.3 $\mu \mathrm{m}$, SD $0.4 \mu \mathrm{m}) \times 4.5-5.5 \mu \mathrm{m}$ (av. $5.2 \mu \mathrm{m}$, SD $0.3 \mu \mathrm{m}) ; \mathrm{Q}=1.4-1.8$ (av. 1.6, SD 0.1) $(\mathrm{n}=$
40), smooth, broadly (sub)amygdaloid, usually without suprahilar depression, apex (sub)acute. Basidia 4-spored. Pleurocystidia $67-89 \mu \mathrm{m}$ (av. $78 \mu \mathrm{m}$, SD $7 \mu \mathrm{m}) \times 14-23$ $\mu \mathrm{m}$ (av. $18 \mu \mathrm{m}, \mathrm{SD} 2 \mu \mathrm{m}) ; \mathrm{Q}=3.1-5.8$ (av. 4.5, SD 0.7) $(\mathrm{n}=$ $15)$, characteristically lanceolate, apex usually crystalliferous, walls up to 1.5 (2.0) $\mu \mathrm{m}$ thick at the apex, intensely yellowgreen with 3\% $\mathrm{KOH}$. Cheilocystidia similar in appearance and size. Paracystidia not observed. Caulocystidia not studied (to preserve the material).

Studied material (holotype of I. conformata), Fig. 23 e: FINLAND, Tavastia, Tammela, Syriä, Mustiala, in a garden at the wayside, 8 Aug 1889, leg. P.A. Karsten (H-6074688). Spores 7.5-9.7 $\mu \mathrm{m}($ av. $8.7 \mu \mathrm{m}$, SD $0.5 \mu \mathrm{m}) \times 4.6-6.0 \mu \mathrm{m}$ (av. $5.2 \mu \mathrm{m}$, SD $0.3 \mu \mathrm{m})$; $\mathrm{Q}=1.4-1.8$ (av. 1.7, SD 0.1) $(\mathrm{n}=$ 40), smooth, (sub)amygdaloid, with (sub)acute to (sub)papillate apex. Basidia generally 4-spored, but also 2spored, and then spores up to $10.7 \mu \mathrm{m}$. Pleurocystidia 56$80 \mu \mathrm{m}$ (av. $65 \mu \mathrm{m}$, SD $6 \mu \mathrm{m}$ ) $\times 9-16 \mu \mathrm{m}$ (av. $13 \mu \mathrm{m}$, SD 2 $\mu \mathrm{m}) ; \mathrm{Q}=4.1-6.3$ (av. 5.1, SD 0.7) $(\mathrm{n}=15)$, mostly slender sublanceolate or subfusiform, with short or rather long neck, with short pedicel, apex usually crystalliferous, walls up to 2.5 (3.0) $\mu \mathrm{m}$ thick at the apex, intensely yellow-green with $3 \%$ $\mathrm{KOH}$. Cheilocystidia similar in appearance and size. Paracystidia not observed. Caulocystidia only near the apex of the stipe, similar in size and shape, only with somewhat thinner walls, intermixed with subclavate paracystidia.

Selected other studied material: AUSTRIA, Salzburg, Tamsweg, ÖK25V 3230-Ost, alt. 1490 m, Picea abies, 19 Sep 2020, leg. D. Bandini; det. D. Bandini \& B. Oertel (STU SMNS-STU-F-0901571; DB19-9-20-14). FINLAND, Tavastia, Tammela, Syriä, Mustiala, at the wayside, 8 Aug 1889, leg. P. A. Karsten (1608b; H-6006855). GERMANY Bayern, Regen, Lindberg, Zwieslerwaldhaus, Bärenloch, TK25 6845/4, alt. 900 m, Fagus sylvatica, Picea abies, Petasites, 19 Aug 2016, leg. D. Bandini, C. Hahn \& J. Christan; det. D. Bandini \& B. Oertel (STU SMNS-STU-F0901575; DB19-8-16-19).

Comments: Kuyper (1989) selected the neotype of I. cincinnata without providing a macromorphological description of the material. Our attempts to sequence the material failed. However, the microscopic details of the neotype fit very well to a species we had been referring to as I. cincinnata for a long time. The pileus surface of I. cincinnata has only a very faint velipellis when young and is verrucose to areolate diffracted at the centre, while finely fibrillose with more or less diverging fibres towards the margin, sometimes also somewhat lacerated with age. The lamellae are broadly adnate and soon intensely rusty to reddish brown with at first whitish, but soon concolourous edge. The stipe is violet-lilac at least near the apex of young basidiomata and mostly covered with brownish villose fibres. The paracystidia of older basidiomata are brownish. There are several descriptions of I. cincinnata in the literature (see e.g. 
Kuyper 1986 as 'I. phaeocomis var. phaeocomis'; Ludwig 2017), but it is not entirely clear, whether they refer to I. cincinnata, or a similar species, e.g. I. drenthensis, I. gaiana or I. tiburtina or mixture of species.

No molecular data could be obtained from the type material of I. conformata. The type of I. pusio P. Karst and the type of I. conformata were collected on the same day in the same location (8 Aug 1889, Mustiala Park, see Karsten 1889). The type material of $I$. pusio consists of two different species, as had already been noted by Kuyper (17 May 1984, herbarium slip) and thence part of the material had been separated and given the new number 1608b, respectively H-6006855). As Kuyper noted, too, this material corresponds very well with the description of I. conformata. It appears very likely that some I. conformata material was erroneously added to the collection of I. pusio. We got a sequence result for collection $1608 \mathrm{~b}$ and this and the microscopic findings match very well with what we consider to be I. cincinnata. Given the circumstances, we consider this sequence as a confirmation that I. conformata is indeed a synonym of I. cincinnata.

Species that are here referred to as the cincinnatagroup' have the same type of lanceolate (sub)fusiform, often rather thick-walled hymenial cystidia with often rather long necks, the walls of which react strongly with $\mathrm{KOH}$. Apart from I. cincinnata, the group comprises, e.g. I. curtispora E. Ludw., I. gracillima Carteret \& Reumaux, I. minima Peck, I. obscuroides P.D. Orton, I. sitibunda and I. tiburtina. They differ from I. cincinnata, e.g. by texture of the pileus, spore-size and length of hymenial cystidia (see below, and personal observation). While I. cincinnata can be found on acid as well as calcareous influenced soils, some of these, e.g. I. sitibunda and I. tiburtina, are according to our observations furthermore restricted to calcareous habitats. The variety I. cincinnata var. major (S. Petersen) Kuyper (Kuyper 1989) deserves species rank and is included here under I. obscuroides. In Fig. 1, two of our own collections, corresponding to the original description of I. cincinnata, were selected to represent the species.

Inocybe clandestina Bandini, B. Oertel \& U. Eberh. sp. nov. Fig. 5

MycoBank number: MB 839155

Etymology: Named 'clandestina', the 'clandestine one', because the species seems to grow only on special and rare locations.

Diagnosis: Inocybe clandestina has a dark reddish brown to almost blackish brown smooth to minutely tomentose, with age towards the margin or entirely paling pileus surface with often areolate diffracted centre, rather distant thickish lamellae, stipes that are getting partially brownish to dark brown with age, smooth spores, measuring 7.6-10.7 $\mu \mathrm{m}$ (av. 9.2 $\mu \mathrm{m}$ ) $\times 4.7-6.0 \mu \mathrm{m}$ (av. $5.3 \mu \mathrm{m}$ ) and often subcylindrical to subfusiform hymenial cystidia, pleurocystidia measuring 38 $74 \mu \mathrm{m}$ (av. $59 \mu \mathrm{m}) \times 11-18 \mu \mathrm{m}$ (av. $14 \mu \mathrm{m}$ ). This combination of characters as well as ITS sequence data distinguishes I. clandestina from superficially similar species such as I. tarda or the phylogenetically related I. astraiana.

Holotype: GERMANY, Bayern, Kelheim, AbensbergOffenstetten, TK25 7137/3, alt. ca. 380 m, Pinus sylvestris, 11 Oct 2017, leg. D. Bandini \& B. Oertel (holotype STU SMNS-STU-F-0901267; isotype priv. herb. D.B. DB11-1017-16). GenBank: ITS + partial LSU = MW845865.

Description: Pileus 10-30 mm wide, conical when young, later subconical, broadly convex to expanded, at first sometimes without, but soon with explicit large umbo; margin at first slightly inflexed to slightly decurved, later straight to weakly uplifted and then depressed around the centre; when young covered with pale greyish velipellis, to be observed later only at the centre of the pileus or sparely also radially scattered towards the margin; colour usually dark reddish brown to dark brown with reddish hue (Mu 5YR 4/4-4/6; 7.5YR 4/4-4/6, 3/2-3/4), at and around the centre also almost blackish brown, towards margin fading in colour with age and then as if the surface were very finely rubbed off in parts and thus looking somewhat marbled or strongly discoloured; thus often with strong colour contrast, but also entirely paler with age; surface at first glabrous to almost satiny smooth, at the umbo usually diffracted to areolate diffracted, with age sometimes finely tomentose towards the margin; young basidiomata with faint remnants of a cortina. Lamellae subdistant to distant (ca. 25-35, 1 = 1-3), thickish, sometimes uneven, adnexed to broadly adnate with decurrent tooth, ventricose, at first whitish, later with ochraceous hue, ochraceous brownish to intensely rusty brown; edge fimbriate, whitish to concolorous. Stipe $25-50 \times 1-3 \mathrm{~mm}$, cylindrical or curved, sometimes slightly widening towards the base, when young finely covered with whitish tomentum, soon longitudinally striate to glabrous, at first watery whitish, later up to reddish-brownish, typically getting brownish to dark brown with age in some parts; sparely and roughly pruinose only near the apex of the stipe. Context watery pale ochraceous with reddish hue in pileus and stipe. Smell spermatical, at least when cut. Colour of exsiccata pileus dark greyish brown, dark brown with or without more or less intense reddish hue $(\mathrm{Mu}$ 7/5YR 3/2-3/4; 10YR 3/3-3/6), lamellae and stipe lighter in colour with or without reddish hue, no darkening or blackening, but in some basidiomata becoming a little greyish on drying.

Spores 7.6-10.7 $\mu \mathrm{m}$ (av. 9.2 $\mu \mathrm{m}$, SD $0.6 \mu \mathrm{m}) \times 4.7-$ $6.0 \mu \mathrm{m}$ (av. $5.3 \mu \mathrm{m}$, SD $0.3 \mu \mathrm{m}$ ); $\mathrm{Q}=1.5-2.0$ (av. 1.7, SD $0.1)(\mathrm{n}=120$ of 3 coll.); smooth, (sub)amygdaloid, sometimes bulgy, often with more or less explicit suprahilar depression, apex subacute, subobtuse, mostly with indistinct pseudoporus. Basidia 25-35 × 7-9 (10) $\mu \mathrm{m}$, generally 4-spored, sometimes 

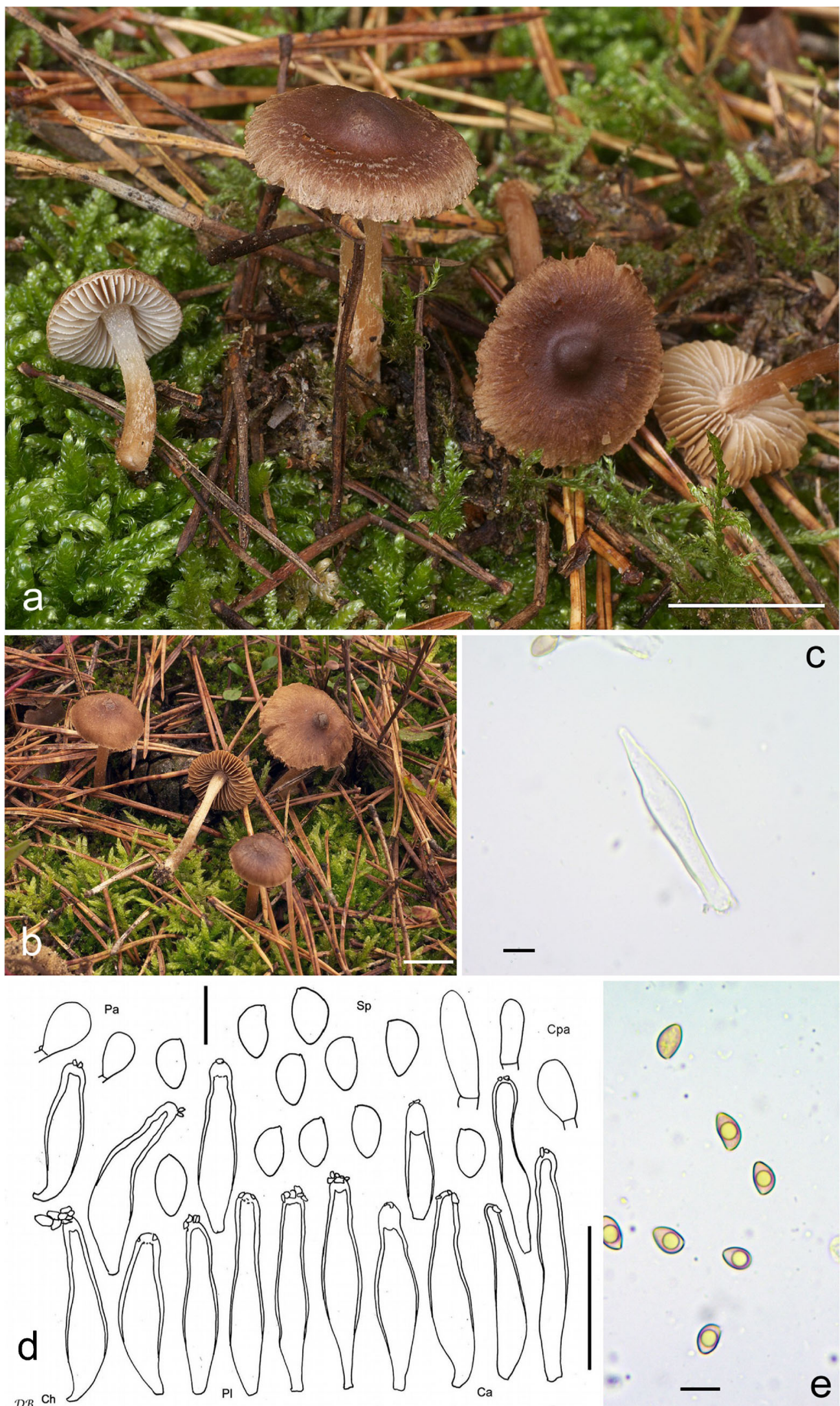

Fig. 5 Inocybe clandestina, a holotype, scale bar: $1 \mathrm{~cm}$. b Coll. DB1210-17-5, scale bar: $1 \mathrm{~cm}$. c Pleurocystide (holotype), scale bar: $10 \mu \mathrm{m}$. d Microscopical characters (holotype), $\mathrm{Ca}=$ Caulocystidia, $\mathrm{Cpa}=$
Cauloparacystidia, $\mathrm{Ch}=$ Cheilocystidia, $\mathrm{Pa}=$ Paracystidia, $\mathrm{Pl}=$ Pleurocystidia, $\mathrm{Sp}=$ Spores; scale bar spores: $10 \mu \mathrm{m}$, scale bar cystidia: $50 \mu \mathrm{m}$. e Spores (holotype), scale bar: $10 \mu \mathrm{m}$ 
also 2-spored, and then spores up to $12.7 \mu \mathrm{m}$. Lamella edge sterile, composed of cheilocystidia and numerous colourless, (sub)clavate, thin-walled paracystidia. Pleurocystidia 38-74 $\mu \mathrm{m}$ (av. $59 \mu \mathrm{m}, \mathrm{SD} 8 \mu \mathrm{m}) \times 11-18 \mu \mathrm{m}$ (av. $14 \mu \mathrm{m}, \mathrm{SD} 2 \mu \mathrm{m}$ ); $\mathrm{Q}=2.5-5.7$ (av. 4.3, SD 0.7 ) ( $\mathrm{n}=45$ of 3 coll.), generally rather slender subcylindrical to subfusiform, also (sub)utriform, usually with short or longer neck, at the apex wide, with short pedicel or with truncate base, apex usually crystalliferous, walls up to $1.5(2.5) \mu \mathrm{m}$ thick at the apex, pale yellowish-greenish with $3 \% \mathrm{KOH}$. Cheilocystidia similar in appearance and size. Pileipellis constituted by an epicutis made up of parallel hyphae $5-11 \mu \mathrm{m}$ wide, with encrusting and parietal ochraceous brownish pigment, subcutis with wider and paler to colourless elements. Caulocystidia only near the apex of the stipe, 40-80 × 9-13 (15) $\mu \mathrm{m}$, mostly rather long and narrow, subcylindrical, (sub)utriform or subfusiform, neck sometimes with undate walls, without or with only short pedicel, apex usually crystalliferous, walls up to $1.0(1.5) \mu \mathrm{m}$ thick at the apex, pale yellowish-greenish with $3 \% \mathrm{KOH}$; intermixed with numerous (sub)clavate cauloparacystidia. Clamp-connections abundant in all tissues.

Habitat and known distribution: Inocybe clandestina has up to now only been found on extreme, rather distinctive locations: once on ashes of a fireplace and the other collections in sandy terrain of inland dunes with Pinus sylvestris. Two sequences in GenBank from collections from Poland (as 'I. spec.', KM409417 and KM409416) are putatively from the species. Several EcM sequences possibly also belong to this species, from Poland (KP731837, with Quercus petraea), Lithuania (MG590039 and MG590040, both with Pinus sylvestris) and Italy (DQ054567 and DQ054573). It appears that the species has also been retrieved from several soil samples (UNITE) and is present in Estonia and Latvia. Apparently, I. clandestina often associates with Pinus sylvestris.

Further collections studied: GERMANY, Bayern, Kelheim, Abensberg-Offenstetten, TK25 7137/3, alt. ca. 380 m, Pinus sylvestris, 9 Oct 2017, leg. D. Bandini, B. Oertel \& J. Christan; det. D. Bandini \& B. Oertel (STU SMNS-STU-F0901436; DB9-10-17-14). Ibidem, in some distance from former location, alt. ca. 380 m, Pinus sylvestris, 11 Oct 2017, leg./det. D. Bandini \& B. Oertel (DB11-10-17-3). Ibidem, in some distance from former location, alt. ca. $380 \mathrm{~m}$, Pinus sylvestris, 11 Oct 2017, leg./det. D. Bandini \& B. Oertel (DB11-10-17-4). Ibidem, in some distance from former location, alt. ca. 380 m, Pinus sylvestris, 11 Oct 2017, leg./det. D. Bandini \& B. Oertel (DB11-10-17-7). Ibidem, in some distance from former location, alt. ca. $380 \mathrm{~m}$, Pinus sylvestris, 12 Oct 2017, leg. D. Bandini, B. Oertel \& J. Christan; det. D. Bandini \& B. Oertel (DB12-10-17-4). Ibidem, in some distance from former location, alt. ca. $380 \mathrm{~m}$, Pinus sylvestris, 12 Oct 2017, leg. D. Bandini, B. Oertel \& J. Christan; det. D.
Bandini \& B. Oertel (DB12-10-17-5). Sachsen-Anhalt, Harz, Oberharz am Brocken, Kramershai, TK25 4229/4, alt. 660 m, on ashes of a campfire, near Picea abies, 3 Oct 2012, leg. D. Bandini \& H. Schubert; det. D. Bandini \& B. Oertel (DB3-1012-10). Sachsen-Anhalt, Jerichower Land, Gommern, TK25 3936/2, alt. $50 \mathrm{~m}$, inland dunes with Pinus sylvestris, 24 Nov 2014, leg. R. Geiter; det. D. Bandini \& B. Oertel (DB24-11-14-Geiter).

Comments: Inocybe clandestina is characterized by smooth to minutely tomentose dark reddish brown to almost blackish brown pilei with often areolate diffracted centres, surface with age partly or entirely strongly paling, rather distant thickish lamellae, and stipes that are becoming partially brownish to dark brown with age. It is quite possible that I. clandestina has often been mistaken for I. tarda Kühner, growing in the same habitat, i.e. sandy inland dunes with Pinus. Furthermore, its caps also are rather smooth and dark to blackish brown. However, it differs, e.g. by the much larger spores and the on average larger hymenial cystidia, and stipes that are pinkish entirely or at least towards the apex and not becoming brown with age (Kühner 1955; personal observation, and see below). Inocybe psammobrunnea Bon, a species also found with Pinus on sandy terrain, differs, e.g. by the robust stature, more velipellis, visible also later as large patch at the pileus centre, and by on average larger spores (Bon 1990; personal observation, and see below).

The pileus colour of I. nitidiuscula is paler, its spores are larger and the neck of the hymenial cystidia is generally narrowing towards the apex (Britzelmayr 1891; Stangl 1983, 1989; Kuyper 1986; Marchetti et al. 2014). Inocybe astraiana Bandini \& B. Oertel also is to be found in the same habitat; however, the pileus of this species is usually somewhat paler in colour, the hymenial cystidia are generally not subcylindrical in shape, and the stipes are not getting brown in parts with age (Bandini et al. 2020a). The species is however related to I. clandestina with 95\% identity in the ITS (see Fig. 1). With $97 \%$ identity in the ITS, even closely related to I. clandestina is I. nemorosa (R. Heim) Grund \& D.E. Stuntz (see Fig. 1). The pileus of this species can also be dark brown, but the hymenial cystidia generally are not subcylindrical but (sub)fusiform in shape, and the spores are wider on average (Grund and Stuntz 1968, and personal observation). It is impossible to know with any degree of certainty whether I. nemorosa ss. Grund \& Stuntz is the same as I. friesii f. nemorosa of R. Heim (Heim 1931). No authentic material exists of this species in the herbarium of Montpellier (email by Caroline Loup, 23 Aug 2019). A collection identified as I. nemorosa in a French article (Lainé 2014) was sequenced by us and turned out to be I. semifulva Grund \& D.E. Stuntz (see Fig. 1), and in Europe frequent but still not well-known 
species (personal observation, and see Grund and Stuntz 1981; Bandini 2014). Inocybe clandestina probably is a rather rare species, but has very likely been mistaken for other species, such as I. tarda.

\section{Inocybe clarkii (Fig. $23 \mathrm{~d}$ ) $\rightarrow$ Inocybe sindonia}

\section{Inocybe conformata (Fig. 23 e) $\rightarrow$ Inocybe cincinnata}

Inocybe costinitii Bizio, Ferisin \& Dovana, Micol. Veg. Medit. 31(2): 95 (2016) Fig. 23 f

Description of the species: Bizio et al. 2016.

Studied material (holotype): Croatia, Istria, Campeggio Lanterna, comune di Tar (Torre), Pinus halepensis, 1 Jan 2014, leg. G. Ferisin \& M. Olivi (MCVE-28974). GenBank ITS $=$ KX686581. Spores 8.7-10.7 $\mu \mathrm{m}$ (av. 9.9 $\mu \mathrm{m}$, SD $0.5 \mu \mathrm{m}) \times 5.2-6.9 \mu \mathrm{m}$ (av. $5.8 \mu \mathrm{m}$, SD $0.4 \mu \mathrm{m})$; Q $=1.4-1.9(\mathrm{av} \cdot 1.7, \mathrm{SD} 0.1)(\mathrm{n}=40)$, smooth, (sub)amygdaloid, with (sub)acute to (sub)papillate apex. Basidia 4-spored, rarely also 2-spored, and then spores misshaped and up to $13 \mu \mathrm{m}$. Pleurocystidia 56-80 $\mu \mathrm{m}$ (av. $67 \mu \mathrm{m}$, SD $7 \mu \mathrm{m}) \times 9-22 \mu \mathrm{m}$ (av. $14 \mu \mathrm{m}$, SD $3 \mu \mathrm{m}) ; \mathrm{Q}=3.0$ 8.0 (av. 5.1, SD 1.3) ( $\mathrm{n}=15)$, mostly (sub)fusiform, also (sub)cylindrical or (sub)clavate, sometimes with rather long pedicel, apex usually crystalliferous, walls usually rather thin, up to $1.5(2.5) \mu \mathrm{m}$ thick, pale yellowish-greenish with $3 \%$ $\mathrm{KOH}$. Cheilocystidia somewhat more variable in shape and size. Paracystidia not observed. Caulocystidia not studied, because stipe not present.

Comments: In molecular analysis, the species is in the same clade as $I$. beatifica, but clearly distinct. All other sequences presumably belonging to this species stem from a single study in France (Napoli et al. 2010). For morphological distinction, see under I. beatifica.

Inocybe crocifolia Herink, Česká Mykol. 8(3): 121 (1954), non Inocybe croceifolia Beller, Docums Mycol. 7(25): 57 (1976) nom. illegit. (homonym) Fig. 23 g

Description of the species: Herink 1954.

Studied material (holotype): Czech Republic, Mnichovo Hradiště (distr. Mladá Boleslav), alt. ca. $250 \mathrm{~m}$, on bare soil with Tilia cordata, 27 Jun 1953, leg. J. Herink (PRM-756500) GenBank: ITS = MW845867. Spores 8.8-11.8 $\mu \mathrm{m}$ (av. 10.5 $\mu \mathrm{m}$, SD $0.6 \mu \mathrm{m}) \times 4.5-5.7 \mu \mathrm{m}$ (av. $5.0 \mu \mathrm{m}$, SD $0.3 \mu \mathrm{m}) ; \mathrm{Q}=$ 1.8-2.6 (av. 2.1 SD 0.2) ( $\mathrm{n}=40$ ), smooth, subamygdaloid, oblong, with subobtuse to subacute apex. Basidia 4-spored. Pleurocystidia 52-69 $\mu \mathrm{m}$ (av. $60 \mu \mathrm{m}$, SD $5 \mu \mathrm{m}) \times 11-17 \mu \mathrm{m}$ (av. $14 \mu \mathrm{m}, \mathrm{SD} 2 \mu \mathrm{m}) ; \mathrm{Q}=3.3-5.6($ av. 4.2, SD 0.7) $(\mathrm{n}=15)$, mostly (sub)fusiform, apex usually crystalliferous, walls up to $1.5(2.0) \mu \mathrm{m}$ thick at the apex, yellowish-greenish with 3\% $\mathrm{KOH}$. Cheilocystidia similar in appearance and size. Paracystidia not observed. Caulocystidia not studied (to preserve the material).
Comments: We are not aware of any published sequences from specimen samples that are likely to be conspecific with I. crocifolia. The closest relatives that have been sequenced have been retrieved from soil or ectomycorrhiza samples (see Fig. 1).

Inocybe drenthensis Bandini \& B. Oertel sp. nov. Fig. 6 MycoBank number: MB 839156

Etymology: Named 'drenthensis', because the type of the species was collected in the province Drenthe in the Netherlands.

Diagnosis: Inocybe drenthensis is a rather small species with often quite rigid stipe, finely rimulose or finely innately fibrillose speckled brown surface with verrucose to areolate diffracted, orange-reddish tinged centre of pileus, at least towards the apex violet stipe, subdistant thickish lamellae, smooth spores, measuring 7.4-10.0 $\mu \mathrm{m}($ av. $8.6 \mu \mathrm{m}) \times 4.3-$ $5.7 \mu \mathrm{m}$ (av. $5.1 \mu \mathrm{m}$ ), mostly subfusiform hymenial cystidia, pleurocystidia measuring $44-82 \mu \mathrm{m}$ (av. $58 \mu \mathrm{m}) \times 10-22 \mu \mathrm{m}$ (av. $14 \mu \mathrm{m}$ ) and mostly (sub)lageniform caulocystidia at the extreme apex of the stipe. This combination of characters as well as ITS sequence data distinguishes $I$. drenthensis from all other species of the I. cincinnata-group, such as I. cincinnata, I. obscuroides or the phylogenetically related I. sitibunda.

Holotype: NETHERLANDS, Drenthe, near Stuifzand, alt. 20 m, Quercus robur, Pinus sylvestris, Salix sp., Betula sp., 30 Sep 2019, leg. D. Bandini (holotype STU SMNS-STU-F0901477; isotype priv. herb. D.B. DB30-9-19-1, AH 56132). GenBank: ITS + partial LSU $=$ MW845869.

Description: Pileus 10-25 mm wide, at first (sub)conical, later broadly convex or expanded, mostly with more or less pronounced large umbo, margin at first decurved, later straight or even uplifted, and then pileus depressed around the umbo; no remnants of a velipellis observed; colour speckled pale brownish with darker brown fibres on paler ones (Mu 10YR 7/3-7/8, 6/6-6/8, 5/6-5/8), sometimes much paler, fallow, dingy beige or pale straw-coloured towards the margin with age, at the centre quite often with orange-reddish hue; surface at first mostly finely tomentose, later verrucose or areolate diffracted at the centre and finely rimulose or finely innately fibrillose towards the margin, sometimes excoriating towards the margin with age; young basidiomata with faint brownish remnants of a cortina. Lamellae subdistant to moderately crowded (ca. 25-35 (40), 1 = 1-3), thickish, broadly adnate with decurrent tooth, subventricose, at first pale greyish, pale greyish-brownish, later pale coffee-brown to brown with greyish or reddish hue; edge fimbriate, whitish. Stipe $30-55$ $\times 1-4 \mathrm{~mm}$, cylindrical, mostly quite rigid, sometimes curved, when young covered with faint whitish tomentum, later longitudinally striate or glabrous, at the apex intensely violet or lilac, beneath pale violet when young, with age pale brownish with or without violet hue below the apex, which remains violet; pruinose only at the extreme apex of the stipe. 

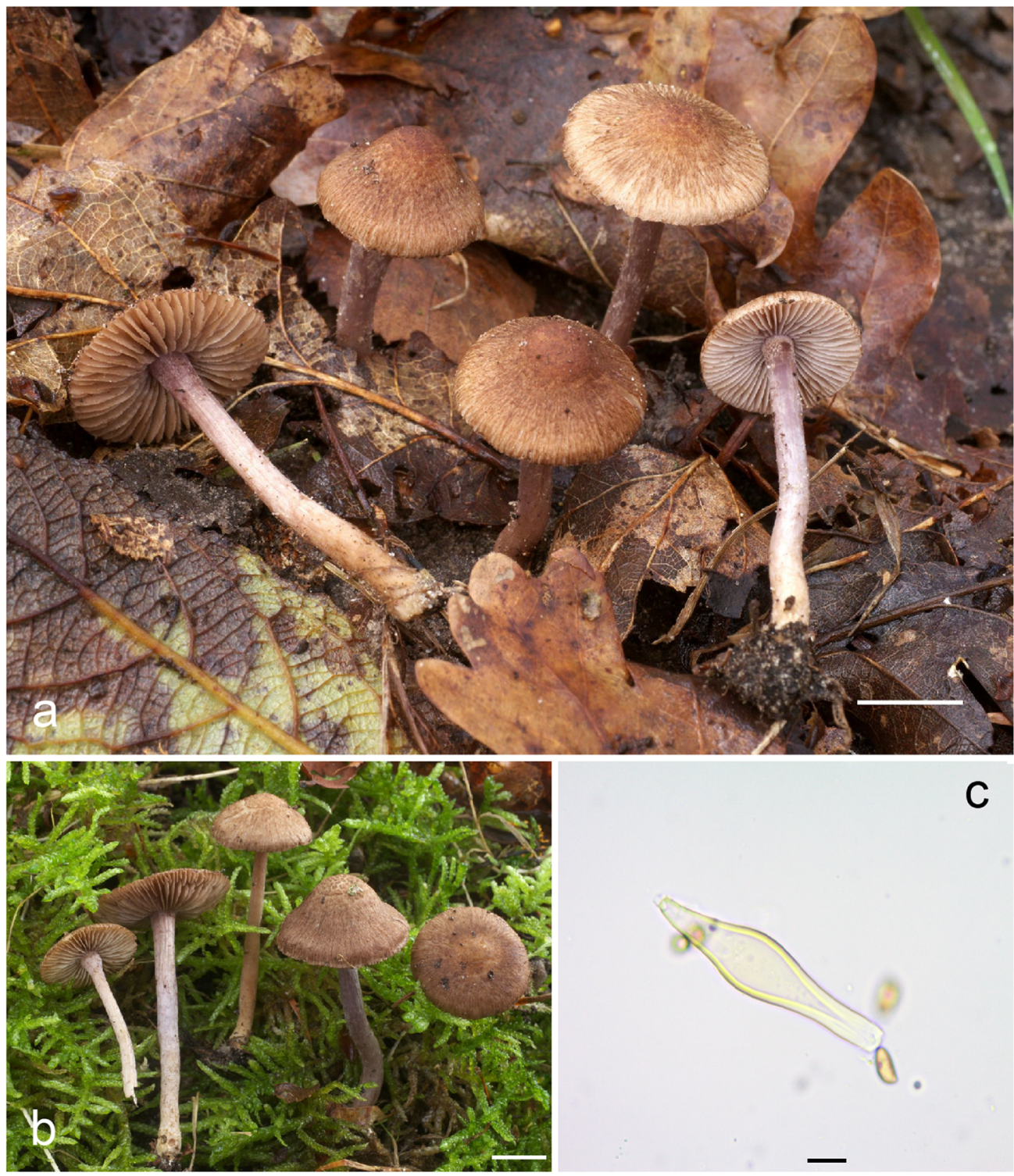

C

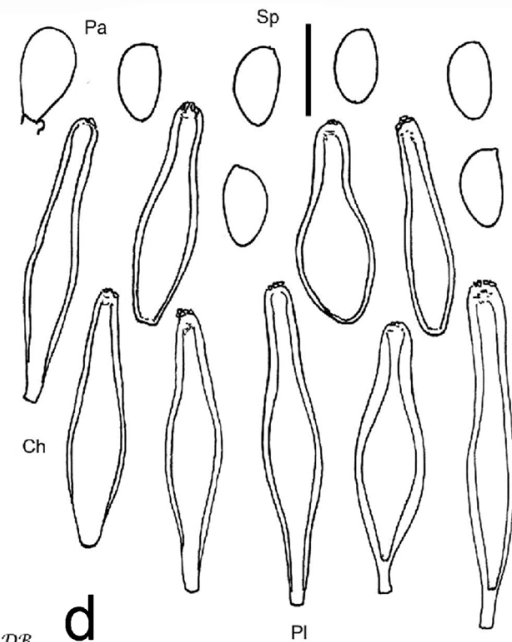

$D^{\prime} B$

Fig. 6 Inocybe drenthensis, a holotype, scale bar: $1 \mathrm{~cm}$. b Coll. DB4-1019-2, scale bar: $1 \mathrm{~cm}$. c Cheilocystide (coll. DB30-9-19-17), scale bar: 10 $\mu \mathrm{m}$. d Microscopical characters (holotype) $\mathrm{Ca}=$ Caulocystidia, $\mathrm{Cpa}=$

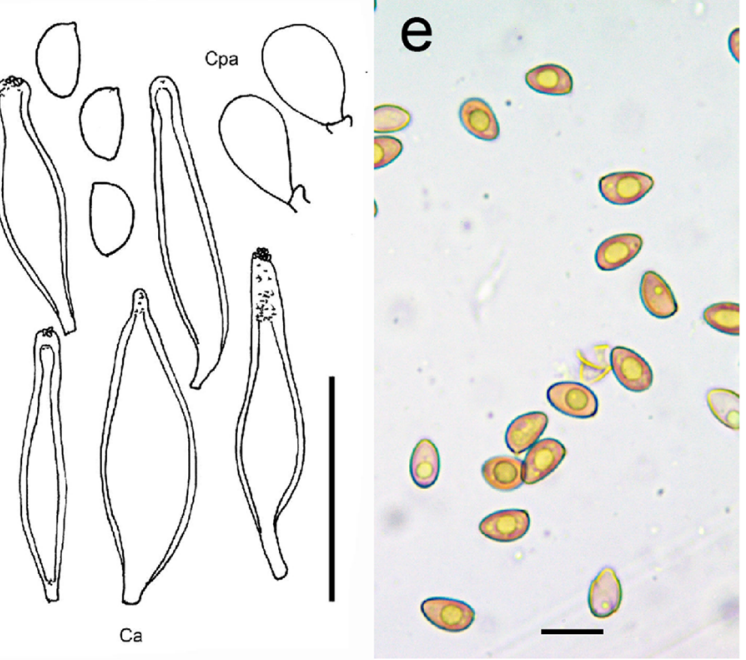

Cauloparacystidia, $\mathrm{Ch}=$ Cheilocystidia, $\mathrm{Pa}=$ Paracystidia, $\mathrm{Pl}=$ Pleurocystidia, $\mathrm{Sp}=$ Spores; scale bar spores: $10 \mu \mathrm{m}$, scale bar cystidia: $50 \mu \mathrm{m}$. e Spores (coll. DB30-9-19-17), scale bar: $10 \mu \mathrm{m}$ 
Context whitish in the pileus, pale lilac in the cortex of the stipe, otherwise whitish in the stipe. Smell (sub)spermatical, at least when cut. Colour of exsiccata pileus brown to dark brown with or without faint reddish hue (Mu 10YR 4/4-4/6; 7/5YR 4/4-4/6), lamellae concolorous or a little lighter in colour, stipe often becoming greyish with faint violet tinge on drying.

Spores 7.4-10.0 $\mu \mathrm{m}($ av. $8.6 \mu \mathrm{m}, \mathrm{SD} 0.5 \mu \mathrm{m}) \times 4.3-$ $5.7 \mu \mathrm{m}$ (av. $5.1 \mu \mathrm{m}, \mathrm{SD} 0.2 \mu \mathrm{m}$ ); $\mathrm{Q}=1.5-2.0$ (av. 1.7, SD $0.1)(n=120$ of 3 coll.); smooth, (sub)amygdaloid, often oblong, without or with only faint suprahilar depression, apex subacute, with indistinct pseudoporus; in basdiomata with many 2-spored basidia often somewhat misshaped or laceroid. Basidia 22-31 × 7-9 (10) $\mu \mathrm{m}, 4$-spored and 2-spored, and then spores up to $12.2 \mu \mathrm{m}$. Lamellae edges sterile, composed of cheilocystidia and numerous colourless, (sub)clavate, thinwalled paracystidia, in some collections also in intermediate states slightly thick-walled. Pleurocystidia 44-82 $\mu \mathrm{m}$ (av. 58 $\mu \mathrm{m}$, SD $9 \mu \mathrm{m}) \times 10-22 \mu \mathrm{m}$ (av. $14 \mu \mathrm{m}$, SD $2 \mu \mathrm{m}) ; \mathrm{Q}=2.6-$ 6.2 (av. 4.3, SD 0.8) ( $\mathrm{n}=45$ of 3 coll.), mostly (sub)fusiform, more rarely (sub)utriform or (sub)lageniform, at the apex somewhat narrowing, with short or longer neck, mostly with short pedicel and in every collection always some cystidia with truncate or rounded base, apex usually minutely crystalliferous, walls up to 2.5 (3.0) $\mu \mathrm{m}$ thick at the apex, mostly quite homogenous wide near bulge and towards the apex, yellow-green with 3\% KOH. Cheilocystidia similar in size, but more variable in shape. Pileipellis constituted by an epicutis made up of parallel hyphae 5-12 $\mu \mathrm{m}$ wide, with encrusting and parietal brownish to dark brown pigment, subcutis with wider and paler to colourless elements. Caulocystidia only near the apex of the stipe, 45-75 $\times 10$ $20 \mu \mathrm{m}$, mostly fusiform to sublageniform, with narrowing, sometimes slightly undate neck towards the apex, apex sometimes subpapillate, usually without or with only short pedicel or truncate base, often minutely crystalliferous, walls up to 1.0 (1.5) $\mu \mathrm{m}$ thick at the apex, yellow-green with $3 \% \mathrm{KOH}$; intermixed with numerous colourless paracystidia in different shapes also in intermediate states and then with slightly thickened walls, sometimes also catenate. Clamp-connections abundant in all tissues.

Habitat and known distribution: Almost all collections known so far were found in the Netherlands, in the province Drenthe. All of them were collected underneath Quercus robur and often also Salix. One collection from Germany was associated with Fagus sylvatica, yet it cannot be entirely excluded that in some distance also Quercus was present. No other sequenced collections are known to us. In GenBank, there are only three EcM sequences from France (KM247646, HQ204682 and HQ204674), for two of them Quercus ilex is noted as host.

Further collections studied: GERMANY, BadenWürttemberg, Rhein-Neckar-Kreis, Lobbach, Haag, TK25
6619/1, alt. 330 m, Fagus sylvatica, 11 Oct 2015, leg. D. Bandini; det. D. Bandini \& B. Oertel (STU SMNS-STU-F0901519; DB11-10-15-3). NETHERLANDS, Drenthe, alt. 20 m, Quercus robur, Pinus sylvestris, Salix sp., 10 Oct 2018, leg./det. D. Bandini (DB10-10-18-25). Ibidem, in some distance from former location, alt. $15 \mathrm{~m}$, Quercus robur, Pinus sylvestris, Salix sp., 10 Oct 2018, leg./det. D. Bandini (DB1010-18-26). Drenthe, Dwingeloo, alt. $22 \mathrm{~m}$, mixed wood with Quercus robur, Salix sp., 11 Oct 2018, leg./det. D. Bandini (DB11-10-18-2). Ibidem, in some distance from former location, alt. 22 m, mixed wood with Quercus robur, Salix sp., 11 Oct 2018, leg. D. Bandini; det. D. Bandini \& B. Oertel (DB11-10-18-4). Drenthe, near Wijster, alt. 22 m, Pinus sylvestris, Quercus robur, Betula sp., 30 Sep 2019, leg./det. D. Bandini (DB30-9-19-16). Drenthe, near Spier, alt. 22 m, Pinus sylvestris, Salix caprea, Quercus robur, Betula sp., 30 Sep 2019, leg./det. D. Bandini (STU SMNS-STU-F-0901478; DB30-9-19-17). Ibidem, in some distance from former location, alt. 20 m, Quercus robur, Pinus sylvestris, Salix caprea, Betula sp., 30 Sep 2019, leg./det. D. Bandini (DB30-9-19-19). Drenthe, near Dwingelderveld, alt. $22 \mathrm{~m}$, Pinus sylvestris, Quercus robur, Salix sp., 4 Oct 2019, leg./det. D. Bandini (STU SMNS-STU-F-0901479; DB4-10-19-2). Drenthe, Pesse, alt. 13 m, Quercus robur, Pinus sylvestris, Picea abies, 5 Oct 2020, leg./det. D. Bandini (DB5-10-20-16). Drenthe, Gijsselte, alt. 15 m, Quercus robur, Pinus sylvestris, Picea abies, 6 Oct 2020, leg./det. D. Bandini (DB6-10-20-12). Drenthe, Diever, alt. $16 \mathrm{~m}$, Quercus robur, Pinus sylvestris, Picea abies, Fagus sylvatica etc., 8 Oct 2020, leg./det. D. Bandini (DB8-10-20-15). Ibidem, in some distance from former location, Quercus robur, Pinus sylvestris, Picea abies, Fagus sylvatica etc., 8 Oct 2020, leg./det. D. Bandini (DB810-20-16).

Comments: Inocybe drenthensis is characterized by rather small basidiomata usually with finely rimulose or finely innately fibrillose pileus surface with verrucose to areolate diffracted, mostly orange-reddish tinged centre of pileus, at least near the apex violet, often quite rigid stipe, covered at first with whitish fibres, often subdistant thickish lamellae, mostly subfusiform hymenial cystidia reacting strongly with $\mathrm{KOH}$ and mostly fusiform to sublageniform caulocystidia at the extreme apex of the stipe.

The pileus of $I$. cincinnata is not orange tinged, the stipe is covered with brownish fibres, the edge of the lamellae are brownish with age and therefore the paracystidia are brownish, too, and the hymenial cystidia often have longer and occasionally somewhat undate necks. A pileus without orange tinge and smaller spores than I. drenthensis has I. curtispora E. Ludw. (Ludwig 2017; Eberhardt et al. in prep.). Inocybe obscuroides P.D. Orton (see below) is a usually larger and stouter species with (sub)squamulose to squarrose pileus surface, with age brown lamellae edges and on average longer spores (e.g. Orton 1960; Kuyper 1986 (as 'I. phaeocomis var. 
major'), 1989; Stangl 1989 (as 'I. phaeocomis var. major'), and personal observation), while I. gracillima Carteret \& Reumaux has a strongly squarrose surface of pileus and hymenial cystidia with long and undate necks (Carteret and Reumaux 2012; personal observation, and see below). Besides, it mostly grows at the moist border of lakes or small rivulets. Inocybe minima Peck differs from I. drenthensis by a beige-coloured velipellis, hymenial cystidia with usually long and slightly undate necks and often (sub)capitate apex. The spores are narrow with a higher average Q-value (Peck 1913, and personal observation). Inocybe tiburtina (see below) has no orange tinge in the pileus colour, an abundant beigecoloured velipellis, and the spores on average are larger. Inocybe lampetiana (see below) has a darker brown pileus, the spores are longer, the hymenial cystidia often have long slightly undate necks, and the species is to be found on very moist acid soil with Alnus. A species with often also orange tinges at the centre of the pileus is I. griseolilacina J.E. Lange, which however differs, e.g. by typically (sub)capitate shortnecked hymenial cystidia, with only pale reaction with $\mathrm{KOH}$ and on average larger spores (Lange 1917; Kuyper 1986; Stangl 1989; Ferrari 2006 etc.). Another species with an orange tinged centre of the pileus is I. dryadiana (see below), which grows with Quercus, too. The pileus colour, however, is speckled ochraceous brownish with almost straw-coloured margin, and the surface is strongly cracking with age. The hymenial cystidia usually are short-necked, and the reaction with $\mathrm{KOH}$ is only weak. Inocybe gaiana (see below) often grows in tufts, the pileus is dull brown or clay-coloured, it has an ample greyish velipellis, the stipes are less intensely violet, the surface is more lanose and the caulocystidia are ventricose. Inocybe knautiana (see below) differs, e.g. by an abundant whitish velipellis and larger spores. Inocybe amethystina Kuyper has a more lanose-squamulose pileus surface, on average larger spores and the caulocystidia have a wide neck (Kuyper 1986, and see below). Inocybe sitibunda (see below) is with $97 \%$ identity in the ITS closely related to I. drenthensis. It differs morphologically, e.g. by more villoselanose pileus surface without orange-reddish tinge, slightly longer spores on average and mostly rather moist habitat with Picea abies.

Inocybe dryadiana Bandini \& B. Oertel sp. nov. Fig. 7 MycoBank number: MB 839157

Etymology: Named 'dryadiana' because of the Dryads, Greek nymphs of oak-trees, since the species seems to be fond of Quercus.

Diagnosis: Inocybe dryadiana is a rather small species with bicoloured aspect of pileus, with age cracky centre of pileus, pale to intensely lilac stipe, smooth spores at the apex of the stipe, measuring 8.3-10.7 $\mu \mathrm{m}$ (av. 9.3 $\mu \mathrm{m}) \times 4.9-$ $6.2 \mu \mathrm{m}$ (av. $5.5 \mu \mathrm{m}$ ), and (sub)fusiform or (sub)utriform hymenial cystidia, pleurocystidia measuring 42-79 $\mu \mathrm{m}$ (av.
$60 \mu \mathrm{m}) \times 10-29 \mu \mathrm{m}$ (av. $14 \mu \mathrm{m}$ ). The species seems to be fond of Quercus and grows on calcareous soil. This combination of characters as well as ITS sequence data distinguishes I. dryadiana from all other described species, including the macroscopically somewhat similar I. griseolilacina and other lilac-stiped species. No closely phylogenetically related species is known so far.

Holotype: GERMANY, Baden-Württemberg, RheinNeckar-Kreis, Wiesloch, cemetery, TK25 6718/1, alt. 134 m, Quercus robur, 31 Aug 2014, leg. D. Bandini (holotype STU SMNS-STU-F-0901259; isotype priv. herb. D.B. DB318-14-1). GenBank: ITS + partial LSU = MW845873.

Description: Pileus $10-30 \mathrm{~mm}$ wide, at first (sub)glandular to conical, later conico-convex or expanded, with more or less pronounced large umbo, margin at first incurved, later decurved, then straight; no remnants of a velipellis observed; colour ochraceous brownish to pale nutbrown in different nuances often with orange hue at the centre, always strongly speckled with darker fibre bundles on much paler, straw-coloured to sometimes almost beige ones $(\mathrm{Mu}$ 10YR 6/6-6/8, 5/6-5/8, 7/4-7/6; 7.5YR 6/6-6/8, 5/6-5/8), towards the margin paler with age; surface finely felty with soon darker appressed fibre bundles on paler fibres, therefore bicoloured, at the centre getting cracked with age; young basidiomata with remnants of a pale ochraceous cortina. Lamellae moderately crowded (ca. 45-60, 1 = 1-3), emarginate adnate with decurrent tooth, (sub)ventricose, at first very pale greyish, sometimes with faint lilac hue, then greyishbrownish to pale brownish; edge fimbriate, whitish. Stipe $25-60 \times 2-5 \mathrm{~mm}$, cylindrical or curved, when young covered with fine whitish tomentum, later longitudinally striate or glabrous, pale to intensely lilac beneath the tomentum, especially near the apex and in young basidiomata, but sometimes because of the whitish tomentum barely to be observed; pruinose only near the apex of the stipe. Context whitish or watery whitish in the pileus, more or less intensely lilac in the upper part of the stipe of young basidiomata, whitish in the lower part, or entirely in older basidiomata, but more or less intensely lilac in the cortex of the stipe. Smell subnull, subspermatical when cut. Colour of exsiccata pileus pale straw, pale ochraceous to pale ochraceous brownish, brown or nutbrown at the centre (Mu 10YR 6/4-6/6, 5/4-5/8), lamellae sometimes somewhat darker and stipe concolorous or a little lighter in colour, no darkening or blackening on drying.

Spores 8.3-10.7 $\mu \mathrm{m}$ (av. 9.3 $\mu \mathrm{m}$, SD $0.5 \mu \mathrm{m}) \times 4.9$ 6.2 $\mu \mathrm{m}$ (av. $5.5 \mu \mathrm{m}$, SD $0.2 \mu \mathrm{m}$ ); $\mathrm{Q}=1.5-2.0$ (av. 1.7, SD 0.1 ) ( $\mathrm{n}=120$ of 3 coll.), smooth, (sub)amygdaloid, mostly without suprahilar depression, apex subacute, with small indistinct pseudoporus. Basidia 23-28 × 7-10 $\mu \mathrm{m}$, generally 4spored, seldom also 2 -spored, and then spores up to $12.2 \mu \mathrm{m}$. Lamellae edges sterile, composed of cheilocystidia and numerous colourless, (sub)clavate or (sub)cylindrical, thinwalled, sometimes rather long paracystidia. Pleurocystidia 

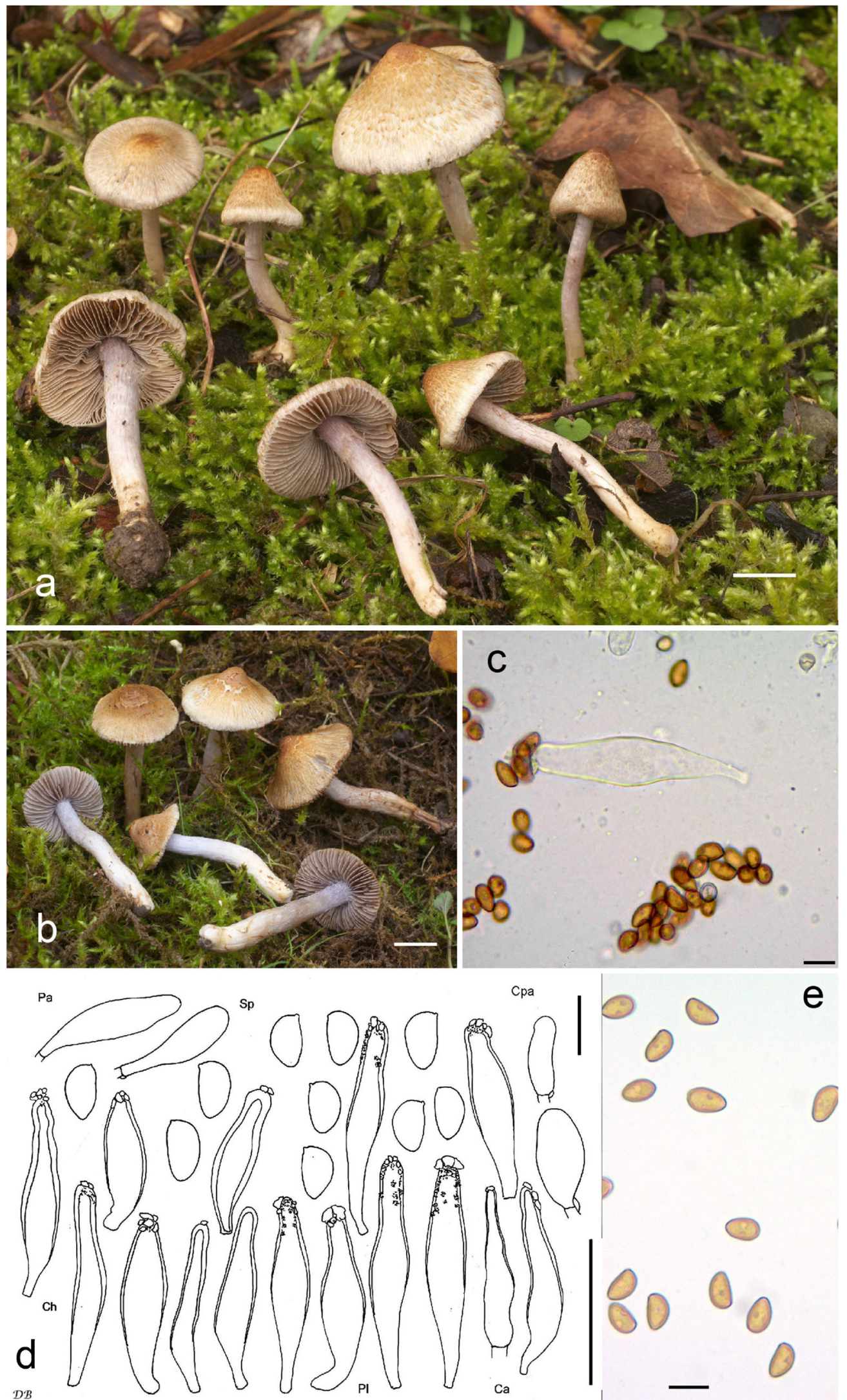

e

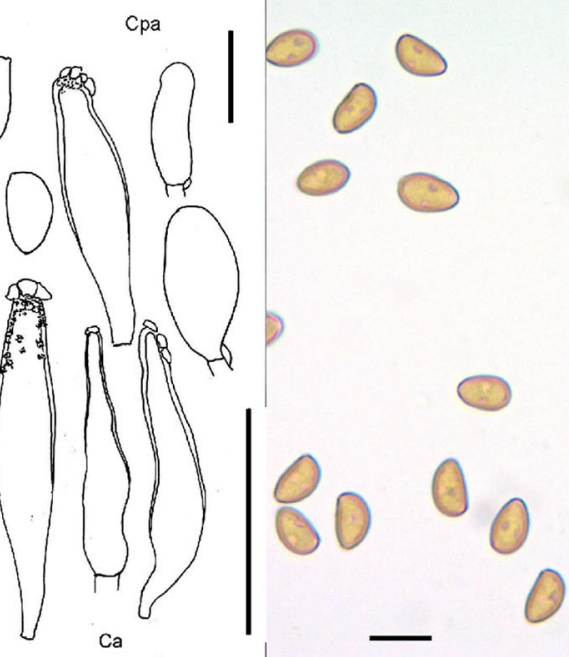

Fig. 7 Inocybe dryadiana, a holotype, scale bar: $1 \mathrm{~cm}$. b Coll. DB22-1015-6, scale bar: $1 \mathrm{~cm}$. c Cheilocystide (holotype), scale bar: $10 \mu \mathrm{m}$. d Microscopical characters (holotype), $\mathrm{Ca}=$ Caulocystidia, $\mathrm{Cpa}=$
Cauloparacystidia, $\mathrm{Ch}=$ Cheilocystidia, $\mathrm{Pa}=$ Paracystidia, $\mathrm{Pl}=$ Pleurocystidia, $\mathrm{Sp}=$ Spores; scale bar spores: $10 \mu \mathrm{m}$, scale bar cystidia: $50 \mu \mathrm{m}$. e Spores (holotype), scale bar: $10 \mu \mathrm{m}$ 
42-79 $\mu \mathrm{m}(\mathrm{av} .60 \mu \mathrm{m}, \mathrm{SD} 8 \mu \mathrm{m}) \times 10-29 \mu \mathrm{m}$ (av. $14 \mu \mathrm{m}, \mathrm{SD}$ $3 \mu \mathrm{m}) ; \mathrm{Q}=2.3-6.6$ (av. 4.5, SD 1.1) ( $\mathrm{n}=45$ of 3 coll.); (sub)utriform, (sub)fusiform, or somewhat deformed, at the apex generally wide, without neck, or with short or longer neck, usually with short pedicel, apex usually crystalliferous, walls up to 2.0 (3.0) $\mu \mathrm{m}$ thick at the apex, pale yellowishgreenish with $3 \% \mathrm{KOH}$. Cheilocystidia similar in appearance and size. Pileipellis constituted by an epicutis made up of parallel hyphae 4-10 $\mu \mathrm{m}$ wide, with unregularly encrusting and parietal brownish to brown pigment, subcutis with wider and paler to colourless elements. Caulocystidia only near the apex of the stipe, 35-70 × 10-15 $\mu \mathrm{m}$, (sub)utriform, (sub)cylindrical or even (sub)clavate, without or with only short neck, without or with only short pedicel, apex usually crystalliferous, walls up to $1.5 \mu \mathrm{m}$ thick at the apex, pale yellowish-greenish with $3 \% \mathrm{KOH}$; intermixed with numerous (sub)cylindrical to (sub)clavate colourless thin-walled cauloparacystidia. Clamp-connections abundant in all tissues.

Habitat and known distribution: Until now, the species is known only from our own collections from Germany, two collections from Karlsruhe (Germany) both found with Quercus cerris (as 'I. spec.', MT005894 and as 'I. spec.', MT006031), as well as from an EcM-sequence from Spain (KX641926, with Quercus ilex). It can thus be assumed that I. dryadiana is associated with Quercus, if not specific to that host genus.

Further collections studied: GERMANY, BadenWürttemberg, Rhein-Neckar-Kreis, near Frauenweiler, TK25 6718/1, alt. 125 m, Quercus robur, 2 Aug 2014, leg. D. Bandini (STU SMNS-STU-F-0901481; DB2-8-14-11). Baden-Württemberg, Rhein-Neckar-Kreis, St. Leon-Rot, TK25 6717/2, alt. 122 m, Quercus robur, 22 Oct 2015; leg./ det. D. Bandini (STU SMNS-STU-F-0901480; DB22-10-156). Rheinland-Pfalz, Rhein-Pfalz-Kreis, Dudenhofen, TK25 6616/3, alt. 125 m, Quercus robur, 25 Oct 2020, leg./det. D. Bandini (DB25-10-20-1).

Comments: Inocybe dryadiana is characterized by a rather small pileus with bicoloured aspect owing to ochraceous brownish to nut-brown fibre bundles overlying strawcoloured ones, with age cracky centre, smooth spores and only near the apex pruinose pale to intensely lilac stipe. The pilei, when young, are often (sub)glandular in shape. Macroscopically most similar is I. griseolilacina J.E. Lange, which differs, e.g. by subcapitate hymenial cystidia, on average smaller spores and a habitat often with Fagus sylvatica or other frondose trees, but sometimes also with conifers (Lange 1917; Kuyper 1986; Stangl 1989; Ferrari 2006 etc., and personal observation). Species of the cincinnata-group, such as I. obscuroides, I. cincinnata or I. minima differ by the typical (sub)lanceolate hymenial cystidia with strongly on $\mathrm{KOH}$ reacting walls (see comments to $I$. cincinnata). In addition, the pileus surface of the named species is not at all or not as speckled as is in I. dryadiana. Inocybe pusio has a darker pileus colour (Karsten 1889) and more ventricose hymenial cystidia (see below). Inocybe knautiana (see below) differs, e.g. by an ample whitish velipellis and on average longer spores and I. amethystina differs, e.g. by darker, lanosesquamulose and not bicoloured pileus surface and with $\mathrm{KOH}$ stronger reacting walls of the hymenial cystidia (Kuyper 1986). We are not aware of any species molecularly (ITS) closely related to I. dryadiana.

\section{Inocybe elegans (Fig. 23 h) $\rightarrow$ Inocybe griseolilacina}

\section{Inocybe fuscidula (Fig. 24 a) $\rightarrow$ Inocybe glabripes}

Inocybe gaiana Bandini \& B. Oertel sp. nov. Fig. 8 MycoBank number: MB 839158

Etymology: Named 'gaiana' after the Greek goddess Gaia, personification of the Earth, because of the clayish earthen colour of the pileus.

Diagnosis: Inocybe gaiana often grows in tufts, has a greyish velipellis, dull clayish to greyish brown pileus colour and fine fibrillose to lanose or subsquamulose pileus surface. The stipe is at least at first violaceous tinged at the apex and only near the apex pruinose. The spores are smooth and on average rather narrow, measuring 7.3-10.3 $\mu \mathrm{m}$ (av. 8.4 $\mu \mathrm{m}) \times 3.7-5.2 \mu \mathrm{m}$ (av. 4.7 $\mu \mathrm{m}$ ), and the hymenial cystidia are mostly (sub)utriform or (sub)fusiform, and on average rather short, pleurocystidia measuring 39-72 $\mu \mathrm{m}$ (av. $53 \mu \mathrm{m}) \times$ 10-19 $\mu \mathrm{m}$ (av. $14 \mu \mathrm{m}$ ). This combination of characters as well as ITS sequence data distinguishes $I$. gaiana from other species of the I. cincinnata-group as, e.g. I. cincinnata or I. obscuroides. No phylogenetically (ITS) closely related species are known so far.

Holotype: NETHERLANDS, Drenthe, Eursinge, alt. 20 m, Quercus robur, Picea abies, 10 Oct 2018, leg. D. Bandini (holotype STU SMNS-STU-F-0901482; isotype priv. herb. D.B. DB10-10-18-22). GenBank: ITS + partial LSU = MW845876.

Description: Pileus 10-30 mm wide, at first (sub)conical, later broadly convex or expanded, with low or rather pronounced large umbo, margin at first incurved to decurved, later straight or even uplifted, and then pileus depressed around the umbo; young basidiomata with abundant greyish remnants of a velipellis, often concentrated at the centre of the pileus; colour dull clayish or greyish brown or chamois $(\mathrm{Mu}$ 10YR 5/3-5/8, 4/6), at the centre often greyish because of remnants of the velipellis; surface from fine fibrillose or innately fibrillose to finely lanose, lanose to entirely subsquamulose or subsquamulose-lanose at the umbo and outwards innately fibrillose; young basidiomata with remnants of a cortina. Lamellae moderately crowded (ca. 40$60,1=1-3$ ), narrowly to broadly adnate, (sub)ventricose, at 

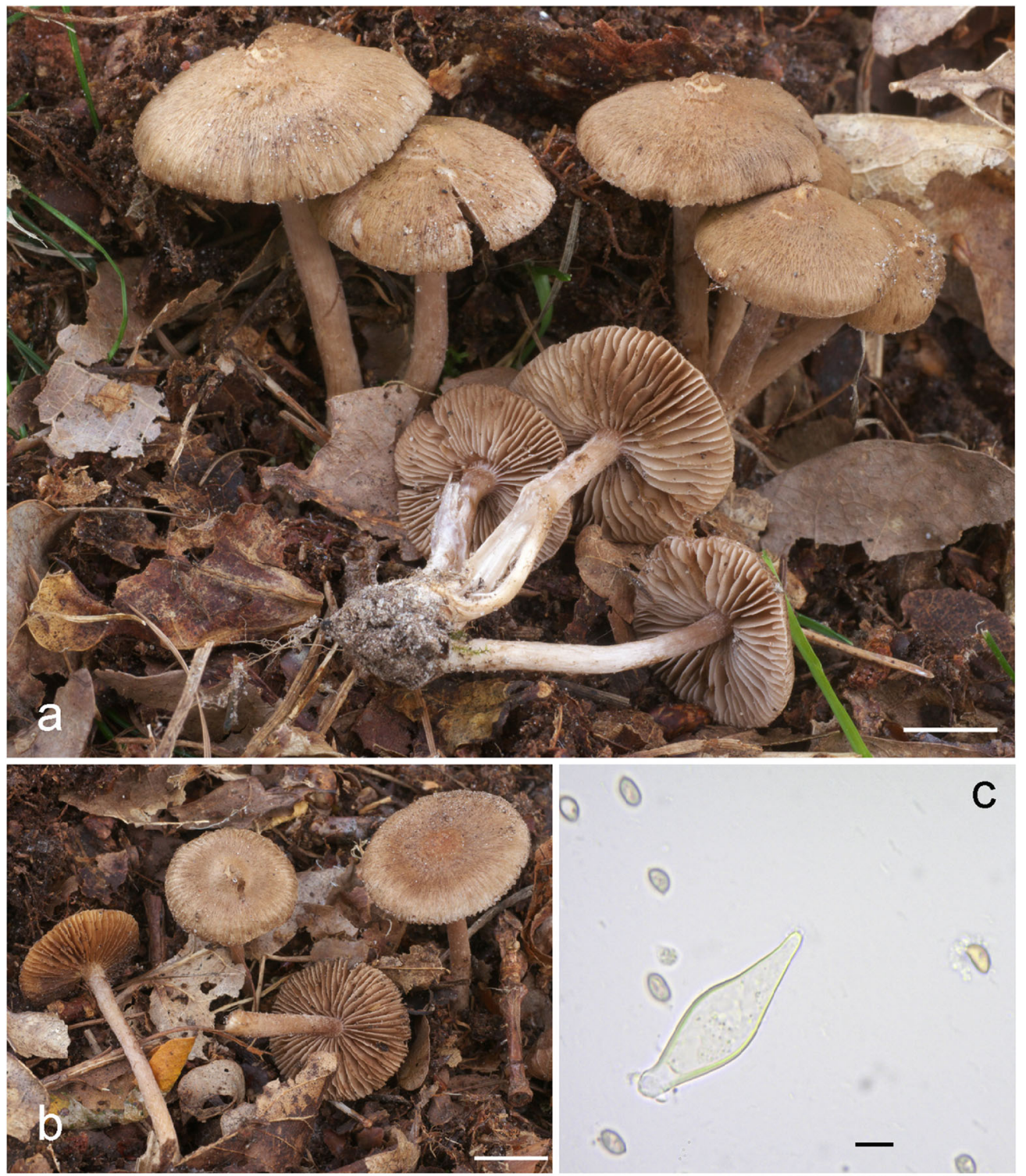

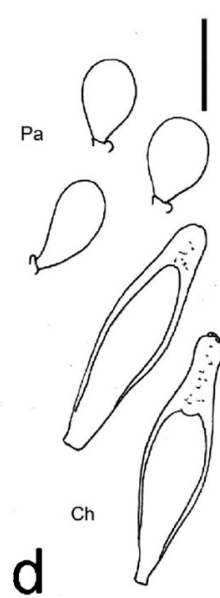

$D B$

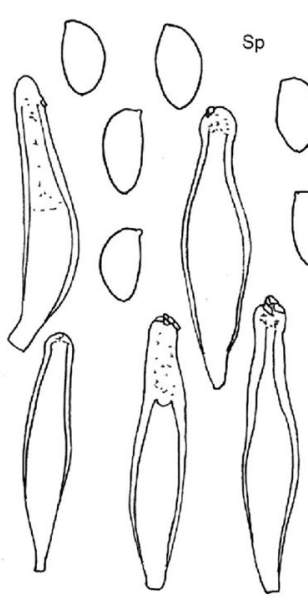

$\mathrm{PI}$

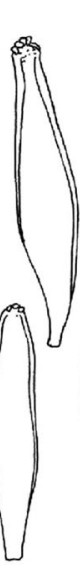

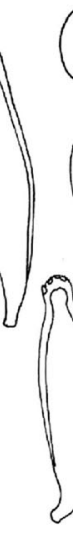

Ca

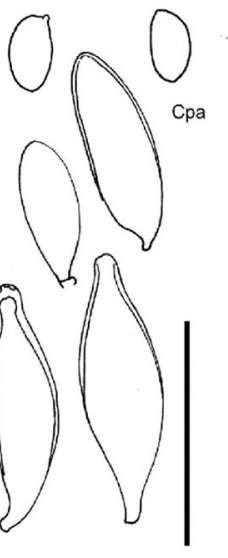

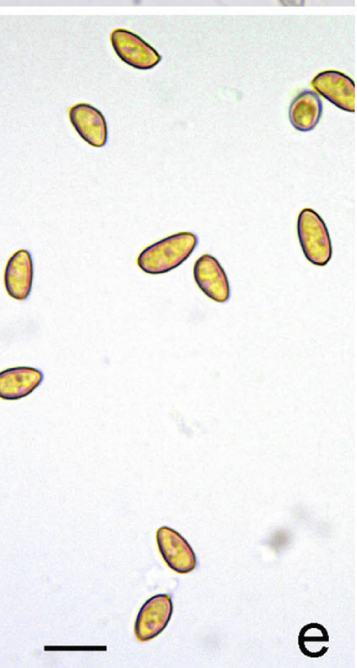

Fig. 8 Inocybe gaiana, a holotype, scale bar: $1 \mathrm{~cm}$. b Coll. DB10-10-1818, scale bar: $1 \mathrm{~cm}$. c Pleurocystide (coll. DB7-7-12-2), scale bar: $10 \mu \mathrm{m}$. d Microscopical characters (holotype), $\mathrm{Ca}=$ Caulocystidia, $\mathrm{Cpa}=$

Cauloparacystidia, $\mathrm{Ch}=$ Cheilocystidia, $\mathrm{Pa}=$ Paracystidia, $\mathrm{Pl}=$ Pleurocystidia, Sp = Spores; scale bar spores: $10 \mu \mathrm{m}$, scale bar cystidia: $50 \mu \mathrm{m}$. e Spores (coll. DB7-7-12-2), scale bar: $10 \mu \mathrm{m}$ 
first pale greyish, later brownish-greyish, or brownish with more or less intense olivaceous-ochraceous hue; sometimes stained darker brown; edge fimbriate, whitish. Stipe 25-50 $\times 2-3 \mathrm{~mm}$, cylindrical or curved, when young covered with thin or thicker whitish tomentum, often soon almost or entirely vanishing, and then reticulate or (almost) glabrous, when young and in some collections also when older with more or less intense violaceous hue at least at the apex, later pale brownish; pruinose only at the extreme apex of the stipe. Context whitish in the pileus, faintly violaceous near the apex of the stipe and in the cortex of the stipe near the apex. Smell subnull. Colour of exsiccata pileus dark brown with faint reddish hue (Mu 7/5YR 4/4-4/6, 3/4), lamellae and stipe concolorous or a little lighter in colour, no darkening or blackening on drying.

Spores 7.3-10.3 $\mu \mathrm{m}$ (av. 8.4 $\mu \mathrm{m}$, SD $0.6 \mu \mathrm{m}) \times 3.7-$ $5.2 \mu \mathrm{m}$ (av. $4.7 \mu \mathrm{m}$, SD $0.2 \mu \mathrm{m}$ ); Q = 1.5-2.3 (av. 1.8, SD $0.1)(n=120$ of 3 coll.); smooth, (sub)amygdaloid, often with rather faint suprahilar depression, apex subobtuse to subacute, in some collections with indistinct pseudoporus. Basidia 23$28 \times 7-9 \mu \mathrm{m}$, generally 4 -spored, but in some collections also 2 -spored, and then spores up to $11.3 \mu \mathrm{m}$. Lamellae edges sterile, composed of cheilocystidia and numerous colourless, (sub)clavate thin-walled paracystidia. Pleurocystidia 39-72 $\mu \mathrm{m}$ (av. $53 \mu \mathrm{m}$, SD $6.3 \mu \mathrm{m}) \times 10-19 \mu \mathrm{m}$ (av. $14 \mu \mathrm{m}, \mathrm{SD}$ $2.1 \mu \mathrm{m}) ; \mathrm{Q}=2.4-6.8$ (av. 4.0, SD 0.9) ( $\mathrm{n}=45$ of 3 coll.), (sub)utriform or (sub)fusiform, seldom also sublageniform, sometimes transition between bulge and neck clearly demarcated, with short or longer neck, at the apex generally wide, sometimes subcapitate and sometimes with flat gelatinous cap, without or usually with only short pedicel, apex usually crystalliferous, walls up to $1.5(2.0) \mu \mathrm{m}$ thick at the apex, yellow-green with $3 \% \mathrm{KOH}$. Cheilocystidia similar in appearance and size. Pileipellis constituted by an epicutis made up of parallel hyphae 5-12 $\mu \mathrm{m}$ wide, with encrusting and parietal brownish pigment, subcutis with wider and paler to colourless elements. Caulocystidia only near the extreme apex of the stipe, 35-60 × 10-20 $\mu \mathrm{m}$, mostly ventricose (sub)fusiform to (sub)utriform, often (sub)capitate, with short neck and short pedicel, apex usually crystalliferous, walls up to $1.5 \mu \mathrm{m}$ thick at the apex, yellow-green with $3 \% \mathrm{KOH}$; intermixed with numerous (sub)clavate to subglobose cauloparacystidia. Clamp-connections abundant in all tissues.

Habitat and known distribution: Our own collections of I. gaiana are from Germany and the Netherlands. For all but one collection Picea abies was noted, but always also frondose trees. In GenBank, a sequence from Spain is published, from a collection determined as I. pseudorubens (KJ32282, 'Riparian forest, under Salix atrocinerea and Pinus sylvestris'). Another sequence, also labelled 'I. pseudorubens', belongs to a soil sample from New Zealand (MN047369), and there are two sequences as well from New Zealand (as ' $I$. spec.', GQ267475 and as ' $I$. spec.', GQ267476, under Pinus radiata). Alnus is noted as tree with EcM sequences from France in GenBank (KU924401, KU924402 and JX989972), which may also belong to this species. From several soil samples (UNITE), it seems that the species also is present in Estonia. It seems that the species is not specific to any host taxon of either conifers or frondose trees. All our own collections were found from July to October on calcareous soil; the collections from the Netherlands were found on the sides of (calcareous) bicycle paths.

Further collections studied: GERMANY, BadenWürttemberg, Heidelberg, Königstuhl, Märchenparadies, TK25 6518/3, alt. 565 m, Fagus sylvatica, Picea abies, 7 Jul 2012, leg. D. Bandini; det. D. Bandini \& B. Oertel (DB7-7-12-2). Bayern, Gmund, Marienstein, Tegernseer Flyschberge, TK25 8236/3, alt. 960 m, Fagus sylvatica, Picea abies, Abies alba, 7 Sep 2013, leg. M. Dondl; det. D. Bandini \& B. Oertel (DB7-9-13-5-Dondl). NETHERLANDS, Drenthe, Eursinge, alt. 20 m, Quercus robur, 10 Oct 2018, leg. D. Bandini; det. D. Bandini \& B. Oertel (STU SMNSSTU-F-0901483; DB10-10-18-18). Ibidem, in some distance from former location, alt. $20 \mathrm{~m}$, Quercus robur, Picea abies 10 Oct 2018, leg. D. Bandini; det. D. Bandini \& B. Oertel (DB10-10-18-23). Drenthe, Hoogeveen, alt. 15 m, Quercus robur, Picea abies, 5 Oct 2020, leg./det. D. Bandini (DB510-20-12). Drenthe, Pesse, alt. 13 m, Pinus sylvestris, Quercus robur, Betula pendula, 5 Oct 2020, leg./det. D. Bandini (DB5-10-20-14). Drenthe, Diever, alt. 16 m, Quercus robur, Picea abies, Pinus sylvestris, Fagus sylvatica, 8 Oct 2020, leg./det. D. Bandini (DB8-10-20-14).

Comments: Inocybe gaiana is characterized by usually rather dull clayish brown pileus colours, ample greyish velipellis and an innately fibrillose to lanose or subquamulose pileus surface; the lamellae are greyish-brownish. The stipe is only pruinose near the apex and has, when young, a more or less intense lilac hue. The spores are smooth and on average rather small and narrow. The walls of the hymenial cystidia react strongly with $\mathrm{KOH}$. The hymenial cystidia are sometimes subcapitate, and/or occasionally show a flat gelatinous cap. Almost all basidiomata of our own collections grew in tufts, and it can be seen on photographs of a collection from New Zealand (GenBank acc. no. MN047369, voucher PDD 107037) that the basidomata also grew in tufts.

Macroscopically, the species may on first sight be mistaken for many different species of Inocybe, because the violaceous tinge at the apex of the stipe is not always clearly visible. Inocybe obscuroides has larger and stouter basidiomata, the pileus surface is often (sub)subsquarrose, the edge of the lamellae soon gets brownish, the stipe is covered by brown fibrils, the spores are larger and the caulocystidia are narrower (see, e.g. Kuyper 1986 (as 'I. phaeocomis var. major'); Stangl 1989 (as 'I. phaeocomis var. major'), and personal observation). Inocybe minima differs from I. gaiana, e.g. by on 
average longer hymenial cystidia with longer and often undate neck, longer spores and on average narrower and mostly (sub)fusiform caulocystidia (Peck 1913, and personal observation), while the pileus of I. cincinnata has only a faint velipellis, the colour is more vivid brown and the hymenial cystidia on average are longer (see above, and personal observation). Inocybe drenthensis equally has no greyish velipellis, a speckled and less lanose pileus surface with orange-reddish tinged centre, intensely violet stipes and narrower caulocystidia. Inocybe knautiana (see below) has an ample whitish velipellis and larger spores, I. amethystina differs by, e.g. darker pileus colour and larger spores (Kuyper 1986), I. sitibunda, e.g. by darker pileus colours, on average larger spores, and habitat mostly rather moist and with Picea abies, and I. lampetiana (see below), e.g. by darker pileus colours, on average larger spores and very moist habitat with Alnus. Inocybe tiburtina has a paler velipellis, more vivid pileus colours and on average larger spores, and is often associated with Salix, while I. pusio has entirely different, ventricose fusiform hymenial cystidia (see below). The stipe of the above mentioned I. pseudorubens Carteret \& Reumaux shows no violet tinges, the pileus often has a bicoloured aspect and with age scaly squamulose surface with areolate diffracted centre as well as larger spores. Furthermore, the walls of the hymenial cystidia are only weakly reacting with $\mathrm{KOH}$ (Carteret and Reumaux 2001, and personal observation).

Inocybe geophylla (Bull.) P. Kumm., Der Führer in die Pilzkunde: 78 (1871) Figs. 9, $27 \mathrm{~h}$

= I. xantholeuca Kuyper, Persoonia, Suppl. 3: 157 (1986)

Basionym and holotype: Agaricus geophyllus Bull., Herbier de la France 11: pl. 522, Fig. 2 (1791).

Description of the species: Kuyper 1986 (as 'I. xantholeuca').

Epitype designated here (MBT 10000529): AUSTRIA, Tirol, Reutte, Höfen, ÖK25V 2215-West, alt. 970 m, Picea abies, 23 Sep 2015, leg. D. Bandini (STU SMNS-STU-F0901531; DB23-9-15-31). GenBank: ITS + partial LSU = MW845949.

Description: Pileus 10-30 mm wide, at first subglobose, (sub)campanulate or subconical, later broadly convex to expanded, with more or less pronounced large umbo, margin at first incurved, later decurved to straight or even uplifted, and then pileus depressed around the umbo; young basidiomata with whitish remnants of a velipellis; colour usually entirely whitish, dingy whitish, beige, but sometimes pale strawcoloured or pale yellowish at least towards the margin (10YR 8/1-8/8, 7/2-7/6; 7.5YR 8/4); surface at first entirely glabrous and smooth to very minutely tomentose, later towards the margin sometimes finely innately fibrillose with appressed fibres; young basidiomata with remnants of a cortina. Lamellae subdistant (ca. 30-45, 1 = 1-3), adnate, (sub)ventricose, at first usually entirely whitish, seldom somewhat yellowish, later with greyish hue and then pale milkcoffee-brown with greyish hue; edge fimbriate, whitish. Stipe $15-50 \times 1-5 \mathrm{~mm}$, cylindrical or curved, sometimes slightly widening towards the base, when young covered with whitish tomentum, later longitudinally striate or glabrous, whitish, pale yellowish to very pale brownish; pruinose only near the apex of the stipe. Context whitish in the pileus and the stipe. Smell spermatical, at least when cut. Colour of exsiccata pileus dingy whitish, beige, ivory, sometimes also pale straw-coloured towards the centre (Mu 10YR 8/3-8/8, $7 / 3-7 / 6$ ), lamellae and stipe concolorous or a little lighter in colour, no darkening or blackening with drying.

Spores 7.1-9.3 $\mu \mathrm{m}$ (av. $8.2 \mu \mathrm{m}$, SD $0.4 \mu \mathrm{m}) \times 4.1-6.1 \mu \mathrm{m}$ (av. $5.0 \mu \mathrm{m}$, SD $0.4 \mu \mathrm{m}) ; \mathrm{Q}=1.3-2.0$ (av. 1.6, SD 0.2) $(\mathrm{n}=$ 120 of 3 coll.); smooth, (sub)amygdaloid, (sub)ellipsoid, sometimes subovoid, without or with only faint suprahilar depression, apex obtuse. Basidia 23-28 $\times 7-9 \mu \mathrm{m}$, generally 4-spored. Lamellae edges sterile, composed of cheilocystidia and numerous colourless, (sub)clavate or subcylindrical thinwalled paracystidia. Pleurocystidia $42-65 \mu \mathrm{m}$ (av. $53 \mu \mathrm{m}$, SD $6.1 \mu \mathrm{m}) \times 10-21 \mu \mathrm{m}($ av. $15 \mu \mathrm{m}, \mathrm{SD} 2.4 \mu \mathrm{m}) ; \mathrm{Q}=2.4$ 5.4 (av. 3.7, SD 0.8$)(n=45$ of 3 coll.), usually rather ventricose (sub)fusiform or (sub)utriform, often transition between bulge and neck clearly demarcated, at the apex generally wide, usually with short neck, with short or rather long pedicel, apex usually crystalliferous, walls up to $1.5(2.5) \mu \mathrm{m}$ thick near the apex, pale yellowish-greenish with $3 \% \mathrm{KOH}$. Cheilocystidia similar in appearance and size. Pileipellis constituted by an epicutis made up of parallel hyphae 4-10 $\mu \mathrm{m}$ wide, without or with only faintly encrusting and parietal pale straw-coloured pigment, subcutis with wider and paler to colourless elements. Caulocystidia only near the apex of the stipe, 40-65 × 10-15 (20) $\mu \mathrm{m}$, mostly (sub)utriform with rather long and often somewhat undate neck and short pedicel, walls up to 1.0 (1.5) $\mu \mathrm{m}$ thick, pale yellowish-greenish with $3 \% \mathrm{KOH}$. Clamp-connections abundant in all tissues.

Habitat and known distribution: Inocybe geophylla is a common species, preferably growing on calcareous soil, often with Picea abies, but also with frondose trees. Our own finds are from Austria and Germany, but there are sequences in GenBank or UNITE of collections from Estonia (as ' $I$. geophylla', UDB019725), Italy (as 'I. posterula', JF908152), Russia (as 'I. whitei', MH930206) and Sweden (as 'I. geophylla', MH310762), as well as several EcM sequences from Estonia (UDB026381, with Tilia cordata; UDB026722, with Fagus sylvatica; UDB026691, with Larix sibirica), Mexico (DQ985376) and Portugal (FJ897193, with Quercus rotundifolia).

Selected other collections studied: GERMANY, BadenWürttemberg, Neckar-Odenwald-Kreis, Waldbrunn, Katzenbuckel, TK 6520/1, alt. ca. 495 m, Picea abies, Pseudotsuga menziesii, Salix sp., 22 Oct 2017, leg. D. Bandini; det. D. Bandini \& B. Oertel (DB22-10-17-4).- 

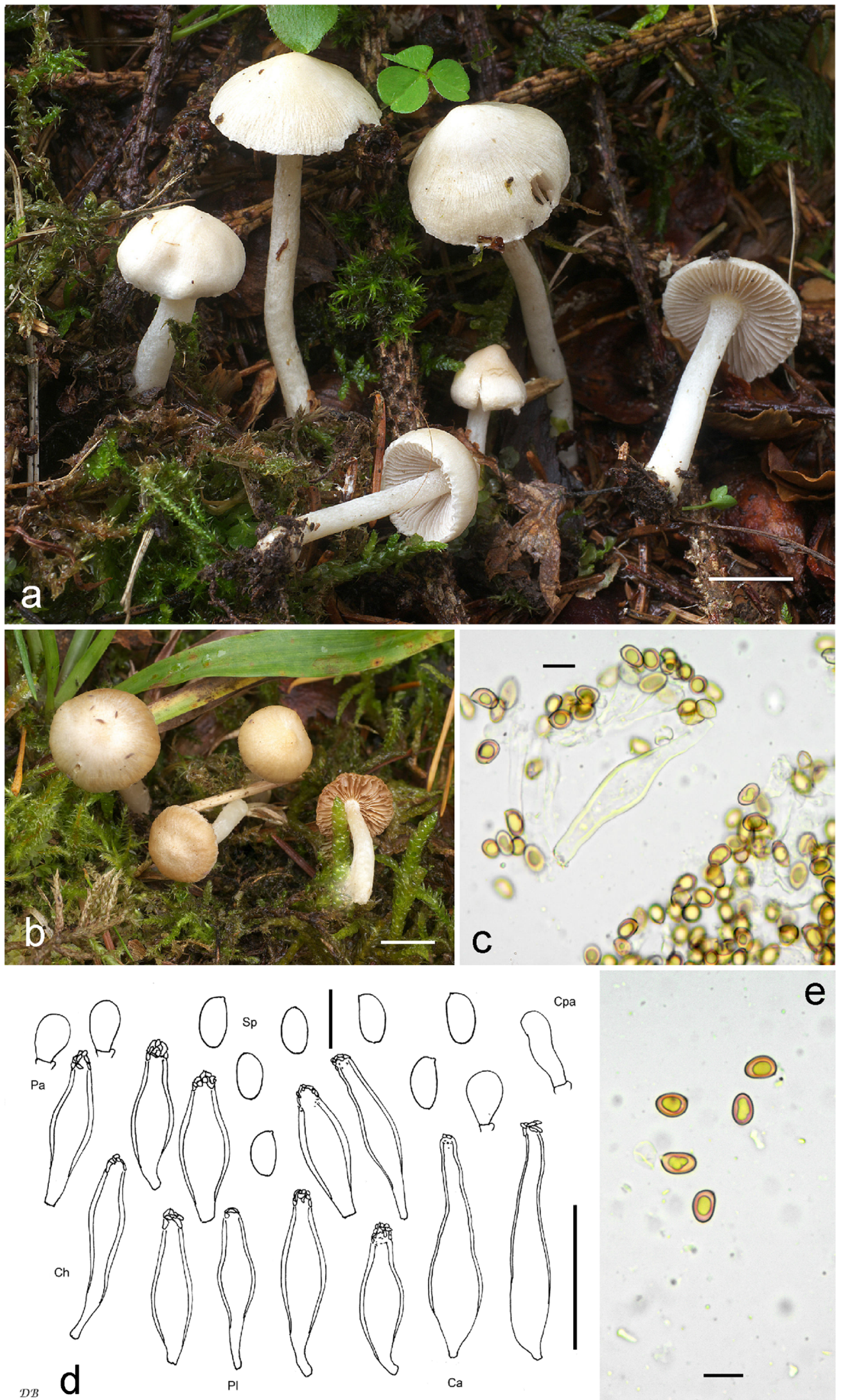

Fig. 9 Inocybe geophylla, a epitype, scale bar: $1 \mathrm{~cm}$. b Coll. DB22-1017-4, scale bar: $1 \mathrm{~cm}$. c Cheilocystide (coll. DB9-11-11-12), scale bar: 10

Cauloparacystidia, $\mathrm{Ch}=$ Cheilocystidia, $\mathrm{Pa}=$ Paracystidia, $\mathrm{Pl}=$ Pleurocystidia, $\mathrm{Sp}=$ Spores; scale bar spores: $10 \mu \mathrm{m}$, scale bar cystidia: $50 \mu \mathrm{m}$. e Spores (coll. DB9-11-11-12), scale bar: $10 \mu \mathrm{m}$ 
Bayern, Garmisch-Patenkirchen, Mittenwald, TK25 8533/3, alt. 1080 m, Fagus sylvatica, 9 Sep 2017, leg. D. Bandini; det. D. Bandini \& B. Oertel (DB9-9-17-11). Bayern, Ostallgäu, Pfronten, Breitenberg, TK25 8429/3, alt. ca. 1650 m, Picea abies, 16 Sep 2018, leg. D. Bandini; det. D. Bandini \& B. Oertel (DB16-9-18-6). Rheinland-Pfalz, Mainz-Bingen, Oberdiebach, Hirtenborn, TK25 5912/3, alt. ca. 150 m, Helianthemum sp., in some distance Picea abies, 9 Nov 2011, leg. H. \& E. Huijser; det. H. \& E. Huijser, D. Bandini \& B. Oertel (DB9-11-11-12). Rheinland-Pfalz, Bad Kreuznach, Gangelsberg bei Duchroth, TK25 6212/1, alt. 335 m, Picea abies, 3 Nov 2013, leg. H. \& E. Huijser; det. H. \& E. Huijser, D. Bandini \& B. Oertel (DB3-11-13-6).

Epitype of I. geophylla, Fig. 9 a, d: Spores 7.5-9.3 $\mu \mathrm{m}$ (av. $8.3 \mu \mathrm{m}$, SD $0.4 \mu \mathrm{m}) \times 4.1-5.5 \mu \mathrm{m}$ (av. $4.8 \mu \mathrm{m}$, SD 0.3 $\mu \mathrm{m}) ; \mathrm{Q}=1.4-2.0$ (av. 1.7, SD 0.1) $(\mathrm{n}=40)$, smooth, (sub)amygdaloid to ellipsoid, mostly with obtuse apex. Basidia 4-spored. Pleurocystidia 45-65 $\mu \mathrm{m}$ (av. $54 \mu \mathrm{m}$, SD $6 \mu \mathrm{m}) \times 12-18 \mu \mathrm{m}($ av. $15 \mu \mathrm{m}$, SD $2 \mu \mathrm{m}) ; \mathrm{Q}=2.9-5.4$ (av. 3.7, SD 0.7) $(\mathrm{n}=15)$, mostly rather ventricose (sub)fusiform, also subutriform, without or with short neck, with short or longer pedicel, apex usually crystalliferous, walls up to $1.5 \mu \mathrm{m}$ thick at the apex, pale yellowishgreenish with $3 \% \mathrm{KOH}$. Cheilocystidia similar in appearance and size. Paracystidia numerous (sub)clavate colourless elements. Caulocystidia only near the apex of the stipe, mostly (sub)utriform with rather long and often somewhat undate neck and short pedicel, walls up to $1.0 \mu \mathrm{m}$, pale yellowishgreenish with $3 \% \mathrm{KOH}$.

Typification of I. xantholeuca: FRANCE, AuvergneRhône-Alpes, Ain, Martignat, 5 Nov 1967, leg. V. Piane (L-3986178). This is a mixed collection, a part of it was separated (L-4370262) and selected here as lectotype (MBT 10000530). GenBank = MW845940.

Lectotype of I. xantholeuca, Fig. 27 h: Spores 6.9$9.4 \mu \mathrm{m}$ (av. 8.2 $\mu \mathrm{m}$, SD $0.6 \mu \mathrm{m}) \times 4.0-5.4 \mu \mathrm{m}(\mathrm{av} .4 .7 \mu \mathrm{m}$, SD $0.3 \mu \mathrm{m}) ; \mathrm{Q}=1.6-2.1$ (av. 1.7, SD 0.1) $(\mathrm{n}=40)$, smooth, (sub)amygdaloid to ellipsoid, mostly with obtuse apex. Basidia 4-spored. Pleurocystidia 48-59 $\mu \mathrm{m}$ (av. $53 \mu \mathrm{m}$, SD $4 \mu \mathrm{m}) \times 11-21 \mu \mathrm{m}($ av. $15 \mu \mathrm{m}$, SD $3 \mu \mathrm{m}) ; \mathrm{Q}=2.5-4.5$ (av. 3.6, SD 0.6), mostly rather ventricose (sub)fusiform, also subutriform, without or with short neck, with short or longer pedicel, apex usually crystalliferous, walls up to $1.5 \mu \mathrm{m}$ thick at the apex, pale yellowish-greenish with $3 \% \mathrm{KOH}$. Cheilocystidia similar in appearance and size. Paracystidia not observed. Caulocystidia not studied (to preserve the material).

Comments: Inocybe geophylla is a name widely used for a group of species that are rather similar, yet it is possible to differentiate between them. The designated epitype fixes the name on a species that is frequent and abundant at low elevations in boreal and in subalpine forests and which fits to the iconotype of Bulliard (1788-1792). By choosing this epitype, we believe that we achieve the best possible solution for maintaining taxonomic stability. Other members of the geophyllagroup include, e.g. I. bellidiana, I. miranda, I. posterula and I. sambucella. Since the differences between them are quite subtle, descriptions of I. geophylla in literature (as e.g. Stangl 1989; Ferrari 2006; Ludwig 2017) probably always comprise several species.

Inocybe geophylla is characterized by generally whitish, sometimes pale yellowish pileus with whitish velipellis, rather small spores with obtuse apex and hymenial cystidia which on average are longer than $50 \mu \mathrm{m}$ and sometimes have a rather long pedicel. The caulocystidia normally have a long and often undate neck. It prefers calcareous soil. Inocybe posterula differs, e.g. by typically helmet-like shape of the caps and on average longer oblong spores, I. miranda by shorter hymenial cystidia and on average longer spores and I. sambucella by very long and very narrow caulocystidia and growth often on acidic soil (Atkinson 1918, and personal observation). The pilei of I. bellidiana with age become yellowish at the centre and the pileus texture is more fibrillose with age. Besides, the spores are more bulgy in shape.

The originally designated type of I. xantholeuca consists of two basidiomata of which one is a nodulose spored species; thus, we declared the other one as lectotype. The original description of I. xantholeuca fits well with the above given description of I. geophylla, and since the ITS of the epitype of I. geophylla and of the lectotype of I. xantholeuca match as well, we consider the two species as conspecific.

Inocybe ghibliana Bandini \& B. Oertel sp. nov. Fig. 10 MycoBank number: MB 839159

Etymology: Named 'ghibliana' after the desert-wind Ghibli, because the species occurs in sun exposed, xeric terrain.

Diagnosis: Inocybe ghibliana normally has a pale ochraceous to nut-brown rather smooth to minutely tomentose pileus, quite distant lamellae, smooth spores, measuring 7.4 $10.4 \mu \mathrm{m}($ av. $8.7 \mu \mathrm{m}) \times 4.6-6.0 \mu \mathrm{m}$ (av. 5.2 $\mu \mathrm{m})$, subfusiform to (sub)lageniform hymenial cystidia, usually with rather uniformly wide walls at bulge and apex, pleurocystidia measuring 41-75 $\mu \mathrm{m}$ (av. 56 $\mu \mathrm{m}) \times 9-17 \mu \mathrm{m}$ (av. $12 \mu \mathrm{m})$ and mostly somewhat deformed caulocystidia only at the extreme apex of the stipe. It is encountered in xeric, exposed locations with conifers. This combination of characters as well as ITS sequence data distinguishes I. ghibliana from all other described species.

Holotype: GERMANY, Rheinland-Pfalz, Mainz, MainzLerchenberg, TK25 6015/1, alt. 235 m, lawn with Betula pendula, 13 Oct 2013, leg. D. Bandini (holotype STU SMNS-STU-F-0901256, isotype priv. herb. D.B. DB13-1013-3). GenBank: ITS + partial LSU = MW845878.

Description: Pileus 15-30 mm wide, at first broadly convex, later expanded, when young without, later with mostly 

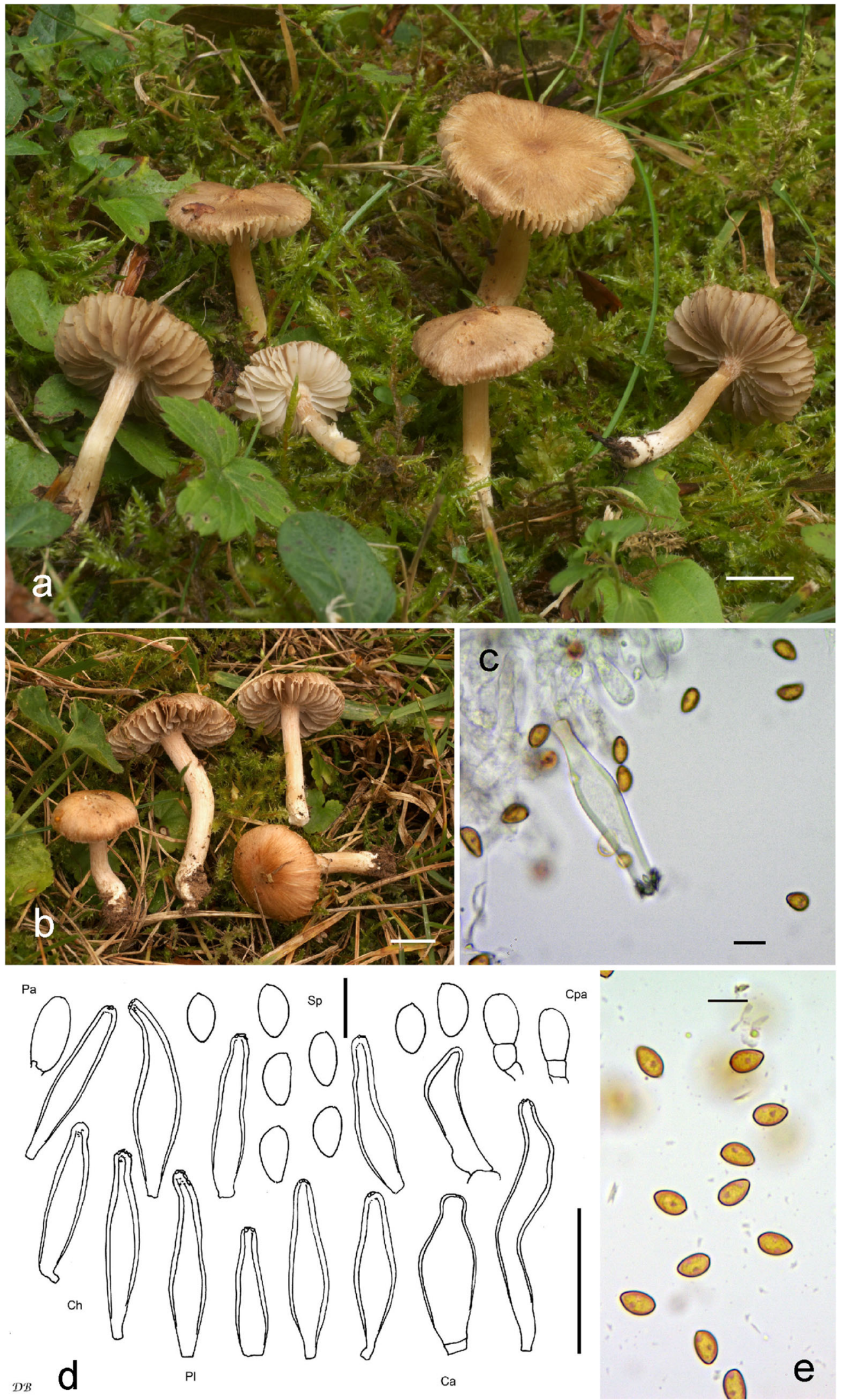

Fig. 10 Inocybe ghibliana, a holotype, scale bar: $1 \mathrm{~cm}$. b Coll. DB25-1015-1, scale bar: $1 \mathrm{~cm}$. c Cheilocystide (coll. DB1-11-13-10), scale bar: 10 $\mu \mathrm{m}$. d Microscopical characters (holotype), $\mathrm{Ca}=$ Caulocystidia, $\mathrm{Cpa}=$

Cauloparacystidia, $\mathrm{Ch}=$ Cheilocystidia, $\mathrm{Pa}=$ Paracystidia, $\mathrm{Pl}=$ Pleurocystidia, $\mathrm{Sp}=$ Spores; scale bar spores: $10 \mu \mathrm{m}$, scale bar cystidia: $50 \mu \mathrm{m}$. e: Spores (holotype), scale bar: $10 \mu \mathrm{m}$ 
rather low large umbo, margin at first decurved, later straight or even uplifted, and then pileus depressed around the umbo; young basidiomata usually with only faint pale greyish remnants of a velipellis at the centre of the pileus; colour mostly pale ochraceous, ochraceous brownish, pale brownish to nutbrown (Mu 10YR 7/6-7/8, 6/6-6/8, 5/6-5/8; 7.5YR 5/6-5/8), sometimes somewhat darker near the umbo, seldom entirely darker brown to dark reddish brown; surface long time smooth and glabrous, later minutely tomentose, and sometimes minutely innately fibrillose towards the margin; occasionally partly excoriated; young basidiomata with faint remnants of a cortina. Lamellae rather distant (ca. 25-40 1 = 1-3), broadly adnate with decurrent tooth, ventricose, at first whitish, beige to cream coloured, later greyish-brownish, or dark greyish with olive tinge, sometimes with darker brown patches; edge sometimes notchy, fimbriate, whitish to concolorous. Stipe 20-50 $\times 2-4 \mathrm{~mm}$, cylindrical or curved, sometimes slightly widening towards the base, when young covered with fine whitish tomentum, later longitudinally striate or glabrous, whitish to pale brownish or even brown with pale reddish hue; pruinose only near the extreme apex of the stipe. Context whitish in the pileus and the stipe. Smell subnull, but subspermatical, when cut. Colour of exsiccata pileus ochraceous brown, light brown, hazel-brown (Mu 10YR 5/6-5/8, 4/4-4/6), lamellae and stipe concolorous or a little lighter in colour, no darkening or blackening on drying.

Spores 7.4-10.4 $\mu \mathrm{m}$ (av. $8.7 \mu \mathrm{m}$, SD $0.6 \mu \mathrm{m}) \times$ 4.6-6.0 $\mu \mathrm{m}$ (av. 5.2 $\mu \mathrm{m}$, SD $0.2 \mu \mathrm{m}$ ); $\mathrm{Q}=1.4-1.9$ (av. 1.7, SD 0.1) ( $\mathrm{n}=120$ of 3 coll.); smooth, (sub)amygdaloid, without or with mostly only faint suprahilar depression, but often with rather flat ventrical side, apex subacute, subobtuse, with small indistinct pseudoporus. Basidia $19-33 \times 7-10 \mu \mathrm{m}$, generally $4-$ spored, sometimes also 2-spored, and then spores up to $11.5 \mu \mathrm{m}$ (and thus with higher average value). Lamellae edges sterile, composed of cheilocystidia and numerous colourless, (sub)clavate or (sub)cylindrical, thin-walled paracystidia, sometimes catenate. Pleurocystidia $41-75 \mu \mathrm{m}$ (av. $56 \mu \mathrm{m}$, SD $7.1 \mu \mathrm{m}$ ) $\times$ 9-17 $\mu \mathrm{m}$ (av. $12 \mu \mathrm{m}, \mathrm{SD} 1.7 \mu \mathrm{m}$ ); Q = 3.6-6.1 (av. 4.7, SD 0.6) ( $\mathrm{n}=45$ of 3 coll.), usually subfusiform to (sub)lageniform, seldom also (sub)cylindrical or (sub)utriform, at the apex generally wide, with short or longer neck, without or with only short pedicel, sometimes with truncate base, apex usually crystalliferous, walls up to 2.5 (3.0) $\mu \mathrm{m}$ thick at the apex, but mostly quite uniformly thick at bulge and apex, pale yellowishgreenish with $3 \% \mathrm{KOH}$. Cheilocystidia similar in appearance and size. Pileipellis constituted by an epicutis made up of parallel hyphae 4-12 $\mu \mathrm{m}$ wide, without or with only finely encrusting and parietal ochraceous brownish pigment, subcutis with wider and paler to colourless elements. Caulocystidia only at the extreme apex of the stipe, $50-80 \times 10-15(25) \mu \mathrm{m}$, often rather long and deformed, often with somewhat constricted apex, apex crystalliferous or not, walls up to $1.5 \mu \mathrm{m}$ (neck) thick, pale yellowish-greenish with $3 \% \mathrm{KOH}$; intermixed with numerous (sub)clavate to subglobose, sometimes catenate cauloparacystidia. Clampconnections abundant in all tissues.

Habitat and known distribution: The species is apparently associated with conifers as well as frondose trees and is thermotolerant, as it was collected in extreme locations. The collections from Germany are from a region with exceptionally dry and exposed habitats, with comparatively little precipitation, given the geographical setting. The other material stems from locations in Italy and Hungary, where the climatic situation is similar. We are not aware of any other collections of this taxon, but there are some EcM-sequences in GenBank and UNITE database from Italy, probably belonging to this species (GQ469525, with Cistus salviifolius; UDB026523 and UDB026563). In UNITE, there are furthermore three sequences of soil samples also from Estonia (UDB0173004, UDB0173436 and UDB0534112).

Further collections studied: GERMANY, RheinlandPfalz, Rhein-Erftkreis, Pulheim, Wingertsberg bei Brauweiler, TK25 6110/4, alt. 280 m, Quercus robur, Corylus avellana, 1 Nov 2013, leg. G. Wölfel; det. D. Bandini \& B. Oertel (STU SMNS-STU-F-0901485; DB111-13-10). Rheinland-Pfalz, Mainz, Mainz-Lerchenberg, TK25 6015/1, alt. 235 m, lawn with Betula pendula, 25 Oct 2015, leg. D. Bandini; det. D. Bandini \& B. Oertel (DB25-10-15-1). HUNGARY, Budapest, Telepesstreet, garden on sandy soil, Picea sp., 17 Sep 2017, leg. Z. Bratek \& M. Csizmár; det. D. Bandini \& B. Oertel (DB17-9-17-Bratek). Budapest, Infopark, sandy soil with Carpinus betulus, 17 Sep 2017, leg. Z. Bratek \& M. Csizmár; det. D. Bandini \& B. Oertel (STU SMNS-STU-F-0901484; DB25-10-15-1). ITALY, Marken, Urbino, direction towards Fossombrone, Pinus nigra, Pinus pinea, Pinus sylvestris, Abies sp., 30 Oct 2015, leg. M. Dondl; det. D. Bandini \& B. Oertel (DB30-10-15-1-Dondl-15-9).

Comments: Inocybe ghibliana is characterized by rather small size, normally pale ochraceous up to nut-brown pileus colours, rather smooth surface with only faint velipellis, only at the extreme apex pruinose stipe, rather wide lamellae, hymenial cystidia with often uniformly wide walls at bulge and apex and only short or truncate pedicel. The spores in most collections are on average shorter than $9 \mu \mathrm{m}$. Inocybe beatifica differs, e.g. by darker brown pileus colour and on average longer oblong spores, hymenial cystidia often with longer neck and narrower walls, and caulocystidia not only at the extreme apex. Inocybe semifulva might also have pale pileus colours, but the surface of pileus is generally less smooth, the stipe is at the apex often slightly pinkish and the spores usually are longer (Grund and Stuntz 1981; Bandini 
2014). Inocybe castorina, a species with sometimes rather pale pileus colour, has a less smooth pileus surface, differently shaped, often slender (sub)utriform hymenial cystidia and on average longer spores. Furthermore, it grows in moist places (Bandini et al. 2020a). Inocybe pseudofuscidula and I. griseovelata differ, e.g. by less smooth pileus surface, ample greyish velipellis and on average larger spores (Kühner 1955; Ludwig 2017, and personal observation). Inocybe derbschii differs by usually darker brown pileus colours, a less smooth surface of pileus, usually an abundant greyish velipellis and on average longer spores (see Schwöbel and Stangl 1982; Bandini et al. 2019b). Inocybe virgatula, finally, usually has a darker brown pileus colour, the pileus surface becomes rimose towards the margin with age, the hymenial cystidia are on average wider, and the spores are on average longer (Kühner 1955, and personal observation). All named species furthermore prefer different, less exposed and dry habitats. With only $91-92 \%$ identity in the ITS, I. ghibliana is only distantly related to I. plurabellae (see below). No closely related described species are known yet.

Inocybe glabrescens Velen., České Houby 2: 373 (1920) Fig. $24 \mathrm{~b}$

Description of the species: Velenovský, 1920-1922; Kuyper 1986; Stangl 1989.

Studied material (lectotype, designated by Kuyper 1985): Czech Republic, Mukařov, Ŕíčany, sep 1915 (PRC-bottle No. 279). Spores 7.1-10.1 $\mu \mathrm{m}$ (av. $8.7 \mu \mathrm{m}$, SD $0.8 \mu \mathrm{m}$ ) $\times 4.4$ $6.0 \mu \mathrm{m}$ (av. $5.2 \mu \mathrm{m}$, SD $0.4 \mu \mathrm{m}$ ); $\mathrm{Q}=1.4-1.9$ (av. 1.7, SD $0.1)(\mathrm{n}=40)$, smooth, (sub)amygdaloid, sometimes also subelliptic with (sub)acute apex, often with faint pseudoporus. Basidia 4-spored. Pleurocystidia 50-63 $\mu \mathrm{m}$ (av. $57 \mu \mathrm{m}$, SD $3.6 \mu \mathrm{m}) \times 15-20 \mu \mathrm{m}($ av. $17 \mu \mathrm{m}$, SD $1.7 \mu \mathrm{m}) ; \mathrm{Q}=2.9-4.1$ (av. 3.4, SD 0.4) ( $=15)$, mostly (sub)fusiform, also (sub)utriform or sublageniform, apex usually crystalliferous, with short pedicel or with truncate base, walls up to 4.0 (4.5) $\mu \mathrm{m}$ thick, yellowish-greenish with $3 \% \mathrm{KOH}$. Cheilocystidia similar in appearance and size. Paracystidia not observed. Caulocystidia not studied (to preserve the material).

Other studied material: GERMANY, Rheinland-Pfalz, Rhein-Pfalz-Kreis, Böhl-Iggelheim, TK25 6615/4alt. 110 m, Pinus sylvestris, Quercus robur, 17 Oct 2017, leg. D. Bandini; det. D. Bandini \& B. Oertel (STU SMNS-STU-F-0901570; DB17-10-17-6).

Comments: The lectotype of I. glabrescens is preserved in formaldehyde, which is a major obstacle for DNA extraction. Thus, no sequence could be obtained. Inocybe metrodii is not, as suggested by Kuyper (1986) and following him by Stangl (1989), synonymous with I. glabrescens, but, as morphological examination of the types showed, a separate species. Both species have an entirely pruinose stipe, but I. glabrescens differs from I. metrodii, e.g. by smaller and less stout basidiomata, felty to sublanose pileus, darker coloured stipe and caulocystidia with undate walls (personal observation). In Fig. 1, two collections are included that represent our understanding of I. glabrescens (STU SMNS-STU-F-0901570; DB17-10-17-6, from Germany). Very similar sequences have been published as I. cincinnata from Scandinavian countries (e.g. MH310760). North American sequences identified as I. glabrescens are rather diverse, but all different from our interpretation.

Inocybe glabripes Ricken, Die Blätterpilze, Fasc. 3/4: 107 (1911) Figs. 11, 24 a

= Inocybe microspora J.E. Lange, Dansk bot. Ark 2(no. 7): 38 (1917)

= Inocybe fuscidula Velen., České Houby 2: 378 (1920)

Description of the species: Ricken 1910-1915; Kuyper 1986; Stangl 1989; Ferrari 2006 (as 'I. microspora').

As no original material survived and no illustration is given in the publication, a neotype is designated here (MBT 10000531), GERMANY, Baden-Württemberg, Karlsruhe, Erzbergerstr., TK25 6916/3, alt. 118 m, Fagus sylvatica, Quercus robur, Betula pendula, 2 Jun 2013, leg./det. D. Bandini \& B. Oertel (STU SMNS-STU-F-0900979; DB2-613-12). GenBank: ITS + partial LSU = MW845881.

Description: Pileus 10-30 mm wide, at first subglobose or (sub)campanulate to subconical, later broadly convex to almost expanded, at first without, later with more or less pronounced large umbo, margin when young strongly involute, later decurved or straight; young basidiomata with conspicuous remnants of a greyish velipellis, mostly concentrated like ashes at the centre of the pileus; colour ochraceous brownish, brownish to brown or rusty to chestnut-brown, up to dark brown (Mu 10YR 5/6-5/8, 4/4-4/6; 7.5YR 3/2-3/4, 4/4-4/ 6 ), at the centre sometimes dark grey; surface long time glabrous and smooth, later finely rimulose towards the margin and sometimes somewhat minutely verrucose at the centre of the pileus; young basidiomata with remnants of a cortina. Lamellae moderately crowded (ca. 35-50, 1 = 1-3), adnate, subventricose, at first whitish, then beige greyish, greyish to greyish-brownish or ochraceous brownish, sometimes blotchy rusty; edge uneven, even to minutely fimbriate, whitish to concolorous. Stipe $20-45 \times 2-3 \mathrm{~mm}$, cylindrical or curved, sometimes widening towards the base, when young entirely covered with rough whitish tomentum, later lacerate fibrillose, longitudinally striate to glabrous, from pale straw-coloured to pale ochraceous or brownish in the middle; pruinose only near the extreme apex of the stipe and also there very sparely, therefore stipe often appearing as if being not pruinose at all. Context whitish in the pileus, pale brownish in the cortex of the stipe. Smell subnull, but (sub)spermatical, when cut. Colour of exsiccata pileus brown to dark brown or greyish dark brown, sometimes with faint reddish hue (Mu 10YR 4/4 $4 / 6,3 / 4-3 / 6$ ), lamellae and stipe concolorous or a little lighter in colour, no darkening or blackening with drying. 

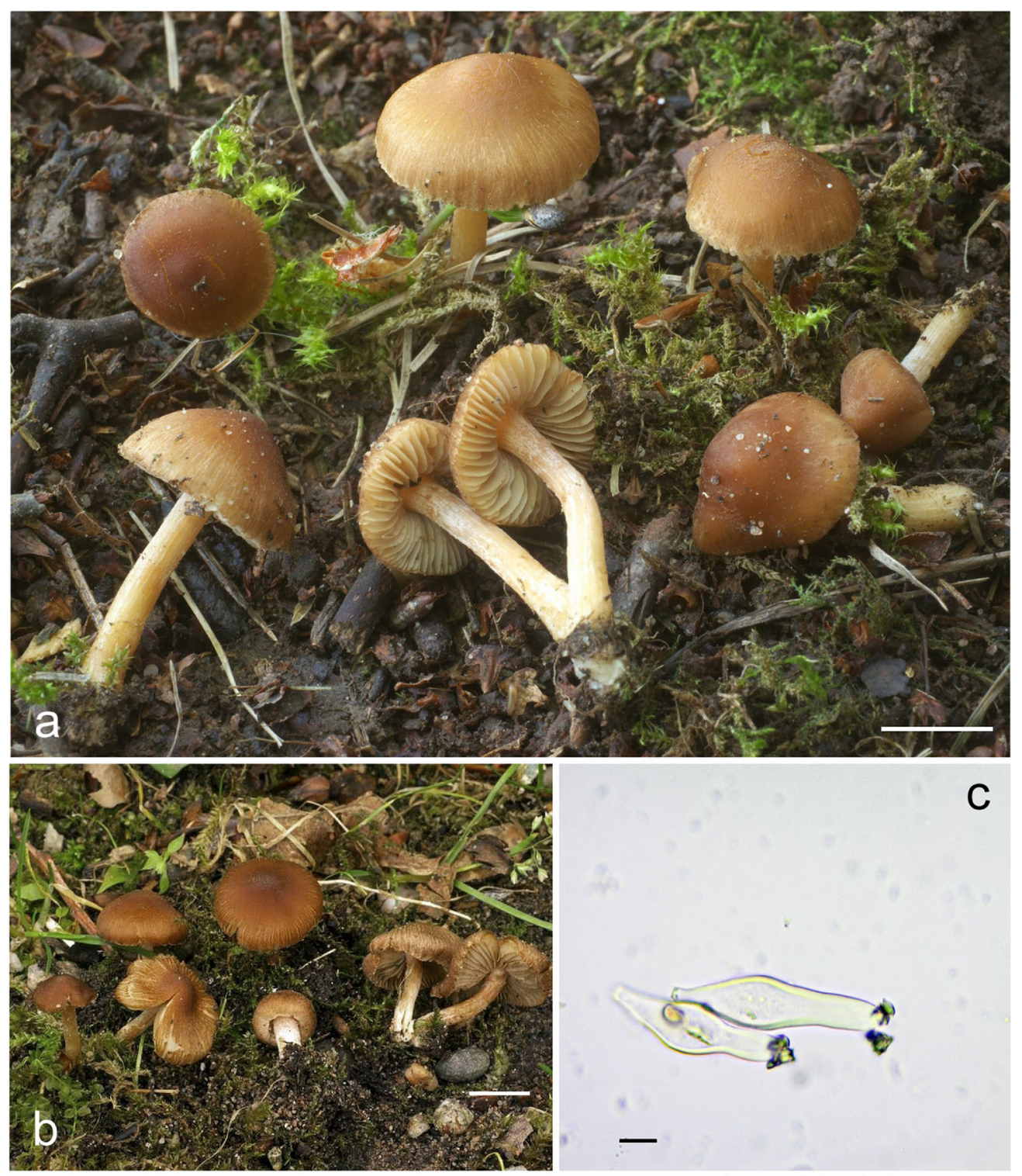

C

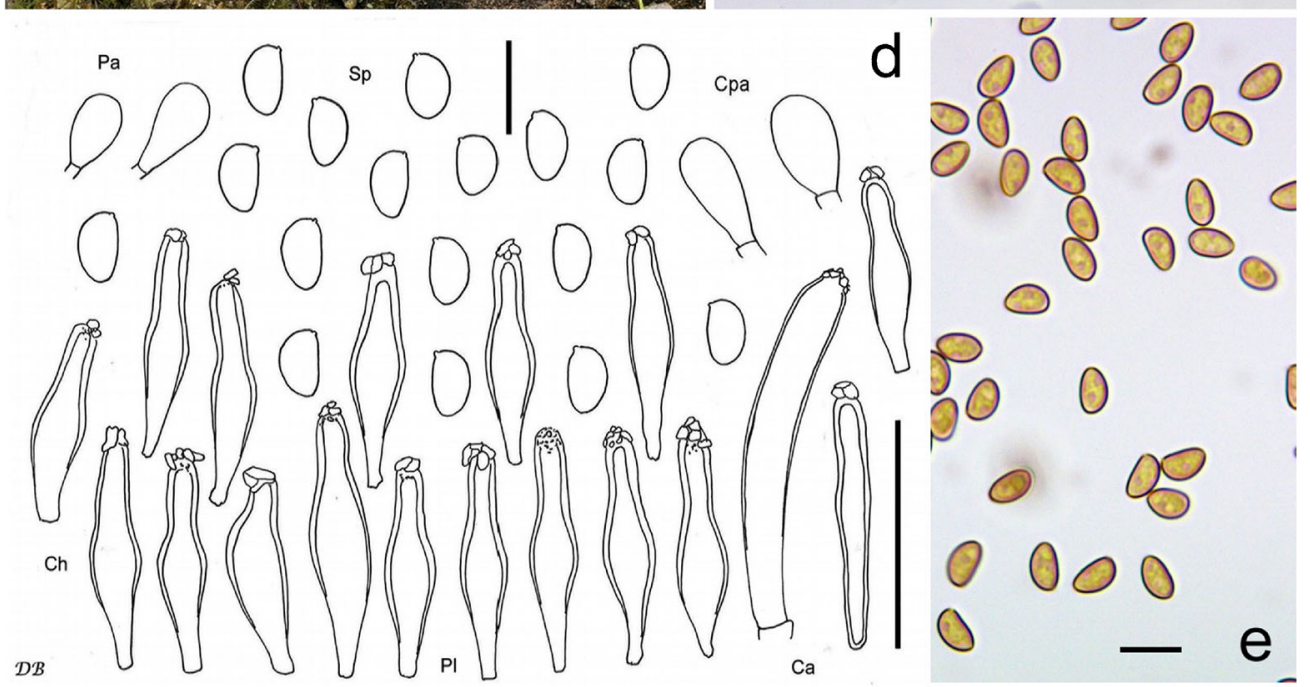

Fig. 11 Inocybe glabripes, a neotype, scale bar: $1 \mathrm{~cm}$. b Coll. DB15-712-5, scale bar: $1 \mathrm{~cm}$. c Cheilocystidia (coll. DB10-7-12-3), scale bar: 10 $\mu \mathrm{m}$. d Microscopical characters (neotype), $\mathrm{Ca}=$ Caulocystidia, $\mathrm{Cpa}=$
Cauloparacystidia, $\mathrm{Ch}=$ Cheilocystidia, $\mathrm{Pa}=$ Paracystidia, $\mathrm{Pl}=$ Pleurocystidia, $\mathrm{Sp}=$ Spores; scale bar spores: $10 \mu \mathrm{m}$, scale bar cystidia: $50 \mu \mathrm{m}$. e Spores (Coll. DB10-7-12-3), scale bar: $10 \mu \mathrm{m}$ 
Spores 6.8-9.3 $\mu \mathrm{m}$ (av. $7.7 \mu \mathrm{m}$, SD $0.5 \mu \mathrm{m}) \times 3.7-4.9 \mu \mathrm{m}$ (av. $4.3 \mu \mathrm{m}$, SD $0.2 \mu \mathrm{m}) ; \mathrm{Q}=1.5-2.2$ (av. 1.8, SD 0.2) $(\mathrm{n}=$ 120 of 3 coll.); smooth, (sub)amygdaloid, in some collections sometimes almost reniform, often with faint suprahilar depression, apex subacute, with indistinct pseudoporus. Basidia 21$28 \times 7-9 \mu \mathrm{m}$, generally 4 -spored, seldom also 2 -spored, and then spores up to $10.8 \mu \mathrm{m}$. Lamellae edges sterile, composed of cheilocystidia and some colourless, (sub)clavate, thinwalled paracystidia. Pleurocystidia 40-58 $\mu \mathrm{m}$ (av. $47 \mu \mathrm{m}$, SD $4.0 \mu \mathrm{m}) \times 8-16 \mu \mathrm{m}($ av. $11 \mu \mathrm{m}$, SD $1.7 \mu \mathrm{m}) ; \mathrm{Q}=2.9$ 5.7 (av. 4.3, SD 0.7) ( $\mathrm{n}=45$ of 3 coll.), generally (sub)fusiform, also (sub)utriform, with short or longer neck, often transition from bulge to neck clearly demarcated, at the apex generally wide, usually with short pedicel, apex usually crystalliferous, walls up to $2.0(2.5) \mu \mathrm{m}$ thick at the apex, pale yellowish-greenish with $3 \% \mathrm{KOH}$. Cheilocystidia similar in appearance and size. Pileipellis constituted by an epicutis made up of parallel hyphae 5-12 $\mu \mathrm{m}$ wide, with encrusting and parietal brown to dark brown pigment, subcutis with wider and paler to colourless elements. Caulocystidia only very sparely near the extreme apex of the stipe, 40-70 $\times 8$ $15 \mu \mathrm{m}$, (sub)utriform to (sub)cylindrical, without or with rather short neck, without or with short pedicel, apex usually crystalliferous, walls up to $1.5 \mu \mathrm{m}$ thick at the apex, pale yellowish-greenish with $3 \% \mathrm{KOH}$. Clamp-connections abundant in all tissues.

Habitat and known distribution: Inocybe glabripes is a common species growing on calcareous soil preferably with Fagus sylvatica, usually from low elevation or submontane region. Our collections are from Germany, as is a sequence from a collection in GenBank (as ' $I$. cf. glabripes', MT005930). Another sequence in GenBank stems from a collection from Estonia (as ' $I$. cf. microspora', AM882808.2) as well as several EcM sequences in GenBank and UNITE that might belong to this species from China (JQ318630 and JQ318641, both with Quercus liaotungensis), England (EU668233), Estonia (UDB013697, with Tilia sp.), Iran (FR852238) and from soil samples from Estonia (UDB074091 and many others) and from Pakistan (UDB0769278).

Selected other collections studied: GERMANY, BadenWürttemberg, Heidelberg, Königstuhl, TK25 6518/1, alt. 560 m, Fagus sylvatica, Picea abies, Pseudotsuga menziesii, 10 Jul 2012, leg./det. D. Bandini (DB10-7-12-3). BadenWürttemberg, Rhein-Neckar-Kreis, Schönbrunn, TK25 6519/4, alt. 380 m, Quercus robur, Salix caprea, 28 Sep 2014, leg. D. Bandini; det. D. Bandini \& B. Oertel (DB289-14-7). Baden-Württemberg, Neckar-Odenwald-Kreis, Neunkirchen, TK25 6519/4, alt. 400 m, Fagus sylvatica, Picea abies, 4 Aug 2017, leg. D. Bandini; det. D. Bandini \& B. Oertel (DB4-8-17-8). Bayern, Landkreis DingolfingLandau, Mamming, TK25 7341/2, alt. 350 m, Salix sp.,
Populus sp., 3 Oct 2013, leg. D. Bandini, B. Oertel \& L. Quecke; det. D. Bandini \& B. Oertel (DB3-10-13-8). Rheinland-Pfalz, Rhein-Pfalz-Kreis, Böhl-Iggelheim, TK25 $6615 / 4$, alt. $110 \mathrm{~m}$, Picea abies, Quercus robur, 15 Jul 2012, leg./det. D. Bandini \& B. Oertel (DB15-7-12-5). Niedersachsen, Hildesheim, Nordstemmen, Heyersum, TK25 3824/2, alt. 64 m, Fagus sylvatica, Quercus robur, 13 Jun 2009, leg. J. Kruse; det. D. Bandini \& B. Oertel (DB13-69-Kruse).

Neotype of I. glabripes, Fig. 11 a, d: Spores 6.7-9.0 $\mu \mathrm{m}$ (av. $7.8 \mu \mathrm{m}$, SD $0.5 \mu \mathrm{m}$ ) $\times 3.9-4.8 \mu \mathrm{m}$ (av. $4.3 \mu \mathrm{m}$, SD 0.2 $\mu \mathrm{m}) ; \mathrm{Q}=1.5-2.1$ (av. 1.7, SD 0.1) $(\mathrm{n}=40)$, smooth, (sub)amygdaloid, with subacute apex. Basidia 4-spored. Pleurocystidia $38-65 \mu \mathrm{m}$ (av. $51 \mu \mathrm{m}$, SD $8 \mu \mathrm{m}) \times 11-17$ $\mu \mathrm{m}$ (av. $13 \mu \mathrm{m}$, SD $1.7 \mu \mathrm{m}$ ); $\mathrm{Q}=2.9-5.4$ (av. 3.9, SD 0.8) (n =15), mostly (sub)fusiform, apex usually crystalliferous, walls up to $1.5(2.0) \mu \mathrm{m}$ thick at the apex, pale yellowishgreenish with $3 \% \mathrm{KOH}$. Cheilocystidia similar in appearance and size. Paracystidia (sub)clavate. Caulocystidia very sparely only near the apex of the stipe, up to $70 \mu \mathrm{m}$ length, (sub)utriform to (sub)cylindrical, apex usually crystalliferous, walls up to $1.5 \mu \mathrm{m}$ thick at the apex, pale yellowish-greenish with $3 \% \mathrm{KOH}$.

Studied material (lectotype of I. fuscidula, designated here MBT 10000532), Fig. 24 a: Czech Republic, Davle, Jul 1918, leg. Kavina (PRC-bottle no. 396). Spores 6.2-8.9 $\mu \mathrm{m}$ (av. 7.5 $\mu \mathrm{m}$, SD $0.6 \mu \mathrm{m}) \times 3.9-5.2 \mu \mathrm{m}$ (av. $4.5 \mu \mathrm{m}$, SD $0.2 \mu \mathrm{m}) ; \mathrm{Q}=$ 1.4-1.9 (av. 1.7, SD 0.1) $(\mathrm{n}=40)$, smooth, (sub)amygdaloid or (sub)ellipsoid, apex (sub)obtuse, subacute. Basidia 4-spored. Pleurocystidia 52-63 $\mu \mathrm{m}$ (av. $58 \mu \mathrm{m}$, SD $3.2 \mu \mathrm{m}$ ) $\times 10-15$ $\mu \mathrm{m}$ (av. $12 \mu \mathrm{m}$, SD $1.3 \mu \mathrm{m}$ ); Q = 3.5-5.5 (av. 4.7, SD 0.5) (n =15), (sub)fusiform, subutriform or (sub)lageniform, apex usually crystalliferous, walls up to $1.5(2.0) \mu \mathrm{m}$ thick, pale yellowish-greenish with 3\% KOH. Cheilocystidia similar in appearance and size. Paracystidia not observed. Caulocystidia not studied (to preserve the material).

Comments: Inocybe glabripes is characterized by usually rather small brown caps with greyish velipellis at the centre of young basidiomata, only near the extreme apex pruinose stipe which therefore appears to be 'naked' (see Ricken 1910 1915), small spores and hymenial cystidia often with clearly demarcated transition from bulge to neck. It often grows on bare calcareous earth with Fagus sylvatica, generally in low altitudes. Inocybe glabripes is common and well known and a number of descriptions exist in the literature (see above). It has often been referred to as I. microspora J.E. Lange (so for instance still in Ludwig 2017). But as Kuyper (1986) points out, there is 'not much doubt' that Ricken had described the same species only two years earlier (see Lange 1917).

Since no holotype or iconotype is existent for I. glabripes, a neotype was chosen by us. By this, we believe that we achieve the best possible solution for maintaining taxonomic stability. Inocybe fuscidula has so far not been considered a synonym of 
I. glabripes (see Kuyper 1985). The synonymization is based on morphological evidence of the microscopic details: shape and size of the spores and shape and size of the hymenial details. Our analyses did not support the synonymization of I. virgatula and I. fuscidula suggested by Kuyper (1986) and others (see below).

The morphologically and phylogenetically related (see Fig. 1) I. minimispora differs, e.g. by on average still smaller spores (see below) and habitat, i.e. in mountainous regions (a habitat in which Ricken did not collect) with Picea abies. Other species with such small spores, such as I. pseudoreducta Stangl \& Glowinski or I. albomarginata Velen. differ, e.g. by entirely pruinose stipes (Stangl and Glowinski 1981; Velenovský 1920-1922).

Inocybe gracillima Bull. Soc. mycol. Fr. 127(1-2): 48 (2012) [2011] Fig. 24 c

Description of the species: Carteret and Reumaux (2012) [2011].

Studied material (isotype): FRANCE, forêt de Mautepas (Yvelines), with Quercus, 30 Oct 1999, leg. X. Carteret (XC99103003). Spores 7.7-9.8 $\mu \mathrm{m}$ (av. $8.5 \mu \mathrm{m}$, SD $0.5 \mu \mathrm{m}) \times$ 4.4-5.6 $\mu \mathrm{m}$ (av. 5.1 $\mu \mathrm{m}, \mathrm{SD} 0.3 \mu \mathrm{m}$ ); Q = 1.4-1.9 (av. 1.7, SD $0.1)(\mathrm{n}=40)$, smooth, (sub)amygdaloid, usually without suprahilar depression, with (sub)obtuse to subacute apex. Basidia 4-spored. Pleurocystidia 54-77 $\mu \mathrm{m}$ (av. $66 \mu \mathrm{m}$, SD $7 \mu \mathrm{m}) \times 11-16 \mu \mathrm{m}$ (av. $13 \mu \mathrm{m}$, SD $2 \mu \mathrm{m}) ; \mathrm{Q}=3.8-6.5$ (av. 5.1, SD 0.8) $(\mathrm{n}=15)$, mostly (sub)fusiform to subcylindrical, apex usually crystalliferous, walls up to 2.5 (3.0) $\mu \mathrm{m}$ thick at the apex, yellow-green with $3 \% \mathrm{KOH}$. Cheilocystidia similar in appearance and size. Paracystidia not observed. Caulocystidia not studied, because not present.

Comments: The ITS sequence suggests that I. gracillima is a sister species of I. obscuroides (see below) and that the ITS-molecular distance between the two species may be just around $1.6 \%$. Although it is impossible to determine based on the available data, whether I. gracillima and I. obscuroides are monophyletic in relation to each other, morphological differences such as size of the basidiomata, habitat, surface of pileus or size and shape of the spores suggest that I. gracillima is clearly distinct from I. obscuroides.

Inocybe griseolilacina J.E. Lange, Dansk bot. Ark. 2(no. 7): 33 (1917) Figs. 23 h, 26 b

= Inocybe personata Kühner, Bull. Soc. nat. Oyonnax 9(Suppl. (Mém. hors sér. 1)): 5 (1955)

= Inocybe elegans Reumaux, Docums Mycol. 30(no. 120): 38 (2001)

Description of the species: Kuyper 1986; Stangl 1989; Breitenbach and Kränzlin 2000; Ferrari 2006; Ludwig 2017.

Studied Material (isotype of I. elegans), Fig. 23 h: FRANCE, Bois de Alleux, Ardennes, Quercus, leg. P. Reumaux (PR-7878). Spores 8.0-10.1 $\mu \mathrm{m}$ (av. $9.0 \mu \mathrm{m}$, SD $0.5 \mu \mathrm{m}) \times 4.7-5.6 \mu \mathrm{m}($ av. $5.2 \mu \mathrm{m}, \mathrm{SD} 0.2 \mu \mathrm{m}) ; \mathrm{Q}=1.5-1.9$ (av. 1.7, SD 0.1) (n = 40), smooth, (sub)amygdaloid, with (sub)acute to subpapillate apex. Basidia generally 4-spored, but also 2 -spored, and then spores up to $13 \mu \mathrm{m}$. Pleurocystidia 37-74 $\mu \mathrm{m}$ (av. $57 \mu \mathrm{m}$, SD $10 \mu \mathrm{m}) \times 12-19$ $\mu \mathrm{m}$ (av. $15 \mu \mathrm{m}, \mathrm{SD} 2 \mu \mathrm{m}) ; \mathrm{Q}=2.5-4.8$ (av. 3.7, SD 0.6) $(\mathrm{n}=$ 15 ), mostly subutriform or (sub)fusiform, apex usually crystalliferous, walls up to 2.0 (3.0) $\mu \mathrm{m}$ thick, pale yellowish-greenish with $3 \% \mathrm{KOH}$. Cheilocystidia similar in appearance and size. Paracystidia not observed. Caulocystidia not studied, because stipe not present.

Lectotype of I. personata, designated by J. Vauras and Larsson (2020), Fig. 26 b: FRANCE, Haute-Savoie, Samoens, 1948 (G-00126459). Spores 8.4-10.0 $\mu \mathrm{m}$ (av. 9.1 $\mu \mathrm{m}, \mathrm{SD} 0.4 \mu \mathrm{m}) \times 5.0-5.8 \mu \mathrm{m}$ (av. $5.4 \mu \mathrm{m}$, SD $0.2 \mu \mathrm{m}) ; \mathrm{Q}=$ 1.5-1.9 (av. 1.7, SD 0.1) $(\mathrm{n}=40)$, smooth, (sub)amygdaloid, apex subacute, often subpapillate. Basidia 4-spored. Pleurocystidia 52-74 $\mu \mathrm{m}$ (av. $60 \mu \mathrm{m}$, SD $7 \mu \mathrm{m}) \times 11-16$ $\mu \mathrm{m}$ (av. $14 \mu \mathrm{m}$, SD $2 \mu \mathrm{m}) ; \mathrm{Q}=3.3-5.3$ (av. 4.3, SD 0.5) (n = 15), subfusiform, (sub)utriform, also (sub)cylindrical, usually with short neck, often subcapitate, with short or longer pedicel, apex usually crystalliferous, walls up to $2.0 \mu \mathrm{m}$ thick at the apex, (pale) yellowish-greenish with $3 \% \mathrm{KOH}$. Cheilocystidia similar in appearance and size. Paracystidia not observed. Caulocystidia not studied (to preserve the material).

Selected other material studied: GERMANY, BadenWürttemberg, Rhein-Neckar-Kreis, Mauer, TK25 6618/4, alt. 140 m, Fagus sylvatica, 15 Sep 2014, leg./det. D. Bandini (SMNS-STU-F-0900999, DB15-914-4). Bayern, Berchtesgadener Land, Berchtesgaden, TK25 8344/3, alt. $900 \mathrm{~m}$, Picea abies, Abies alba, 16 Aug 2011, leg./det. D. Bandini (KR-M-0038014, DB168-11-12).

Comments: We did not have original material of I. griseolilacina available for study, since no such material exists (personal communication H. Knudsen, C), but owning to the original description of Lange we are confident that our concept of the species (and that of Kuyper 1986; Stangl 1989; Breitenbach and Kränzlin 2000; Ryberg et al. 2008; Ludwig 2017 etc.) coincide with that of Lange (1917). Microscopically, I. personata and I. elegans cannot be distinguished from I. griseolilacina and are thus synonymized here. In Fig. 1, I. griseolilacina is represented by two recent collections studied by us; sequence data for the types of I. elegans and I. personata are not available.

Inocybe griseovelata Kühner, Bull. Soc. nat. Oyonnax 9(Suppl. (Mém. hors sér. 1)): 4 (1955) Figs. 24 d, 27 b

= Inocybe subvirgata Reumaux, Docums Mycol. 31(no. 121): 9 (2001)

Description of the species: Kühner 1955; Kuyper 1986; Stangl 1989. 
Typification of I. griseovelata: FRANCE, Paris, Bois de Vincennes, 14 Jul [1927], leg. R. Kühner. Designated here as lectotype (MBT 10000533; G00058738).

Studied material (lectotype of $\boldsymbol{I}$. griseovelata), Fig. $24 \mathrm{~d}$ : Spores 9.2-11.8 $\mu \mathrm{m}$ (av. 10.4 $\mu \mathrm{m}$, SD $0.7 \mu \mathrm{m}) \times 5.4-6.5 \mu \mathrm{m}$ (av. $6.0 \mu \mathrm{m}, \mathrm{SD} 0.3 \mu \mathrm{m}) ; \mathrm{Q}=1.5-2.0$ (av. 1.7, SD 0.1) $(\mathrm{n}=$ 40), smooth, (sub)amygdaloid, with (sub)obtuse, (sub)acute apex. Basidia 4-spored, seldom also 2-spored. Pleurocystidia 56-74 $\mu \mathrm{m}$ (av. $63 \mu \mathrm{m}$, SD $4.7 \mu \mathrm{m}) \times 12-16$ $\mu \mathrm{m}$ (av. $14 \mu \mathrm{m}, \mathrm{SD} 1.2 \mu \mathrm{m}) ; \mathrm{Q}=3.9-5.3$ (av. 4.5, SD 0.4) (n = 15), (sub)cylindrical, (sub)fusiform or subutriform, apex usually crystalliferous, walls up to 3.0 (3.5) $\mu \mathrm{m}$ thick, pale yellowish-greenish with $3 \% \mathrm{KOH}$. Cheilocystidia similar in appearance and size. Paracystidia not observed. Caulocystidia not studied (to preserve the material).

Isotype of $\boldsymbol{I}$. subvirgata, Fig. 27 b: FRANCE, Bois des Alleux, Ardennes, with frondose trees, 4 Sep 1986, leg. P. Reumaux (PR1068). GenBank: ITS = MW856436. Spores 8.6-12.3 $\mu \mathrm{m}$ (av. $10.5 \mu \mathrm{m}$, SD $0.8 \mu \mathrm{m}) \times 5.1-6.3 \mu \mathrm{m}$ (av. $5.6 \mu \mathrm{m}, \mathrm{SD} 0.3 \mu \mathrm{m}) ; \mathrm{Q}=1.6-2.3$ (av. 1.9, SD 0.1) $(\mathrm{n}=40)$, smooth, oblong (sub)amygdaloid, with (sub)conical apex. Basidia 4-spored. Pleurocystidia 53-74 $\mu \mathrm{m}$ (av. $63 \mu \mathrm{m}$, SD $6 \mu \mathrm{m}) \times 13-18 \mu \mathrm{m}($ av. $15 \mu \mathrm{m}$, SD $2 \mu \mathrm{m}) ; \mathrm{Q}=3.3-5.7$ (av. 4.2, SD 0.7) $(n=15)$, subcylindrical, also (sub)fusiform, (sub)utriform, at the apex generally wide, walls up to 1.5 (2.0) $\mu \mathrm{m}$ thick at the apex, subnull or only pale yellowish-greenish with $3 \% \mathrm{KOH}$. Cheilocystidia similar in appearance and size. Paracystidia not observed. Caulocystidia not studied, because stipe not present.

Selected other material studied: GERMANY, Bayern, Dingolfing-Landau, Mamming, TK25 7341/2, alt. $345 \mathrm{~m}$, Salix sp., Betula pendula, Populus sp., 1 Oct 2013, leg. D. Bandini \& B. Oertel; det. D. Bandini (STU SMNS-STU-F-0901567, DB1-10-13-2). Sachsen-Anhalt, Harz, Ilsenburg, TK25 4130/1, Picea abies, 30 Sep 2012, leg. /det. D. Bandini \& B. Oertel (STU SMNS-STU-F-0901568; DB30-9-12-1). NETHERLANDS, Friesland, Ameland, Hollum, alt. 4 m, Pinus sylvestris, Populus sp. 15 Oct 2014, leg. D. Bandini; det. D. Bandini \& B. Oertel (SMNS-STU-F0901457, DB15-10-14-5).

Comments: Originally, J. Poirier (herbarium slip 16 Jan 1995) intended another collection (G388327) to become the lectotype of I. griseovelata. We are not aware, though, that this was ever published. This material has been lost (personal communication, $\mathrm{Ph}$. Clerc, former curator of $\mathrm{G})$. The lectotype collection that is selected here stems from the same locality as the holotype, but is without a year. According to Ph. Clerc, there is some evidence that the material was collected in 1927 and is thus likely to be suitable as lectotype. Sequence data of the lectotype is not available. It is represented by own collections with matching morphology in Fig. 1. Judging from ITS sequence data (FN550931), our concept of I. griseovelata is, e.g. shared by Ryberg et al. (2010), while what has been referred to as I. griseovelata in America appears to be a different taxon.

Since the morphological details of an isotype of I. subvirgata were very similar to those of I. griseovelata and the ITS matches the ITS of own collections of I. griseovelata (see Fig. 1), we consider I. subvirgata to be synonymous with $I$. griseovelata.

Inocybe grusiana Bandini \& B. Oertel sp. nov. Fig. 12 MycoBank number: MB 839160

Etymology: Named 'grusiana' because of the greyish velipellis of young basidiomata reminding the colour of the feathers of the Eurasian crane (Grus grus).

Diagnosis: Inocybe grusiana has an ample, but often fugacious greyish velipellis when young, rather glabrous to rimose brown pileus, only at the apex pruinose stipe, smooth spores,

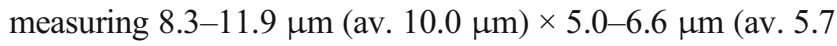
$\mu \mathrm{m}$ ), (sub)utriform or (sub)lageniform hymenial cystidia sometimes with truncate base, pleurocystidia measuring 52 $93 \mu \mathrm{m}($ av. $65 \mu \mathrm{m}) \times 10-24 \mu \mathrm{m}($ av. $16 \mu \mathrm{m})$, often catenate paracystidia and long narrow caulocystidia, mostly with undate walls. The species can be distinguished from other brown species with greyish pelipellis such as I. griseovelata by the combination of the named characters as well as by ITS sequence data.

Holotype: GERMANY, Baden-Württemberg, RheinNeckar-Kreis, Spechbach, direction to Waldwimmersbach, TK25 6519/4, alt. 400 m, Picea abies, 21 May 2017, leg. D. Bandini (holotype STU SMNS-STU-F-0901262; isotype priv. herb. D.B. DB21-5-17-1). GenBank: ITS + partial LSU = MW845884.

Description: Pileus 15-40 mm wide, (sub)globose, (sub)campanulate or (sub)conical, later broadly convex or expanded, without or with rather low broad umbo, margin at first involute, later decurved to straight, when old also uplifted, then with undate margin and pileus depressed around the centre; when young with abundant remnants of a greyish velipellis, to be seen as thick layer at least at the centre of the pileus, but often vanishing very soon; colour usually brown with reddish tinge to dark reddish brown $(\mathrm{Mu} 10 \mathrm{YR}$ 4/6; 7.5YR 3/4; 5YR 3/3-3/4), but also much paler, straw to pale brown (10YR 7/4-7/8), and sometimes only much paler at the margin; surface at first smooth and glabrous, later (sub)rimulose to rimose; sometimes in the centre more or less areolate diffracted and/or subscaly; young basidiomata with abundant remnants of a whitish cortina. Lamellae moderately crowded or subdistant (ca. 45-55 (60), 1=1-3), rather thickish and sometimes uneven, mostly emarginate adnate and sometimes subdecurrent, (sub)ventricose, at first whitish, then slightly greyish, faintly ochraceous to ochraceous brownish; edge fimbriate, whitish. Stipe 20-60 × 2-5 (6) mm, mostly rather stout, cylindrical or curved, often slightly widening 

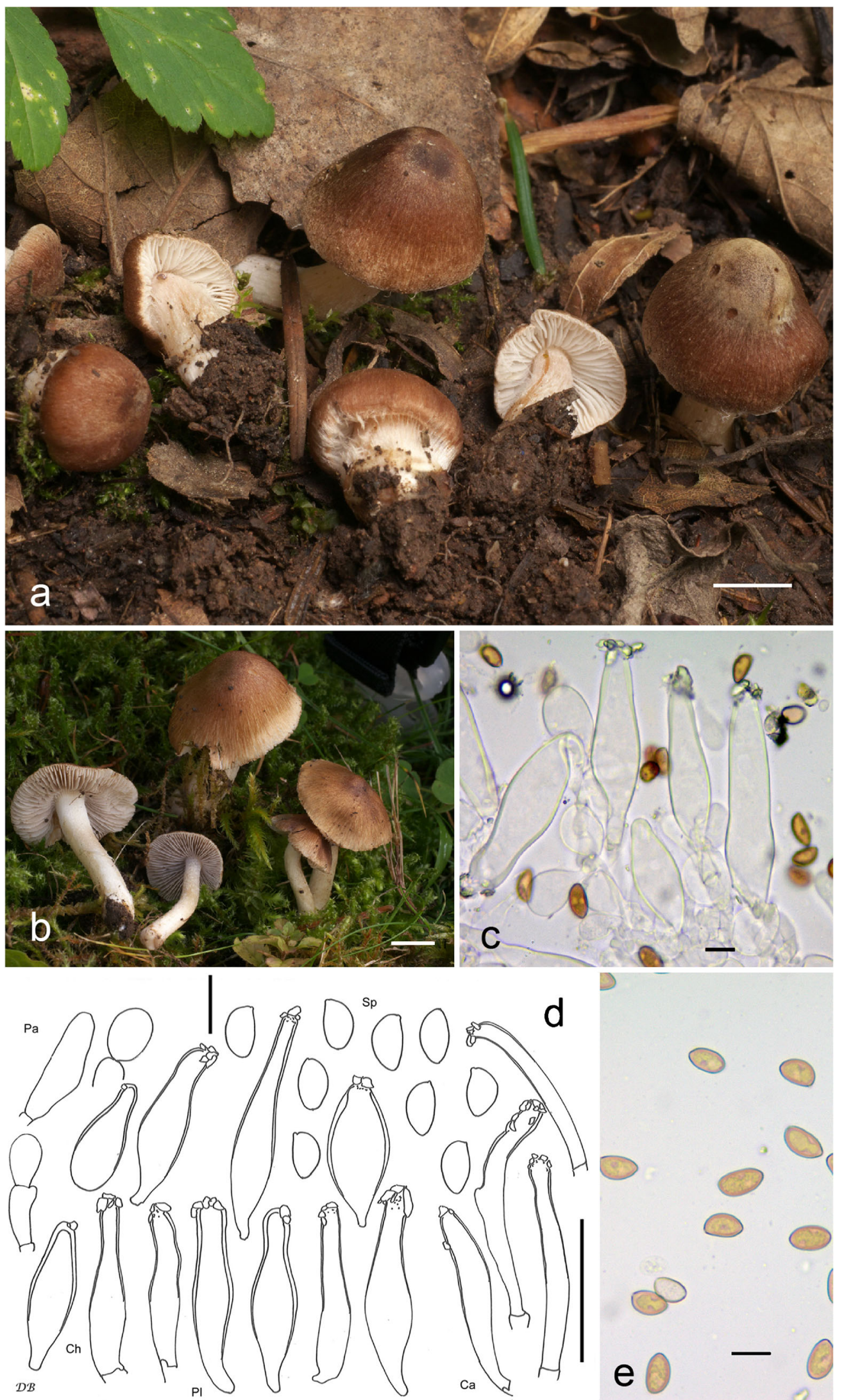

Fig. 12 Inocybe grusiana, a: holotype, scale bar: $1 \mathrm{~cm}$. b Coll. DB12-1016-1, scale bar: $1 \mathrm{~cm}$. c Cheilocystidia (coll. DB28-5-16-2), scale bar: 10 $\mu \mathrm{m}$. $\mathbf{d}$ Microscopical characters (holotype) $\mathrm{Ca}=$ Caulocystidia, $\mathrm{Cpa}=$

Cauloparacystidia, $\mathrm{Ch}=$ Cheilocystidia, $\mathrm{Pa}=$ Paracystidia, $\mathrm{Pl}=$ Pleurocystidia, $\mathrm{Sp}=$ Spores; scale bar spores: $10 \mu \mathrm{m}$, scale bar cystidia: $50 \mu \mathrm{m}$. e Spores (coll. DB28-5-16-2), scale bar: $10 \mu \mathrm{m}$ 
towards apex and base, when young entirely covered with whitish tomentum, later longitudinally striate, then glabrous, long time whitish, later beige with faint yellowish hue; pruinose near the apex of the stipe. Context whitish in pileus and stipe. Smell subspermatical or disagreeably faintly cadaverous, at least when cut. Colour of exsiccata pileus dark brown with or without reddish hue (Mu 5YR 3/2-3/4; 7.5YR 3/2-3/ 4), lamellae and stipe light brown, no darkening or blackening on drying.

Spores $8.3-11.9 \mu \mathrm{m}$ (av. $10.0 \mu \mathrm{m}$, SD $0.8 \mu \mathrm{m}) \times 5.0$ $6.6 \mu \mathrm{m}$ (av. $5.7 \mu \mathrm{m}$, SD $0.4 \mu \mathrm{m}$ ); Q $=1.5-2.1$ (av. 1.8, SD $0.1)$ ( $n=120$ of 3 coll.); smooth, (sub)amygdaloid, with explicit suprahilar depression or ventrically applanate, apex (sub)acute to subpapillate, in some collections with indistinct pseudoporus. Basidia 25-34 × 7-11 $\mu \mathrm{m}$, generally 4-spored, seldom also 2 -spored, and then spores up to $14 \mu \mathrm{m}$. Lamella edge sterile, composed of cheilocystidia and numerous colourless, variably shaped, often catenate thin-walled paracystidia. Pleurocystidia 52-93 $\mu \mathrm{m}$ (av. $65 \mu \mathrm{m}$, SD 10.3 $\mu \mathrm{m}) \times 10-24 \mu \mathrm{m}($ av. $16 \mu \mathrm{m}, \mathrm{SD} 3.2 \mu \mathrm{m}$ ); Q = 2.4-6.9 (av. 4.1, SD 1.0) ( $\mathrm{n}=45$ of 3 coll.), mostly (sub)utriform or (sub)lageniform, also (sub)cylindrical, at the apex generally wide, usually with rather short, but sometimes with long tapering neck, near the apex sometimes slightly constricted, usually with short pedicel or with truncate base, apex usually crystalliferous, walls up to $1.5(2.0) \mu \mathrm{m}$ thick at the apex, but mostly quite thin-walled, yellowish-greenish with $3 \% \mathrm{KOH}$. Cheilocystidia similar in appearance and size. Pileipellis constituted by an epicutis made up of parallel hyphae 6-12 $\mu \mathrm{m}$ wide, often but not always with finely encrusting and parietal dark brown pigment, subcutis with wider and paler to colourless elements. Caulocystidia up to $80 \times 8-11 \mu \mathrm{m}$, characteristically long and narrow subcylindrical, mostly with undate walls, base often truncate, sometimes intermixed with cystidia in shape and size like the hymenial cystidia, apex usually crystalliferous, walls up to $1.0 \mu \mathrm{m}$ thick at the apex, yellowish-greenish with $3 \% \mathrm{KOH}$. Clamp-connections abundant in all tissues.

Habitat and known distribution: The species was collected by us in Austria and Germany, always with Picea abies on calcareous soil. Apart from the cited collections, a sequence putatively belonging to $I$. grusiana exists from Italy (as 'Inocybe spec.', JF908243). Furthermore, an EcMsequence is published in the UNITE database from Turkey (UDB004930, with Cedrus libani) and a sequence from a soil sample from Estonia (UDB0588511) that could also belong to I. gruisiana. The species fructifies as early as May and up to October.

Further collections studied: AUSTRIA, Oberösterreich, Schalchen, Kobernausser Wald, ÖK25V, 3328-Ost, alt. 525 m, Picea abies, Abies alba, Larix decidua, 17 Aug 2014, leg. D. Bandini, J. Christan \& L. Quecke; det. D. Bandini \& B. Oertel (DB17-8-14-22). GERMANY, Baden-Württemberg,
Rhein-Neckar-Kreis, Wiesenbach, Panoramastrasse, TK25 6618/2, alt. 175 m, Picea abies, 1 Sep 2014, leg. D. \& G. Bandini; det. D. Bandini \& B. Oertel (DB1-9-14-1). BadenWürttemberg, Rhein-Neckar-Kreis, Spechbach, direction to Waldwimmersbach, TK25 6519/4, alt. 400 m, Picea abies, 28 Mai 2016, leg. D. Bandini; det. D. Bandini \& B. Oertel (STU SMNS-STU-F-0901486; DB28-5-16-2). Ibidem, 21 Mai 2017, leg. D. Bandini; det. D. Bandini \& B. Oertel (DB21-5-17-1). Bayern, Schwaben, Ostallgäu, Füssen, cemetery, TK25 8430/1, alt. 820 m, Picea abies, 12 Oct 2016, leg. D. Bandini; det. D. Bandini \& B. Oertel (STU SMNS-STU-F0901487; DB12-10-16-1). Ibidem, in some distance from former location, alt. $820 \mathrm{~m}$, Picea abies, 12 Oct 2016, leg. D. Bandini; det. D. Bandini \& B. Oertel (DB12-10-16-2). Ibidem, in some distance from former location, alt. $820 \mathrm{~m}$, Picea abies, 12 Oct 2016, leg. D. Bandini; det. D. Bandini \& B. Oertel (DB12-10-16-6). Ibidem, in some distance from former location, alt. $820 \mathrm{~m}$, Picea abies, 12 Oct 2016, leg. D. Bandini; det. D. Bandini \& B. Oertel (DB12-10-16-11).

Comments: Inocybe grusiana is characterized by a usually rather stout habit, ample greyish, yet often fugacious velipellis when young, and generally rather long hymenial cystidia (on average $>60 \mu \mathrm{m}$ ) with wide necks. Thus, it can easily be mistaken for I. griseovelata, a species that also has rather stout basidiomata, a greyish velipellis and often a similar texture and colour of pileus. However, the stipe of the latter often is reddish near the apex, the spores on average are longer, the paracystidia are not catenate and the caulocystidia even though as well long and narrow usually are subfusiform without undate walls and without truncate base (Kühner 1955, and personal observation). Another species with similar caulocystidia is I. plurabellae (see below) which differs, however, e.g. by mostly tomentose to squamulose surface of pileus and on average shorter and often ventricose subfusiform hymenial cystidia. Inocybe grusiana can also be mistaken for I. virgatula, which differs, e.g. by rather faint traces of a velipellis, on average smaller spores, differently shaped, ventricose subfusiform hymenial cystidia and by caulocystidia that are not long and narrow (Kühner 1955, and personal observation). The surface of the pileus of $I$. derbschii usually is less smooth, the hymenial cystidia are shorter on average and differently shaped and the caulocystidia are not as narrow and long as those of I. grusiana (see Schwöbel and Stangl 1982; Bandini et al. 2019b). Inocybe scolopacis (see below) differs, e.g. by subfusiform or (sub)utriform caulocystidia and on average narrower spores, and I. beatifica by an entirely pruinose stipe, on average narrower hymenial cystidia and less long and wider caulocystidia.

None of these species is particularly closely related to I. grusiana. Based on ITS and LSU, the closest described relative appears to be I. subdestricta Kauffman with 94\% identity in the ITS and I. multifolia Braaten, M.G. Wood \& Matheny with $93 \%$ identity in the ITS. 
The former differs from I. grusiana, e.g. by rufous tinged stipes and smaller spores (Kauffman 1924), and I. multifolia, e.g. by smaller size, much paler pileus colour, extensive velipellis, and on average longer spores as well as a different habitat, growing in California (see Braaten et al. 2014). In Fig. 1, sequences identified as I. griseovelata (but different from $I$. grisovelata proper) form the sister clade to I. grusiana.

Inocybe gypsea Carteret \& Reumaux, Cahiers de la FMBDS 2: 43 (2013) Fig. 24 e

Description of the species: Carteret and Reumaux 2013.

Studied material (isotype): FRANCE, forêt de Rambouillet (Yvelines), leg. G. Redeuilh, Oct 1985 (XC2012-71). Spores 9.3-12.8 $\mu \mathrm{m}$ (av. $11.0 \mu \mathrm{m}$, SD 0.6 $\mu \mathrm{m}) \times 5.0-6.1 \mu \mathrm{m}($ av. $5.4 \mu \mathrm{m}$, SD $0.3 \mu \mathrm{m}) ; \mathrm{Q}=1.8-2.3$ (av. 2.0 SD 0.1) ( $\mathrm{n}=40$ ), (sub)amygdaloid, oblong, apex (sub)acute to often (sub)papillate. Basidia 4-spored and 2spored. Pleurocystidia 50-63 $\mu \mathrm{m}$ (av. $56 \mu \mathrm{m}$, SD $3 \mu \mathrm{m}$ ) $\times$ 10-16 $\mu \mathrm{m}$ (av. $12 \mu \mathrm{m}, \mathrm{SD} 2 \mu \mathrm{m}$ ); Q $=3.5-5.7$ (av. 4.8, SD $0.6)(\mathrm{n}=15)$, (sub)cylindrical, (sub)fusiform or subutriform, apex usually crystalliferous, walls up to $2.0 \mu \mathrm{m}$ thick at the apex, almost incolorous with $3 \% \mathrm{KOH}$. Cheilocystidia similar in appearance and size. Paracystidia (sub)clavate. Caulocystidia not studied, because stipe not present.

Comments: See above, comment to I. bolbitioides.

Inocybe huijsmanii Kuyper, Persoonia, Suppl. 3: 134 (1986) Fig. $24 \mathrm{f}$

Description of the species: Kuyper 1986; Stangl 1989; Ludwig 2017.

Studied material (paratype): FRANCE, Lougres, Doubs, 4 Oct 1955 leg. H.S.C. Huijsman (L-3986181). GenBank: ITS $=$ MW845924. Spores 8.6-10.7 $\mu \mathrm{m}$ (av. $9.6 \mu \mathrm{m}$, SD $0.6 \mu \mathrm{m})$ $\times 4.4-5.8 \mu \mathrm{m}$ (av. 5.2 $\mu \mathrm{m}$, SD $0.3 \mu \mathrm{m}$ ); Q = 1.6-2.2 (av. 1.9, SD 0.1) $(\mathrm{n}=40)$, smooth, oblong subamygdaloid, with subacute, sometimes subpapillate apex. Basidia 4-spored. Pleurocystidia $49-73 \mu \mathrm{m}$ (av. $62 \mu \mathrm{m}$, SD $6 \mu \mathrm{m}) \times 12-$ $18 \mu \mathrm{m}$ (av. $15 \mu \mathrm{m}$, SD $2 \mu \mathrm{m}$ ); $\mathrm{Q}=3.1-6.1$ (av. 4.1, SD 0.7 ) ( $\mathrm{n}=15$ ), mostly (sub)fusiform or (sub)utriform, apex usually crystalliferous, walls up to $1.0(1.5) \mu \mathrm{m}$ thick at the apex, (almost) colourless with $3 \% \mathrm{KOH}$. Cheilocystidia similar in appearance and size. Paracystidia not observed. Caulocystidia not studied (to preserve the material).

Comments: This and another examined paratype (L3986179, from 25 Aug 1956) of I. huijsmanii were collected in the same place as the holotype of the species, albeit in different years. Both collections correspond well to the description of the species given by Kuyper (1986). Although no sequence could be obtained from the studied paratype, the material collected a year later yielded a sequence (see Fig. 1). Apparently, the species is not common, although possibly widespread. The only other published sequence that might belong to this species is from Iran (FR852248, Bahram et al. 2012).

Inocybe hypophaea Furrer-Ziogas, Schweiz. Z. Pilzk. 30: 131 (1952) Fig. 24 g

$=$ ? Inocybe virgatula Kühner, Bull. Soc. nat. Oyonnax 9(Suppl. (Mém. hors sér. 1)): 7 (1955)

Description of the species: Furrer-Ziogas 1952; Kühner 1955.

Studied material (holotype): SWITZERLAND, Aargau, Schöftland-Hirschthal, Abies alba (as Abies pectinata), Picea excelsa, 27 Oct 1947, leg. R. Haller (ZTMYC-56731). Spores 8.6-10.3 $\mu \mathrm{m}$ (av. 9.3 $\mu \mathrm{m}$, SD $0.4 \mu \mathrm{m}) \times 4.4-5.5 \mu \mathrm{m}$ (av. 5.1 $\mu \mathrm{m}$, SD $0.3 \mu \mathrm{m}) ; \mathrm{Q}=1.7-2.0$ (av. 1.9, SD 0.1) $(\mathrm{n}=40)$, smooth, oblong subamygdaloid with (sub)acute apex. Basidia 4-spored, also 2-spored, and then spores up to 12.6 $\mu \mathrm{m}$. Pleurocystidia 45-73 $\mu \mathrm{m}$ (av. $57 \mu \mathrm{m}$, SD $7.2 \mu \mathrm{m}) \times 14$ $20 \mu \mathrm{m}$ (av. $17 \mu \mathrm{m}, \mathrm{SD} 1.7 \mu \mathrm{m}$ ); Q = 2.8-3.9 (av. 3.3, SD 0.3) $(\mathrm{n}=15)$, subutriform, (sub)fusiform, apex usually crystalliferous, walls up to $2.0(2.5) \mu \mathrm{m}$ thick, pale yellowish-greenish with $3 \% \mathrm{KOH}$. Cheilocystidia similar in appearance and size. Paracystidia not observed. Caulocystidia not studied (to preserve the material).

Comments: The holotype material of I. hypophaea has been preserved for some time in formaldehyde, which is a major obstacle for DNA extraction. Our studies did not support Kuyper's (1986) synonymization of. I. hypophaea and I. fuscidula (see above under I. glabripes). We have not been able to come to a conclusion whether I. hypophaea and I. virgatula are, as suggested by Kuyper (1986, see also comments to I. virgatula in Kühner 1955), synonymous or not, since there are differences in the microscopic characters. Inocybe hypophaea differs also macroscopically from I. virgatula: According to the original description, the pileus is, when young, entirely 'albo-tectus' (FurrerZiogas 1952; Kühner 1955). According to our own observations on numerous own collections, this is never the case in I. virgatula (see also Kühner 1955). We do not know what I. hypophaea is and do not use the name. For a microscopic description of I. virgatula see below.

Inocybe knautiana Bandini \& B. Oertel sp. nov. Fig. 13 MycoBank number: MB 839161

Etymology: Named 'knautiana' after the flower Knautia arvensis, because of the violet colour of the stipe.

Diagnosis: Inocybe knautiana has a finely felty to rim(ul)ose brown pileus surface with ample whitish velipellis when young, and at least at the apex or in the cortex lilacviolet stipe, smooth spores, measuring 8.2-11.0 $\mu \mathrm{m}$ (av. 9.8 $\mu \mathrm{m}) \times 4.7-6.2 \mu \mathrm{m}$ (av. $5.5 \mu \mathrm{m})$, hymenial cystidia with wide necks, usually rather thin walls and short pedicel, 

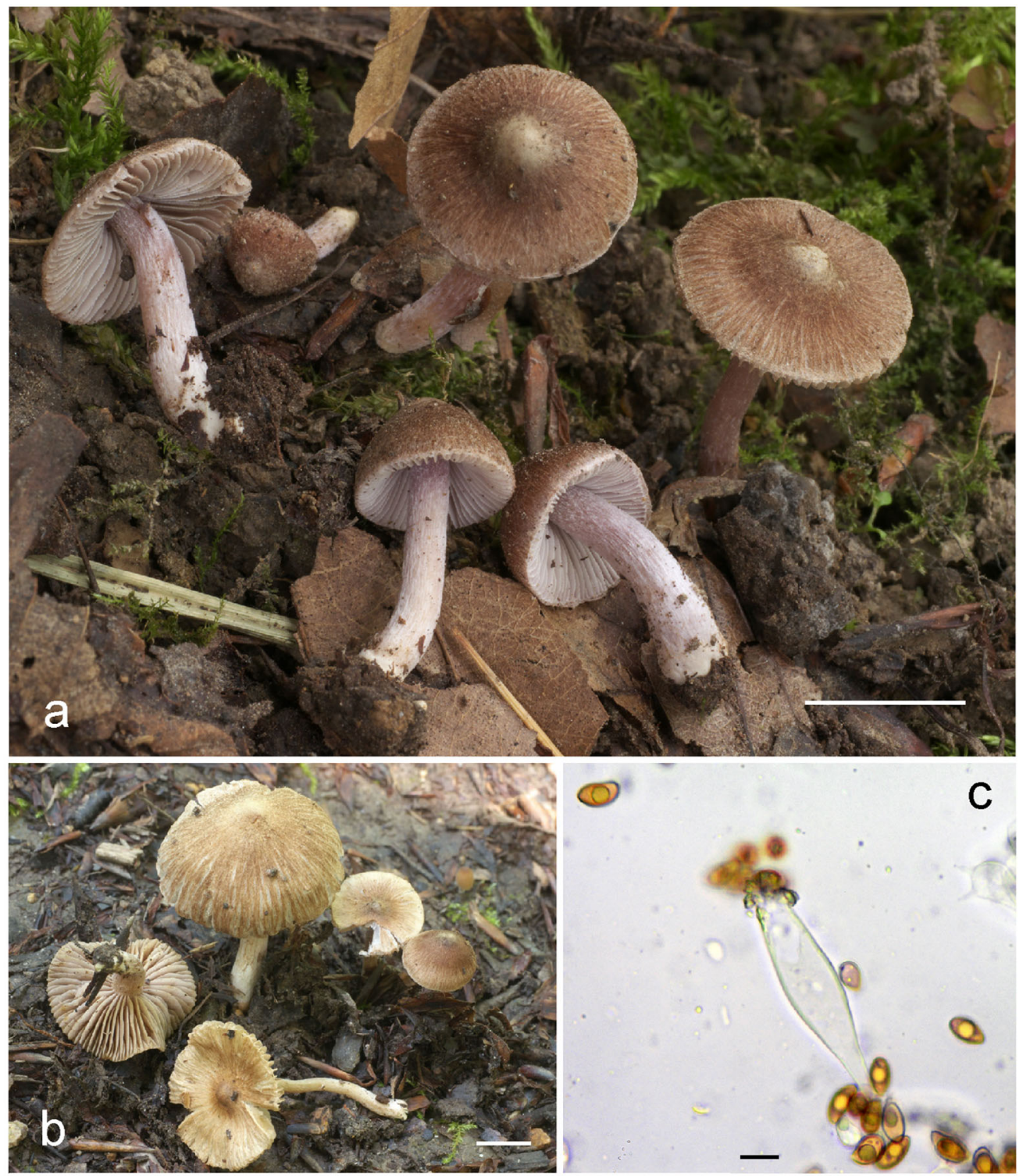

C
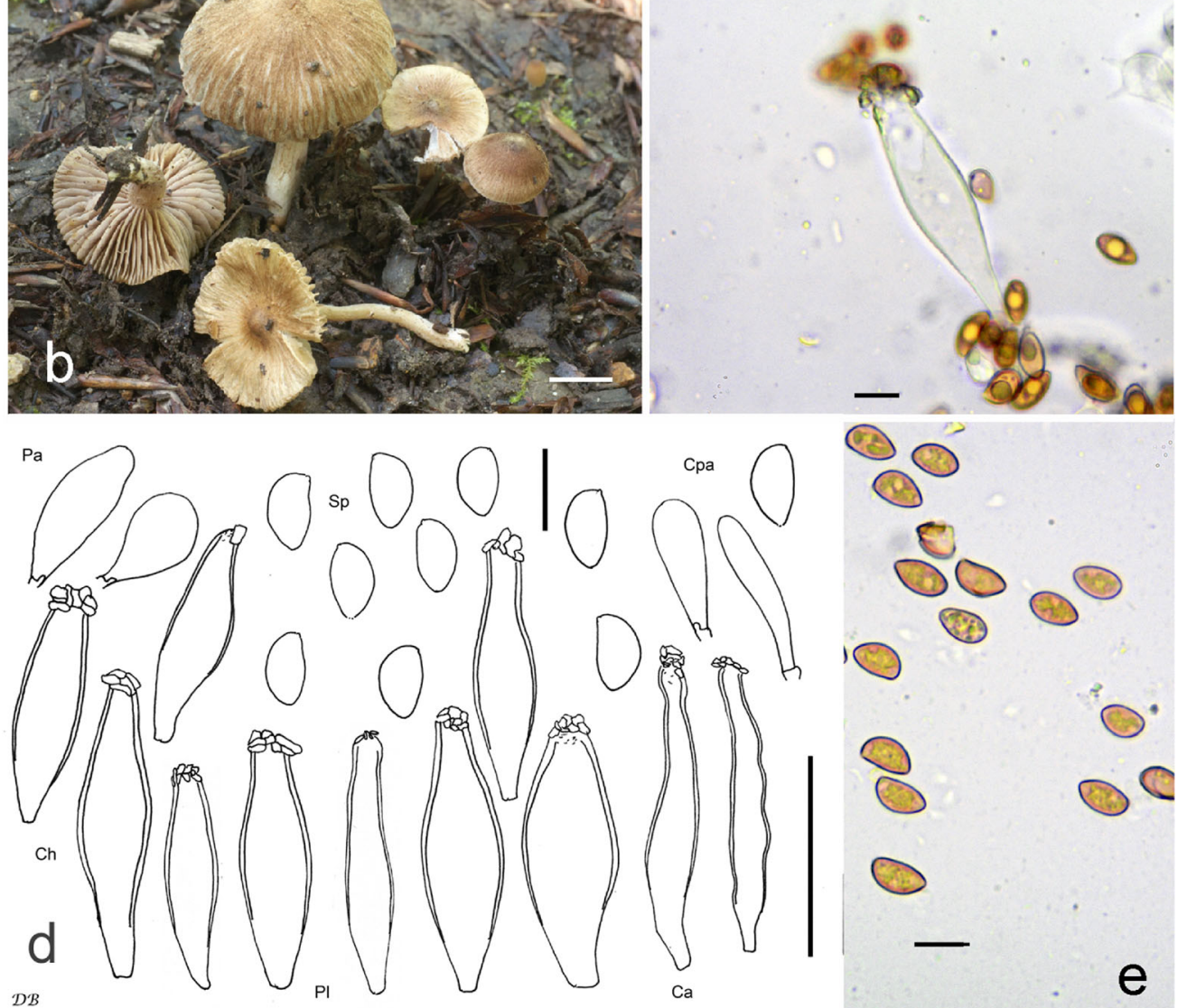

Fig. 13 Inocybe knautiana, a holotype, scale bar: $1 \mathrm{~cm}$. b Coll. DB19-819-3, scale bar: $1 \mathrm{~cm}$. c Cheilocystide (coll. DB9-9-17-1), scale bar: 10

Cauloparacystidia, $\mathrm{Ch}=$ Cheilocystidia, $\mathrm{Pa}=$ Paracystidia, $\mathrm{Pl}=$ $\mu \mathrm{m}$. d Microscopical characters (holotype), $\mathrm{Ca}=$ Caulocystidia, $\mathrm{Cpa}=$ Pleurocystidia, $\mathrm{Sp}=$ Spores; scale bar spores: $10 \mu \mathrm{m}$, scale bar cystidia: $50 \mu \mathrm{m}$. e Spores (coll. DB19-8-19-3), scale bar: $10 \mu \mathrm{m}$ 
pleurocystidia measuring 45-76 $\mu \mathrm{m}($ av $57 \mu \mathrm{m}) \times 9-21 \mu \mathrm{m}$ (av. $15 \mu \mathrm{m}$ ), only weak reaction of the walls with $\mathrm{KOH}$, and growth with frondose trees on basic or calcareous soil. This combination of characters as well as ITS sequence data distinguishes I. knautiana from all described species, including other species with lilac-violet stipe such as I. pusio or I. griseolilacina. No phylogenetically closely related species is known so far.

Holotype: GERMANY, Baden-Württemberg, Wiesenbach, Langenzeller Buckel, TK25 6618/2, alt. 230 m, Fagus sylvatica, 22 Aug 2016, leg. D. Bandini (holotype STU SMNS-STU-F-0901491; isotypes priv. herb. D.B. DB22-816-1; AH 56133). GenBank: ITS + partial LSU = MW845887.

Description: Pileus 5-35 mm wide, at first (sub)conical or (sub)campanulate, later broadly convex and then expanded, with more or less pronounced large umbo, margin at first slightly decurved, but soon straight or even uplifted, and then pileus depressed around the umbo; young basidiomata with abundant whitish remnants of a velipellis centred at the umbo, vanishing soon; colour when young brown to dark brown with or without reddish hue (Mu 7.5YR 4/4-4/6, 3/4; 10YR 3/4-3/ $6,5 / 3-5 / 8$ ), often somewhat darker brown at the umbo when the velipellis is vanished, with age becoming much paler, up to (almost) ivory-coloured, especially towards the margin; surface finely tomentose, later rimulose to rimose towards the margin, so that the paler trama beneath is visible; young basidiomata with remnants of a pale cortina. Lamellae moderately crowded (ca. 40-50, 1 = 1-3), broadly emarginate adnate, (sub)ventricose, at first whitish, later greyish-brownish to grey-brown; edge roughly fimbriate, whitish. Stipe $25-50 \times$ 2-5 mm, cylindrical or curved, sometimes rather stout, when young roughly covered with whitish tomentum, later striate or glabrous, at the apex when young more or less intensely lilacviolet, still but only faintly to be observed in most older basidiomata, but sometimes with age entirely fading, below the apex at first whitish, later pale straw-coloured; pruinose only near the apex of the stipe. Context whitish in the pileus, pale or (when young) intensely lilac-violet in the cortex of the apex of the stipe, and whitish below. Smell unusual, not spermatical. Colour of exsiccata pileus dark brown with reddish hue (Mu 5YR 4/3-4/6, 3/3-3/4), lamellae and stipe lighter in colour, no darkening or blackening with drying.

Spores $8.2-11.0 \mu \mathrm{m}$ (av. $9.8 \mu \mathrm{m}$, SD $0.5 \mu \mathrm{m}) \times 4.7-$ $6.2 \mu \mathrm{m}$ (av. $5.5 \mu \mathrm{m}$, SD $0.3 \mu \mathrm{m}$ ); Q = 1.5-2.2 (av. 1.8, SD $0.1)(n=120$ of 3 coll.), smooth, (sub)amygdaloid, without or with rather faint suprahilar depression, apex subacute, subobtuse. Basidia 25-34 × 7-11 $\mu \mathrm{m}$, generally 4-spored. Lamellae edges sterile, composed of cheilocystidia and numerous colourless, oblong (sub)clavate, subcylindrical, thinwalled paracystidia. Pleurocystidia 45-76 $\mu \mathrm{m}$ (SD $57 \mu \mathrm{m}$, SD $7 \mu \mathrm{m}) \times 9-21 \mu \mathrm{m}$ (av. $15 \mu \mathrm{m}$, SD $3 \mu \mathrm{m}$ ); $\mathrm{Q}=2.5-5.8$ (av. 3.9, SD 0.8) ( $\mathrm{n}=45$ of 3 coll.); subfusiform to (sub)utriform, without neck, usually rather short neck, wide at the apex, and with only short pedicel, apex usually crystalliferous, walls up to $1.0(1.5) \mu \mathrm{m}$ thick at the apex, pale yellowish-greenish with $3 \% \mathrm{KOH}$. Cheilocystidia similar in appearance and size. Pileipellis constituted by an epicutis made up of parallel hyphae 4.5-11 $\mu \mathrm{m}$ wide, with strongly encrusting and parietal dark brown pigment, subcutis with wider and paler to colourless elements. Caulocystidia only near the apex of the stipe, 50-80 ×9-13 $\mu \mathrm{m}$, usually long and rather slim somewhat misshaped subutriform, subfusiform or subcylindrical with undate walls, apex usually crystalliferous, walls up to $1.0 \mu \mathrm{m}$ (neck) thick at the apex, pale yellowish-greenish with $3 \% \mathrm{KOH}$; intermixed with numerous oblong (sub)clavate cauloparacystidia. Clamp-connections abundant in all tissues.

Habitat and known distribution: Inocybe knautiana was found by us always next to frondose trees, apparently with some affinity to Fagus sylvatica, sometimes also with Picea abies nearby, and always on calcareous or at least soil with a high $\mathrm{pH}$. It seems to be a fairly common species, because there are several sequences in GenBank or UNITE database: from basidiomata in Sweden (as 'I. cf. fuscidula', AM882842.2), Great Britain (as ' $I$. sp.', UDB0754125) and Estland (as ' $I$. sp.', UDB032954 and as 'I. pusio', UDB024674 and UDB031390); and from EcM (probably belonging to this species) from Belgium (KR082218), from Estland with Betula pendula, Populus alba, Tilia platyphyllos, Tilia sp. (JX316545; UDB008001; UDB008007; UDB008811; UDB013658; UDB0751197), from Italy with Ostrya carpinifolia (HM370475) and JX625284, from Poland with Carya laciniosa (MG835423), from Russia with Tilia cordata (MT554409) and from Iran (FR852266; UDB017439). Thus all trees noted are frondose trees. Our own collections were found from August to October.

Further collections studied: AUSTRIA, Tirol, Imst, Stams, ÖK25V 2221-Ost, alt. ca. 910 m, mixed wood with Fraxinus excelsior, 9 Sep 2017, leg. D. Bandini; det. D. Bandini \& B. Oertel (DB9-9-17-1). GERMANY, BadenWürttemberg, Rhein-Neckar-Kreis, Schönbrunn, TK25, 6519/4, alt. 380 m, Picea abies, Fagus sylvatica, 26 Aug 2011, leg. D. Bandini; det. D. Bandini \& B. Oertel (DB26-8-11-6). Ibidem, in some distance from former location, alt. 390 m, Picea abies, Abies alba, Fagus sylvatica, 3 Aug 2014, leg./det. D. Bandini (DB3-8-14-7). BadenWürttemberg, Rhein-Neckar-Kreis, Wiesenbach, TK25 6618/2, alt. 185 m, Fagus sylvatica, 13 Aug 2016, leg. D. Bandini; det. D. Bandini \& B. Oertel (DB13-8-16-2). Baden-Württemberg, Rhein-Neckar-Kreis, Moosbrunn, TK25 6519/3, alt. ca. 400 m, Fagus sylvatica, leg. D. Bandini; det. D. Bandini \& B. Oertel (STU SMNS-STU-F0901492; DB14-8-17-20). Baden-Württemberg, RheinNeckar-Kreis, Wiesenbach, TK25 6619/1, alt. 230 m, Fagus sylvatica, Quercus robur, 29 Sep 2018, leg. D. Bandini; det. 
D. Bandini \& B. Oertel (DB29-9-18-3). Ibidem, in some distance from former location, alt. 225 m, Fagus sylvatica, 19 Aug 2019, leg. D. Bandini; det. D. Bandini \& B. Oertel (STU SMNS-STU-F-0901493; DB19-8-19-3). Ibidem, in some distance from former location, alt. 225 m, Fagus sylvatica, 19 Aug 2019, leg. D. Bandini; det. D. Bandini \& B. Oertel (STU SMNS-STU-F-0901522; DB 19-8-19-5). Bayern, Regensburg, Donaustauf, Walhalla, TK25, alt. 396 m, Salix sp., Tilia sp., Betula pendula, Carpinus betulus, 10 Oct 2017, leg. D. Bandini \& J. Christan; det. D. Bandini \& B. Oertel (DB10-10-17-3).

Comments: Inocybe knautiana is characterized, e.g. by abundant whitish velipellis, finely felty to rim(ul)ose pileus surface, often lilac-violet stipe at least at the apex or at least in the cortex of the stipe, hymenial cystidia with wide necks and rather thin walls, and growth often with Fagus sylvatica or other frondose trees on basic or calcareous soil. The pileus of I. griseolilacina becomes subsquamulose or (sub)squarrose with age, the pileus centre often has an orange hue, the spores are smaller and the hymenial cystidia are often (sub)capitate (Kuyper 1986; Stangl 1989; Ferrari 2006, and personal observation). Inocybe dryadiana has a strongly speckled pileus-colour, no velipellis, the umbo becomes cracky with age and the spores on average are shorter. Species of the cincinnata-group, as I. obscuroides, I. cincinnata, I. minima, I. gaiana, I. lampetiana and I. sitibunda differ by (sub)lanceolate hymenial cystidia with thicker walls and stronger reaction upon $\mathrm{KOH}$ (see above, comments to I. cincinnata). No whitish velipellis is mentioned in the protologue of I. pusio, the spores of this species on average are smaller and the hymenial cystidia are more ventricose ('uppblåst', Karsten 1889, and see below) fusiform and with narrower necks than those of I. knautiana. The species is on a rather isolated branch in Fig. 1; as far as we are aware, there is no phylogenetically closely related species described.

Inocybe lampetiana Bandini \& B. Oertel sp. nov. Fig. 14 MycoBank number: MB 839162

Etymology: Named 'lampetiana', after the Greek goddess Lampetia, who according to Vergil was transformed into an Alder tree after her death, because the species grows with Alnus.

Diagnosis: Inocybe lampetiana has a brown to dark brown felty to sublanose pileus, a greyish to brownish velipellis, an at least at the apex pale to dark violet, only near the apex pruinose stipe, smooth spores, measuring 8.4-11.9 $\mu \mathrm{m}$ (av. 10.0 $\mu \mathrm{m}) \times$ 4.6-6.5 $\mu \mathrm{m}$ (av. $5.4 \mu \mathrm{m}$ ), and often hymenial cystidia with long straight necks and rather thin walls, pleurocystidia measuring 49-84 $\mu \mathrm{m}$ (av. $66 \mu \mathrm{m}) \times 9-17 \mu \mathrm{m}$ (av. $13 \mu \mathrm{m})$. The species is fond of Alnus and moist to boggy acid ground. This combination of characters as well as ITS sequence data distinguishes I. lampetiana from all other described species.

Holotype: GERMANY, Baden-Württemberg, RheinNeckar-Kreis, Schönbrunn, TK25 6519/4, alt. 360 m, boggy acid terrain next to a small rivulet with Alnus glutinosa, Picea abies, 6 Jul 2014, leg. D. Bandini (holotype STU SMNSSTU-F-0901494; isotypes priv. herb. D.B. DB6-7-14-3, AH56134). GenBank: ITS + partial LSU = MW845891.

Description: Pileus 5-20 mm wide, at first (sub)globose to (sub)conical, later conico-convex or expanded, mostly with pronounced large umbo, margin at first incurved to decurved, later straight or even uplifted and then pileus depressed around the umbo; young basidiomata with a layer of pale greyishbrownish velipellis, later visible sometimes at the centre or at the border of the pileus; colour usually brown to dark brown with or without greyish hue, sometimes with faint reddish tinge (Mu 10YR 4/2-4/4, 3/4-3/6; 7.5YR 4/2-4/4, 3/2-3/4), often darker at the centre and with age discolouring towards the margin; surface finely felty to felty, sometimes sublanose, mostly with appressed fibres, but sometimes also (sub)squamulose; young basidiomata with remnants of a cortina. Lamellae rather distant (ca. 25-35, 1 = 1-3), thickish, adnate, often with (sub)decurrent tooth, (sub)ventricose, at first dingy whitish, later pale milkcoffee-brownish to dark brown with reddish or rusty tinge; edge often uneven, fimbriate, whitish to subconcolorous. Stipe $10-30 \times 1-2 \mathrm{~mm}$, mostly curved, sometimes thickening towards the base, at first covered with fine whitish tomentum, soon longitudinally striate or glabrous, at first either entirely or in the upper half or at least near the apex pale to dark violet, later entirely or at least in the lower part flesh-coloured to brownish or brown; roughly pruinose only near the apex of the stipe. Context waterywhitish in the pileus, violet to pinkish or pinkish-brownish at least near the apex of the stipe when young, with age paler, and then longitudinally striate very pale pinkish and dingy whitish in the lower part. Smell spermatical, at least when cut. Colour of exsiccata pileus reddish brown (Mu 7/5YR $4 / 3-4 / 6,3 / 3-3 / 4)$, lamellae and stipe concolorous or a little lighter in colour, no darkening or blackening on drying.

Spores 8.4-11.9 $\mu \mathrm{m}$ (av. $10.0 \mu \mathrm{m}$, SD $0.7 \mu \mathrm{m}) \times 4.6$ $6.5 \mu \mathrm{m}$ (av. $5.4 \mu \mathrm{m}$, SD $0.3 \mu \mathrm{m}$ ); Q $=1.6-2.2$ (av. 1.9, SD $0.1)(\mathrm{n}=120$ of 3 coll.), smooth, (sub)amygdaloid, often oblong, usually without or with only faint suprahilar depression,

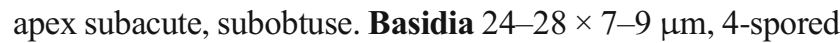
and mostly also 2 -spored, therefore in some collections quite incoherent in size. Lamellae edges sterile, composed of cheilocystidia and numerous colourless, (sub)clavate or subcylindrical, thin-walled paracystidia. Pleurocystidia 49$84 \mu \mathrm{m}$ (av. $66 \mu \mathrm{m}$, SD $8 \mu \mathrm{m}) \times 9-17 \mu \mathrm{m}$ (av. $13 \mu \mathrm{m}$, SD 2 $\mu \mathrm{m}) ; \mathrm{Q}=3.7-7.0$ (av. 5.2, SD 0.8) ( $\mathrm{n}=45$ of 3 coll.); often slenderly subcylindrical, also (sub)utriform or (sub)fusiform, usually with rather long straight wide neck and often very 

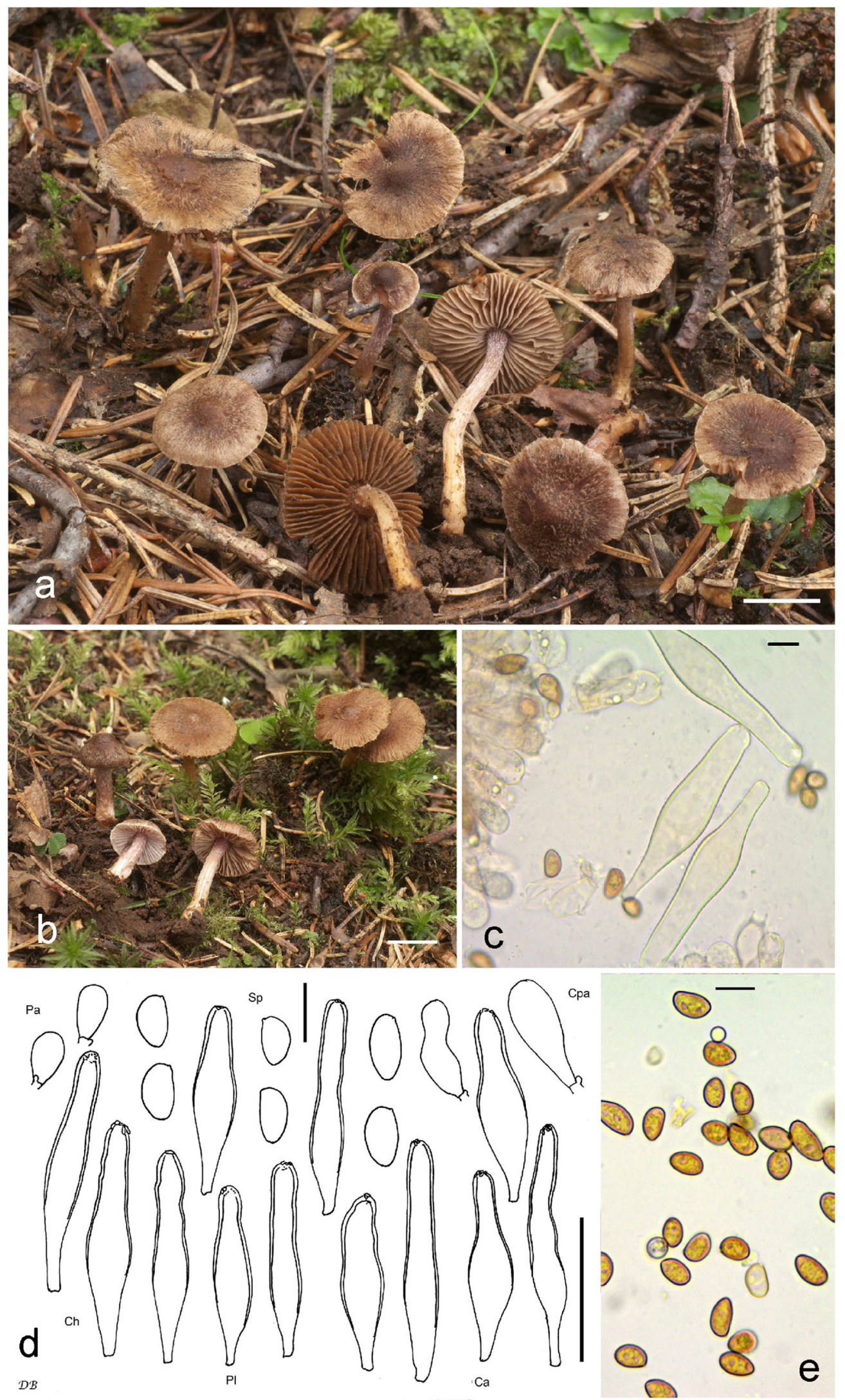

Fig. 14 Inocybe lampetiana, a holotype, scale bar: $1 \mathrm{~cm}$. b Coll. DB1-614-1, scale bar: $1 \mathrm{~cm}$. c Cheilocystidia (coll. DB1-6-14-1), scale bar: 10 $\mu \mathrm{m}$. d Microscopical characters (holotype), $\mathrm{Ca}=$ Caulocystidia, $\mathrm{Cpa}=$
Cauloparacystidia, $\mathrm{Ch}=$ Cheilocystidia, $\mathrm{Pa}=$ Paracystidia, $\mathrm{Pl}=$ Pleurocystidia, $\mathrm{Sp}=$ Spores; scale bar spores: $10 \mu \mathrm{m}$, scale bar cystidia: $50 \mu \mathrm{m}$. e Spores (coll. DB1-6-14-1), scale bar: $10 \mu \mathrm{m}$ 
slightly undate walls, sometimes subcapitate and with thickened roundish apex or 'cap', at the apex generally wide, with short pedicel, apex usually crystalliferous, walls up to 1.0 (1.5) $\mu \mathrm{m}$ thick at the apex, yellowish-greenish with $3 \%$ $\mathrm{KOH}$, sometimes filled with rather pale amorphous content. Cheilocystidia sometimes more variable in shape. Pileipellis constituted by an epicutis made up of parallel hyphae 5-13 $\mu \mathrm{m}$ wide, with encrusting and parietal dark brown to almost blackish brown pigment, subcutis with wider and paler to colourless elements. Caulocystidia only near the apex of the stipe, $45-80 \times 10-15 \mu \mathrm{m}$, (sub)utriform, subcylindrical or somewhat misshaped, often with undate walls, with long neck and short pedicel, apex with or without small crystals, walls up to $1.0 \mu \mathrm{m}$ thick at the apex, yellowish-greenish with $3 \%$ $\mathrm{KOH}$; intermixed with numerous (sub)clavate cauloparacystidia. Clamp-connections abundant in all tissues.

Habitat and known distribution: Inocybe lampetiana was up to now always found in moist to wet terrain with Alnus and also Picea abies nearby. The type collection and several others were from boggy acid ground at the banks of a small rivulet. The species is known from own collections from Austria, Finland and GERMANY. In GenBank is a sequence from a collection from Canada (HQ604317) and in UNITE database a soil sample sequence from Estonia (UDB062249), both putatively belonging to I. lampetiana. We are not aware of any other sequences or collections of this species.

Further collections studied: AUSTRIA, Salzburg, Tamsweg, Prebersee, ÖK25V 3230-Ost, alt. 1450 m, Alnus incana, Picea abies, 14 Aug 2013, leg./det. D. Bandini \& B. Oertel (DB14-8-13-14). Ibidem, in some distance from former location, ÖK25V 3230-Ost, ca. $1500 \mathrm{~m}$, Alnus incana, Picea abies, 15 Aug 2013, leg./det. D. Bandini \& B. Oertel (DB158-13-14). Salzburg, Tamsweg, ÖK25V 3230-Ost, alt. 1470 m, Alnus incana, Picea abies, 17 Sep 2020, leg./det. D. Bandini (DB17-9-20-9). FINLAND, Koillismaa, Kuusamo municipality, Vuotunki, near Kuusinkijoki, alt. ca. 220 m, Alnus incana, Pinus sylvestris, Betula sp., Picea abies, Prunus padus, 24 Aug 2015, leg. D. Bandini, J. Vauras \& B. Oertel; det. D. Bandini \& B. Oertel (DB24-8-15-11). GERMANY, BadenWürttemberg, Rhein-Neckar-Kreis, Schönbrunn, TK25 6519/4, alt. 370 m, Alnus glutinosa, Picea abies, 5 Aug 2011, leg./det. D. Bandini (DB5-8-11-2). Ibidem, in some distance from former location, alt. $375 \mathrm{~m}$, Alnus glutinosa, Picea abies, 4 Aug 2013, leg./det. D. Bandini (DB4-8-13-7). Baden-Württemberg, Rhein-Neckar-Kreis, near Haag, TK25 6619/2, alt. 400 m, Alnus glutinosa, Picea abies, 30 Aug 2013 (DB30-8-13-3). Baden-Württemberg, Rhein-Neckar-Kreis, Schönbrunn, TK25 6519/4, alt. 360 m, Alnus glutinosa, Picea abies, 1 Jun 2014, leg. D. Bandini; det. D. Bandini \& B. Oertel (DB1-6-14-1).

Comments: Inocybe lampetiana is characterized by rather small size, brown to dark brown felty to sublanose pilei with greyish-brownish velipellis, stipes that are pruinose only near the apex, which is more or less intensely violet at least when young, and thickish rather distant lamellae. The cystidia are often subcylindrical with long straight necks and rather thin walls. Inocybe drenthensis has smaller spores, no velipellis, a speckled surface of pileus, mostly (sub)fusiform hymenial cystidia, and it grows on calcareous soil. Inocybe dryadiana has a paler pileus colour, the hymenial cystidia are not (sub)cylindrical in shape and it grows on calcareous dry soil with Quercus. Inocybe gaiana grows on much dryer calcareous terrain, the spores are smaller and the hymenial cystidia are mostly (sub)utriform or (sub)fusiform. I. cincinnata, I. gaiana, I. minima differ, e.g. by more lanceolate (sub)fusiform hymenial cystidia and on average smaller spores (Peck 1913, personal observation, and see above comments to I. cincinnata), while I. tiburtina (see below) grows on calcareous soil, and the hymenial cystidia are not subcylindrical. Inocybe amethystina differs by e.g. lanosesquamulose pileus surface, generally not (sub)cylindrical hymenial cystidia and habitat not with Alnus (Kuyper 1986). Inocybe crocifolia is with $90 \%$ identity in the ITS distantly related to I. lampetiana. It can easily be distinguished from the latter by its intensely foxy or orange-red coloured lamellae (see Herink 1954, and personal observation).

Inocybe lutescens Velen., České Houby 2: 375 (1920) Fig. $24 \mathrm{~h}$

Description of the species: Stangl and Veselský 1980; Ferrari 2006.

Studied material (neotype, designated by Stangl and Veselský 1980): GERMANY, Kühnbach versus Schrobenhausen, loco arenoso in Pineto, 15 May 1977, leg./ det. J. Stangl, rev. J. Veselský (PRM-823229). GenBank: ITS $=$ MW845894. Spores 9.0-11.2 $\mu \mathrm{m}$ (av. $9.8 \mu \mathrm{m}$, SD $0.5 \mu \mathrm{m}$ ) $\times 5.1-6.0 \mu \mathrm{m}$ (av. $5.4 \mu \mathrm{m}, \mathrm{SD} 0.2 \mu \mathrm{m}$ ); $\mathrm{Q}=1.7-2.1$ (av. 1.8, SD 0.1) $(n=40)$, smooth, with (sub)acute to (sub)papillate apex, with rather distinct pseudoporus. Basidia 4-spored. Pleurocystidia $41-58 \mu \mathrm{m}$ (a v. $51 \mu \mathrm{m}$, SD $5 \mu \mathrm{m}) \times 11-18$ $\mu \mathrm{m}$ (av. $15 \mu \mathrm{m}, \mathrm{SD} 2 \mu \mathrm{m}) ; \mathrm{Q}=2.6-4.8$ (av. 3.6, SD 0.6) $(\mathrm{n}=$ 15), mostly (sub)lageniform to subfusiform, apex usually crystalliferous, walls up to $1.5(2.0) \mu \mathrm{m}$ thick at the apex, yellowish-greenish with $3 \% \mathrm{KOH}$. Cheilocystidia similar in appearance and size. Paracystidia not observed. Caulocystidia only near the apex of the stipe, long and narrow subcylindrical with undate walls, up to $>100 \mu \mathrm{m}$.

Comments: A sequence of the neotype is available (see Fig. 1). Very similar sequences have been isolated from plant roots or soil samples from Italy and Estonia, respectively. In Fig. 1, the clade is somewhat isolated and its phylogenetic position is not well resolved with respect to I. rufuloides and I. nitidiuscula.

Inocybe metrodii Stangl \& J. Veselský, Česká Mykol. 33(4): 220 (1979) Fig. 25 a 
Description of the species: Stangl and Veselský 1979.

Studied material (holotype): GERMANY, Bayern, Landsberg am Lech, Kaltenberg, in pineto, 20 Oct 1973, leg. J. Stangl (PRM-756354). GenBank: ITS = MN319692. Spores 6.7-9.9 $\mu \mathrm{m}(\mathrm{av} .8 .7 \mu \mathrm{m}$, SD $0.6 \mu \mathrm{m}) \times 5.1-6.2 \mu \mathrm{m}$ (av. $5.7 \mu \mathrm{m}, \mathrm{SD} 0.3 \mu \mathrm{m}) ; \mathrm{Q}=1.2-1.9$ (av. 1.5, SD 0.1) $(\mathrm{n}=$ 40), smooth, (sub)amygdaloid, with (sub)obtuse to (sub)acute apex. Basidia 4-spored. Pleurocystidia 46-64 $\mu \mathrm{m}$ (av. 55 $\mu \mathrm{m}, \mathrm{SD} 5 \mu \mathrm{m}) \times 13-19 \mu \mathrm{m}($ av. $15 \mu \mathrm{m}, \mathrm{SD} 2 \mu \mathrm{m}) ; \mathrm{Q}=$ 2.9-4.5 (av. 3.7, SD 0.5) ( $=15)$, mostly (sub)fusiform or subutriform, apex usually crystalliferous, walls up to 2.0 (2.5) $\mu \mathrm{m}$ thick at the apex, pale yellowish-greenish with $3 \% \mathrm{KOH}$. Cheilocystidia similar in appearance and size. Paracystidia not observed. Caulocystidia on entire length of the stipe, in shape and size like hymenial cystidia.

Comments: The sequence of the holotype places I. metrodii is in a rather isolated position in relation to the species discussed in this study. The most closely related species for which ITS data is published is I. cuniculina Bandini \& B. Oertel. Some very similar sequences were published under the name of I. tenebrosa Quél. by Ryberg et al. (2008). The name has apparently also been used by others (e.g. V. Liv, UDB032020 or J. Vauras, MH310747) for other taxa. Morphologically, I. tenebrosa can easily be distinguished from $I$. metrodii, e.g. by the name giving feature of stipes blackening in the lower half with age (Quélet 1885; Kuyper 1986; Stangl 1989, and personal observation), which is never the case with I. metrodii.

Inocybe minimispora Reumaux, Bull. trimest. Féd. Mycol. Dauphiné-Savoie 25(no. 100): 17 (1986) Fig. 25 b

Description of the species: Reumaux 1986.

Studied material (holotype): FRANCE, Bois des Alleux (French Ardennes), Sep 1984, leg. P. Reumaux (G-00126998). Spores 6.1-7.7 $\mu \mathrm{m}$ (av. $6.8 \mu \mathrm{m}$, SD $0.4 \mu \mathrm{m}$ ) $\times 3.8-4.7 \mu \mathrm{m}$ (av. $4.1 \mu \mathrm{m}, \mathrm{SD} 0.2 \mu \mathrm{m}$ ); Q = 1.4-1.9 (av. 1.7, SD 0.1) $(n=40)$, smooth, (sub)amygdaloid, with (sub)obtuse to (sub)acute apex. Basidia 4-spored. Pleurocystidia 41-55 $\mu \mathrm{m}$ (av. $49 \mu \mathrm{m}, \mathrm{SD} 4 \mu \mathrm{m}) \times 12-17 \mu \mathrm{m}$ (av. $14 \mu \mathrm{m}$, SD $2 \mu \mathrm{m})$; $\mathrm{Q}=2.6-4.4$ (av. 3.6, SD 0.5) $(\mathrm{n}=15)$, mostly (sub)fusiform or subutriform, with short neck and short pedicel, apex usually crystalliferous, walls up to $1.5(2.0) \mu \mathrm{m}$ thick at the apex, pale yellowish-greenish with $3 \% \mathrm{KOH}$. Cheilocystidia similar in appearance and size. Paracystidia not observed. Caulocystidia similar in shape, but often with slightly undate walls and somewhat narrower.

Selected other material studied: AUSTRIA, Tirol, Reutte, Tannheimer Tal, near Tannheim, ÖK25V 2214-Ost, alt. 1250 m, Picea abies, 12 Jul 2017, leg. D. Bandini; det. D. Bandini \& B. Oertel (STU SMNS-STU-F-0901264; DB12-717-9).

Comments: See the above comment on I. glabripes. Unfortunately, we did not have the opportunity to try and sequence the type of I. minimispora. The species is represented in Fig. 1 by one of our collections, macro and microscopically matching the type material.

Inocybe miranda Carteret \& Reumaux, Cahiers de la FMBDS 2: 23 (2013) Fig. 25 c

Description of the species: Carteret and Reumaux 2013.

Studied material (isotype): FRANCE, bois de Voncq, Les Alleux (Ardennes), Quercus, 18 Sep 1985, leg. P. Reumaux (XC2012-2). GenBank: ITS = MW845954. Spores 8.0$9.6 \mu \mathrm{m}($ av. $8.7 \mu \mathrm{m}$, SD $0.4 \mu \mathrm{m}) \times 4.2-5.1 \mu \mathrm{m}$ (av. $4.7 \mu \mathrm{m}$, SD $0.2 \mu \mathrm{m}) ; \mathrm{Q}=1.6-2.1$ (av. 1.8, SD 0.1) $(\mathrm{n}=40)$, oblong subamygdaloid, with faint suprahilar depression, obtuse apex. Basidia 4-spored. Pleurocystidia 39-56 $\mu \mathrm{m}$ (av. $46 \mu \mathrm{m}$, SD $5 \mu \mathrm{m}) \times 12-17 \mu \mathrm{m}$ (av. $14 \mu \mathrm{m}$, SD $2 \mu \mathrm{m}) ; \mathrm{Q}=2.6-3.7$ (av. 3.3, SD 0.3) $(\mathrm{n}=15)$, mostly (sub)fusiform or subutriform, apex usually crystalliferous, walls up to 1.5 (2.5) $\mu \mathrm{m}$ thick at the apex, yellowish-greenish with $3 \% \mathrm{KOH}$. Cheilocystidia similar in appearance and size. Paracystidia not observed. Caulocystidia not studied, because stipe not present.

Selected other studied material: GERMANY, Rheinland-Pfalz, Bad-Kreuznach, Hochstetten-Dhaun, TK25 6111/3, alt. 355 m, Quercus robur, 8 Nov 2011, leg./det. D. Bandini (STU SMNS-STU-F-0901510; DB8-11-19-7).

Comments: An ITS1 sequence of the isotype is available (see Fig. 1), as is a full sequence of material collected from Germany.

\section{Inocybe obscurella (Fig. 25d) $\rightarrow$ Inocybe obscuroides}

Inocybe obscurobadia (J. Favre) Grund \& D.E. Stuntz, Mycologia 69(2): 407 (1977) Fig. 25 e

Basionym: Inocybe furfurea var. obscurobadia, Ergebn. wiss. Unters. schweiz. NatnParks 5(33): 200 (1955)

Description of the species: Favre 1955 (as 'I. furfurea var. obscurobadia').

Studied material: SWITZERLAND, Val Nüglia, alt. 2400 m, Dryas, calcareous soil (G-00126141). Spores 7.5$9.8 \mu \mathrm{m}$ (av. 8.6 $\mu \mathrm{m}$, SD $0.5 \mu \mathrm{m}) \times 5.6-6.7 \mu \mathrm{m}$ (av. 6.1 $\mu \mathrm{m}$, SD $0.3 \mu \mathrm{m}) ; \mathrm{Q}=1.2-1.6$ (av. 1.4, SD 0.1) ( $\mathrm{n}=40)$, smooth, (sub)amygdaloid, (broadly) ellipsoid. Basidia 4-spored, seldom also 2-spored, and then some spores up to $10.7 \mu \mathrm{m}$. Pleurocystidia 43-75 $\mu \mathrm{m}$ (av. $60 \mu \mathrm{m}$, SD $9 \mu \mathrm{m}) \times 11-14$ $\mu \mathrm{m}$ (av. $13 \mu \mathrm{m}, \mathrm{SD} 1.1 \mu \mathrm{m}) ; \mathrm{Q}=3.6-6.3$ (av. 4.8, SD 0.8) (n =15), (sub)cylindrical or subutriform, or ampulliformous, mostly with wider subcapitate rounded apex, usually with few crystals, walls up to $1.0(1.5) \mu \mathrm{m}$ thick, pale yellowishgreenish with $3 \% \mathrm{KOH}$. Cheilocystidia similar in appearance and size. Paracystidia not observed. Caulocystidia not studied, because stipe not present.

Comments: We did not have the above collection of I. obscurobadia available for sequencing. Yet, based on the 
microscopic results from the material (and see also Favre 1955) and the type of I. tenuicystidiata (see below), we cannot follow Kuyper (1986), who synonymized I. obscurobadia with I. tenuicystidiata.

Grund and Stuntz (1977), when raising the rank of I. furfurea var. obscurobadia, did not see Favre's material. The collection they used to illustrate the taxon, ACAD 10529, was sequenced and published by Matheny and Hobbs. This and other sequences representing different interpretations of the name I. obscurobadia (ss. E. Bizio from Osmundson et al. 2013 and (presumably) ss. S. Jacobsson from Ryberg et al. 2008) are included in Fig. 1 . We cannot be sure whether any of them truly represents the species.

Inocybe obscuroides P.D. Orton, Trans. Br. mycol. Soc. 43(2): 276 (1960) Fig. 25 d, f

= Inocybe obscurella Carteret \& Reumaux, Bull. Soc. mycol. Fr. 127(1-2): 49 (2012) [2011]

Description of the species: Kuyper 1986 (as 'phaeocomis var. major'); Stangl 1989 (as 'phaeocomis var. major'); Carteret and Reumaux 2012 (as 'obscurella'); Ludwig 2017 (as 'cincinnata var. major').

Studied material (isotype of I. obscuroides), Fig. 25 f: Great Britain, Yorkshire Dales Nat. Park, Malham Tarn, Tarn House Plantation, on soil, 31 Aug 1958, leg. P.D. Orton (K(M)-97307). Spores 8.5-10.8 $\mu \mathrm{m}$ (av. $9.5 \mu \mathrm{m}$, SD $0.5 \mu \mathrm{m}) \times 5.1-6.4 \mu \mathrm{m}$ (av. $5.6 \mu \mathrm{m}$, SD $0.3 \mu \mathrm{m}$ ); $\mathrm{Q}=1.5-1.8$ (av. 1.7, SD 0.1) $(\mathrm{n}=40)$, smooth, (sub)amygdaloid, with (sub)acute to (sub)papillate apex. Basidia 4-spored. Pleurocystidia 54-89 $\mu \mathrm{m}$ (av. $67 \mu \mathrm{m}$, SD $9 \mu \mathrm{m}) \times 9-21$ $\mu \mathrm{m}$ (av. $14 \mu \mathrm{m}, \mathrm{SD} 4 \mu \mathrm{m}$ ); Q = 3.0-8.2 (av. 5.3, SD 1.8) (n $=15$ ), sublanceolate or subfusiform, mostly without or with rather short neck, with short pedicel, apex usually crystalliferous, walls up to 2.5 (3.0) $\mu \mathrm{m}$ thick at the apex, intensely yellow-green with $3 \% \mathrm{KOH}$. Cheilocystidia similar in appearance and size. Paracystidia not observed. Caulocystidia only near the apex of the stipe, usually similar in size and shape, but sometimes somewhat deformed, often with subcapitate apex and with thinner walls.

Studied material (isotype of $\boldsymbol{I}$. obscurella), Fig. 25 d: FRANCE, Yvelines, forêt de Maurepas, Quercus, 13 Nov 2003, leg. X. Carteret (XC2003-59). Spores 8.1$10.7 \mu \mathrm{m}$ (av. 9.4 $\mu \mathrm{m}$, SD $0.8 \mu \mathrm{m}) \times 5.0-6.4 \mu \mathrm{m}$ (av. $5.6 \mu \mathrm{m}$, SD $0.4 \mu \mathrm{m}$ ); $\mathrm{Q}=1.4-2.0$ (av. 1.7, SD 0.1) (n = 40), smooth, (sub)amygdaloid, with (sub)acute to (sub)papillate apex. Basidia generally 4-spored, but also 2-spored, and then spores up to $11.7 \mu \mathrm{m}$. Pleurocystidia 52-78 $\mu \mathrm{m}$ (av. $63 \mu \mathrm{m}$, SD $7 \mu \mathrm{m}$ ) $\times$ 9-17 $\mu \mathrm{m}$ (av. $14 \mu \mathrm{m}, \mathrm{SD} 2 \mu \mathrm{m}$ ); $\mathrm{Q}=3.3-6.8$ (av. 4.7, SD 0.9) $(\mathrm{n}=15)$, sublanceolate or subfusiform, also subutriform, without or with rather short neck, with short pedicel, apex usually crystalliferous, walls up to
$2.5(3.5) \mu \mathrm{m}$ thick at the apex, intensely yellow-green with $3 \% \mathrm{KOH}$. Cheilocystidia similar size, more variable in shape. Paracystidia not observed. Caulocystidia not studied, because stipe not present.

Selected other material studied: GERMANY, BadenWürttemberg, Rhein-Neckar-Kreis, Schönbrunn, TK25 6519/4, alt. 370 m, Abies alba, Picea abies, Fagus sylvatica, 30 Jun 2012, leg./det. D. Bandini \& B. Oertel (DB30-6-12-4).

Comments: The microscopic results of the type material of I. obscuroides and I. obscurella agree, thus the synonymization. As discussed under I. cincinnata above, I. obscuroides is not synonymous with $I$. cincinnata, while the above cited descriptions of I. phaecomis var. major or I. cincinnata var. major (both based on the same basionym, I. obscura var. major S. Petersen) appear to refer to $I$. obscuroides rather than to I. cincinnata.

We were not given permission to sequence the type of I. obsccuroides and the attempt to sequences the type material of $I$. obscurella failed. Our understanding of the species is represented in Fig. 1 by one of our collections, macro and microscopically matching I. obscuroides.

\section{Inocybe obscuromellea (Fig. 25 g) $\rightarrow$ Inocybe semifulva}

Inocybe oetziana Bandini \& B. Oertel sp. nov. Fig. 15

MycoBank number: MB 839163

Etymology: Named 'oetziana' because one collection was found near the valley where the famous 'Ötzi', the Iceman, was found.

Diagnosis: The pileus colour of Inocybe oetziana is ochraceous brownish to brownish with coppery or reddish hue, the surface is subhygrophanous smooth to rim(ul)ose. It has an only very faint and fugacious thin velipellis, only near the apex pruinose stipe, smooth spores, measuring 8.2-11.1 $\mu \mathrm{m}($ av. $9.5 \mu \mathrm{m}) \times 4.9-$ $6.4 \mu \mathrm{m}$ (av. $5.7 \mu \mathrm{m}$ ) and mostly subutriform hymenial cystidia, pleurocystidia measuring 42-73 $\mu \mathrm{m}$ (av. 59 $\mu \mathrm{m}) \times 12-23 \mu \mathrm{m}($ av. $15 \mu \mathrm{m})$, with quite thin walls, wide neck and short pedicel. This combination of characters as well as ITS sequence data distinguishes I. oetziana from all other smooth-spored species of somewhat similar appearance as for instance I. griseovelata.

Holotype: AUSTRIA, Tirol, Imst, Haiming towards Ochsengarten, ÖK25V 2221-Ost, alt. ca. 1650 m, Picea abies, 13 Sep 2017, leg. D. Bandini (holotype STU SMNS-STU-F0901526; isotype priv. herb. D.B. DB13-9-17-23). GenBank: ITS + partial LSU $=$ MW845897.

Description: Pileus $10-30 \mathrm{~mm}$ wide, at first (sub)campanulate or (sub)conical, later broadly convex or expanded, without or with explicit umbo, margin at first incurved, later decurved to straight or even uplifted and then 

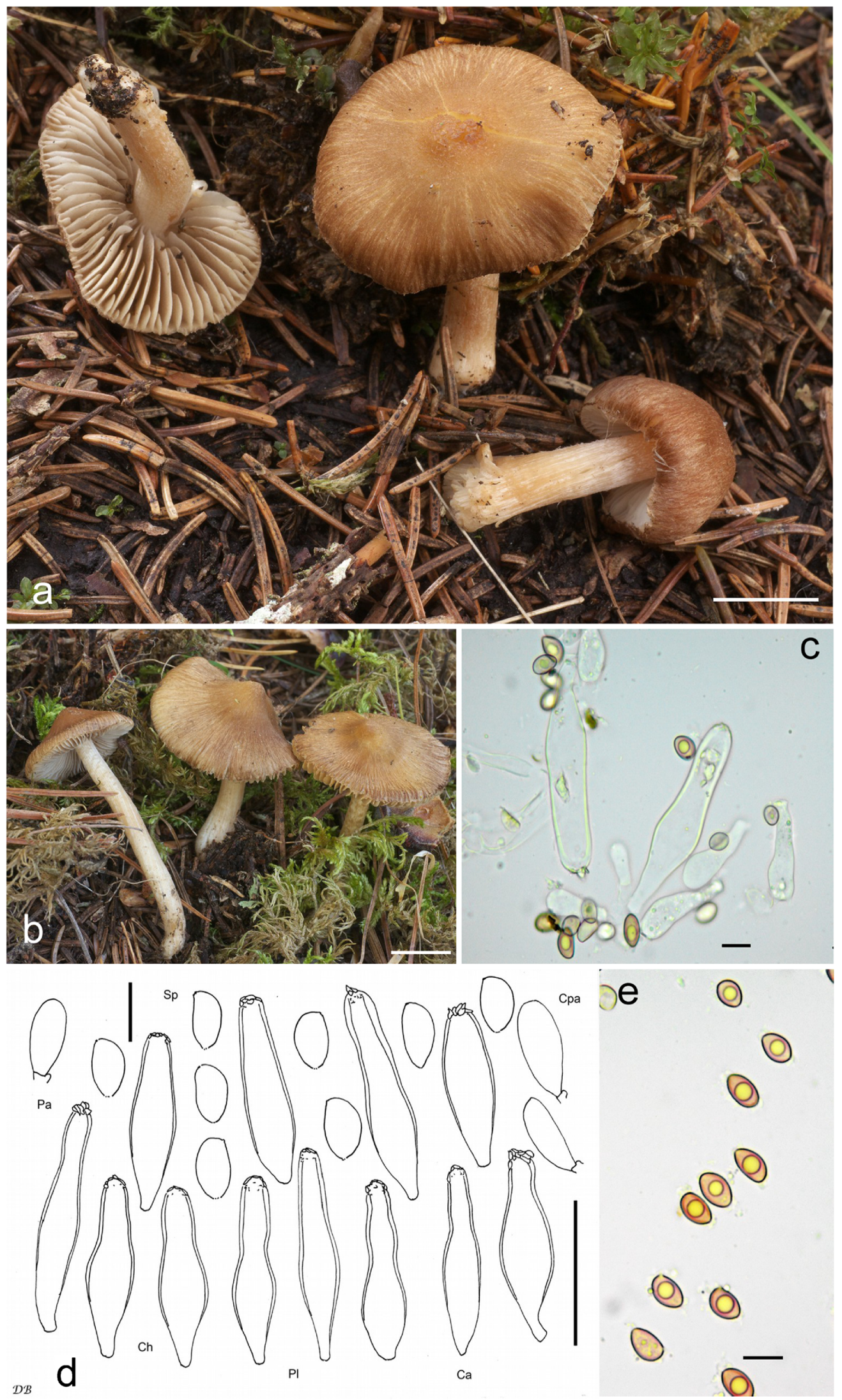

Fig. 15 Inocybe oetziana, a holotype, scale bar: $1 \mathrm{~cm}$. b Coll. DB12-919-19, scale bar: $1 \mathrm{~cm}$. c Cheilocystidia (holotype), scale bar: $10 \mu \mathrm{m}$. d Microscopical characters (holotype), $\mathrm{Ca}=$ Caulocystidia, $\mathrm{Cpa}=$

Cauloparacystidia, $\mathrm{Ch}=$ Cheilocystidia, $\mathrm{Pa}=$ Paracystidia, $\mathrm{Pl}=$ Pleurocystidia, $\mathrm{Sp}=$ Spores; scale bar spores: $10 \mu \mathrm{m}$, scale bar cystidia: $50 \mu \mathrm{m}$. e Spores (holotype), scale bar: $10 \mu \mathrm{m}$ 
depressed around the centre; young basidiomata with very faint and fugacious traces of a whitish-greyish velipellis; colour ochraceous-brownish to brownish with coppery or reddish hue (Mu 7.5YR 5/4-5/8; 10YR 5/4-5/8, 6/6-6/8), with age paler towards the margin; surface at first smooth and glabrous, later finely rimulose to rimose with or without diverging fibres; with age subygrophanous; young basidiomata with remnants of a whitish cortina. Lamellae subdistant (ca. 30-40, 1 = 1-3), thickish, adnate, (sub)ventricose, at first whitish, later pale greyish; edge fimbriate, whitish. Stipe $25-45 \times 2-3 \mathrm{~mm}$, mostly widening towards the base, when young covered with whitish tomentum, later longitudinally striate or glabrous, shimmering sericeous, brownish with reddish hue; pruinose only near the apex of the stipe. Context whitish in the pileus and the stipe. Smell spermatical, at least when cut. Colour of exsiccata pileus brown with reddish hue (Mu 7/5YR 4/4-4/6), lamellae and stipe somewhat lighter in colour, no darkening or blackening on drying.

Spores $8.2-11.1 \mu \mathrm{m}($ av. $9.5 \mu \mathrm{m}$, SD $0.6 \mu \mathrm{m}) \times 4.9$ $6.4 \mu \mathrm{m}$ (av. $5.7 \mu \mathrm{m}$, SD $0.3 \mu \mathrm{m}$ ); Q = 1.5-2.0 (av. 1.7, SD $0.1)(\mathrm{n}=80$ of 2 coll.); smooth, (sub)amygdaloid to broadly subelliptic, usually without suprahilar depression, apex subacute, sometimes with indistinct pseudoporus. Basidia 25-31 $\times 7-10 \mu \mathrm{m}$, generally 4 -spored, seldom also 2 -spored, and then spores up to $12.0 \mu \mathrm{m}$. Lamellae edges sterile, composed of cheilocystidia and numerous colourless, (sub)clavate or (sub)cylindrical, thin-walled paracystidia. Pleurocystidia 42-73 $\mathrm{m}$ (av. $59 \mu \mathrm{m}$, SD $9 \mu \mathrm{m}) \times 12-23 \mu \mathrm{m}$ (av. $15 \mu \mathrm{m}$, SD $2 \mu \mathrm{m}$ ); $\mathrm{Q}=2.4-5.6$ (av. 3.9, SD 0.8) ( $\mathrm{n}=30$ of 2 coll.), mostly (sub)utriform, sometimes also subfusiform or subcylindrical, often transition between bulge and neck clearly demarcated, usually with only short, but sometimes also with longer and undate neck, at the apex generally wide, with rather short pedicel or with subtruncate or roundish base, apex usually crystalliferous, walls $1.5 \mu \mathrm{m}$ thick at the apex, pale yellowish-greenish with 3\% KOH. Cheilocystidia similar in appearance and size. Pileipellis constituted by an epicutis made up of parallel hyphae 5-13 $\mu \mathrm{m}$ wide, with faintly encrusting and parietal brownish to dark brown pigment, subcutis with wider and paler to colourless elements. Caulocystidia only near the apex of the stipe, 35-65 $\times 10$ $20 \mu \mathrm{m}$, usually (sub)utriform, often with clearly demarcated transition from bulge to apex, with short pedicel, apex usually crystalliferous, walls $1.0 \mu \mathrm{m}$ thick at the apex, pale yellowishgreenish with $3 \% \mathrm{KOH}$; intermixed with numerous (sub)clavate cauloparacystidia. Clamp-connections abundant in all tissues.

Habitat and known distribution: The species was collected by us in subalpine regions of Austria with conifers, along a pebbled wayside, thus probably on calcareous ground. Apart from these collections, the species has been sequenced from basidiomata (as ' $I$. cf. friesii', FJ845413 and
'I. sindonia', HQ604384) and from root tips, e.g. sequence from California or from Estonia.

Further collections studied: AUSTRIA, Tirol, Imst, near Ötztal, ÖK25V 2221-Ost, alt. ca. 1700 m, Picea abies, Pinus cembra, 12 Sep 2019, leg. D. Bandini; det. D. Bandini \& B. Oertel (DB12-9-19-19).

Comments: Inocybe oetziana is characterized by glabrous to rim(ul)ose subhygrophanous surface of pileus, ochraceous brownish to coppery or reddish brownish pileus colour, only faint velipellis, mostly (sub)utriform hymenial cystidia with wide neck and short pedicel and rather thin walls. The stipe is pruinose only near the apex, and the species seems to be fond of calcareous terrain with conifers. At first glance, the species may be mistaken for I. nitidiuscula. However, the colour of pileus of the latter species normally is more reddish tinged, the surface is not subhygrophanous, the spores on average are longer and the hymenial cystidia often are narrow at the apex and usually are thicker walled (Britzelmayr 1891; Stangl 1983, 1989; Kuyper 1986; Marchetti et al. 2014, and personal observation). Inocybe involuta, too, is usually more reddish tinged in colour, with strong colour-contrast between the lamellae and the stipe when young, and the spores on average are larger (Kuyper 1989; Bandini et al. 2020a, 2020c. Inocybe perchtana, a species growing in the same habitat, differs, e.g. by usually more red-brown pileus colour, less rimose surface of pileus with age, on average smaller spores and long and narrow caulocystidia with undate walls. The stipe furthermore often gets reddish when bruised and is - even though sparely - pruinose also in the lower half (Bandini et al. 2020a). Inocybe griseovelata differs, e.g. by generally thicker and less fugacious velipellis, paler stipe, larger spores and often (sub)cylindrical hymenial-cystidia (Kühner 1955, and personal observation), while I. grusiana also has a thicker velipellis, on average longer spores and long and narrow caulocystidia with truncate base. We are not aware of any species more than $85 \%$ similar to I. oetziana.

Inocybe olivaceobrunnea J. Favre ex Kuyper, Persoonia, Suppl. 3: 117 (1986) Fig. 25 h

Description of the species: Favre 1960.

Studied material (isotype): SWITZERLAND, God dal Fuorn, $1850 \mathrm{~m}$ (G-00126151). Spores 8.1-11.1 $\mu \mathrm{m}$ (av. 9.3 $\mu \mathrm{m}, \mathrm{SD} 0.7 \mu \mathrm{m}) \times 5.8-7.2 \mu \mathrm{m}$ (av. $6.4 \mu \mathrm{m}$, SD $0.4 \mu \mathrm{m}) ; \mathrm{Q}=$ 1.3-1.7 (av. 1.4, SD 0.1) ( $\mathrm{n}=40)$, smooth, mostly broadly elliptic to subovoid with obtuse apex and faint pseudoporus. Basidia 4-spored. Pleurocystidia 45-79 $\mu \mathrm{m}$ (av. $61 \mu \mathrm{m}, \mathrm{SD}$ $8.6 \mu \mathrm{m}) \times 18-32 \mu \mathrm{m}($ av. $23 \mu \mathrm{m}, \mathrm{SD} 3.6 \mu \mathrm{m}) ; \mathrm{Q}=1.9-4.1$ (av. 2.7, SD 0.6) $(\mathrm{n}=15)$, mostly plump, either ventricose utriform or (sub)cylindrical or sac-shaped to subovoid or deformed, apex usually without or with only small crystals, walls up to $0.5 \mu \mathrm{m}$ thick, no reaction with $3 \% \mathrm{KOH}$. Cheilocystidia similar in appearance and size. Paracystidia 
not observed. Caulocystidia not studied, because stipe not present.

Comments: We do not have DNA data available for I. olivaceobrunnea. To our knowledge no sequence data were published under this name. Based on the microscopic details, we do consider it as a good species.

Inocybe orionis Bandini, B. Oertel \& U. Eberh. sp. nov. Fig. 16

\section{MycoBank number: MB 839164}

Etymology: Named 'orionis' because the somewhat blurred colour of the centre of the pileus that reminds of the Orion Nebula.

Diagnosis: Inocybe orionis resembles macroscopically a species of the genus Hebeloma with an orange-brownish blurred to streaky centre of the pileus and whitish to ivory-coloured outer parts. The surface of pileus is smooth to finely felty. The smooth spores are rather small, measuring 6.6-9.7 $\mu \mathrm{m}$ (av. 8.3 $\mu \mathrm{m}) \times 4.2-5.3 \mu \mathrm{m}$ (av. 4.7 $\mu \mathrm{m}$ ), the hymenial cystidia are generally (sub)utriform or (sub)fusiform and rather short and slender, pleurocystidia measuring 35-63 $\mu \mathrm{m}$ (av. $45 \mu \mathrm{m}) \times$ 9-16 $\mu \mathrm{m}$ (av. 11 $\mu \mathrm{m})$. This combination of characters as well as ITS sequence data distinguishes $I$. orionis from somewhat similar species such as I. agglutinata.

Holotype: GERMANY, Baden-Württemberg, RheinNeckar-Kreis, Lobbach, TK25 6619/1, alt. 185 m, Fagus sylvatica, Carpinus betulus, Quercus robur, 29 Oct 2016, leg. D. Bandini (holotype STU SMNS-STU-F-0901455; isotypes priv. herb. D.B. DB29-10-16-2, TUR-A 209194). GenBank: ITS + partial LSU = MW845898.

Description: Pileus 15-40 mm wide, at first (sub)conical, later expanded, without or with low large umbo, margin at first slightly decurved, soon straight, then mostly uplifted, and then pileus depressed around the umbo; young basidiomata with a fine layer of a whitish velipellis; colour whitish, dingy whitish, pale straw or ivory, at the centre somewhat blurred to streaky pale orange, pale greyish, orangebrownish, ochraceous brownish or greyish-brownish $(\mathrm{Mu}$ 10YR 8/2-8/4, 7/3-7/6, 6/3-6/4; 7.5YR 7/4-7/8, 6/4-6/8); surface at first and long time smooth and glabrous, later remaining smooth or becoming very finely tomentose; young basidiomata with remnants of a whitish cortina. Lamellae subdistant to moderately crowded (ca. 35-45, 1 = 1-3), adnate with decurrent tooth, subventricose, at first whitish, greyishwhitish, later brownish; edge fimbriate, whitish. Stipe 20-50 $\times 2-5 \mathrm{~mm}$, cylindrical or flattened and/or curved, long time covered with whitish tomentum, later longitudinally striate, at first whitish, later pale straw-coloured; pruinose only near the apex of the stipe. Context whitish in the pileus and the stipe. Smell faintly sweetish aromatical. Colour of exsiccata pileus pale straw, pale orange or pale brownish (Mu 10YR 6/3-6/4, 7/4-7/6, 5/3-5/4; 7/5YR 7/6), lamellae and stipe concolorous or a little lighter in colour, no darkening or blackening on drying.

Spores 6.6-9.7 $\mu \mathrm{m}($ av. $8.3 \mu \mathrm{m}$, SD $0.5 \mu \mathrm{m}) \times 4.2-5.3 \mu \mathrm{m}$ (av. $4.7 \mu \mathrm{m}$, SD $0.2 \mu \mathrm{m}) ; \mathrm{Q}=1.5-2.0$ (av. 1.8, SD 0.1) $(\mathrm{n}=$ 120 of 3 coll.), smooth, (sub)amygdaloid, without or with only faint suprahilar depression, apex subacute, subobtuse, sometimes with indistinct pseudoporus. Basidia 21-26 × 7-9 $\mu \mathrm{m}$, generally 4-spored. Lamellae edges sterile, composed of cheilocystidia and numerous colourless, (sub)clavate, thinwalled paracystidia, sometimes in intermediate states. Pleurocystidia 35-63 $\mu \mathrm{m}$ (av. $45 \mu \mathrm{m}$, SD $6 \mu \mathrm{m}) \times 9-16$ $\mu \mathrm{m}$ (av. $11 \mu \mathrm{m}, \mathrm{SD} 2 \mu \mathrm{m}) ; \mathrm{Q}=2.3-5.4$ (av. 4.0, SD 0.6) (n $=45$ of 3 coll.); generally (sub)utriform or (sub)fusiform, sometimes also subcylindrical or (sub)clavate, at the apex usually wide, without or with only short neck and with only short pedicel, apex usually crystalliferous, walls up to 1.5 (2.0) $\mu \mathrm{m}$ thick at the apex, pale yellowish-greenish to yellowish-greenish with $3 \% \mathrm{KOH}$. Cheilocystidia similar in appearance and size. Pileipellis constituted by an epicutis made up of parallel hyphae 5-12 $\mu \mathrm{m}$ wide, without or only barely encrusting and parietal brownish pigment, subcutis with wider and paler to colourless elements. Caulocystidia only near the apex of the stipe, 35-55 × 10-15 (20) $\mu \mathrm{m}$, mostly (sub)fusiform or (sub)utriform, without or with only short neck and with short pedicel, apex usually crystalliferous, walls up to $1.5 \mu \mathrm{m}$ thick at the apex, pale yellowish-greenish to yellowish-greenish with $3 \% \mathrm{KOH}$; intermixed with numerous (sub)clavate to subglobose cauloparacystidia. Clampconnections abundant in all tissues.

Habitat and known distribution: Inocybe orionis was collected by us next to frondose trees, Fagus sylvatica, Carpinus betulus and Quercus robur, on calcareous soil in shady and thus even in summer somewhat humid locations. It is only known from our own collections from Germany up to now, and from a soil sample sequence from Iran in GenBank (HE687057).

Further collections studied: GERMANY, BadenWürttemberg, Rhein-Neckar-Kreis, Wiesenbach, TK25 6619/1, alt. 180 m, Carpinus betulus, Fagus sylvatica, 29 Oct 2019, leg./det. D. Bandini (STU SMNS-STU-F0901454; DB29-10-19-2). Baden-Württemberg, RheinNeckar-Kreis, Lobbach, TK25 6619/1, alt. 210 m, Carpinus betulus, Fagus sylvatica, 29 Oct 2019, leg./det. D. Bandini (DB29-10-19-5). Baden-Württemberg, Rhein-Neckar-Kreis, near Waldwimmersbach, TK25 6619/1, alt. 205 m, Carpinus betulus, Quercus robur, Fagus sylvatica, 29 Oct 2019, leg./det. D. Bandini (STU SMNS-STU-F0901453; DB29-10-19-6). Ibidem, in some distance from former location, alt. 195 m, Carpinus betulus, Quercus robur, Fagus sylvatica, 29 Oct 2019, leg./det. D. Bandini (DB29-1019-7).

Comments: Inocybe orionis is characterized by the whitish to ivory-coloured outer surface of pileus and 

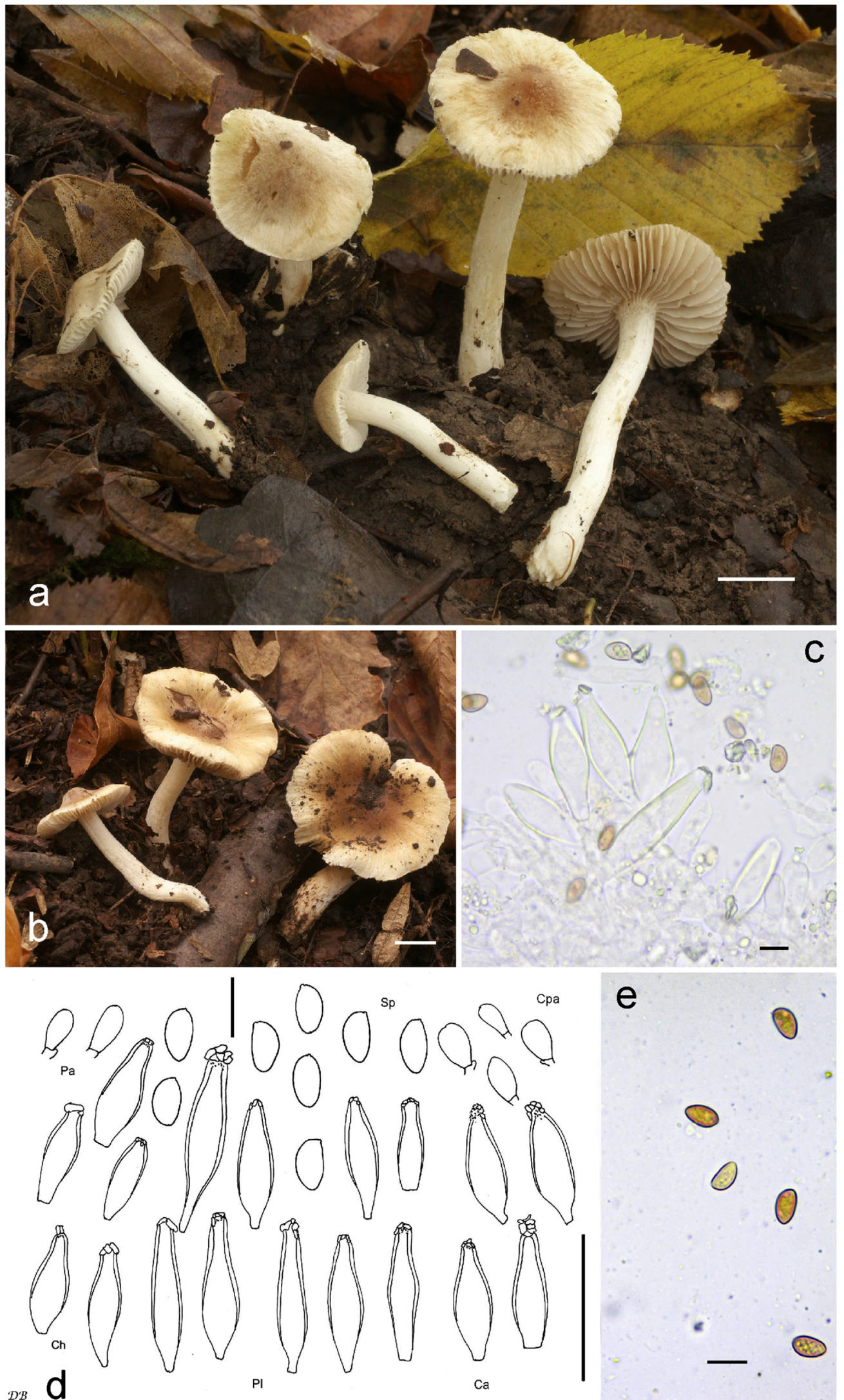

Fig. 16 Inocybe orionis, a holotype, scale bar: $1 \mathrm{~cm}$. b Coll. DB29-1019-6, scale bar: $1 \mathrm{~cm}$. c Cheilocystidia (coll. DB29-10-19-6), scale bar: 10 $\mu \mathrm{m}$. d Microscopical characters (holotype), $\mathrm{Ca}=$ Caulocystidia, $\mathrm{Cpa}=$

Cauloparacystidia, $\mathrm{Ch}=$ Cheilocystidia, $\mathrm{Pa}=$ Paracystidia, $\mathrm{Pl}=$ Pleurocystidia, $\mathrm{Sp}=$ Spores; scale bar spores: $10 \mu \mathrm{m}$, scale bar cystidia: $50 \mu \mathrm{m}$. e Spores (holotype), scale bar: $10 \mu \mathrm{m}$ 
orange-, greyish- or ochraceous brownish centre. It thus resembles macroscopically very much species of the genus Hebeloma. Microscopically, it has rather small spores and quite short hymenial cystidia. Inocybe phaeodisca var. geophylloides (see comments to I. bolbitioides) has a yellowish-orange-pileus centre with dingy beige or ivory-coloured outer parts, but the basidiomata usually are very small, and the spores and hymenial cystidia are larger than those of I. orionis (Kühner 1955; Kuyper 1986, and personal observation). From species of the geophyllagroup, such as I. geophylla, I. miranda, I. bellidiana, I. sambucella or $I$. posterula, it differs by the 'Hebeloma-'aspect, i.e. the much more intensely coloured centre of the pileus. Inocybe phaeodisca Kühner differs from I. orionis, e.g. by brown pileus centre and much paler margin as well as on average larger spores (Kühner 1955, and see below). Assuming Stuntz' concept of Inocybe agglutinata Peck is correct, i.e. corresponding to collection WTU Stz1178, I. agglutinata may be the sister species of I. orionis (Fig. 1) with $93 \%$ identity in the ITS, and differs, e.g. by smaller size, a with tawny spots speckled fibrillose pileus surface and larger spores (Peck 1888; see also Carteret and Reumaux 2013; Matheny and Swenie 2018).

Inocybe patibilis (Fig. 26 a) $\rightarrow$ Inocybe tigrina

Inocybe personata (Fig. 26 b) $\rightarrow$ Inocybe griseolilacina

Inocybe petroselinolens (Fig. $26 \mathrm{~d}$ ) $\rightarrow$ Inocybe tenuicystidiata

Inocybe phaeodisca Kühner, Bull. Soc. nat. Oyonnax 9(Suppl. (Mém. hors sér. 1)): 5 (1955) Fig. 26 d

Description of the species: Kühner 1955; Kuyper 1986; Stangl 1989.

Studied material (intended lectotype, [herbarium slip Esteve-Raventos 2 Apr 2008]): FRANCE, Isère, La Grande Chartreuse, mixed wood, 8 Aug 1934, leg. R. Kühner (G00118411). Spores 7.5-10.6 $\mu \mathrm{m}$ (av. $9.0 \mu \mathrm{m}$, SD 0.6 $\mu \mathrm{m}) \times 4.9-6.0 \mu \mathrm{m}($ av. $5.5 \mu \mathrm{m}, \mathrm{SD} 0.3 \mu \mathrm{m}) ; \mathrm{Q}=1.5-1.9$ (av. 1.7, SD 0.1) (n = 40), smooth, (sub)amygdaloid, with subobtuse to subacute apex. Basidia 4-spored. Pleurocystidia 43-56 $\mu \mathrm{m}$ (av. $49 \mu \mathrm{m}$, SD $4 \mu \mathrm{m}) \times 10-21$ $\mu \mathrm{m}$ (a v. $15 \mu \mathrm{m}$, SD $3 \mu \mathrm{m}) ; \mathrm{Q}=2.1-5.2$ (av. 3.5, SD 0.8) (n = 15), (sub)fusiform or (sub)utriform, without or with only short neck and with short pedicel, apex usually crystalliferous, walls up to $1.0(1.5) \mu \mathrm{m}$ thick at the apex, pale yellowish-greenish with 3\% KOH. Cheilocystidia similar in appearance and size. Paracystidia not observed. Caulocystidia not studied (to preserve the material).

Further collection studied: GERMANY, Bayern, München, Grünwald, Isarauen, TK25 7835/3, alt. 550 m,
Fagus sylvatica, 19 Aug 2007, leg./det. M. Dondl; conf. D. Bandini (STU SMNS-STU-F-0901574; DB19-8-7-Dondl).

Comments: Sequencing was not permitted. As far as we are aware, the lectotypification has not been published yet and is thus not valid. The name has been interpreted in various ways (see Fig. 1). In Fig. 1, the species is represented by a sequence from a collection morphologically matching the type material. This material could be serving as epitype of the species, but as we did not see and analyse the material when it was fresh, we decided not to use it as epitype.

Inocybe plurabellae Bandini, B. Oertel \& U. Eberh. sp. nov. Fig. 17

MycoBank number: MB 839165

Etymology: The name 'plurabellae' refers to the name of the multiformed character, Anna Livia Plurabelle, in James Joyce' 'Finnegans Wake', because of the very variable morphological features of this species.

Diagnosis: Inocybe plurabellae typically has a minutely squamulose, as if 'roughened' pileus surface with only faint and fugacious velipellis, and the pileus colour usually is brown to dark brown, but sometimes also much paler. The stipe is only near the apex pruinose, the spores are smooth, measuring 7.6-12.2 $\mu \mathrm{m}$ (av. 9.6 $\mu \mathrm{m}) \times 4.9-6.5 \mu \mathrm{m}$ (av. 5.6 $\mu \mathrm{m})$, the hymenial cystidia mostly are rather ventricose (sub)fusiform to (sub)utriform, often with truncate base, pleurocystidia measuring 34-80 $\mu \mathrm{m}$ (av. $55 \mu \mathrm{m}) \times 8-25 \mu \mathrm{m}$ (av. $15 \mu \mathrm{m}$ ), and the caulocystidia typically are rather long and narrow subcylindrical or deformed with undate walls. This combination of characters as well as ITS sequence data distinguishes I. plurabellae from other brown smooth-spored species with caulocystidia only near the apex, such as I. virgatula.

Holotype: GERMANY, Baden-Württemberg, RheinNeckar-Kreis, Bammental, TK25 6618/2, alt. 148 m, lawn with Picea abies, 31 Oct 2016, leg. D. Bandini (holotype STU SMNS-STU-F-0901260; isotypes priv. herb. D. Bandini DB31-10-16-9, AH 56135, TUR-A 209195). GenBank: ITS + partial LSU = MW845901.

Description: Pileus 15-40 (45) mm wide, (sub)conical, (sub)campanulate or almost subglobose when young, later broadly convex to expanded, mostly with umbo, which in some collections is low and large, in others more prominent, margin involute when young, but soon decurved to straight, seldom also uplifted and then depressed around the centre; with faint and fugacious pale greyish remnants of a velipellis when young; colour extremely variable, but mostly brown to dark brown with or without faint or intense reddish tinge $\mathrm{Mu}$ 10YR 5/4-5/8, 4/4-4/6; 7.5YR 5/6-5/8, 4/4-4/6), but also pale straw or beige ochraceous to pale brown or ochraceous brown (Mu 10YR 8/3-8/4, 7/4-7/8), at the centre in case of pale-straw-coloured basidomata sometimes almost dark red or orange, in brown-coloured specimens often somewhat darker 

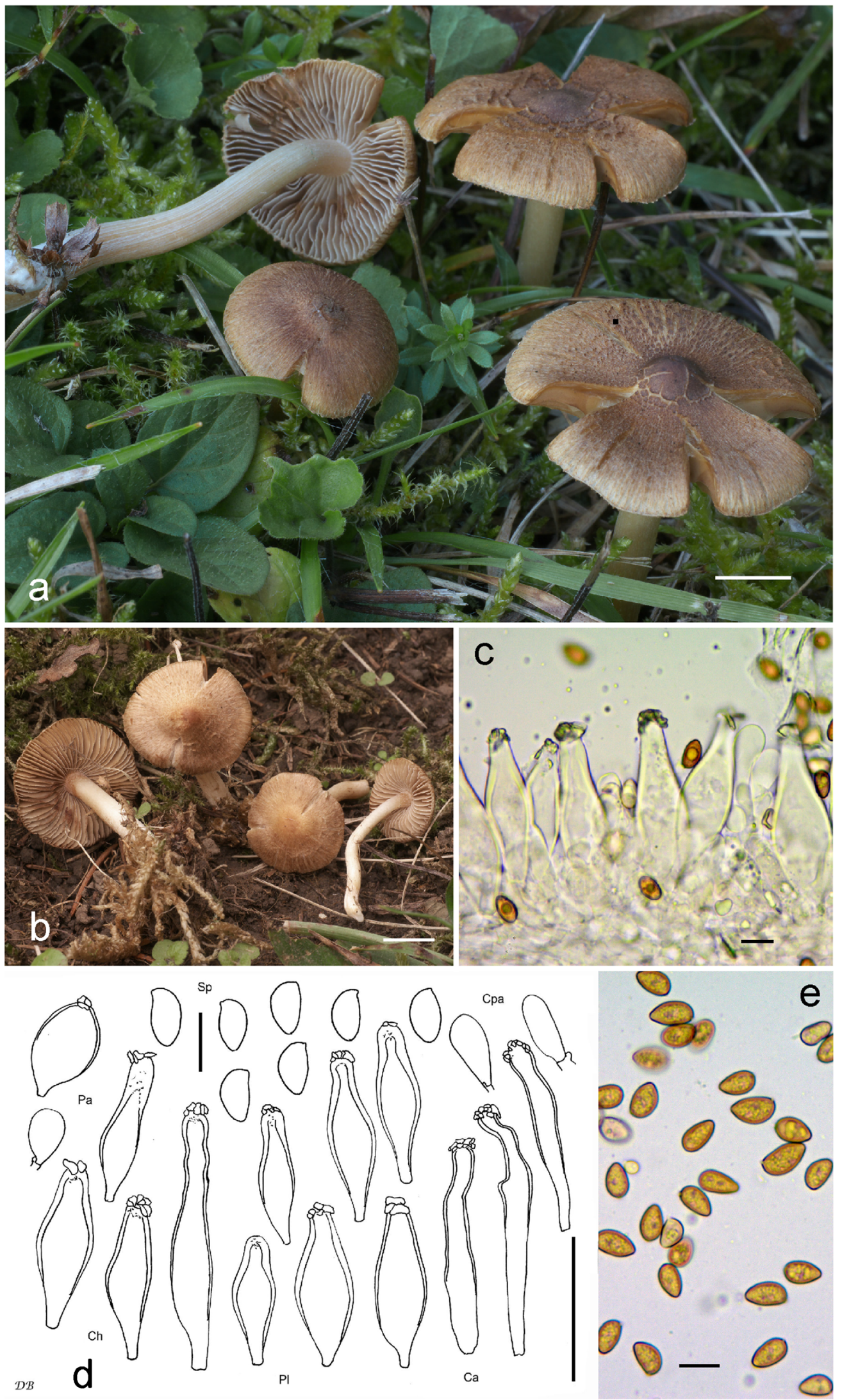

Fig. 17 Inocybe plurabellae, a holotype, scale bar: $1 \mathrm{~cm}$. b Coll. DB311-17-6, scale bar: $1 \mathrm{~cm}$. c Cheilocystidia (coll. DB17-8-14-4), scale bar: $10 \mu \mathrm{m}$. d Microscopical characters (holotype) $\mathrm{Ca}=$ Caulocystidia, $\mathrm{Cpa}=$

Cauloparacystidia, $\mathrm{Ch}=$ Cheilocystidia, $\mathrm{Pa}=$ Paracystidia, $\mathrm{Pl}=$ Pleurocystidia, $\mathrm{Sp}=$ Spores; scale bar spores: $10 \mu \mathrm{m}$, scale bar cystidia: $50 \mu \mathrm{m}$. e Spores (coll. DB7-11-15-6), scale bar: $10 \mu \mathrm{m}$ 
or faintly orange in colour; surface typically finely tomentose with minutely squamules as if roughened outwards the centre, but with age sometimes almost rim(ul)ose or innate fibrillose towards the margin; sometimes cracked or fissured mainly at the centre; young basidiomata with whitish cortina, sometimes pending from the border. Lamellae subdistant to moderately crowded (ca. 30-50, 1 = 1-3), from almost free or adnexed to adnate, even to (sub)ventricose, at first whitish, then greyishbrownish, brown to chocolate-brown with age; edge fimbriate, whitish to concolorous. Stipe $20-60 \times 1-4 \mathrm{~mm}$, cylindrical or curved, sometimes slightly widening towards the base, at first covered with whitish tomentum, then longitudinally striate or glabrous, whitish to pale wood-coloured, pale flesh-coloured to brownish, often faintly pinkish near the apex, base often covered with whitish tomentum; pruinose only at the apex of the stipe. Context whitish in pileus, in stipe pale reddishbrownish at the cortex at least near the apex. Smell often somewhat aromatical or with fruity tinge and subspermatical when cut. Colour of exsiccata pileus chestnut-brown, dark brown with or without reddish hue (Mu 10YR 4/3-4/6; 7.5YR 4/3-4/4), lamellae concolorous or somewhat paler, stipe often near the apex or entirely faintly or clearly pinkishreddish, no darkening or blackening on drying.

Spores 7.6-12.2 $\mu \mathrm{m}$ (av. 9.6 $\mu \mathrm{m}$, SD 0.8) × 4.9-6.5 $\mu \mathrm{m}$ (av. $5.6 \mu \mathrm{m}, \mathrm{SD} 0.3 \mu \mathrm{m}$ ); $\mathrm{Q}=1.4-2.1 \mu \mathrm{m}$ (av. $1.7 \mu \mathrm{m}, \mathrm{SD} 0.1$ $\mu \mathrm{m})(\mathrm{n}=240$ of 6 coll.); smooth, (sub)amygdaloid, mostly without, seldom with faint suprahilar depression, apex subacute to subobtuse, in some collections with indistinct pseudoporus. Basidia 21-33 × 7-10 $\mu \mathrm{m}$, generally 4-spored, seldom also 2-spored, and then spores up to $16 \mu \mathrm{m}$. Lamella edge sterile, composed of cheilocystidia and numerous colourless, (sub)clavate to subglobose, thin-walled to slightly thick-walled paracystidia. Pleurocystidia 34-80 $\mu \mathrm{m}$ (av. 55 $\mu \mathrm{m}, \mathrm{SD} 10 \mu \mathrm{m}) \times 8-25 \mu \mathrm{m}$ (av. $15 \mu \mathrm{m}$, SD $3 \mu \mathrm{m}) ; \mathrm{Q}=1.8-$ 7.8 (av. 3.8, SD 0.9) ( $\mathrm{n}=90$ of 6 coll.), mostly rather ventricose (sub)fusiform or (sub)utriform, seldom (sub)cylindrical or subclavate, often quite different from collection to collection and with rather long cystidia inmidst of mostly quite short ones, usually with short, sometimes also with longer necks, often narrowing towards the apex, with short pedicel or with truncate base, apex usually crystalliferous, walls up to 2.5 (3.5) $\mu \mathrm{m}$ thick at the apex, pale yellowish-greenish with $3 \%$ $\mathrm{KOH}$. Cheilocystidia similar in appearance and size. Pileipellis constituted by an epicutis made up of parallel hyphae 5-13 $\mu \mathrm{m}$ wide, often but not always with finely encrusting and parietal, corresponding to the colour of the collection, brownish or almost yellowish pigment, subcutis with wider and paler sometimes balloon-shaped also faintly encrusting and parietal brownish to colourless elements. Caulocystidia only at the apex of the stipe, (35) 40-95 (97) $\times 7-15 \mu \mathrm{m}$, characteristically long and narrow subcylindrical or deformed and often with undate walls, often with subcapitate apex, apex usually crystalliferous, walls up to
$1.0 \mu \mathrm{m}$ thick at the apex, pale yellowish-greenish with $3 \%$ $\mathrm{KOH}$; intermixed with numerous (sub)cylindrical to subclavate cauloparacystidia. Clamp-connections abundant in all tissues.

Habitat and known distribution: Our collections are from Austria and Germany. All without exception were associated with Picea, several of them without any other trees in the vicinity. Apart from these countries, sequences putatively belonging to I. plurabellae have been published in GenBank from EcM sequences from China (with Pinus tabuliformis, LC013747, and with Picea crassifolia, LC203840). Sequences from soil samples that may belong to I. plurabellae are in the UNITE database, from Latvia (e.g. UDB0311849) and Estonia (e.g. UDB0239809), and in GenBank from Northern Canada (KF297194). There are also very similar EcM sequences from China, sampled from the roots of frondose trees, such as Ostryopsis davidiana (JX129150), and Quercus liaotungensis (KX444295). The association with broadleaves does not agree with our observations for this species; thus, it is not clear whether the data indeed refer to the same taxon. All of our own collections were gathered next to Picea abies. The species appears to prefer calcareous substrates. It was mostly found by us along pebbled waysides.

Our own collections are as well from low altitudes as from montane regions from August to end of November.

Further collections studied: The following collections are only a selection from more than 80 samples: AUSTRIA, Oberösterreich, Schalchen, Kobernausser Wald, ÖK25V 3328-Ost, alt. $530 \mathrm{~m}$, Picea abies, Larix decidua, Abies alba, 17 Aug 2014, leg. D. Bandini, J. Christan \& L. Quecke; det. D. Bandini \& B. Oertel (DB17-8-14-4). Salzburg, Zederhaus, Riedingtal, ÖK25V 3229-Ost, alt. ca. 1500 m, Picea abies, Larix decidua, Salix sp., 13 Aug 2013, leg./det. D. Bandini \& B. Oertel (DB13-8-13-4). Tirol, Reutte, Tannheimer Tal, near Tannheim, ÖK25V 2214-Ost, alt. 1150 m, Picea abies, Salix sp., 16 Sep 2016, leg. D. Bandini; det. D. Bandini \& B. Oertel (DB16-9-16-1). Tirol, Imst, Mötz, Locherboden, ÖK25V 2221-Ost, alt. 760 m, Picea abies, 13 Sep 2017, leg./det. D. Bandini (DB13-9-17-6). Tirol, Reutte, Rieden, ÖK25V 2215West, alt. 870 m, Picea abies, Betula sp., 20 Sep 2018, leg. D. Bandini; det. D. Bandini \& B. Oertel (DB20-9-18-1). GERMANY, Baden-Württemberg, Rhein-Neckar-Kreis, Mauer, TK25 6618/4, alt. 230 m, Picea abies, 26 Oct 2012, leg./det. D. Bandini (DB26-10-12-2). Baden-Württemberg, Heidelberg, Johanneskirche, TK25 6518/3, alt. $117 \mathrm{~m}$, Betula pendula, Picea omorica, 2 Sep 2014, leg. D. Bandini; det. D. Bandini \& B. Oertel (SMNS-STU-F0901497, DB2-9-14-3). Baden-Württemberg, Freudenstadt, Baiersbronn, Wilder See, Hornisgrinde, TK25 7415/1, alt. 870 m, Abies alba, Picea abies, 20 Sep 2015, leg./det. D. Bandini \& B. Oertel (KR-M-0042672, DB20-9-15-14). Baden-Württemberg, Rhein-Neckar-Kreis, Wiesenbach, 
TK25 6618/2, alt. 190 m, Picea abies, Prunus avium, 4 Nov 2016, leg. D. Bandini; det. D. Bandini \& B. Oertel (SMNS-STU-F-0901499, DB4-11-16-1). BadenWürttemberg, Neckar-Odenwald-Kreis, Aglasterhausen, near Michelbach, TK25 6619/2, alt. 325 m, Fagus sylvatica, Picea abies, 5 Aug 2017, leg. D. Bandini; det. D. Bandini \& B. Oertel (SMNS-STU-F-0901523, DB5-8-17-7). BadenWürttemberg, Freudenstadt, Baiersbronn, Nature Reserve 'Wilder See', Hornisgrinde, TK25 7415/1, alt. 870 m, Picea abies, Abies picea, 20 Sep 2015, leg./det. D. Bandini \& B. Oertel (DB20-9-15-12). Baden-Württemberg, Rhein-NeckarKreis, Lobbach, Haag, TK25 6519/4, alt. 420 m, Picea abies, 30 Oct 2015, leg. D. Bandini; det. D. Bandini \& B. Oertel (DB30-10-15-8). Baden-Württemberg, Rhein-Neckar-Kreis, Helmstadt-Bargen, Schwanheim, TK25 6619/2, alt. 390 m, Picea abies, 7 Nov 2015, leg. D. Bandini; det. D. Bandini \& B. Oertel (DB7-11-15-6). Baden-Württemberg, RheinNeckar-Kreis, Wiesenbach, TK25 6618/2, alt. 190 m, meadow with Picea abies and Prunus avium, 13 Nov 2015, leg. D. Bandini; det. D. Bandini \& B. Oertel (STU SMNS-STU-F0901501; DB13-11-15-1). Baden-Württemberg, RheinNeckar-Kreis, Bammental, cemetery, TK25 6618/2, alt. 148 m, Picea abies, 3 Nov 2017, leg. D. Bandini; det. D. Bandini \& B. Oertel (STU SMNS-STU-F-0901498; DB3-11-17-6). Baden-Württemberg, Rhein-Neckar-Kreis, Schönbrunn, TK25 6519/4, alt. 390 m, Picea abies, 17 Aug 2019, leg. D. Bandini; det. D. Bandini \& B. Oertel (STU SMNS-STU-F0901488; DB17-8-19-3). Baden-Württemberg, RheinNeckar-Kreis, Epfenbach, TK25 6619/2, alt. 300 m, Picea abies, 19 Oct 2019, leg. D. Bandini; det. D. Bandini \& B. Oertel (STU SMNS-STU-F-0901500; DB19-10-19-1). Bayern, Berchtesgadener Land, Ramsau, Hintersee, TK25 8343/3, alt. 795 m, Picea abies, Salix spec., 22 Aug 2014, leg. D. Bandini; det. D. Bandini \& B. Oertel (DB22-8-14-5). Bad Tölz-Wolfratshausen, Lenggries, Fall, Hühnerberg, TK25 8534/2, alt. 1280 m, Picea abies, 1 Aug 2015, leg. M. Dondl; det. D. Bandini \& B. Oertel (DB1-8-15-2-Dondl). Bayern, Ostallgäu, Füssen, TK25 8430/1, alt. 795 m, Picea abies, Pinus sylvestris, 12 Oct 2016, leg. D. Bandini; det. D. Bandini \& B. Oertel (DB12-10-16-4). Sachsen-Anhalt, Harz, Oberharz am Brocken, Nature Reserve 'Kramershai', TK25 4229/4, alt. 670 m, Picea abies, 2 Oct 2012, leg./det. D. Bandini \& B. Oertel (DB2-10-12-7).

Comments: Inocybe plurabellae is a very common species but must have been mistaken for other species. It can be extremely variable macroscopically in both the colour and texture of pileus. The species can vary also microscopically, because the hymenial cystidia often are a mixture of rather shortand long-necked cystidia. In most collections, however, the pileus surface when in good condition looks as if roughened, the colour is brown to dark brown with or without reddish hue and the hymenial cystidia on average are shorter than $60 \mu \mathrm{m}$ and rather ventricose often with narrowing necks, and often with a truncate base. Characteristically are also the narrow and long subcylindrical or somewhat deformed caulocystidia directly at the apex of the stipe. Such caulocystidia are known from I. grusiana, which differs, e.g. by the never roughened, more glabrous pileus surface, ample velipellis when young, on average longer spores and hymenial cystidia. Inocybe griseovelata also has long and slender caulocystidia, but it differs, e.g. by often ample velipellis and often (sub)cylindrical hymenial cystidia with wide necks. Furthermore, the spores and hymenial cystidia on average are longer (Kühner 1955, and personal observation). These latter two features also are true for I. costinitii, which also has differently shaped caulocystidia (Bizio et al. 2016). Inocybe derbschii, which can be found in the same locations as I. plurabellae, differs, e.g. by the not roughened pileus surface and its caulocystidia are not as long and narrow (see Schwöbel and Stangl 1982; Bandini et al. 2019b). Inocybe beatifica has an entirely pruinose stipe, a smoother pileus surface and on average narrower spores, and I. pseudorubens often has an areolate diffracted centre of pileus and also on average narrower spores. It furthermore grows with frondose trees (Carteret and Reumaux 2001, and personal observation). Inocybe castorina grows with Alnus and/or Salix in rather moist locations, the velipellis is whitish, the surface is smoother and the spores are on average somewhat narrower and longer (Bandini et al. 2020a). Inocybe scolopacis has a smoother surface, shorter and differently shaped, mostly sublageniform caulocystidia and on average narrower spores. Inocybe virgatula differs e.g. by smoother pileus surface, oblong on average narrower spores with explicit suprahilar depression, and the caulocystidia are wider and mostly (sub)fusiform (Kühner 1955, and personal observation). Inocybe tigrina differs from I. plurabellae, e.g. by the not roughened surface of the pileus, the on average narrower spores, not as long and narrow and mostly sublageniform caulocystidia and stronger with $\mathrm{KOH}$ reacting walls of hymenial cystidia (see Heim 1931; Reumaux et al. 1988; Carteret and Reumaux 2012, and personal observation). Inocybe semifulva differs from I. plurabellae, e.g. by the not roughened surface of the pileus, by the often subcapitate hymenial cystidia with walls that are mostly conformously wide at bulge and apex and oblong spores, which on average are smaller than those of I. plurabellae (Grund and Stuntz 1981). Besides, we always have found it with frondose trees (Bandini 2014). The clade named I. plurabellae in Fig. 1 appears deeply split, but this is at least in part due to intraspecific ITS variation that is also observed as intragenomic ITS variation. Presumably, the two sequences originally identified as $I$. (cf.) flocculosa that appear in the same clades I. plurabellae, but slightly apart, also belong to I. plurabellae, although they include sequence variation in a few alignment positions not displayed in material we have studied. We are not aware of any known species that is 
molecularly closely related to I. plurabellae. With $91-92 \%$ identity in the ITS, distantly related is I. ghibliana.

Inocybe psammobrunnea Bon, Docums Mycol. 20(78): 63 (1990) Fig. 26 e

= Inocybe griseotarda Poirier, Docums Mycol 31 (124): 4 (2002)

Description of the species: Bon 1990; Ludwig 2017.

Studied material (holotype of I. psammobrunnea): FRANCE, St. Quentin-en-Tourmont, Somme, Parc du Marquenterre, with Pinus in sandy terrain, 18 Nov 1989 (LIL-89226, M. Bon 89226). GenBank: ITS = MW845926. Spores $8.5-11.8 \mu \mathrm{m}$ (av. $10.0 \mu \mathrm{m}$, SD $0.8 \mu \mathrm{m}$ ) $\times 5.0-7.0 \mu \mathrm{m}$ (av. $6.2 \mu \mathrm{m}$, SD $0.4 \mu \mathrm{m}) ; \mathrm{Q}=1.4-2.0$ (av. 1.6, SD 0.1) $(\mathrm{n}=$ 40), smooth, (sub)amygdaloid, with (sub)obtuse to (sub)acute apex. Basidia 4-spored. Pleurocystidia 53-75 $\mu \mathrm{m}$ (av. 63 $\mu \mathrm{m}$, SD $6 \mu \mathrm{m}) \times 12-17 \mu \mathrm{m}($ av. $15 \mu \mathrm{m}$, SD $2 \mu \mathrm{m}) ; \mathrm{Q}=$ 3.6-4.7 (av. 4.3, SD 1.5) ( $\mathrm{n}=15)$, mostly (sub)fusiform, also (sub)utriform or (sub)cylindrical, without or with only short neck and with short pedicel, apex usually crystalliferous, walls up to $1.5 \mu \mathrm{m}$ thick at the apex, pale yellowish-greenish with $3 \% \mathrm{KOH}$. Cheilocystidia similar in appearance and size. Paracystidia not observed. Caulocystidia only near the apex of the stipe, (sub)fusiform, (sub)lageniform or (sub)cylindrical, often somewhat deformed, apex usually crystalliferous, walls up to $1.0 \mu \mathrm{m}$ thick at the apex.

Selected other studied material: AUSTRIA, Tirol, Reutte, Höfen, cemetery, ÖK25V 2215-West, alt. 896 m, Pinus sylvestris, 29 Sep 2015, leg. D. Bandini; det. D. Bandini \& B. Oertel (DB29-9-15-1). GERMANY, BadenWürttemberg, Rhein-Neckar-Kreis, Nähe Epfenbach, TK25 6619/1, alt. 275 m, Pinus sp., Fagus sylvatica, Quercus robur, Carpinus betulus, 30 Oct 2016, leg. D. Bandini; det. D. Bandini \& B. Oertel (DB30-10-16-3). Rheinland-Pfalz, Rhein-Pfalz-Kreis, Nähe Dudenhofen, TK25 6616/3, alt. 105 m, Pinus sylvestris, Quercus robur, Corylus avellana, 3 Oct 2017, leg. D. Bandini; det. D. Bandini \& B. Oertel (DB310-17-11). NETHERLANDS, Friesland, Ameland, Buren, alt. 6 m, Pinus sylvestris, 18 Sep 2011, leg. D. Bandini; det. D. Bandini \& B. Oertel (KR-M-0038015, DB18-9-11-1).

Comments: Descriptions of I. griseotarda can be found in Poirier (2002), Bizio et al. (2017) and Bandini and Huijser (2017). The ITS holotype of I. griseotarda (GenBank MF361839) was published by Bizio et al. (2017). The sequences of the types of $I$. psammobrunnea and I. griseotarda hardly differ ( 2 bp different and 5 ambiguities in the type sequence of I. psammobrunnea, matching unambiguous reads in I. griseotarda). The synonymization of the two species was based on sequence similarity and on the comparison of the original descriptions, including the watercolour of I. psammobrunnea in Bon (1990). Further, morphological analysis of our own collections shows that it is not possible to find constant differences that could sustain a distinction between the two taxa.
Inocybe pseudorubens Carteret \& Reumaux, Boll. Gruppo Micol. 'G. Bresadola' (Trento) 44(3): 34 (2001) Fig. 26 f, h

= Inocybe rubidofracta E. Ferrari, Fungi Non Delineati, Raro vel Haud Perspecte et Explorate Descripti aut Definite Picti 54-55: 56 (2010)

Description of the species: Carteret and Reumaux 2001; Ferrari 2010 (as 'I. rubidofracta').

Studied material (isotype of I. pseudorubens), Fig. $26 \mathrm{f}$ : FRANCE, forest of Belval (Ardennes), Betulus, Corylus, Carpinus, Populus tremula, 18 Aug 2000, leg. P. Reumaux (XC2000-103). GenBank: ITS $=$ MW845952. Spores 7.7$11.1 \mu \mathrm{m}$ (av. $9.3 \mu \mathrm{m}$, SD $0.7 \mu \mathrm{m}) \times 4.2-5.5 \mu \mathrm{m}$ (av. 4.7 $\mu \mathrm{m}$, SD $0.3 \mu \mathrm{m}) ; \mathrm{Q}=1.7-2.3($ av. 2.0, SD 0.2) $(\mathrm{n}=40)$, smooth, oblong subamygdaloid, subellipsoid, with (sub)conical to subpapillate apex. Basidia 4-spored. Pleurocystidia $40-57 \mu \mathrm{m}$ (av. $47 \mu \mathrm{m}$, SD $5 \mu \mathrm{m}) \times 9-13$ $\mu \mathrm{m}$ (av. $11 \mu \mathrm{m}, \mathrm{SD} 1 \mu \mathrm{m}) ; \mathrm{Q}=3.6-5.8$ (av. 4.5, SD 0.6) (n $=15$ ), (sub)fusiform or subutriform, apex usually crystalliferous, walls up to $1.5(2.0) \mu \mathrm{m}$ thick at the apex, pale yellowish-greenish with $3 \% \mathrm{KOH}$. Cheilocystidia similar in appearance and size. Paracystidia not observed. Caulocystidia not studied, because stipe not present.

Holotype of I. rubidofracta, Fig. 26 h: Italy, Masserano (Biella), Baragge, alt. ca. $300 \mathrm{~m}$, Alnus, on loamy humid soil with Corylus, Quercus, Carpinus, 31 Oct 2009, leg. D. Bolognini \& E. Ferrari (Tr-gmb-00980). GenBank: ITS = MW845927. Spores 8.9-10.7 $\mu \mathrm{m}$ (av. $9.7 \mu \mathrm{m}$, SD $0.5 \mu \mathrm{m}$ ) $\times 4.5-5.8 \mu \mathrm{m}$ (av. 5.2 $\mu \mathrm{m}$, SD $0.3 \mu \mathrm{m}$ ); Q = 1.6-2.1 (av. 1.9, SD 0.1) $(n=40)$, smooth, oblong, subamygdaloid to almost laceroid, mostly with (sub)papillate apex. Basidia 4-spored. Pleurocystidia 50-64 $\mu \mathrm{m}($ av. $57 \mu \mathrm{m}$, SD $5 \mu \mathrm{m}) \times 9-13 \mu \mathrm{m}$ (av. $10 \mu \mathrm{m}, \mathrm{SD} 1 \mu \mathrm{m}) ; \mathrm{Q}=4.7-7.0($ av. 5.6, $\mathrm{SD} 0.7)(\mathrm{n}=15)$, mostly (sub)cylindrical, also subfusiform to subutriform, sometimes subcapitate, without or with only short pedicel, apex usually crystalliferous, walls up to $1.5(2.0) \mu \mathrm{m}$ thick at the apex, pale yellowish-greenish with $3 \% \mathrm{KOH}$. Cheilocystidia similar in appearance and size. Paracystidia not observed. Caulocystidia only near the apex of stipe, (sub)fusiform to (sub)utriform, somewhat shorter than hymenial cystidia.

Selected other studied material: GERMANY, BadenWürttemberg, Rhein-Neckar-Kreis, Wiesenbach, TK25 6618/2, alt. 180 m, Fagus sylvatica, Quercus robur, 24 Oct 2011, leg. D. Bandini; det. D. Bandini \& B. Oertel (KR-M-0043231, DB24-10-11-2).- BadenWürttemberg, Karlsruhe, Erzbergerstr., TK25 6916/3, alt. 118 m, Quercus robur, Fagus sylvatica, Betula pendula, 2 Jun 2013, leg./det. D. Bandini \& B. Oertel (DB2-6-13-8).

Comments: The synonymization is based on morphology and molecular data: The microscopic characters of the types of the two species match. The ITS sequences of the types (only ITS2 exists for I. pseudorubens) are identical. 
Inocybe pusio P. Karst., Bidr. Känn. Finl. Nat. Folk 48: 465 (1889) Fig. 26 g

Typification of I. pusio: FINLAND, Tavastia, Tammela, Mustiala, Syriä, side of path, 8 Aug 1889, leg. P.A. Karsten (1889). This was a mixed collection. H-6006856 (part 1608a) designated here as lectotype (MBT 10000534).

Description of the species: Karsten 1889; Kuyper 1986.

Studied material (lectotype), Fig. 25 g. Spores $8.2-$ $10.2 \mu \mathrm{m}$ (av. $9.2 \mu \mathrm{m}$, SD $0.4 \mu \mathrm{m}) \times 4.5-5.9 \mu \mathrm{m}$ (av. 5.4 $\mu \mathrm{m}, \mathrm{SD} 0.3 \mu \mathrm{m}) ; \mathrm{Q}=1.6-2.0($ av. 1.7, SD 0.1) $(\mathrm{n}=40)$, smooth, (sub)amygdaloid, mostly without suprahilar depression, with (sub)acute apex. Basidia 4-spored. Pleurocystidia 43-70 $\mu \mathrm{m}$ (av. $55 \mu \mathrm{m}$, SD $7 \mu \mathrm{m}) \times 17-25 \mu \mathrm{m}$ (av. $21 \mu \mathrm{m}$, SD $3 \mu \mathrm{m}) ; \mathrm{Q}=2.3-3.1$ (av. 2.6, SD 0.2) $(\mathrm{n}=15)$, mostly ventricose fusiform, without or with only short neck, with short pedicel, apex usually crystalliferous, walls up to 2.0 (2.5) $\mu \mathrm{m}$ thick at the apex, pale yellowish-greenish with $3 \%$ $\mathrm{KOH}$. Cheilocystidia similar in appearance and size. Paracystidia not observed. Caulocystidia not studied (to preserve the material).

Comments: When Kuyper studied the material, he apparently divided the original type material without formally assigning a lectotype (Kuyper 1986). We agree with Kuyper that one part (currently labeled 'Type A') agrees with the original description (for 'Type B', see above comments to I. conformata). This part is here selected as lectotype (sequencing not permitted). There are many descriptions of I. pusio in the literature; however, it remains somewhat doubtful, whether I. pusio is described, and not one of the other species with lilac stipes, as for instance I. knautiana, since the microscopic characters of $I$. pusio are quite distinctive with rather ventricose fusiform cystidia, with an average width of $21 \mu \mathrm{m}$. This feature is not present in descriptions, where microdetails are given (e.g. Stangl 1989; Breitenbach and Kränzlin 2000; Ludwig 2017). Sequences of various taxa have been published under the name of I. pusio. Based on material we have seen, the concept of I. pusio of S. Jacobsson and J. Vauras seems to correspond to the type. In Fig. 1, it is represented by two sequences of their material.

Inocybe rivierana Bandini \& B. Oertel sp. nov. Fig. 18 MycoBank number: MB 839166

Etymology: Named 'rivierana' because the species was found near a place called 'Riviera' by local people.

Diagnosis: Inocybe rivierana has a reddish (dark) brown minutely verrucose-squamulose surface of pileus with age, subdistant thickish lamellae, a stipe being roughly pruinose in the upper third, and mostly even though sparely also below the middle, smooth spores, measuring 8.7-12.2 $\mu \mathrm{m}$ (av. 10.2 $\mu \mathrm{m}) \times 5.6-7.6 \mu \mathrm{m}($ av. $6.4 \mu \mathrm{m})$ and quite long and (sub)cylindrical hymenial cystidia often with somewhat undate walls, pleurocystidia measuring 56-91 $\mu \mathrm{m}$ (av. 73 $\mu \mathrm{m}) \times 10-16 \mu \mathrm{m}($ av. $13 \mu \mathrm{m})$. By the combination of the named characteristics as well as by ITS sequence data, it differs from other in some way similar brown species, such as I. tenuicystidiata or the distantly genetically related I. catalaunica.

Holotype: AUSTRIA, Oberösterreich, Braunau am Inn, Oberrothenbuch, 'Riviera', ÖK25V 3321-Ost, alt. 355 m, Corylus avellana, Fagus sylvatica, Picea abies, $24 \mathrm{Jul} 2018$, leg. D. Bandini (holotype STU SMNS-STU-F-0901249; isotype priv. herb. D.B. DB24-7-18-16). GenBank: ITS + partial LSU = MW845910.

Description: Pileus 10-25 mm wide, at first subconical, later broadly convex to expanded, with large umbo, margin at first more or less incurved to decurved, later straight to uplifted, and then pileus depressed around the umbo; no remnants of a velipellis observed; colour reddish brown to dark reddish brown (Mu 5YR 4/4-4/6, 3/3-3/6; 7.5YR 3/4), usually somewhat darker at the centre; surface at first glabrous, then minutely warty especially at the centre, outwards slightly verrucose to finely (sub)squamulose, sometimes also finely split into very small pieces; no remnants of a cortina observed. Lamellae (sub)distant (ca. 35-45, 1 = 1-3), thickish, narrowly adnate, ventricose, at first whitish, whitish with greyish hue, later greyish-brownish with ochraceous hue; edge fimbriate, whitish. Stipe 15-30 × 1-3 mm, cylindrical or slightly curved, when young covered with whitish tomentum, later longitudinally striate or glabrous, at first whitish, soon pale strawcoloured to pale brownish; roughly pruinose in the upper third of the stipe, but mostly even though sparely also below the middle of the stipe. Context whitish in the pileus and the stipe. Smell subspermatical or faintly aromatical, at least when cut. Colour of exsiccata pileus dark brown with reddish hue $(\mathrm{Mu}$ 7/5YR 3/4; 5YR 3/3-3/4, 4/4-4/6), lamellae and stipe concolorous or a little lighter in colour, no darkening or blackening on drying.

Spores 8.7-12.2 $\mu \mathrm{m}$ (av. $10.2 \mu \mathrm{m}$, SD $0.7 \mu \mathrm{m}) \times 5.6-$ $7.6 \mu \mathrm{m}$ (av. $6.4 \mu \mathrm{m}$, SD $0.3 \mu \mathrm{m}$ ); Q = 1.3-1.9 (av. 1.6, SD $0.1)$ ( $\mathrm{n}=120$ of 3 coll.); smooth, mostly broadly (sub)amygdaloid, seldom almost subnodulose, without or with only faint suprahilar depression, apex subacute, subobtuse, sometimes subpapillate. Basidia 23-28 × 7-10 $\mu \mathrm{m}$, in all collections 4 -spored and 2 -spored. Lamellae edges sterile, composed of cheilocystidia and numerous colourless, (sub)clavate to (sub)cylindrical, sometimes catenate, thinwalled paracystidia. Pleurocystidia 56-91 $\mu \mathrm{m}$ (av. $73 \mu \mathrm{m}$, SD $8 \mu \mathrm{m}) \times 10-16 \mu \mathrm{m}($ av. $13 \mu \mathrm{m}$, SD $1 \mu \mathrm{m}) ; \mathrm{Q}=4.4-7.7$ (av. 5.8, SD 0.8) ( $\mathrm{n}=45$ of 3 coll.), mostly long and narrow (sub)cylindrical, very often with somewhat undate walls, sometimes subcapitate, without neck, at the apex generally wide, without or with only short pedical, apex usually crystalliferous, walls up to $1.5(2.0) \mu \mathrm{m}$ thick at the apex, yellowish-greenish with $3 \% \mathrm{KOH}$. Cheilocystidia similar in appearance and size. Pileipellis constituted by an epicutis made up of parallel hyphae 5-12 $\mu \mathrm{m}$ wide, with encrusting 

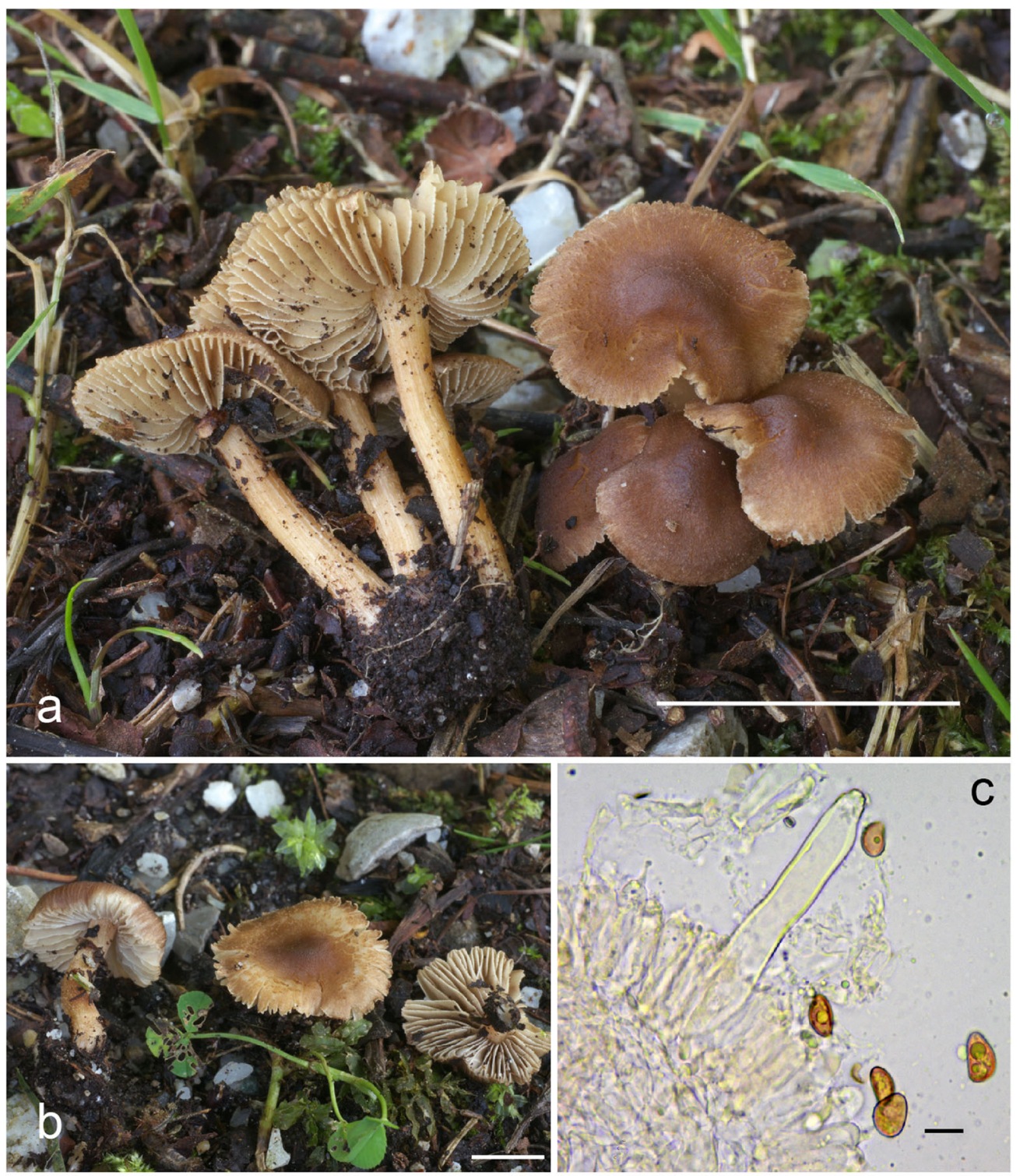

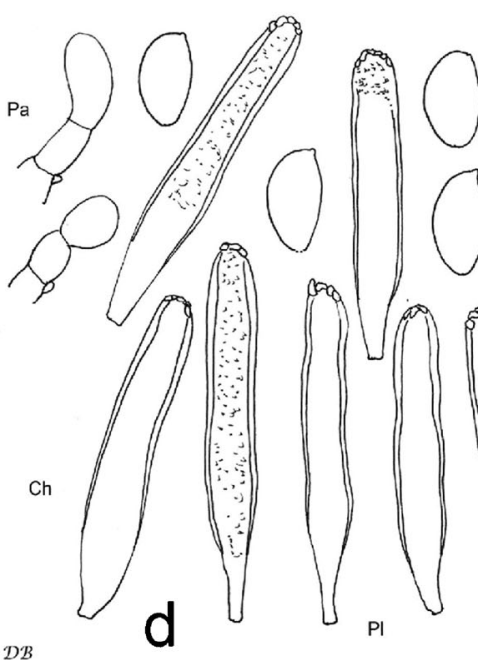

Fig. 18 Inocybe rivierana, a holotype, scale bar: $1 \mathrm{~cm}$. b Coll. DB24-718-18, scale bar: $1 \mathrm{~cm}$. c Cheilocystide (holotype), scale bar: $10 \mu \mathrm{m}$. d Microscopical characters (holotype), $\mathrm{Ca}=$ Caulocystidia, $\mathrm{Cpa}=$
Cauloparacystidia, $\mathrm{Ch}=$ Cheilocystidia, $\mathrm{Pa}=$ Paracystidia, $\mathrm{Pl}=$ Pleurocystidia, $\mathrm{Sp}=$ Spores; scale bar spores: $10 \mu \mathrm{m}$, scale bar cystidia: $50 \mu \mathrm{m}$. e Spores (coll. DB24-7-18-18), scale bar: $10 \mu \mathrm{m}$ 
and parietal dark brown pigment, subcutis with wider and paler to colourless elements. Caulocystidia in the upper third, but mostly, though sparely, also in the lower half of the stipe, 50-85 $\times 10-15 \mu \mathrm{m}$, usually (sub)cylindrical, without neck and only short pedicel, apex usually crystalliferous, walls up to $1.0(1.5) \mu \mathrm{m}$ thick at the apex, yellowish-greenish with $3 \%$ $\mathrm{KOH}$; intermixed with numerous (sub)clavate to subglobose cauloparacystidia. Clamp-connections abundant in all tissues.

Habitat and known distribution: Our own collections are from the banks of the river Inn in Austria. There is only one sequence of another collection in UNITE database putatively of the same species, from Estonia (as 'I. muricellata', UDB024657) and there are sequences of soil samples, also from Estonia, which may belong to this species. We are not aware of any other sequences or collections of I. rivierana.

Further collections studied: AUSTRIA, Oberösterreich, Braunau am Inn, Oberrothenbuch, in some distance from holotype location, alt. $357 \mathrm{~m}$, Corylus avellana, Fagus sylvatica, Picea abies, 24 Jul 2018, leg. D. Bandini; det. D. Bandini \& B. Oertel (STU SMNS-STU-F-0901502; DB 24-7-18-18). Oberösterreich, Braunau am Inn, Überackern, alt. 360 m, Fagus sylvatica, Picea abies, 24 Jul 2018, leg. D. Bandini; det. D. Bandini \& B. Oertel (STU SMNS-STU-F-0901503; DB 24-7-18-19).

Comments: Inocybe rivierana is characterized by a reddish (dark) brown pileus becoming minutely verrucosesquamulose with age, (sub)distant thickish lamellae, the mostly also in the lower half (sparely) pruinose stipe, spores that on average are longer than $10 \mu \mathrm{m}$ and rather long and (sub)cylindrical hymenial cystidia often with somewhat undate walls. Because of the shape of the hymenial cystidia, I. rivierana might be mistaken for I. tenuicystidiata E. Horak \& Stangl (Horak and Stangl 1980), a very frequent species at least in Germany (personal observation, and see discussion below), which differs from I. rivierana e.g. by the ample whitish-greyish velipellis when young, the only near the apex pruinose stipe, smaller spores and shorter hymenial cystidia with often decidedly undate walls, while $I$. obscurobadia also has smaller spores and clearly shorter hymenial cystidia with often subcapitate apex (see Fig. 25 e). Inocybe griseovelata also has (sub)cylindrical hymenial cystidia, but usually without somewhat undate walls. Furthermore, it has a greyish velipellis and often pinkish tinges near the apex of the stipe (Kühner 1955, and personal observation). Inocybe grusiana differs, e.g. by a greyish velipellis and (sub)utriform or (sub)lageniform hymenial cystidia sometimes with truncate base. We are not aware of any species similar in the ITS to I. rivierana. Inocybe muricellata Bres. (i.e. the original identification of the above mentioned Estonian collection referred to I. rivierana) differs by usually paler brown pileus colours, often with an orange-red hue, abundant pruina also in the lower half of the stipe, smaller spores and mostly (sub)fusiform hymenial cystidia (Bresadola 1905; Kuyper 1986; Stangl 1989, and personal observation). We are not aware of any molecularly closely related described species. With $91 \%$ identity in the ITS, I. catalaunica Singer is only distantly related. It differs from I. rivierana by an ample whitish-greyish velipellis, the often more felty or feltylanose surface of the pileus and smaller spores (Singer 1947; Larsson et al. 2014, and personal observation).

\section{Inocybe rubidofracta (Fig. 26h) $\rightarrow$ Inocybe pseudorubens}

Inocybe scolopacis Bandini \& B. Oertel sp. nov. Fig. 19 MycoBank number: MB 839167

Etymology: Named 'scolopacis' after the Eurasian woodcock (Scolopax rusticola) because the species is well camouflaged among similar species as the bird is camouflaged in its habitat.

Diagnosis: Inocybe scolopacis has a rather dark brown smooth to rimose pileus surface, only near the apex pruinose stipe, often oblong smooth spores, measuring 8.3-11.8 $\mu \mathrm{m}$ (av. $9.6 \mu \mathrm{m}) \times 4.3-6.0 \mu \mathrm{m}$ (av. $5.2 \mu \mathrm{m}$ ), generally rather narrow subfusiform hymenial cystidia, pleurocystidia measuring 46-84 $\mu \mathrm{m}$ (av. $64 \mu \mathrm{m}) \times 11-21 \mu \mathrm{m}$ (av. $14 \mu \mathrm{m})$, and mostly somewhat misshaped subfusiform to sublageniform caulocystidia with undate walls. This combination of characters as well as ITS sequence data distinguishes I. scolopacis from all described species, including other brown species such as I. plurabellae or I. virgatula.

Holotype: GERMANY, Bayern, Kirchdorf am Inn, Hitzenau, TK25 7743/2, alt. 435 m, Picea abies, 15 Aug 2014, leg. D. Bandini \& J. Christan (holotype STU SMNS-STU-F-0901527; isotype priv. herb. D.B. DB15-814-10). GenBank: ITS + partial LSU = MW845913.

Description: Pileus $15-40 \mathrm{~mm}$ wide, at first (sub)campanulate or subconical, later broadly convex or expanded, with or without more or less pronounced large umbo, margin at first strongly incurved, later decurved to straight; young basidiomata with whitish to pale greyish remnants of a velipellis; colour rather dark brown (Mu 10YR 4/2-4/6; 7.5YR 4/3-4/6), sometimes somewhat paler in some parts due to remnants of the velipellis, and often somewhat darker brown at the centre; surface at first smooth and glabrous, with age finely rimulose to strongly rimose with diverging fibres; young basidiomata with ample remnants of a whitish cortina, often pending as white rim from the margin. Lamellae moderately crowded (ca. 40-50, 1 = 1-3), adnate to broadly adnate, even to subventricose, at first whitish, then greyish to greyishbrownish; edge uneven fimbriate, whitish. Stipe 30-70 $\times 2-5$ $\mathrm{mm}$, cylindrical or curved, sometimes slightly widening towards the base, when young covered with whitish tomentum, later longitudinally striate or glabrous, at first dingy beige, faintly brownish, later wood-coloured to brownish; pruinose only near the apex of the stipe. Context watery whitish in the 

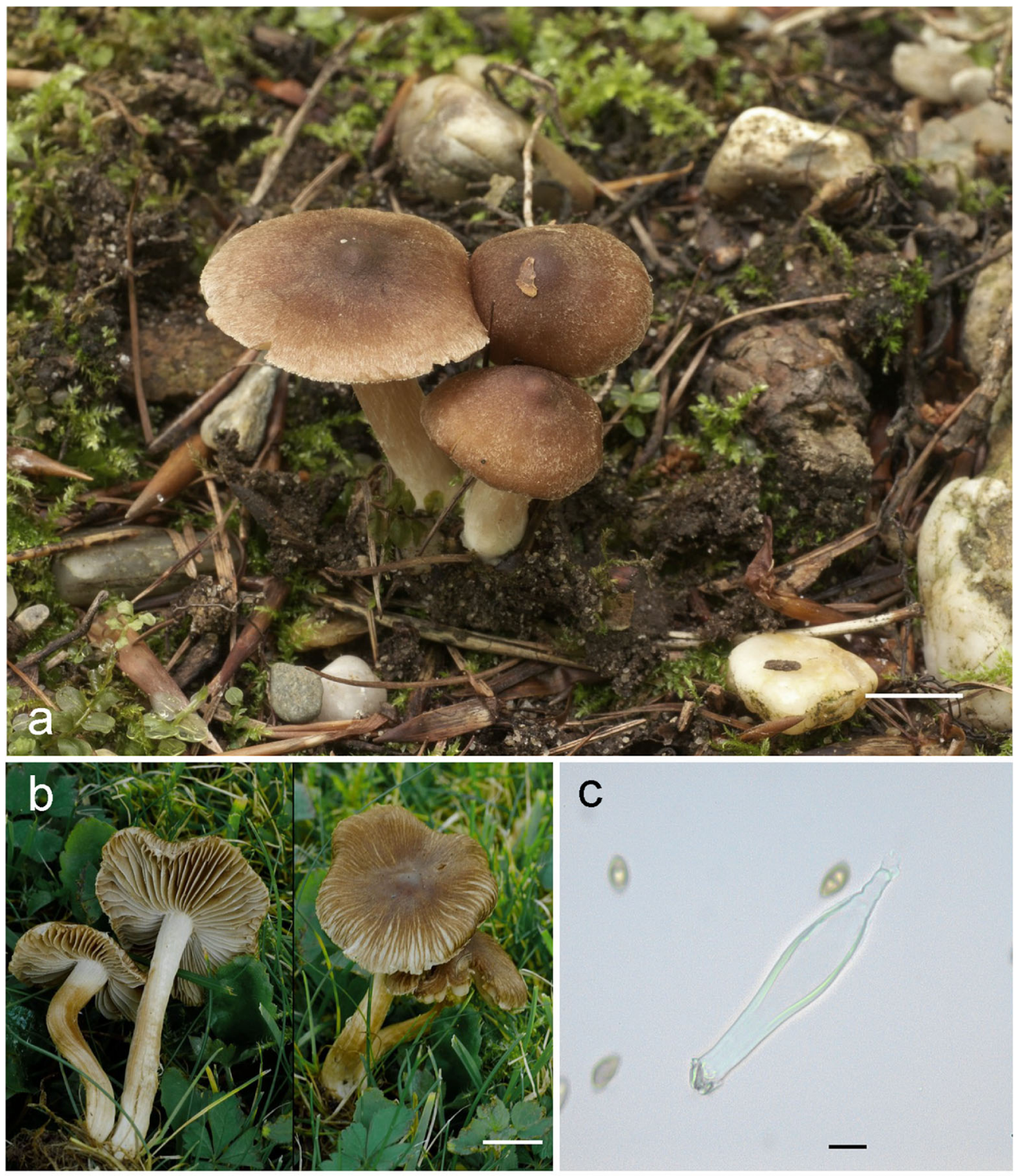

C

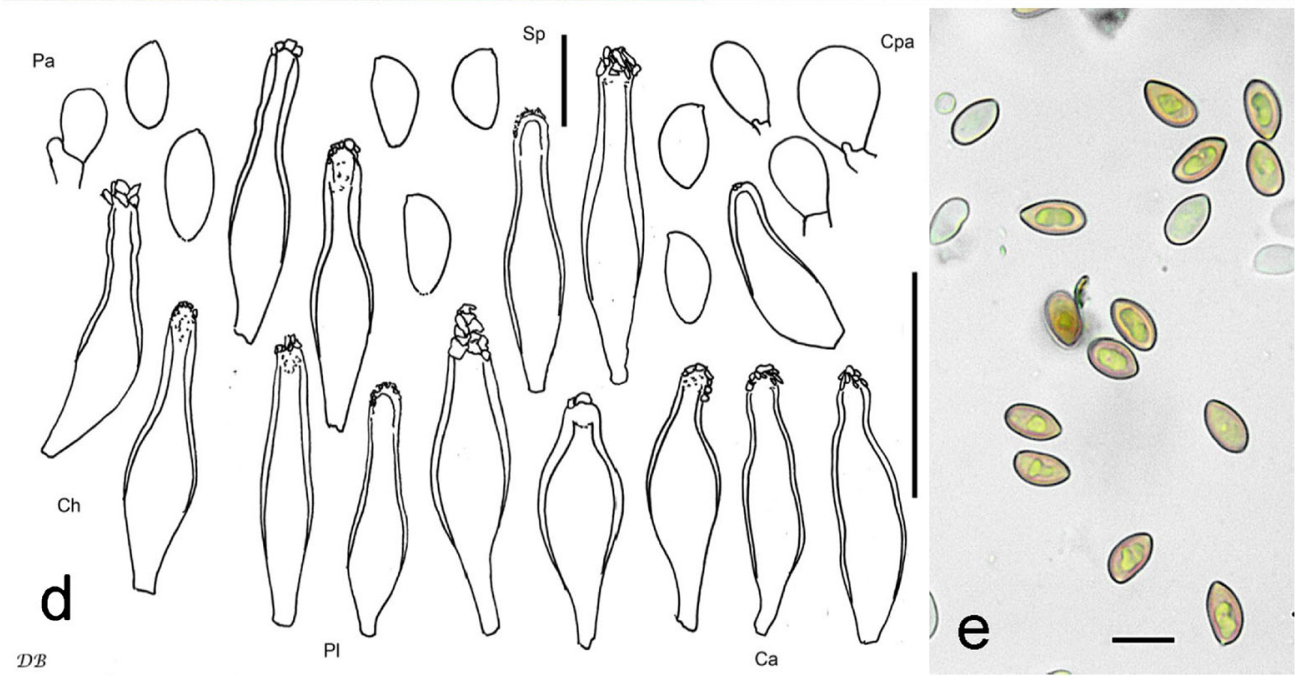

Fig. 19 Inocybe scolopacis, a holotype, scale bar: $1 \mathrm{~cm}$. b Coll. DB13-811-12, scale bar: $1 \mathrm{~cm}$. c Cheilocystide (holotype), scale bar: $10 \mu \mathrm{m}$. d

Cauloparacystidia, $\mathrm{Ch}=$ Cheilocystidia, $\mathrm{Pa}=$ Paracystidia, $\mathrm{Pl}=$ Microscopical characters (holotype), $\mathrm{Ca}=$ Caulocystidia, $\mathrm{Cpa}=$ Pleurocystidia, $\mathrm{Sp}=$ Spores; scale bar spores: $10 \mu \mathrm{m}$, scale bar cystidia: $50 \mu \mathrm{m}$. e Spores (holotype), scale bar: $10 \mu \mathrm{m}$ 
pileus, striate brownish to pale reddish in the cortex of the stipe. Smell subnull or subspermatical, at least when cut. Colour of exsiccata pileus brown to dark brown with reddish or coppery hue or dark brown (Mu 7/5YR 4/2-4/6, 3/4; $10 \mathrm{YR}$ 3/4-3/6) lamellae and stipe concolorous or a little lighter in colour, no darkening or blackening on drying.

Spores $8.3-11.8 \mu \mathrm{m}$ (av. 9.6 $\mu \mathrm{m}$, SD $0.6 \mu \mathrm{m}) \times 4.3-$ $6.0 \mu \mathrm{m}$ (av. $5.2 \mu \mathrm{m}$, SD $0.3 \mu \mathrm{m}$ ); Q = 1.4-2.4 (av. 1.9, SD 0.2 ) ( $\mathrm{n}=120$ of 3 coll.); smooth, (sub)amygdaloid, in some collections rather oblong, often with more or less explicit suprahilar depression, apex subacute, subobtuse, with indistinct pseudoporus. Basidia 25-29 × 7-9 $\mu \mathrm{m}$, generally 4spored, seldomly also 2 -spored. Lamellae edges sterile, composed of cheilocystidia and numerous colourless, (sub)clavate thin-walled paracystidia. Pleurocystidia 46-84 $\mu \mathrm{m}$ (av. 64 $\mu \mathrm{m}$, SD $8.5 \mu \mathrm{m}) \times 11-21 \mu \mathrm{m}$ (av. $14 \mu \mathrm{m}$, SD $2.8 \mu \mathrm{m}) ; \mathrm{Q}=$ 2.5-7.1 (av. 4.6, SD 1.1) ( $\mathrm{n}=45$ of 3 coll.), mostly narrow subfusiform, but in some collections also ventricose (sub)utriform, with short or longer and then sometimes somewhat undate neck, at the apex generally wide, usually with short pedicel, apex usually crystalliferous, walls up to 2.0 (2.5) $\mu \mathrm{m}$ thick at the apex, yellowish-greenish with $3 \%$ $\mathrm{KOH}$. Cheilocystidia similar in size, but somewhat more variable in shape. Pileipellis constituted by an epicutis made up of parallel hyphae 5-12 $\mu \mathrm{m}$ wide, with encrusting and parietal brownish to dark brown pigment, subcutis with wider and paler to colourless elements. Caulocystidia only near the apex of the stipe, $40-70 \times 10-15 \mu \mathrm{m}$, usually somewhat misshaped subfusiform or sublageniform with undate walls and short often clearly demarcated neck, without or with only short pedicel, apex crystalliferous or not, walls up to $1.0 \mu \mathrm{m}$ thick at the apex, yellowish-greenish with $3 \% \mathrm{KOH}$; intermixed with numerous (sub)clavate to subglobose cauloparacystidia.

Clamp-connections abundant in all tissues.

Habitat and known distribution: All own collections are from Germany or the Netherlands with conifers on calcareous soil, sometimes in pure sand with Pinus sylvestris on the Dutch island of Ameland, but also on pebbled pathsides in mountainous regions. Apart from these collections, there is a sequence from another collection from Germany (SchleswigHolstein) in GenBank (as 'I. sp.', with Picea omorika, KR-M0048249), and two other sequences in UNITE database from Estonia (as 'I. nitidiuscula', UDB017920 and as 'I. aeruginascens', UDB017934) putatively belonging to I. scolopacis. Furthermore, there is an EcM sequence in GenBank, which may be formed by I. scolopacis from Great Britain (with Pinus sylvestris, MF352729). Soil sample sequences are to be found in GenBank from Alaska (KC966278) and from Greenland (MF181108) and in UNITE soil sample sequences from Estonia. Based on current evidence, the species is associated with conifers, often with Pinus.
Further collections studied: GERMANY, Bayern, Miesbach, Darching, Fentberg, TK25 8136/2, alt. 680 m, Abies alba, Picea abies, Fagus sylvatica, 28 Jul 2012, leg. M. Dondl; det. D. Bandini \& B. Oertel (STU SMNS-STUF-0901529; DB28-7-12-2-Dondl). Bayern, Berchtesgadener Land, Berchtesgaden, TK25 8344/3, alt. 580 m, Pinus sp. on lawn, 13 Aug 2013, leg./det. D. Bandini \& B. Oertel (DB138-11-12). Rheinland-Pfalz, Rhein-Pfalz-Kreis, BöhlIggelheim, TK25 6615/4, alt. 110 m, Pinus sylvestris, Quercus robur, Alnus glutinosa, Corylus avellana, 9 Aug 2014, leg. D. Bandini; det. D. Bandini \& B. Oertel (DB9-8-14-9). NETHERLANDS, Friesland, Ameland, Hollum, alt. 5 m, Pinus sylvestris, 6 Oct 2014, leg. D. Bandini; det. D. Bandini \& B. Oertel (STU SMNS-STU-F0901528; DB 6-10-14-2). Ibidem, in some distance from former location, Pinus sylvestris, 9 Oct 2014, leg. D. Bandini; det. D. Bandini \& B. Oertel (DB9-10-14-10).

Comments: Inocybe scolopacis is characterized by a dark brown pileus with a smooth to rimose pileus surface, smooth often oblong spores, mostly rather narrow subfusiform hymenial cystidia and mostly somewhat misshaped subfusiform to sublageniform caulocystidia with undate walls. It may at the first glance be mistaken for several brown species such as I. virgatula, which species differs, e.g. by on average wider mostly neckless subfusiform hymenial cystidia and not misshaped subfusiform caulocystidia (Kühner 1955). Inocybe derbschii has a more felty to innately fibrillose surface of pileus with age, on average wider spores and shorter hymenial cystidia (see Schwöbel and Stangl 1982; Bandini et al. 2019b), I. griseovelata differs, e.g. by often (sub)cylindrical hymenial cystidia and larger spores as well as longer and narrower caulocystidia (Kühner 1955), I. plurabellae, e.g. by usually somewhat roughened pileus surface, on average wider spores, more heterogeneous shaped and on average shorter hymenial cystidia and long and narrow caulocystidia. Inocybe perchtana is more reddish tinged in colour, the velipellis is whitish, the stipe is entirely pruinose and may redden when bruised and the spores on average are shorter (Bandini et al. 2020a). Inocybe nitidiuscula and I. involuta usually have a more reddish tinged pileus colour, too, and the spores on average are larger (Britzelmayr 1891; Stangl 1983, 1989; Kuyper 1986, 1989; Marchetti et al. 2014; Bandini et al. 2020a, 2020c), while I. beatifica has a finer textured pileus surface, an entirely pruinose stipe and on average larger spores. Inocybe alberichiana differs, e.g. by generally more reddish tinged pileus colour, on average shorter, but wider spores, and long and narrow caulocystidia. We are not aware of any species that is genetically closely or even somewhat distantly related to I. scolopacis.

Inocybe semifulva Grund \& D.E. Stuntz, Mycologia 73(4): 659 (1981) Fig. 25 g 
= Inocybe obscuromellea Poirier, Docums Mycol. 31(no. 124): 4 (2002)

Description of the species: Grund and Stuntz 1981; Poirier 2002 (as 'I. obscuromellea'); Bandini 2014.

Studied material (holotype of I. obscuromellea), Fig. 25 g: FRANCE, Domaine des Barres, Nogent-sur-Vernisson, Loiret, on calcareous soil with frondose trees, leg. J. Poirier (G00052210). Spores 8.5-11.2 $\mu \mathrm{m}$ (av. $9.8 \mu \mathrm{m}$, SD $0.5 \mu \mathrm{m}$ ) $\times 4.8-5.7 \mu \mathrm{m}$ (av. 5.2 $\mu \mathrm{m}$, SD $0.2 \mu \mathrm{m}$ ); Q = 1.7-2.1 (av. 1.9, SD 0.1) $(n=40)$, smooth, (sub)amygdaloid, with (sub)acute apex. Basidia 4-spored. Pleurocystidia 54-67 $\mu \mathrm{m}$ (av. 60 $\mu \mathrm{m}$, SD $4 \mu \mathrm{m}) \times 10-14 \mu \mathrm{m}($ av. $13 \mu \mathrm{m}$, SD $1 \mu \mathrm{m}) ; \mathrm{Q}=$ 4.2-5.6 (av. 4.8, SD 0.5) $(\mathrm{n}=15)$, (sub)fusiform or (sub)cylindrical, without or with only short neck, sometimes subcapitate, apex usually crystalliferous, walls up to 2.0 (2.5) $\mu \mathrm{m}$ thick at the apex, but mostly uniformly thick at bulge and neck, pale yellowish-greenish with $3 \% \mathrm{KOH}$. Cheilocystidia similar in appearance and size. Paracystidia not observed. Caulocystidia not studied (to preserve the material).

Selected other material studied: FRANCE, BaraqueChaalis, forêt d' Ėrmenonville (Oise), frondose trees, 17 Nov 2013, leg. P. Lainé; det. D. Bandini \& B. Oertel (SMNS-STU-F-0901450, DB17-11-13-Lainé). GERMANY, Baden-Württemberg, Rhein-Neckar-Kreis, Wiesenbach, TK25 6618/2, alt. 160 m, Salix caprea, Prunus spinosa, 28 Aug 2014, leg. D. Bandini; det. D. Bandini \& B. Oertel (SMNS-STU-F-0901000, DB28-8-14-4).

Comments: We did not have the opportunity to sequence the type of I. obscuromellea, but based on the morphological observations on the type and the description of I. obscuromellea as well as examination of own collections of I. semifulva, for which a type-sequence has been published in GenBank (see Fig. 1), we consider I. obscuromellea a later synonym of I. semifulva. The occasional occurrence of subcapitate hymenial cystidia with walls that are often uniformly thick at bulge and neck is a typical feature of I. semifulva (see Bandini 2014). The differences between the type sequence of I. semifulva and the sequences from own collections are 2 or $4 \mathrm{bp}$, respectively. Apart from the North American continent and Europe, based on available sequence data, the species may also occur in New Zealand (KM522817, Bogar et al. 2015) and South America (MH930387, A.B. Mujic and M.E. Smith, M.E. direct submission 18 Sep 2018).

Inocybe sindonia (Fr.) P. Karst., Bidr. Känn. Finl. Nat. Folk 32: 465 (1879)

= Inocybe clarkii (Berk. \& Broome) Sacc., Syll. fung. (Abellini) 5: 784 (1887)

Description of the species: Berkeley \& Broome (1873, as 'Agaricus clarkii'); Kuyper 1986; Stangl 1989; Ludwig 2017.

Studied material (holotype of I. clarkii), Fig. 23 d: Great Britain, Street, 20 Oct 1871 , leg. J.A. Clark (K(M):000173536). Spores 7.4-9.1 $\mu \mathrm{m}$ (av. $8.5 \mu \mathrm{m}$, SD 0.4 $\mu \mathrm{m}) \times 4.4-5.3 \mu \mathrm{m}$ (av. $4.8 \mu \mathrm{m}, \mathrm{SD} 0.2 \mu \mathrm{m}) ; \mathrm{Q}=1.5-2.0$ (av. 1.8, SD 0.1) ( $=40)$, smooth, oblong, with obtuse apex. Basidia 4-spored. Pleurocystidia 53-74 $\mu \mathrm{m}$ (av. $62 \mu \mathrm{m}$, SD $7 \mu \mathrm{m}) \times 11-18 \mu \mathrm{m}($ av. $14 \mu \mathrm{m}$, SD $2 \mu \mathrm{m}) ; \mathrm{Q}=3.6-5.5$ (av. 4.4, SD 0.6) $(\mathrm{n}=15)$, mostly (sub)fusiform or subutriform, apex usually crystalliferous, walls up to 2.0 (2.5) $\mu \mathrm{m}$ thick at the apex, pale yellowish-greenish with $3 \%$ $\mathrm{KOH}$. Cheilocystidia similar in appearance and size. Paracystidia not observed. Caulocystidia not studied (to preserve the material).

Selected other studied material: GERMANY, Rheinland-Pfalz, Rhein-Pfalz-Kreis, Böhl-Iggelheim, TK25 $6615 / 4$, alt. $110 \mathrm{~m}$, Pinus sylvestris, Betula pendula, Quercus robur, 29 Oct 2011, leg./det. D. Bandini \& B. Oertel (KR-M-0038268; DB29-10-11-6). Ibidem, in some distance from former location, alt. $110 \mathrm{~m}$, Pinus sylvestris, Fagus sylvatica, 29 Oct 2011, leg./det. D. Bandini \& B. Oertel (DB29-10-11-9). NETHERLANDS, Friesland, Ameland, Hollum, alt. 4 m, Pinus sylvestris, 4 Dec 2012, leg./det. D. Bandini (DB4-12-12-1).

Comments: Kuyper (1986) suspected that I. clarkii was a member of the geophylla-group, but this is not supported by the results of the re-examination of the type. Sequencing was not allowed, but we rather agree with the authors of the species (Berkeley and Broome 1873) that I. clarkii is 'allied' to I. sindonia. Inocybe sindonia, a very frequent and wellknown species at least in Germany and surrounding countries and has even been reported from exotic pine plantations in the southern hemisphere (Matheny and Bougher 2017) and may have been redescribed as I. diversa (Horak 2018; type material not seen) from New Zealand.

Inocbe sindonia is characterized by rather small oblong and narrow spores and slender (sub)fusiform to subutriform hymenial cystidia (see, e.g. Kuyper 1986, Stangl 1989, Ludwig 2017, and personal observation). Since spores and cystidia size and shape match those of I. sindonia and as we were not able to find any distinguishing characters, we consider the two species as conspecific and synonymize them here. Inocybe sindonia is represented in Fig. 1 by sequences from own material matching the type. The concept of I. sindonia applied here appears to be in consensus that with other Inocybe experts (see Fig. 1).

Inocybe sitibunda Bandini, B. Oertel \& U. Eberh. sp. nov. Fig. 20

\section{MycoBank number: MB 839168}

Etymology: Named 'sitibunda', from Latin sitibundus, 'demanding for moisture', because the species is often to be found in somewhat moist locations.

Diagnosis: Inocybe sitibunda is a rather small species with brown to dark brown, felty to felty-lanose pileus, with villose whitish fibres covered stipe that is lilac-violet at least at the apex when young, smooth spores, measuring 8.3-10.2 $\mu \mathrm{m}$ 

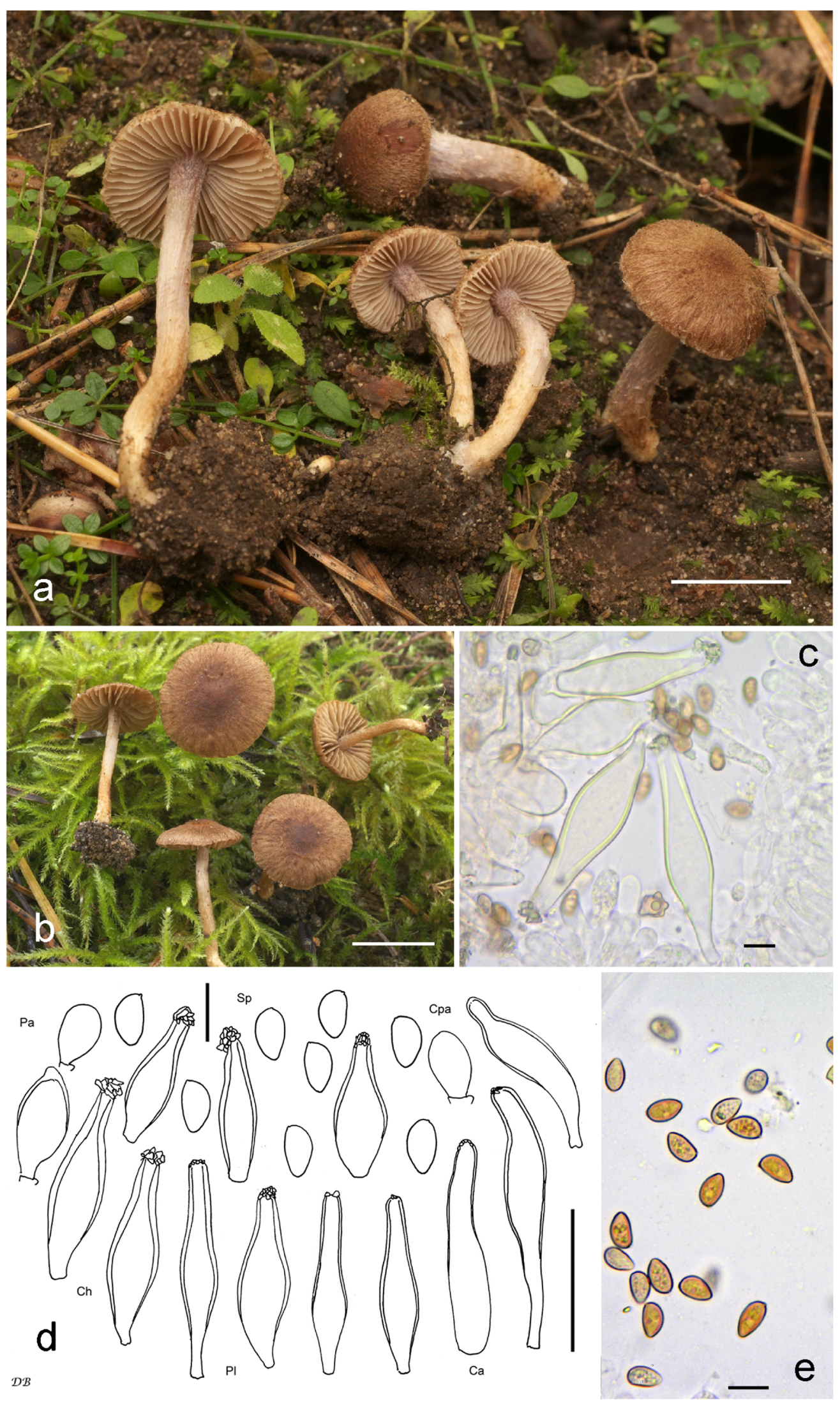

Fig. 20 Inocybe sitibunda, a holotype, scale bar: $1 \mathrm{~cm}$. b Coll. DB12-1017-12, scale bar: $1 \mathrm{~cm}$. c Cheilocystidia (holotype), scale bar: $10 \mu \mathrm{m}$. d Microscopical characters (holotype), $\mathrm{Ca}=$ Caulocystidia, $\mathrm{Cpa}=$

Cauloparacystidia, $\mathrm{Ch}=$ Cheilocystidia, $\mathrm{Pa}=$ Paracystidia, $\mathrm{Pl}=$ Pleurocystidia, $\mathrm{Sp}=$ Spores; scale bar spores: $10 \mu \mathrm{m}$, scale bar cystidia: $50 \mu \mathrm{m}$. e Spores (holotype), scale bar: $10 \mu \mathrm{m}$ 
(av. 9.2 $\mu \mathrm{m}) \times 4.7-5.7 \mu \mathrm{m}(\mathrm{av} .5 .1 \mu \mathrm{m})$ and mostly (sub)fusiform to (sub)utriform hymenial cystidia, pleurocystidia measuring 48-80 $\mu \mathrm{m}(\mathrm{av} .62 \mu \mathrm{m}) \times 10-18$ $\mu \mathrm{m}$ (av. $14 \mu \mathrm{m}$ ) and often misshaped long caulocystidia with undate walls at the extreme apex of the stipe. It often grows on somewhat moist terrain. This combination of characters as well as ITS sequence data distinguishes I. sitibunda from other species with lilac-pinkish stipes, such as I. drenthensis, with which species it is most similar (94\%) in the ITS.

Holotype: GERMANY, Rheinland-Pfalz, Rhein-PfalzKreis, Böhl-Iggelheim, TK25 6615/4, alt. 110 m, Tilia sp., Corylus avellana, Pinus sylvestris, Quercus robur, 10 Oct 2015, leg. D. Bandini (holotype STU SMNS-STU-F0901504; isotypes priv. herb. D. Bandini DB10-10-15-9, AH 56136, TUR-A 209196). GenBank: ITS + partial LSU = MW845918.

Description: Pileus 5-15 (20) $\mathrm{mm}$ wide, at first subglobose, (sub)campanulate to subconical, later broadly convex or expanded, without or with only low, but sometimes also with pronounced large umbo, margin sometimes at first slightly incurved, but mostly decurved, later decurved to straight; young basidiomata covered with a fugitive silvery greyish velipellis; colour vividly brown to dark brown, often with reddish hue (Mu 7.5YR 4/4 4/6; 10YR 3/4 3/2-3/ 4; 5YR 4/4-4/6, 3/3-3/4), mostly somewhat darker at the centre; surface finely to strongly felty, felty-lanose or lanose to villose-lanose with appressed fibres, with age also excoriated towards the margin; young basidiomata with remnants of a pale brownish cortina. Lamellae subdistant (ca. 20-35, $1=$ 1-3), rather thickish, adnate with (sub)decurrent tooth, (sub)ventricose, at first very pale greyish, then more or less intense greyish-brownish, with age intensely red-brown; edge strongly fimbriate, whitish. Stipe 20-40 × 1-3 mm, sometimes rather stout, cylindrical or curved, when young covered with villose-lanose dingy whitish fibres especially towards the base, older basidiomata reticulate or also (almost) glabrous, lilac-violet at least towards the apex, but sometimes also entirely in different intensity when young, often vanishing with age and then becoming dingy beige to yellowish-fleshcoloured, sometimes with violet tinge; pruinose only near the apex of the stipe. Context dingy whitish in the pileus, more or less intensely violet in the stipe, especially near the apex, sometimes paler in the cortex. Smell (sub)spermatical, at least when cut. Colour of exsiccata pileus dark brown with reddish hue (Mu 5YR 3/3-3/4; 7.5YR 3/4), lamellae and stipe a little lighter in colour, no darkening or blackening with drying.

Spores 8.3-10.2 $\mu \mathrm{m}$ (av. 9.2 $\mu \mathrm{m}$, SD $0.4 \mu \mathrm{m}) \times 4.7-$ $5.7 \mu \mathrm{m}$ (av. 5.1 $\mu \mathrm{m}, \mathrm{SD} 0.2 \mu \mathrm{m}$ ); $\mathrm{Q}=1.6-2.0$ (av. 1.8, SD 0.1 ) ( $n=120$ of 3 coll.), smooth, (sub)amygdaloid, without or with only faint suprahilar depression, apex subacute, subobtuse, in some collections with indistinct pseudoporus. Basidia 24-30 × 7-9 $\mu \mathrm{m}$, generally 4-spored. Lamellae edges sterile, composed of cheilocystidia and numerous colourless, (sub)clavate, thin-walled to slightly thick-walled paracystidia. Pleurocystidia $48-80 \mu \mathrm{m}$ (av. $62 \mu \mathrm{m}$, SD 7 $\mu \mathrm{m}) \times 10-18 \mu \mathrm{m}$ (av. $14 \mu \mathrm{m}$, SD $2 \mu \mathrm{m}) ; \mathrm{Q}=3.1-7.8$ (av. $4.6, \mathrm{SD} 0.9)$ ( $\mathrm{n}=45$ of 3 coll.); mostly (sub)fusiform to (sub)utriform, sometimes also (sub)lageniform, usually with rather long neck, sometimes with slightly undate walls, occasionally transition between bulge and neck clearly demarcated, with only short pedicel or with truncate or rounded base, at the apex generally wide, apex usually crystalliferous, walls up to 2.0 (3.0) $\mu \mathrm{m}$ thick at the apex, intensely yellow-green with $3 \% \mathrm{KOH}$. Cheilocystidia more variable in appearance and size. Pileipellis constituted by an epicutis made up of parallel hyphae 5-12 $\mu \mathrm{m}$ wide, with encrusting and parietal brown to dark brown pigment, subcutis with wider and paler to colourless elements. Caulocystidia only near the apex of the stipe, 50-80 × 10-15 $\mu \mathrm{m}$, usually rather misshaped subutriform, subcylindrical or subfusiform, often with undate walls, without or with only short neck and with short or longer pedicel, apex usually without or with only very small crystals, walls up to $0.5(1.0) \mu \mathrm{m}$ thick at the apex, intensely yellowgreen with $3 \% \mathrm{KOH}$; intermixed with numerous (sub)clavate to subglobose cauloparacystidia. Clamp-connections abundant in all tissues.

Habitat and known distribution: Our own collections of I. sitibunda were mostly associated with Picea abies in moist mountainous regions, but also with Pinus and frondose trees at lower altitudes, but there in rather humid ditches, on calcareous soil. They are from Austria, Germany and the Netherlands. Other sequences putatively generated from I. sitibunda are in GenBank, from a collection from Italy (named 'I. amethystina', JF908123) and from EcM, also from Italy (e.g. with Quercus suber, GU256194, GU256195), as well as from EcM from Portugal (with Quercus rotundifolia, FJ897199), from Iran (HE687066) and from China (MK961161). In UNITE are several soil sequences from Estonia.

Further collections studied: AUSTRIA Salzburg, Tamsweg, Prebersee, ÖK25V 3230-Ost, alt. 1500 m, Picea abies, Alnus incana, 9 Aug 2013, leg. D. Bandini; det. D. Bandini \& B. Oertel (DB9-8-13-6). Tirol, Reutte, Tannheimer Tal, near Grän, ÖK25V 2214-Ost, alt. 1200 m, Picea abies, 19 Sep 2016, leg. D. Bandini; det. D. Bandini \& B. Oertel (DB19-9-16-19). Tirol, Reutte, Tannheimer Tal, near Tannheim, ÖK25V 2214-West, alt. 1200 m, Picea abies, 22 Sep 2016, leg. D. Bandini; det. D. Bandini \& B. Oertel (DB22-9-16-10). Tirol, Reutte, Tannheimer Tal, near Haldensee, ÖK25V 2214-Ost, alt. 1250 m, Picea abies, Salix sp., 21 Sep 2018, leg. D. Bandini; det. D. Bandini \& B. Oertel (DB21-9-18-20). GERMANY, BadenWürttemberg, Neckar-Odenwald-Kreis, Waldbrunn, Katzenbuckel, TK25 6520/1, alt. 560 m, Pseudotsuga menziesii, Salix sp., Carpinus betulus, 20 Oct 2019, leg. D. 
Bandini; det. D. Bandini \& B. Oertel (SMNS-STU-F0901511, DB20-10-19-3). Bayern, Kelheim, AbensbergOffenstetten, TK25 7137/3, alt. ca. 380 m, Pinus sylvestris, Populus tremula, Salix caprea, Betula pendula, 12 Oct 2017, leg. D. Bandini, B. Oertel \& J. Christan; det. D. Bandini \& B. Oertel (STU SMNS-STU-F-0901505; DB12-10-17-12). Bayern, Ostallgäu, Pfronten, Achtal, TK25 8429/1, alt. 1050 m, Picea abies, 13 Sep 2018, leg. D. Bandini; det. D. Bandini \& B. Oertel (DB13-9-18-12). Bayern, Oberallgäu, Wertach, Jungholz, TK25 8428/2, alt. 1015 m, next to a small brook with Fagus sylvatica, Picea abies, 14 Sep 2018, leg./det. D. Bandini (SMNS-STU-F-0901506, DB14-9-18-14). Ibidem, in some distance from former location, alt. $1035 \mathrm{~m}$, next to a small brook with Fagus sylvatica, Picea abies, 14 Sep 2018, leg./det. D. Bandini (DB14-9-18-21). Rheinland-Pfalz, RheinPfalz-Kreis, Böhl-Iggelheim TK25 6615/4, alt. 110 m, Quercus robur, Alnus glutinosa, Corylus avellana, Pinus sylvestris, 1 Nov 2014, leg. D. Bandini; det. D. Bandini \& B. Oertel (DB1-11-14-5). NETHERLANDS, Drenthe, Dieverveld, Drents Friesewold, wayside with Picea abies, 2 Oct 2019, leg. R. Chrispijn; det. D. Bandini \& B. Oertel (DB210-19-6).

Comments: Inocybe sitibunda is characterized by its rather small size, a felty to felty-lanose brown pileus and an at first with villose whitish fibres covered stipe, that is lilac-violet at least at the apex when young. We found the species most often on the wet banks of small rivulets in mountainous regions with Picea abies, but judging from collections from other countries putatively belonging to this species, it may also grow next to Quercus. Inocybe cincinnata (see above), I. gracillima (see above, and own observations) and I. minima (Peck 1913, and personal observation) differ, e.g. by on average shorter spores. Furthermore, the pileus of I. gracillima is squamulosesquarrose and the apex of the hymenial cystidia of I. minima is often subcapitate, while the stipe of I. cincinnata is covered with brownish fibres. Inocybe tiburtina (see below) has an abundant beige-coloured velipellis and on average somewhat wider spores, while I. obscuroides has stouter and larger basidiomata, a squamulose-squarrose pileus surface, lamellae edges becoming brownish with age, and the stipe is covered with brown fibres (see above). Inocybe pusio has entirely different ventricose hymenial cystidia without or with only short neck and on average wider spores (see Fig. 26g) and I. gaiana has a dull clayish to greyish pileus colour and the spores are on average smaller. Most closely molecularly related to I. sitibunda is I. drenthensis with $94 \%$ similarity in the ITS. It differs by a paler pileus colour, an often areolate diffracted and orange hued centre of the pileus, a stipe that is not covered with villose whitish fibres, on average shorter spores and more heterogeneous shaped hymenial cystidia.

Inocybe subporospora (Fig. 27 a) $\rightarrow$ Inocybe tjallingiorum

\section{Inocybe subvirgata (Fig. 27 b) $\rightarrow$ Inocybe griseovelata}

Inocybe tarda Kühner, Bull. Soc. nat. Oyonnax 9(Suppl. (Mém. hors sér. 1)): 6 (1955) Fig. 27 c

Description of the species: Kühner 1955; Poirier 2012.

Studied material (isotype): FRANCE, Paris, Bois de Vincennes, Pinus (G00058745). Spores $8.8-13.1 \mu \mathrm{m}$ (av. $10.7 \mu \mathrm{m}$, SD $1.0 \mu \mathrm{m}) \times 5.3-7.6 \mu \mathrm{m}$ (av. $6.2 \mu \mathrm{m}$, SD $0.5 \mu \mathrm{m}) ; \mathrm{Q}=1.4-2.0$ (av. 1.7, SD 0.2) $(\mathrm{n}=40$ ), smooth, (sub)amygdaloid, with subacute apex, often with slight pseudoporus. Basidia 4-spored. Pleurocystidia 52-84 $\mu \mathrm{m}$ (av. $66 \mu \mathrm{m}$, SD $9.3 \mu \mathrm{m}) \times$ 12-20 $\mu \mathrm{m}$ (av. $16 \mu \mathrm{m}, \mathrm{SD} 2.0 \mu \mathrm{m}$ ); $\mathrm{Q}=3.3-6.0$ (av. 4.2, SD 0.7) ( $\mathrm{n}=15)$, mostly (sub)cylindrical, also subfusiform or subutriform, apex usually crystalliferous, walls up to 3.0 (3.5) $\mu \mathrm{m}$ thick, pale yellowish-greenish with $3 \% \mathrm{KOH}$. Cheilocystidia similar in appearance and size. Paracystidia not observed. Caulocystidia not studied, because stipe not present.

Selected other studied material: GERMANY, BadenWürttemberg, Rhein-Neckar-Kreis, Sandhausen, TK25 $6617 / 4$, alt. $110 \mathrm{~m}$, Pinus sylvestris, Quercus robur, Helianthemum, 21 Oct 2012, leg./det. D. Bandini \& B. Oertel (SMNS-STU-F-0901443, DB21-10-12-28).

Comments: No sequence data are available of the type, but a sequence of an own collection is included in the tree (see Fig. 1).

Inocybe tenuicystidiata E. Horak \& Stangl, Sydowia 33: 148 (1980) Figs. 26 c, 27 d

$=$ Inocybe petroselinolens Carteret \& Reumaux, Bull. Soc. mycol. Fr. 127(1-2): 49 (2012) [2011]

Description of the species: Horak and Stangl 1980; Stangl 1989 (as 'I. obscurobadia'); Ferrari 2006; Carteret and Reumaux 2012 (as 'I. petroselinolens'); Ludwig 2017 (as 'I. obscurobadia').

Studied material (holotype of I. tenuicystidiata), Fig. 27 d: GERMANY, Baden-Württemberg, Sigmaringen, Inzigkofen, Schlosspark, 25 Sep 1974, leg. J. Stangl (M M-0281792). GenBank: ITS = MW856453, MW856454. Spores 8.0-9.9 $\mu \mathrm{m}$ (av. $9.0 \mu \mathrm{m}$, SD $0.5 \mu \mathrm{m}) \times 4.4-5.4 \mu \mathrm{m}$ (av. $4.9 \mu \mathrm{m}$, SD $0.2 \mu \mathrm{m}) ; \mathrm{Q}=1.6-2.0$ (av. 1.8, SD 0.1) $(\mathrm{n}=$ 40), smooth, (sub)amygdaloid, often with flattened sides, apex (sub)conical, often (sub)papillate. Basidia 4-spored. Pleurocystidia 45-68 $\mu \mathrm{m}$ (av. $54 \mu \mathrm{m}$, SD $6 \mu \mathrm{m}) \times 10-15$ $\mu \mathrm{m}$ (av. $12 \mu \mathrm{m}$, SD $1 \mu \mathrm{m}) ; \mathrm{Q}=3.4-5.7$ (av. 4.4, SD 0.7) (n= 15), (sub)lageniform, (sub)cylindrical, also subutriform or subfusiform, often with undate walls, apex usually crystalliferous, rather thin-walled, walls up to $1.5 \mu \mathrm{m}$ thick at the apex, almost colourless to pale yellowish in $3 \% \mathrm{KOH}$ Cheilocystidia similar in appearance and size. Paracystidia not observed. Caulocystidia only near the apex of the stipe, 
long and slim (sub)lageniform or (sub)cylindrical with undate walls, length $>100 \mu \mathrm{m}$.

Isotype of I. petroselinolens, Fig. 26 c: FRANCE, forêt de Ferrières (Seine-et-Marne), 17 Oct 2001, leg. A. \& R. Bardet (XC2001-128). Spores 7.7-10.5 $\mu \mathrm{m}$ (av. $8.9 \mu \mathrm{m}$, SD $0.7 \mu \mathrm{m}) \times 4.4-5.7 \mu \mathrm{m}$ (av. $4.8 \mu \mathrm{m}$, SD $0.3 \mu \mathrm{m}) ; \mathrm{Q}=1.6-2.2($ av. 1.8, SD 0.1) $(\mathrm{n}=40)$, (sub)amygdaloid, with (sub)acute, sometimes also subpapillate apex. Basidia 4-spored. Pleurocystidia 44-69 $\mu \mathrm{m}$ (av. $54 \mu \mathrm{m}$, SD $6 \mu \mathrm{m}) \times 11-14 \mu \mathrm{m}$ (av. $13 \mu \mathrm{m}$, SD $1 \mu \mathrm{m}$ ); $\mathrm{Q}=3.8-5.8$ (av. 4.3, SD 0.5) (n = 15), (sub)fusiform, (sub)cylindrical, subutriform, sometimes sublageniform, often with undate walls, apex usually crystalliferous, walls up to $1.0 \mu \mathrm{m}$ thick at the apex, almost colourless with $3 \% \mathrm{KOH}$. Cheilocystidia similar in appearance and size. Paracystidia not observed. Caulocystidia not studied, because stipe not present.

Comments: Compare also I. obscurobadia (see above). The synonymization of $I$. petroselinolens with I. tenuicystidiata is based on the original descriptions and the microscopic characters observed from the types. For I. tenuicystidiata, a sequence is available for the holotype.

Inocybe tiburtina Bandini \& G. Bandini sp. nov. Fig. 21 MycoBank number: MB 839169

Etymology: Named 'tiburtina' from the Latin name of travertine, a form of limestone, because the species was often found in an old limestone quarry.

Diagnosis: Inocybe tiburtina has a brown felty to lanose pileus with ample beige-coloured velipellis, (sub)distant thickish lamellae, violet tinges at the apex of the stipe at least in the context, smooth spores, measuring 7.9-11.1 $\mu \mathrm{m}$ (av. 9.2 $\mu \mathrm{m}) \times 4.8-6.1 \mu \mathrm{m}$ (av. 5.5 $\mu \mathrm{m}$ ) and mostly rather long and slender hymenial cystidia, pleurocystidia measuring 33-88 $\mu \mathrm{m}($ av. $60 \mu \mathrm{m}) \times 8-22 \mu \mathrm{m}$ (av. $14 \mu \mathrm{m})$. Collected from at times rather hot and dry calcareous ground with Salix and other frondose trees. This combination of characters as well as ITS sequence data distinguishes I. tiburtina from other members of the cincinnata-group, such as I. cincinnata, I. obscuroides or I. gracillima.

Holotype: GERMANY, Baden-Württemberg, RheinNeckar-Kreis, Eschelbronn, Nature Reserve Kallenberg, TK25 6619/3, alt. 196 m, 25 Oct 2019, Salix sp., leg. D. \& G. Bandini (holotype STU SMNS-STU-F-0901565; isotype priv. herb. D.B. DB25-10-19-15). GenBank: ITS + partial LSU $=$ MW845939.

Description: Pileus $10-30 \mathrm{~mm}$ wide, subconical or subcampanulate when young, but soon broadly convex, later expanded, some basidiomata with (sub)acute umbo, others without or with only faint large umbo, margin at first slightly incurved to decurved, then straight or even uplifted and then pileus depressed around the umbo; young basidiomata with abundant beige-coloured velipellis scattered radially on the pileus or covering as thick layer the entire pileus or at least the centre; colour ochraceous brownish, brownish, nut-brown, brown to seldom red-brown (Mu 10YR 5/6-5/8, 4/3-4/6; 7.5YR $4 / 5-4 / 8,4 / 4-4 / 6$ ), yet often appearing somewhat mottled because of remnants of the velipellis; with age sometimes becoming much paler in colour towards the margin, and when young often quite pale because of the velipellis; surface thickish felty to finely lanose, seldom also subsquamulose or strongly lanose around the centre; young basidiomata with faint traces of brownish to almost violaceous cortina. Lamellae subdistant to distant (ca. 25-35, 1 = 1-3), thickish, mostly almost free to adnate, but sometimes also broadly adnate with (sub)decurrent tooth, ventricose, at first greyishwhitish, later greyish-brownish to coffee-brown or intensely red-brown with or without violaceous hue; edge strongly fimbriate, whitish to concolorous or even darker brown. Stipe $15-60 \times 1-3 \mathrm{~mm}$, cylindrical or curved, when young entirely covered with whitish tomentum, soon longitudinally striate or glabrous or near the base with brownish fibres, pale flesh coloured to coffee-brown or brown, and especially when young often violet or with violaceous or violaceous pinkish tinge near the apex in different intensity from collection to collection or even within one collection; with faint rough whitish pruina near the apex of the stipe. Context whitish in the upper part of the pileus, watery beneath and violaceous in the upper stipe, sometimes with faint yellowish tinge, and whitish below. Smell spermatical, at least when cut. Colour of exsiccata pileus brown with reddish hue in different intensity (Mu 5YR 4/3-4/6; 7.5YR 4/4-4/6), lamellae and stipe concolorous or a little lighter in colour, no darkening or blackening with drying.

Spores 7.9-11.1 $\mu \mathrm{m}$ (av. 9.2 $\mu \mathrm{m}$, SD $0.7 \mu \mathrm{m}) \times 4.8-$ $6.1 \mu \mathrm{m}$ (av. $5.5 \mu \mathrm{m}$, SD $0.3 \mu \mathrm{m}$ ); $\mathrm{Q}=1.4-2.1$ (av. 1.7, SD 0.1 ) ( $\mathrm{n}=160$ of 4 coll.); smooth, (sub)amygdaloid, with or without rather faint suprahilar depression, apex subacute to acute, also subpapillate, sometimes with indistinct pseudoporus. Basidia 25-32 × 7-10 $\mu \mathrm{m}$, generally 4-spored, seldom also 2 -spored, and then deformed spores up to $\mu \mathrm{m}$ $12.6 \mu \mathrm{m}$. Lamella edge sterile, composed of cheilocystidia and numerous often brownish, (sub)clavate or subglobose, thin-walled paracystidia. Pleurocystidia 33-88 $\mu \mathrm{m}$ (av. 60 $\mu \mathrm{m}, \mathrm{SD} 12 \mu \mathrm{m}) \times 8-22 \mu \mathrm{m}$ (av. $14 \mu \mathrm{m}$, SD $3 \mu \mathrm{m}) ; \mathrm{Q}=$ 1.7-7.3 (av. 4.4, SD 1.1) ( $\mathrm{n}=60$ of 4 coll.), mostly rather long and slim, (sub)fusiform, also (sub)utriform or sublageniform, at the apex generally wide, with short or long(er) neck, often with clearly demarcated transition from bulge to neck, generally with rather short pedicel or roundish or truncate base, apex usually crystalliferous, walls up to 2.0 (2.5) $\mu \mathrm{m}$ thick at the apex, mostly quite uniformly thick at bulge and apex, yellow-green with $3 \% \mathrm{KOH}$. Cheilocystidia more variable in shape and size. Pileipellis constituted by an epicutis made up of parallel hyphae 4-10 (12) $\mu \mathrm{m}$ wide, often but not always 

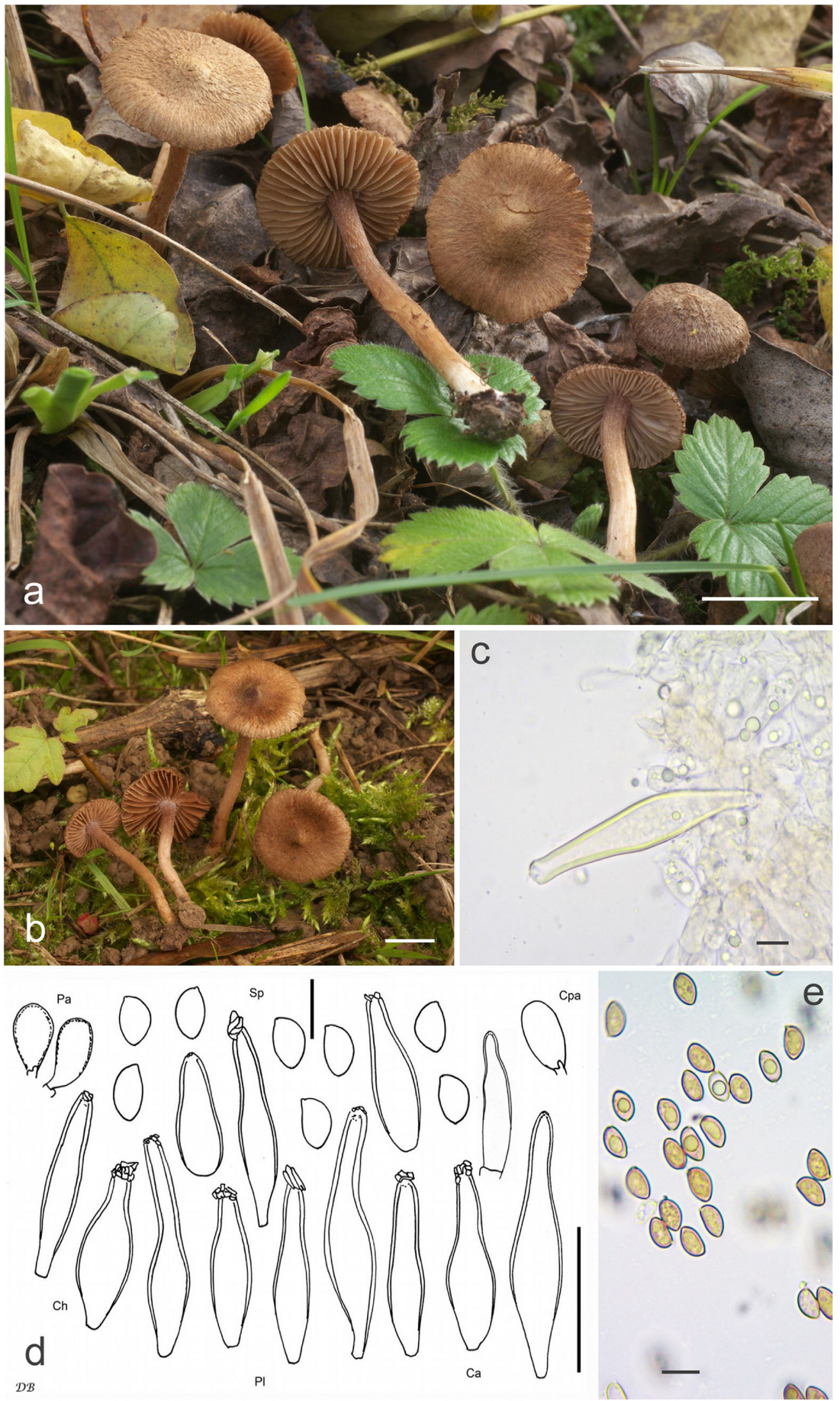

Fig. 21 Inocybe tiburtina, a holotype, scale bar: $1 \mathrm{~cm}$. b Coll. DB16-1015-1, scale bar: $1 \mathrm{~cm}$. c Cheilocystide (coll. DB16-10-15-1), scale bar: 10 Cauloparacystidia, $\mathrm{Ch}=$ Cheilocystidia, $\mathrm{Pa}=$ Paracystidia, $\mathrm{Pl}=$ Pleurocystidia, $\mathrm{Sp}=$ Spores; scale bar spores: $10 \mu \mathrm{m}$, scale bar cystidia: $\mu \mathrm{m}$. d Microscopical characters (holotype) $\mathrm{Ca}=$ Caulocystidia, $\mathrm{Cpa}=$ $50 \mu \mathrm{m}$. e Spores (coll. DB1-8-12-1), scale bar: $10 \mu \mathrm{m}$ 
with finely encrusting and parietal brownish pigment, subcutis with wider and paler to colourless elements. Caulocystidia only near the apex of the stipe, $40-85 \times 10-15 \mu \mathrm{m}$, ventricose subutriform or subfusiform, with rather long neck and short pedicel, apex usually crystalliferous, walls up to $1.0(1.5) \mu \mathrm{m}$ thick at the apex, yellow-green with $3 \% \mathrm{KOH}$, intermixed with segmented hyphoid elements often with (sub)papillate final element. Clamp-connections abundant in all tissues.

Habitat and known distribution: Inocybe tiburtina is up to now only known from our own collections from Germany and through a sequence in GenBank from Italy (as 'I. cincinnata', JF908155) and environmental samples from Estonia. Our own collections were found from August up to November. Even though also Picea abies was noted with two collections, the species is more likely associating with frondose trees and especially Salix, in strictly calcareous terrain. Many collections were found in old limestone quarries at locations that in summer often are very hot and dry, but with Salix nearby.

Further collections studied: GERMANY, BadenWürttemberg, Heidelberg, war cemetery, TK 6618/1, alt. 290 m, Quercus robur, Picea abies, Fagus sylvatica, 1 Aug 2012, leg. D. Bandini; det. D. Bandini \& B. Oertel (STU SMNS-STU-F-0901467; DB1-8-12-1). BadenWürttemberg, Rhein-Neckar-Kreis, Eschelbronn, near Nature Reserve Kallenberg, an old limestone quarry, TK25 6619/3, alt. 190 m, Salix caprea, Alnus glutinosa, 14 Oct 2012, leg./det. D. Bandini (DB14-10-12-4). Ibidem, in some distance from former location, alt. 195 m, Salix sp. Alnus glutinosa, 14 Oct 2012, leg./det. D. Bandini (DB1410-12-5). Ibidem, in some distance from former location, alt. 200 m, Salix sp. Alnus glutinosa, 14 Oct 2012, leg./det. D. Bandini (DB14-10-12-6). Baden-Württemberg, RheinNeckar-Kreis, Wiesenbach, TK25 6618/2, alt. 180 m, calcareous soil with Salix sp., 22 Oct 2012, leg./det. D. Bandini (DB22-10-12-3). Baden-Württemberg, Rhein-Neckar-Kreis, Wiesenbach, TK 6618/2, alt. 175 m, Fagus sylvatica, Quercus robur, Corylus avellana, 16 Oct 2015, leg. D. \& G. Bandini (STU SMNS-STU-F-0901465; DB16-10-15-1). Baden-Württemberg, Rhein-Neckar-Kreis, Bammental, TK 6618/2, alt. 225 m, Fagus sylvatica, 16 Oct 2015, leg. D. Bandini; det. D. Bandini \& B. Oertel (SMNS-STU-F0901466, DB16-10-15-6). Baden-Württemberg, NeckarOdenwald-Kreis, Waldbrunn, Katzenbuckel, old limestone quarry, TK25 6520/1, alt. ca. 495 m, Carpinus betulus, Salix sp., Populus sp., 14 Aug 2017, leg. D. Bandini; det. D. Bandini \& B. Oertel (DB14-8-17-17). Baden-Württemberg, Rhein-Neckar-Kreis, Eschelbronn, near Nature Reserve Kallenberg, TK25 6619/3, alt. 190 m, Salix caprea, Alnus glutinosa, 21 Oct 2017, leg. D. Bandini; det. D. Bandini \& B. Oertel (DB21-10-17-3). Ibidem, in some distance from former location, alt. $185 \mathrm{~m}$, Salix caprea, Alnus glutinosa, 21 Oct 2017, leg./det. D. Bandini (DB21-10-17-4). Baden-
Württemberg, Rhein-Neckar-Kreis, Leimen, Nature Reserve Steinbruch Leimen, old limestone quarry, TK 6618/1, alt. 140 m, Salix sp., 3 Nov 2017, leg. D. \& G. Bandini; det. D. Bandini \& B. Oertel (DB3-11-17-2). Ibidem, in some distance from former location, alt. 140 m, Salix sp., 3 Nov 2017, leg. D. \& G. Bandini; det. D. Bandini \& B. Oertel (DB3-11-17-3). Ibidem, in some distance from former location, alt. $145 \mathrm{~m}$, Salix sp., 3 Nov 2017, leg. D. \& G. Bandini; det. D. Bandini \& B. Oertel (DB3-11-17-4). Ibidem, in some distance from former location, alt. 145 m, Salix sp., 3 Nov 2017, leg. D. \& G. Bandini; det. D. Bandini \& B. Oertel (DB3-11-17-5). BadenWürttemberg, Rhein-Neckar-Kreis, Eschelbronn, Nature Reserve Kallenberg, TK25 6619/3, alt. 198 m, Salix sp., 25 Oct 2019, leg. D. \& G. Bandini; det. D. Bandini (STU SMNSSTU-F-0901512; DB25-10-19-11). Ibidem, in some distance from former location, alt. 192 m, 2 Nov 2020, Salix caprea, leg. D. \& G. Bandini; det. D. Bandini (DB2-11-20-2). Bayern, Ostallgäu, Schwangau, Drehhütte, TK25 8430/2, alt. 910 m, Salix sp., Fraxinus excelsior, Picea abies, 20 Sep 2018, leg. D. Bandini; det. D. Bandini \& B. Oertel (DB20-9-18-15).

Comments: Inocybe tiburtina is characterized by an abundant beige-coloured velipellis and the often somewhat mottled appearance of the pileus of young basidiomata because of remnants of the velipellis, a thickish felty to finely lanose surface of pileus, subdistant and thickish lamellae, violaceous to violaceous pinkish tinges in the upper part of stipe, rather long hymenial cystidia with positive reaction on $\mathrm{KOH}$. The caulocystidia are (sub)lageniform to (sub)utriform with an often rather long neck. The habitus of the basidiomata often reminds the aspect of nails, with their disproportionally long stipes.

Inocybe tiburtina is a member of cincinnata-group. Because of the violet stipe and the often rather long and narrow (sub)fusiform hymenial cystidia, which are typical for species of the cincinnata-group, the species might for instance be mistaken for I. cincinnata. This species differs from I. tiburtina, e.g. by only faint velipellis, more vivid pileus colour and often verrucose to areolate diffracted centre of pileus, while the margin is fibrillose (see above). Inocybe obscuroides P.D. Orton has normally larger and stouter basidiomata with a squamulose to (sub)squarrose surface, usually without a velipellis, broadly adnate lamellae with brown edges when older and stipes covered with brown fibres (see, e.g. Orton 1960; Kuyper 1986 (as 'I. phaeocomis var. major'); Stangl 1989 (as 'I. phaeocomis var. major'), and personal observation). Inocybe gracillima Carteret \& Reumaux is usually found in rather moist locations with Salix or other frondose trees. It is a small species with strongly squarrose pileus surface, missing velipellis and on average longer hymenial cystidia with often undate walls (Carteret and Reumaux 2012, and personal observation). Since I. minima also has an abundant velipellis and a similar texture of the pileus surface, it can be mistaken for I. tiburtina 
macroscopically. It differs from the latter named, however, by often oblong spores, the width of which on average is $<$ $5.0 \mu \mathrm{m}$ and by on average somewhat slimmer, often subcapitate hymenial cystidia with long and tapering necks. Furthermore, the velipellis is usually concentrated on the umbo and thus the pilei do not appear mottled as is the case with I. tiburtina (Peck 1913, and personal observation). Inocybe sitibunda is a small species with usually darker brown pileus, with villose whitish fibres on the stipe and often found with Picea abies at the banks of mountainous brooks. Inocybe lampetiana, likewise described here, is another dark brown species, with longer spores, growing on very moist acid soil with Alnus. Inocybe gaiana is more clayish or dull brown with greyish velipellis and on average smaller spores and generally wider caulocystidia, while I. curtispora differs, e.g. by missing velipellis and shorter spores (Ludwig 2017; Eberhardt et al. in prep.). We are not aware of a closely molecularly related species. Distantly related are with $94 \%$ identity in the ITS I. gracillima and with $93 \%$ I. obscuroides.

Inocybe tigrina R. Heim, Encyclop. Mycol., 1 Le Genre Inocybe (Paris): 230 (1931) Figs. 22, 26 a, 27 e

= Inocybe patibilis Reumaux, in Reumaux, Poirier \& Moënne-Loccoz, Bull. trimest. Soc. mycol. Fr. 103(4): Atlas [1] (1988) [1987]

= Inocybe tigrinella Carteret \& Reumaux, Bull. Soc. mycol. Fr. 127(1-2): 50 (2012) [2011]

Typification of I. tigrina: Holotype: FRANCE, near Meaux, Pinus, Oct 1929, leg. Mauguin, Plate XIX, Fig. 6 (Heim 1931). No original material survived (Kuyper 1986). Designated here as epitype (MBT 10000528): GERMANY, Rheinland-Pfalz, Bad Kreuznach, Lützelsoon, near Kellenbach, alt. 400 m, Picea abies, Fagus sylvatica, Pseudotsuga menziesii, 24 Oct 2015, leg. D. Bandini \& B. Oertel (STU SMNS-STU-F-0901532; DB24-10-15-3). GenBank: ITS + partial LSU = MW845933.

Description of the species: Heim 1931; Reumaux et al. 1988 (as 'patibilis'); Ferrari 2006; Carteret and Reumaux 2012 (as 'tigrinella'); Ludwig 2017.

Description: Pileus 15-30 (40) $\mathrm{mm}$ wide, at first (sub)campanulate, semiglobose or (sub)conical, later semiglobose, conico-convex, broadly convex or expanded, without umbo or with more or less pronounced large to subacute umbo, margin at first slightly incurved to decurved, later straight or even uplifted, and then pileus depressed around the umbo; no remnants of a velipellis observed; colour brown, nut-brown, brown with faint reddish hue, brown with greyish hue (Mu 10YR 4/3$4 / 6$; 7.5 YR $5 / 4-5 / 6$ or $4 / 4-4 / 6$ ); surface felty to (sub)lanose and often with diffracted fibres, breaking up in small lacerate often concentric fibrebundles, showing the pale trama below, and therefore typically bicoloured, but also remaining more or less unicoloured felty-lanose without any diffracted fibres; young basidiomata with remnants of a whitish cortina. Lamellae moderately crowded to subdistant (ca. 40$50,1=1-3)$, adnate to broadly adnate, sometimes with (sub)decurrent tooth, even to subventricose, at first whitish, then greyish to greyish-brownish or brown; edge fimbriate, whitish. Stipe $25-50 \times 2-3 \mathrm{~mm}$, cylindrical or widening towards the base, when young covered with whitish tomentum, later longitudinally striate, somewhat floccose or glabrous, at first whitish, later pale brownish to brownish; pruinose only near the apex of the stipe. Context whitish in the pileus and usually as well in the stipe, but sometimes faintly brownish in the stipe. Smell (sub)spermatical, at least when cut. Colour of exsiccata pileus brown with greyish hue (Mu 10YR 4/3-4/6, 3/3), lamellae without greyish hue, stipe concolorous or a little lighter in colour, no darkening or blackening with drying.

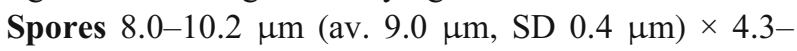
$5.7 \mu \mathrm{m}$ (av. $4.9 \mu \mathrm{m}, \mathrm{SD} 0.3 \mu \mathrm{m}$ ); $\mathrm{Q}=1.6-2.1$ (av. 1.8, SD $0.1)$ ( $\mathrm{n}=120$ of 3 coll.); smooth, mostly oblong (sub)amygdaloid, without or with only faint suprahilar depression, apex (sub)acute, sometimes subpapillate, with indistinct pseudoporus. Basidia 24-28 × 7-9 (10) $\mu \mathrm{m}$, generally 4spored, but in some collections also 2-spored and then spores up to $11.7 \mu \mathrm{m}$, and then average values up to $10.2 \times 5.2 \mu \mathrm{m}$. Lamellae edges sterile, composed of cheilocystidia and numerous colourless, (sub)clavate or (sub)cylindrical, thinwalled paracystidia. Pleurocystidia 43-76 $\mu \mathrm{m}$ (av. $58 \mu \mathrm{m}$, SD $6 \mu \mathrm{m}) \times 10-19 \mu \mathrm{m}($ av. $14 \mu \mathrm{m}$, SD $2 \mu \mathrm{m}) ; \mathrm{Q}=2.7-5.9$ (av. 4.3, SD 0.7) ( $\mathrm{n}=45$ of 3 coll.), (sub)fusiform, (sub)utriform, often with rather long and often slightly undate neck, at the apex generally wide, usually with only short pedicel, apex usually crystalliferous, walls up to $2.0(2.5) \mu \mathrm{m}$ thick at the apex, yellow-green with $3 \% \mathrm{KOH}$. Cheilocystidia more variable in appearance. Pileipellis constituted by an epicutis made up of parallel hyphae 3-10 $\mu \mathrm{m}$ wide, with encrusting and parietal brown to dark brown pigment, subcutis with wider and paler to colourless elements. Caulocystidia only near the apex of the stipe, 40-80 × 10-15 $\mu \mathrm{m}$, mostly (sub)lageniform and with rather long neck, with short or without pedicel, apex usually crystalliferous, walls up to $1.0 \mu \mathrm{m}$ thick at the apex, yellow-green with $3 \% \mathrm{KOH}$; intermixed with numerous (sub)clavate to subglobose cauloparacystidia. Clamp-connections abundant in all tissues.

Habitat and known distribution: Our own finds are from Austria, GERMANY and the Netherlands. In GenBank there are sequences from collections from Algeria (as 'I. tigrina', KP826726; as 'I. tigrina', KP826740), Italy (as 'I. tigrina', JF908147, as 'I. tigrina', JF908254, as 'I. tigrina', MT594512, as 'I. tigrina', MT594513, as 'I. tigrina', MT594514, as 'I. flocculosa', JF908150 and as 'Inocybe 

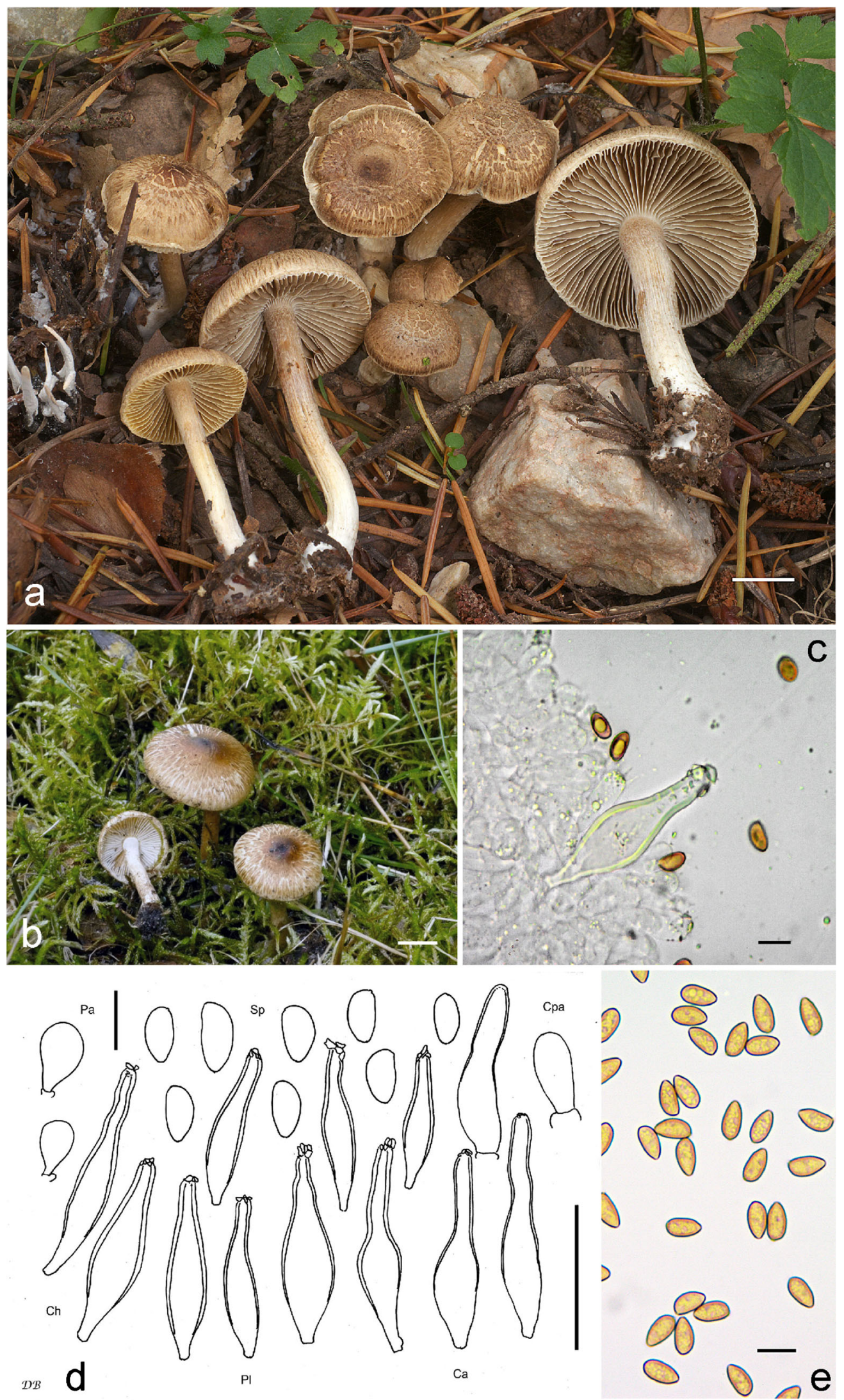

Fig. 22 Inocybe tigrina, a epitype, scale bar: $1 \mathrm{~cm}$. b Coll. DB15-10-118, scale bar: $1 \mathrm{~cm}$. c Cheilocystide (coll. DB15-10-11-8), scale bar: 10 $\mu \mathrm{m}$. d Microscopical characters (epitype), $\mathrm{Ca}=$ Caulocystidia, $\mathrm{Cpa}=$

Cauloparacystidia, $\mathrm{Ch}=$ Cheilocystidia, $\mathrm{Pa}=$ Paracystidia, $\mathrm{Pl}=$ Pleurocystidia, $\mathrm{Sp}=$ Spores; scale bar spores: $10 \mu \mathrm{m}$, scale bar cystidia: $50 \mu \mathrm{m}$. e Spores (coll. DB30-9-14-5), scale bar: $10 \mu \mathrm{m}$ 


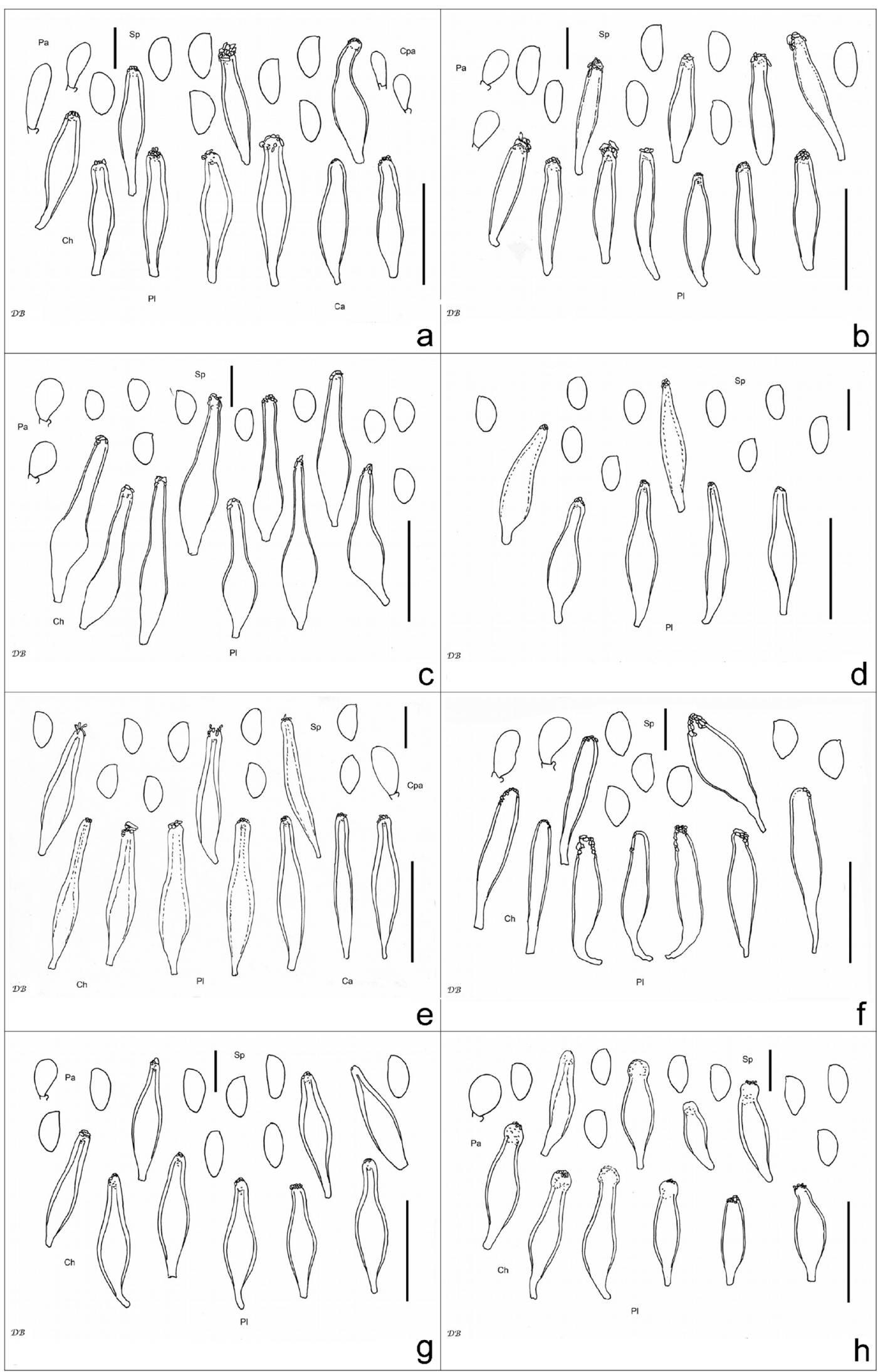

Fig. 23 Microscopic characters of type collections. a Inocybe amethystina (L-0053531). b I. bolbitioides (XC2012-72). c I. cincinnata (IB-19800323). d I. clarkii (K-M000173536). e I. conformata (H-6074688). f I. costinitii (MCVE-28974). g
I. crocifolia (PRM-756500). h I. elegans (PR-7878). $\mathrm{Ca}=$ Caulocystidia, $\mathrm{Cpa}=$ Cauloparacystidia, $\mathrm{Ch}=$ Cheilocystidia, $\mathrm{Pa}=$ Paracystidia, $\mathrm{Pl}=$ Pleurocystidia, $\mathrm{Sp}=$ Spores; scale bar spores: $10 \mu \mathrm{m}$, scale bar cystidia: $50 \mu \mathrm{m}$ 
sp.', MT594516) and from EcM from Belgium (with Tilia tomentosa, MH801343), Estonia (with Populus alba, JX316568), Italy (with Quercus rubra, HF565064) and China (with Quercus mongolica, KJ000656), as well as several more sequences without indication of the symbiont or the country. From Estonia, there are many soil sample sequences like UDB071692 in UNITE. Inocybe tigrina is a rather frequent species, which prefers calcareous soil and associates with frondose trees as well as with conifers.

Selected collections examined: AUSTRIA, Tirol, Reutte, Höfen, ÖK25V 2215-West, alt. 970 m, Betula pendula, Salix sp., Picea abies, 24 Sep 2015, leg. D. Bandini; det. D. Bandini \& B. Oertel (DB24-9-15-4). GERMANY, BadenWürttemberg, Heidelberg, Königstuhl, Märchenparadies, TK25 6618/1, alt. 565 m, Fagus sylvatica, 29 Mai 2014, leg. D. Bandini, X. Hielscher; det. D. Bandini \& B. Oertel (DB29-5-14-1). Baden-Württemberg, Kreis Freudenstadt, Baiersbronn, Wilder See, Hornisgrinde, TK25 7415/1, alt. 1000 m, Abies alba, Picea abies, 13 Sep 2014, leg. D. Bandini; det. D. Bandini \& B. Oertel (DB13-9-14-29). Baden-Württemberg, Rhein-Neckar-Kreis, Lobbach, Haag, TK25 6519/4, alt. 420 m, Picea abies, 30 Oct 2015, leg. D. Bandini; det. D. Bandini \& B. Oertel (DB30-10-15-2). Bayern, Garmisch-Partenkirchen, Mittenwald, TK25 8533/3, alt. 1050 m, Fagus sylvatica, Picea abies, 12 Sep 2017, leg. D. Bandini; det. D. Bandini \& B. Oertel (DB12-9-17-11). Bayern, Ostallgäu, Pfronten, Breitenberg, TK25 8429/3, alt. ca. 1650 m, Picea abies, 16 Sep 2018, leg. D. Bandini; det. D. Bandini \& B. Oertel (DB16-9-18-15). Hessen, Bergstraße, Viernheim, near Viernheimer Heide, TK25 6417/1, Pinus sylvestris, 8 Nov 2014, leg. W. Prüfert \& B. Oertel; det. D. Bandini \& B. Oertel (DB8-11-14-1b). Rheinland-Pfalz, Rhein-Pfalz-Kreis, Böhl-Iggelheim, TK25 6615/4, alt. 110 m, Betula pendula, Pinus sylvestris, Quercus robur, 15 Oct 2011, leg./det. D. Bandini \& B. Oertel (KR-M-0038273, DB15-10-11-8).- Rheinland-Pfalz, Freudenburg, TK25 6405/3, alt. 390 m, Salix sp., 30 Sep 2014, leg. B. Haberl \& B. Fellmann; det. D. Bandini \& B. Oertel (DB30-9-14-5). NETHERLANDS, Friesland, Ameland, Hollum, alt. $3 \mathrm{~m}$, Pinus sylvestris, 17 Sep 2011, leg. D. Bandini; det. D. Bandini \& B. Oertel (DB17-9-11-12).

Epitype of I. tigrina, Fig. 21 a, d: Spores 8.2-10.2 $\mu \mathrm{m}$ (av. $9.1 \mu \mathrm{m}$, SD $0.5 \mu \mathrm{m}) \times 4.4-5.5 \mu \mathrm{m}$ (av. $5.0 \mu \mathrm{m}$, SD $0.3 \mu \mathrm{m})$; $\mathrm{Q}=1.7-2.0$ (av. 1.8, SD 0.1) $(\mathrm{n}=40)$, smooth, oblong (sub)amygdaloid, with (sub)acute apex. Basidia generally 4spored. Pleurocystidia 49-76 $\mu \mathrm{m}$ (av. $60 \mu \mathrm{m}$, SD $6 \mu \mathrm{m}) \times$ 10-19 $\mu \mathrm{m}$ (av. $15 \mu \mathrm{m}$, SD $2 \mu \mathrm{m}$ ); Q = 3.3-5.4 (av. 4.0, SD $0.6)(\mathrm{n}=15)$, (sub)fusiform, (sub)utriform, often with rather long neck and undate walls, apex usually crystalliferous, walls up to $2.0(2.5) \mu \mathrm{m}$ thick at the apex, yellow-green with $3 \%$ $\mathrm{KOH}$. Cheilocystidia similar in appearance and size. Paracystidia subclavate. Caulocystidia 40-80 × 10-15 $\mu \mathrm{m}$, mostly (sub)lageniform, mostly with rather long neck, with short or without pedicel, apex usually crystalliferous, walls up to $1.0 \mu \mathrm{m}$ (neck) thick, yellowish-greenish with $3 \% \mathrm{KOH}$.

Isotype of I. patibilis, Fig. 26 a: FRANCE, Vandy (Ardennes), Picea, Betula, Carpinus betulus, Castanea sativa, 2 Nov 1979, leg. P. Reumaux (PR1208). GenBank: ITS = MW845951. Spores 8.8-11.3 $\mu \mathrm{m}$ (av. 10.0 $\mu \mathrm{m}$, SD 0.7 $\mu \mathrm{m}) \times 4.8-6.1 \mu \mathrm{m}$ (av. 5.3 $\mu \mathrm{m}, \mathrm{SD} 0.3 \mu \mathrm{m}) ; \mathrm{Q}=1.6-2.2$ (av. 1.9, SD 0.1) $(\mathrm{n}=40)$, smooth, often oblong, apex (sub)obtuse to (sub)acute. Basidia 4-spored. Pleurocystidia 60-77 $\mu \mathrm{m}$ (av. $65 \mu \mathrm{m}$, SD $4.6 \mu \mathrm{m}) \times 12-17 \mu \mathrm{m}($ av. $15 \mu \mathrm{m}$, SD 1.6 $\mu \mathrm{m}) ; \mathrm{Q}=3.6-6.4$ (av. 4.5, SD 0.7) ( $=15)$, mostly (sub)lageniform or (sub)fusiform, also subutriform or subcylindrical, apex usually crystalliferous, with only short pedical, sometimes with slightly undate walls and thickened apex, walls up to 3.5 (4.0) $\mu \mathrm{m}$ thick, yellow-green with $3 \%$ $\mathrm{KOH}$. Cheilocystidia similar in appearance and size. Paracystidia not observed. Caulocystidia not studied, because stipe not present.

Isotype of I. tigrinella, Fig. 27 e: FRANCE, Ussy-surMarne (Seine-et-Marne), 30 Sep 2010, leg. P. Reumaux (XC2010-95). GenBank: ITS = MW845953. Spores 8.1$10.6 \mu \mathrm{m}$ (av. 9.1 $\mu \mathrm{m}$, SD $0.5 \mu \mathrm{m}) \times 4.5-5.5 \mu \mathrm{m}$ (av. 5.0 $\mu \mathrm{m}, \mathrm{SD} 0.2 \mu \mathrm{m}) ; \mathrm{Q}=1.7-2.1$ (av. 1.8, SD 0.1) $(\mathrm{n}=40)$, smooth, (sub)amygdaloid, with (sub)acute, sometimes (sub)papillate apex. Basidia generally 4-spored, but also 2spored, and then spores up to $12.0 \mu \mathrm{m}$. Pleurocystidia 49$84 \mu \mathrm{m}$ (av. $63 \mu \mathrm{m}$, SD $10 \mu \mathrm{m}) \times 8-17 \mu \mathrm{m}$ (av. $12 \mu \mathrm{m}$, SD 3 $\mu \mathrm{m}) ; \mathrm{Q}=4.0-8.4$ (av. 5.5, SD 1.3) $(\mathrm{n}=15)$, mostly (sub)fusiform, (sub)cylindrical, often with undate walls and rather long neck, apex usually crystalliferous, walls up to $3.0 \mu \mathrm{m}$ thick at the apex, yellow-green with $3 \% \mathrm{KOH}$ (in contrast to what is stated in the protologue!). Cheilocystidia similar in appearance and size. Paracystidia not observed. Caulocystidia not studied, because stipe not present.

Comments: The selected epitype agrees fully with the original description and illustration of I. tigrina (Heim 1931). We also believe that it agrees well with the current use of the name, e.g. all sequences assigned to I. tigrina in GenBank are included in a single UNITE species hypothesis at the $1.5 \%$ level. Morphological and molecular examination of isotypes of I. patibilis and I. tigrinella showed that the two species are synonymous with I. tigrina (see above and Fig. 1).

Inocybe tigrina is normally characterized by felty to sublanose pilei often with concentrically diffracted fibres and therefore with a bicoloured aspect, but more uniformly coloured specimens and whole collections have also been observed. They can be recognized by the combination of stipes that are pruinose only near the apex, oblong and on quite narrow spores - on average measuring $9.0 \times 4.9 \mu \mathrm{m}$, in collections with 2 -spored basidia also up to $10.2 \times 5.2 \mu \mathrm{m}$ - and hymenial cystidia with rather long and often slightly undate necks, the walls of which react rather strongly on $\mathrm{KOH}$. The 
caulocystidia usually are (sub)lageniform with quite long neck. By the combination of these characters, I. tigrina can be distinguished from other brown-capped species such as I. castorina, I. derbschii, I. plurabellae, I. virgatula or I. semifulva.

Inocybe flocculosa Sacc. and I. semifulva appear to be the closest relatives of I. tigrina (see Fig. 1; ITS similarity between I. tigrina and I. semifulva or I. flocculosa $96.5 \%$, respectively 93\%). Inocybe flocculosa differs, e.g. by often (sub)squamulose pileus texture and shorter and not oblong spores (Kuyper 1986; Stangl 1989, and personal observation).

\section{Inocybe tjallingiorum Kuyper 1986 Fig. 27 a, f}

= Inocybe subporospora Kuyper, Persoonia Supplement 3: 95 (1986)

Description of the species: Kuyper 1986; Stangl 1989.

Studied material (holotype of I. tjallingiorum, Fig. $27 \mathrm{f}$ : NETHERLANDS, Oost Flevoland, Ijsselmeerpolders, Roggebotzand, 9 Oct 1981, leg. Th. W. Kuyper (L-0053540). GenBank: ITS = MW845929. Spores 7.5$9.8 \mu \mathrm{m}$ (av. $8.7 \mu \mathrm{m}$, SD $0.5 \mu \mathrm{m}) \times 5.0-6.0 \mu \mathrm{m}$ (av. $5.4 \mu \mathrm{m}$, SD $0.3 \mu \mathrm{m}) ; \mathrm{Q}=1.4-1.9$ (av. 1.6, SD 0.1) $(\mathrm{n}=40)$, smooth, (sub)amygdaloid, mostly with (sub)obtuse, but also with (sub)conical apex. Basidia 4-spored. Pleurocystidia 40-56 $\mu \mathrm{m}$ (av. $47 \mu \mathrm{m}$, SD $5 \mu \mathrm{m}) \times 14-19 \mu \mathrm{m}$ (av. $16 \mu \mathrm{m}$, SD 2 $\mu \mathrm{m}) ; \mathrm{Q}=2.5-4.0$ (av. 3.1, SD 0.4) $(\mathrm{n}=15)$, mostly broadly (sub)fusiform, seldom also subclavate, mostly without neck and only short pedicel, apex usually crystalliferous, walls up to $2.0(2.5) \mu \mathrm{m}$ thick at the apex, pale yellowish-greenish with $3 \% \mathrm{KOH}$. Cheilocystidia similar in appearance and size. Paracystidia not observed. Caulocystidia on entire length of the stipe, but in some basidiomata only sparely below the middle, in shape and size similar to hymenial cystidia.

Typification of $\boldsymbol{I}$. subporospora: NETHERLANDS, Wassenaar, Meijendel, Pinus sylvestris, in dune sand, 2 Sep 1982, leg. Th.W. Kuyper (L-0043124). This is a mixed collection; part (L-4370261) selected here as lectotype (MBT 10000535). GenBank: ITS = MW845928.

Lectotype of I. subporospora, Fig. 27 a. Spores 8.0-9.7 $\mu \mathrm{m}$ (av. 8.6 $\mu \mathrm{m}$, SD $0.4 \mu \mathrm{m}) \times 5.0-6.0 \mu \mathrm{m}$ (av. $5.3 \mu \mathrm{m}, \mathrm{SD} 0.2 \mu \mathrm{m}$ ); $\mathrm{Q}=1.5-1.8$ (av. 1.6, SD $0.1)(\mathrm{n}=40)$, smooth, (sub)amygdaloid, with (sub)obtuse, (sub)acute apex. Basidia 4-spored. Pleurocystidia 32-54 $\mu \mathrm{m}$ (av. $45 \mu \mathrm{m}$, SD $6 \mu \mathrm{m}$ ) $\times$ 11-18 $\mu \mathrm{m}$ (av. $15 \mu \mathrm{m}, \mathrm{SD} 2 \mu \mathrm{m}$ ); $\mathrm{Q}=2.5-3.6$ (av. 3.1, SD 0.3) ( $=15)$, mostly broadly (sub)fusiform, mostly without neck and with only short pedicel, apex usually crystalliferous, walls up to $1.5(2.5) \mu \mathrm{m}$ thick at the apex, pale yellowish-greenish with $3 \% \mathrm{KOH}$. Cheilocystidia similar in appearance and size. Paracystidia not observed. Caulocystidia down to the middle of the stipe, and sparely also below the middle, in shape and size similar to hymenial cystidia.

Comments: The type collection of I. subporospora was mixed. One part has very distinctive extraordinary long and narrow caulocystidia and hymenial cystidia mostly with a clearly differentiated neck and a length of up to $80 \mu \mathrm{m}$. None of these characters fits the protologue. Another part matches the description of Kuyper (1986) very well and was thus selected as lectoype. However, our observations on the material and the microdrawings of Kuyper (1986) also match his protologue of I. tjallingiorum published simultaneously: Pileus colour, colour of stipe, size and shape of hymenial cystidia (I. subporospora: '46-57 × 14-20 $\mu \mathrm{m}$ ', I. tjallingiorum: '41-59 × 14-20 $\mu \mathrm{m}$ ', Kuyper 1986), size and shape of the spores (I. subporospora: av. '8.1-9.6 $\times$ 5.4-6.0 $\mu \mathrm{m}$ ', I. tjallingiorum: av. '7.9-9.7 $\times 5.2-5.7 \mu \mathrm{m}$ ', Kuyper 1986). The ITS sequences of the I. tjallingiorum and I. subporospora are identical apart from two ambiguous positions in the lectotype sequence for I. subporospora. In this case, none of the two species has priority over the other. Given that I. subporospora was published with a mixed type, we suggest to use the name I. tjallingiorum to refer to this species.

Inocybe virgatula Kühner, Bull. Soc. nat. Oyonnax 9(Suppl. (Mém. hors sér. 1)): 7 (1955) Fig. 27 g

Studied material (lectotype, selected by Poirier 2016): FRANCE, Doubs, Le Russey, sapinière de la Grande Aise, near Russey, 29 Aug 1938, leg. R. Kühner (G00058741). GenBank: ITS = MW845923. Spores 8.7-10.6 $\mu \mathrm{m}$ (av. 9.6 $\mu \mathrm{m}, \mathrm{SD} 0.6 \mu \mathrm{m}) \times 4.8-5.6 \mu \mathrm{m}$ (av. $5.3 \mu \mathrm{m}$, SD $0.2 \mu \mathrm{m}) ; \mathrm{Q}=$ 1.6-2.0 (av. 1.8, SD 0.1) $(\mathrm{n}=40)$, smooth, oblong, with (sub)acute apex. Basidia 4-spored. Pleurocystidia 50-68 $\mu \mathrm{m}$ (av. $60 \mu \mathrm{m}$, SD $6 \mu \mathrm{m}) \times 15-21 \mu \mathrm{m}$ (av. $17 \mu \mathrm{m}$, SD 2 $\mu \mathrm{m}) ; \mathrm{Q}=2.6-4.3$ (av. 3.5, SD 0.4) $(\mathrm{n}=15)$, mostly ventricose (sub)fusiform, apex usually crystalliferous, walls up to 1.5 (2.0) $\mu \mathrm{m}$ thick at the apex, almost colourless to pale yellowish-greenish with $3 \% \mathrm{KOH}$. Cheilocystidia similar in appearance and size. Paracystidia not observed. Caulocystidia not studied (to preserve the material).

Selected other material studied: AUSTRIA, Tirol, Reutte, Tannheimer Tal, ÖK25V 2214-Ost, alt. $1200 \mathrm{~m}$, Picea abies, 10 Aug 2014, leg./det. D. Bandini (DB10-814-15). FINLAND, Koillismaa, Kuusamo municipality, Oulanka National Park, Liikasenvaara, Pinus sylvestris, Betula sp., Picea abies, 25 Aug 2015, leg./det. D. Bandini, J. Vauras \& B. Oertel (DB25-8-15-5). GERMANY, Baden-Württemberg, Schwarzwald-BaarKreis, Rensberg, TK25 7815/1, alt. 1000 m, Picea abies, Abies alba, 20 Jul 2012, leg./det. D. Bandini \& B. Oertel (DB20-7-12-12). Bayern, Berchtesgadener Land, Berchtesgaden, TK25 8344/3, alt. ca. 1100 m, Picea abies, 21 Aug 2014, leg./det. D. Bandini (DB21-8-14- 
29). Rheinland-Pfalz, Trier-Saarburg, Kell am See, TK25 6306/4, alt. 450 m, Picea abies, Fagus sylvatica, 1 Oct 2011, leg./det. D. Bandini (KR-M-0038116, DB110-11-2). Sachsen-Anhalt, Harz, Oberharz am Brocken, TK25 4229/4, alt. $680 \mathrm{~m}$, Picea abies, 2 Oct 2012, leg./ det. D. Bandini \& B. Oertel (DB2-10-12-14).

Comments: We accept $I$. virgatula here as independent species from I. hypophaea, which we cannot interpret (see above under I. hypophaea). We do not follow the synonymization of $I$. virgatula with $I$. fuscidula done by Kuyper (1986), either. The spores of I. fuscidula are very small, and the cystidia are shorter and narrower than those of I. virgatula (see above I. glabripes). The sequences of the type and of our own collection of $I$. virgatula differ only by 2 ambiguous reads that are matched by an unambiguous read in the other sequence.

\section{Inocybe xantholeuca (Fig. 27 h) $\rightarrow$ Inocybe geophylla}

\section{Discussion}

The selection of species treated here was guided by morphology and taxonomy. In some cases, species discussed as similar or belonging to a 'group' or 'complex' are not all sister taxa in the phylogenetic analysis. This may or may not be the same result one would be getting in a multi-locus analysis with a more inclusive selection of taxa and unnamed groups. The phylogenetic analysis presented here is only based on ITS and LSU data, with the LSU lacking for around half of the sequences. What we wanted to show - and what is shown - is that the species we here accept are distinct and the species that are described as new, form well supported clades. Known species are discussed and linked to sequence clades, showing that there are no earlier names available for species described as new.

We would have liked to be able to use type sequences for all species discussed, but that was not possible. Collections serving as representatives for species with unavailable types were carefully selected, but obviously even a careful selection could not overcome issues associated with the occurrence of cryptic species. However, many years of careful morphological and anatomical study of Inocybe have shown that it is possible to find even small differences between species. As far as we are aware, there are no competing cryptic species for the taxa for which representatives were selected in the absence of type sequences. At least in some of these cases, the lack of type sequences may be temporary and future results will show how good these selections were.

We have been careful with the designation of types from new material and have gone ahead only where we did not see any other way around for resolving the situation, when we felt confident that we 'know' the species well, and that the selection fixes the name in consensus with the original description, and, as far as possible, with the current use of the name.

Several of the species described above, even if they-like I. plurabellae - are quite common, were hidden within one or more well-known taxa and thus remained undescribed until now. One of the reasons for this may be owing to the trend of 'lumping' species, which was followed by Kuyper and many other researchers, as for instance J. Stangl (1989), about 30 years ago. Naming only two examples, the brown-capped I. virgatula was synonymized with $I$. fuscidula, and I. derbschii with I. pseudodestricta (see Kuyper 1986). This trend was not accepted by many French and Italian researchers, who mostly use(d) the key of M. Bon (1997), in which many more smooth-spored species are accepted than in the books of Kuyper and Stangl. However, the years or even decades after the publication of the books of Kuyper and Stangl were characterized by a general feeling of insecurity as to whether certain observed characters were just indications for the great variability of already described species, or else were attributes of new ones (see for instance Alessio 1989, 1997, or the remarks to several species in Bon 1997).

With the help of DNA analysis and the close examination of own fresh collections, it emerged that, for example, I. derbschii and I. pseudodestricta are two different species (see Bandini et al. 2019b). Even though the type material of I. fuscidula, preserved in formaldehyde, could not be sequenced by us, the morphological examination showed that I. virgatula and I. fuscidula, too, are separate species: the spores of I. fuscidula are very small, and the cystidia are shorter and narrower than those of I. virgatula (see above the evaluation of the types). Thus, what is called I. fuscidula by Kuyper (1986) and Stangl (1989) and elsewhere (e.g. Breitenbach and Kränzlin 2000; Ferrari 2006; Ludwig 2017), corresponds to I. virgatula, a very common species, while I. fuscidula, according to our analysis, is synonymous with I. glabripes (Ricken 1910-1915). Both species have the same very small spores and the same type of narrow and rather short hymenial cystidia. In order to make the species more accessible, a neotype for I. glabripes, as well as an epitype for I. tigrina, was designated here.

In spite of our efforts, I. hypophaea remained unclear; we have never come across material matching the description and type material (see above). The description, type material and sequence of $I$. virgatula, on the other hand, pointed towards a species we were able to recognize from own collections. Given the doubts we have in relation to I. hypophaea, we do not follow Kühner (1955) and do not synonymize I. virgatula with it, nor with I. fuscidula, either (Figs. $24 \mathrm{a}, \mathrm{g}$ and $27 \mathrm{~g}$ ).

Inocybe plurabellae, I. scolopacis, I. beatifica and I. ghibliana belong to this group of 'fuscidula-species', assigned by Bon to the section Tardae M. Bon (Bon 1997). 


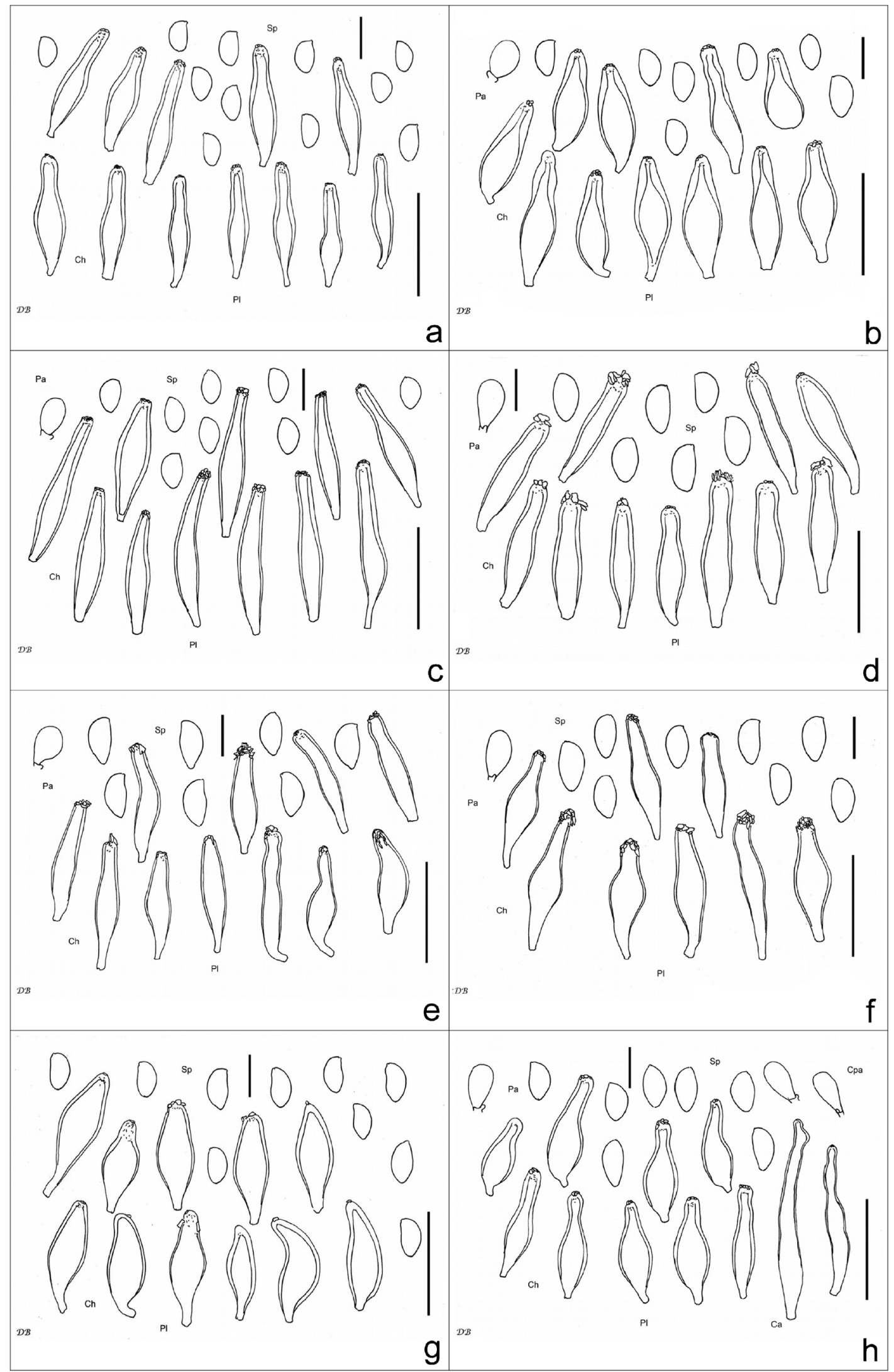

Fig. 24 Microscopic characters of type collections. a Inocybe fuscidula (PRC-bottle no. 396). b I. glabrescens (PRC-bottle no. 279). c I. gracillima (XC-99103003). d I. griseovelata (G00058738). e I. gypsea (XC2012-71). f I. huijsmanii (L-3986181). g I. hypophaea

(ZTMYC-56731). h I. lutescens I. (PRM-823229). Ca = Caulocystidia, $\mathrm{Cpa}=$ Cauloparacystidia, $\mathrm{Ch}=$ Cheilocystidia, $\mathrm{Pa}=$ Paracystidia, $\mathrm{Pl}=$ Pleurocystidia, $\mathrm{Sp}=$ Spores; scale bar spores: $10 \mu \mathrm{m}$, scale bar cystidia: $50 \mu \mathrm{m}$ 
Presumably, I. rivierana would have been identified as I. obscurobadia by those who followed the concept of Stangl (1989) and Kuyper (1986), or as I. tenuicystidiata by those who followed the concept of Bon. Inocybe tenuicystidiata was synonymized by Kuyper (1986) with I. obscurobadia - however, the shape and size of the spores and cystidia are different as can be seen in Figs. $25 \mathrm{e}$ and $27 \mathrm{~d}$. Furthermore, the macroscopic aspect as well as the habitat are different; thus, both, in our opinion, are good, distinct species. Inocybe obscurobadia probably is a very rare species of the alpine region (Favre 1955), while, at least in Germany, I. tenuicystidiata occurs mainly at lower altitudes where it is very common. In conclusion, what is called I. obscurobadia in the book of Kuyper (1986), Stangl (1989), Breitenbach and Kränzlin (2000) and also of Ludwig (2017) and others, should according to our analysis be referred to as I. tenuicystidiata.

Inocybe grusiana and also I. oetziana are macroscopically and microscopically quite close to $I$. griseovelata (section Inocybe according to Bon 1997), and therefore may be have been mistaken for this rather common species (Fig. 24 d).

The species with lilac-pinkish stipes described here are another difficult group, which in the key of Bon (1997) would belong to the section Lilacinae (R. Heim). Well known and very common is I. cincinnata var. major (see Kuyper 1989). Genetical and morphological differences, however, show that it is a taxon deserving species rank. At this rank, it has to be called I. obscuroides P.D. Orton (Orton 1960, and see above). Whereas this species is relatively easy to recognize, this is not the case with I. cincinnata var. cincinnata. The same type of lanceolate cystidia, typical for this species, can be found with several other species, belonging to the same group, as for instance with $I$. drenthensis, I. gaiana, I. minima, I. sitibunda or I. tiburtina. The named species differ from I. cincinnata not only in molecular respect but also by a combination of deviating characters, such as habitat, presence or absence of velipellis, size of spores etc. (see above). Inocybe lampetiana might be confused with I. amethystina, which according to our own observation is a rather rare species and is not associated with Alnus (see Kuyper 1986) as is the case with I. lampetiana. The similarly lilac-pinkishstiped I. dryadiana may be mistaken for I. griseolilacina on first sight, which species however differs, e.g. in typically subcapitate hymenial cystidia. Inocybe knautiana differs from all named species with violet-lilac stipe by differently shaped hymenial cystidia. Inocybe pusio differs from the latter by distinctly ventricose and fusiform hymenial cystidia, smaller spores and, following the original description, no whitish velipellis (Karsten 1889).

Another species-complex-according to the key of Bon (1997) belonging to the Tardae-is around
I. geophylla, which comprises several species, such as I. miranda, I. posterula and I. sambucella as well as I. bellidiana, described above, which differs from all mentioned, e.g. in the peculiar ventricose shape of spores. Of I. geophylla, only an iconotype exists (see Bulliard 1788-1792), and thus we chose an epitype of this frequent species, which is to be found as well in lowland terrain as in higher mountainous regions, and which is identical with the lectotype of I. xantholeuca by Kuyper (1986). The name-giving feature of the latter, i.e. the yellow-tinged lamellae, is not a constant factor of this species.

Inocybe clandestina grows on dry sandy terrain with Pinus; thus, in the same locations as I. tarda, and since the pilei of both are very dark brown, they might be confused. However, the spores of the latter species are much larger and the cystidia have a different shape (Kühner 1955; Poirier 2012, and personal observation). Inocybe tarda belongs to the section Tardae Bon as well as I. psammobrunnea, a species growing on sandy terrain as well. ITS analysis and morphological examination of the type of I. psammobrunnea as well as the comparison with the protologues of both species (Bon 1990; Poirier 2002; Bizio et al. 2017) and analysis of own collections strongly suggest that $I$. griseotarda is synonymous with I. psammobrunnea (see Fig. 1). In the protologue of I. psammobrunnea, Bon stresses the point that the context is blueish near the apex of the stipe (Bon 1990). However, the type collection was found on 18 November, a date where the temperature quite probably already has gone below the freezing point. We know from such collections, especially from $I$. tarda, that after such drops in temperature the context in the stipe often gets blueish. Also the pileus colour may change due to this.

Inocybe tjallingiorum is another one of the species with entirely pruinose stipe. However, we have collections where the stipes are only quite sparely pruinose below the middle, so that it seems as if the stipe were pruinose only in the upper half. Maybe this fact attributed to the description of I. subporospora Kuyper. The type of $I$. subporospora is a mixed collection, of which one part has very distinctive extraordinary long and narrow caulocystidia and hymenial cystidia mostly with a clearly differentiated neck and a length to up to $80 \mu \mathrm{m}$. None of these characters fits the protologue. The other part of which a lectotype is chosen here fits in the microscopic details to the protologue, but also matches I. tjallingiorum. Also in the ITS, it is identical with the one of I. tjallingiorum. We therefore consider I. subporospora as a synonym of I. tjallingiorum.

A problem for correct determination is the question in keys, if the stipe is entirely pruinose or only in the upper third or quarter (Kuyper 1986; Stangl 1989; Bon 


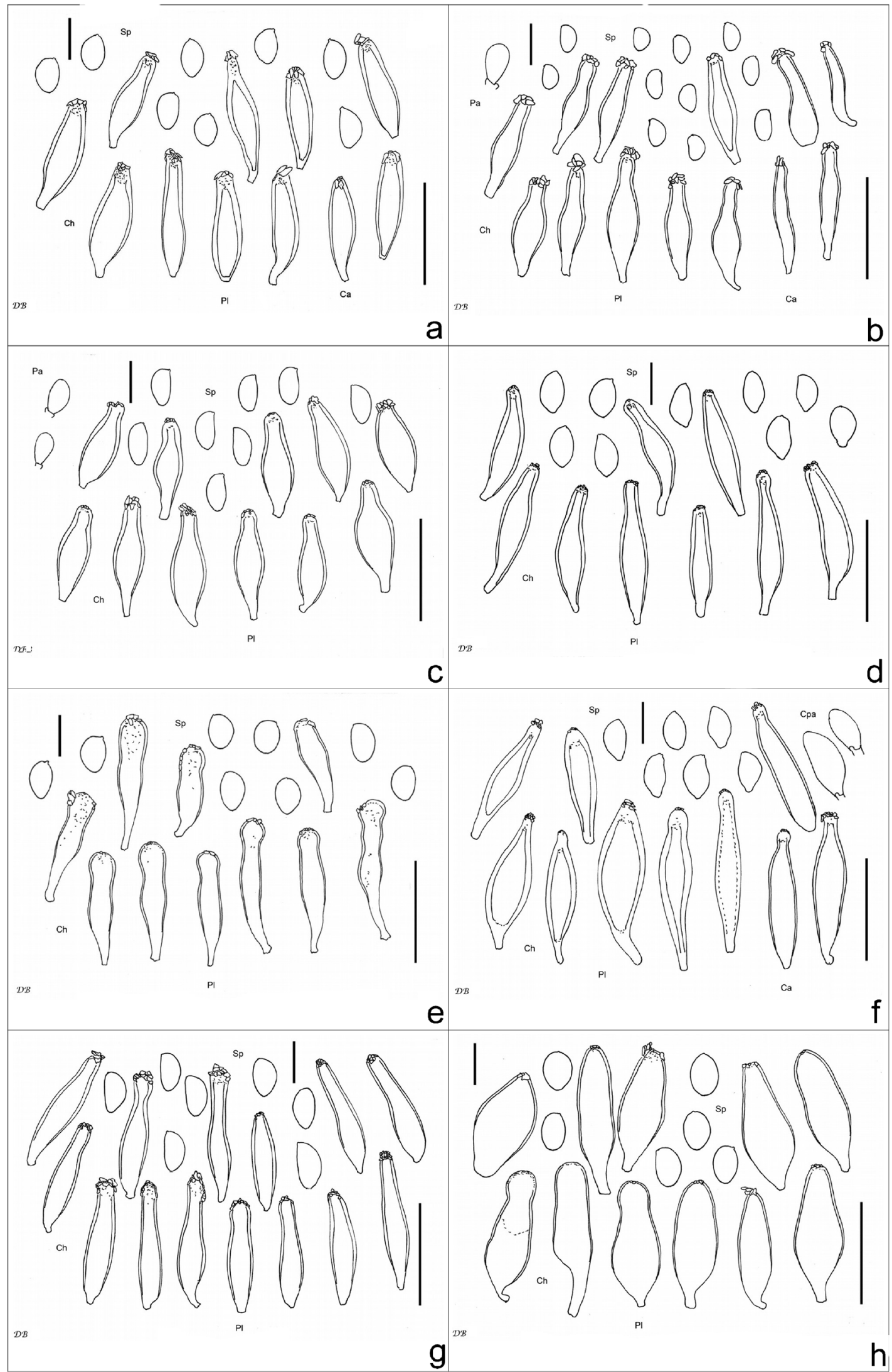

Fig. 25 Microscopic characters of type collections. a Inocybe metrodii (PRM-756354). b I. minimispora (G-00126998). c I. miranda (XC20122). d I. obscurella (XC2003-59). e I. obscurobadia (G-00126141). f I. obscuroides (K(M)-97307). g I. obscuromellea (G00052210). h

I. olivaceobrunnea $(\mathrm{G}-00126151) . \mathrm{Ca}=$ Caulocystidia, $\mathrm{Cpa}=$ Cauloparacystidia, $\mathrm{Ch}=$ Cheilocystidia, $\mathrm{Pa}=$ Paracystidia, $\mathrm{Pl}=$ Pleurocystidia, $\mathrm{Sp}=$ Spores; scale bar spores: $10 \mu \mathrm{m}$, scale bar cystidia: $50 \mu \mathrm{m}$ 


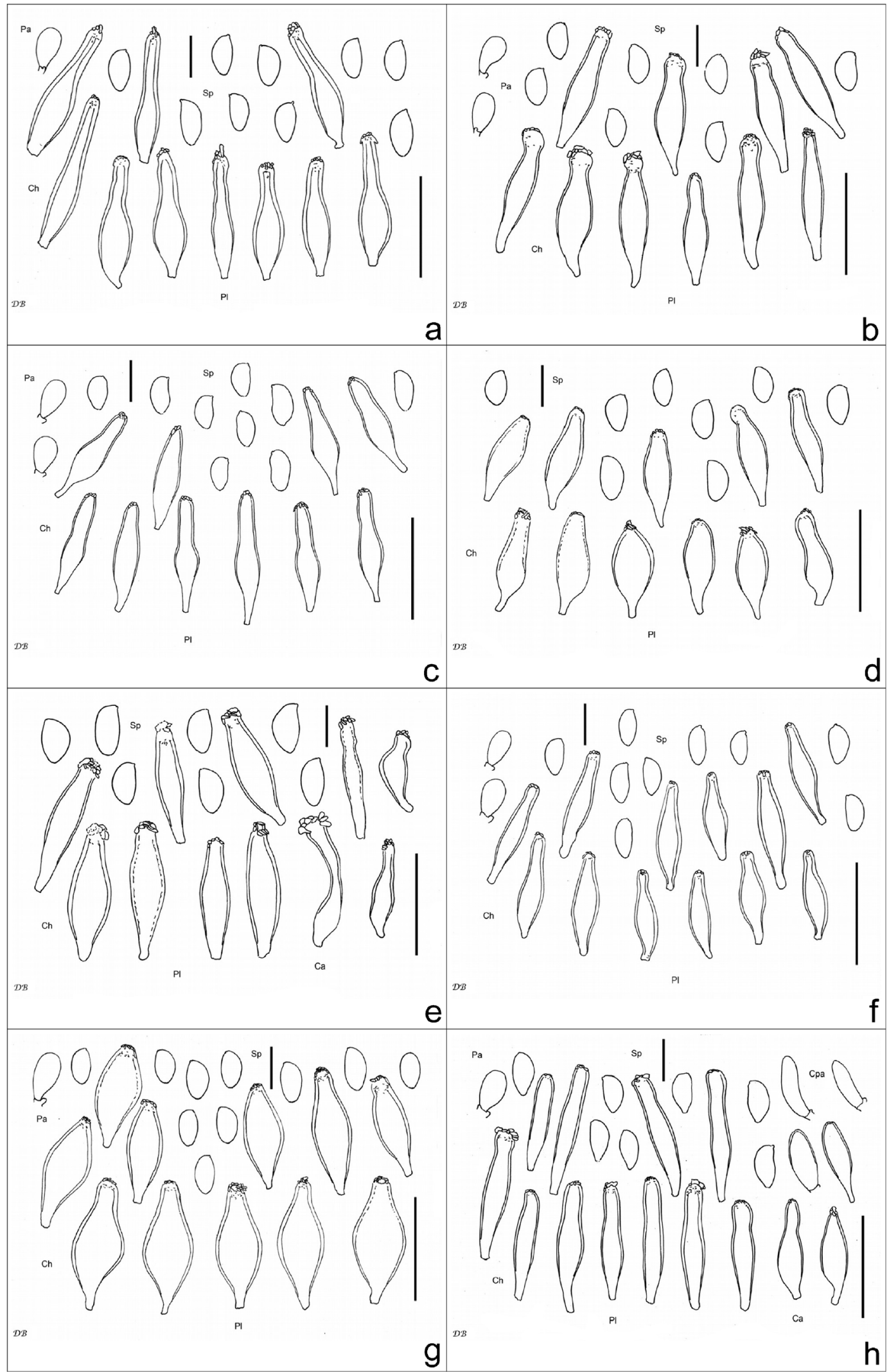

Fig. 26 Microscopic characters of type collections. a Inocybe patibilis

(Tr-gmb-00980). Ca = Caulocystidia, $\mathrm{Cpa}=$ Cauloparacystidia, $\mathrm{Ch}=$ (PR1208). b I. personata (G-00126459). c I. petroselinolens (XC2001Cheilocystidia, $\mathrm{Pa}=$ Paracystidia, $\mathrm{Pl}=$ Pleurocystidia, $\mathrm{Sp}=$ Spores; scale bar sp ores: $10 \mu \mathrm{m}$, scale bar cystidia: $50 \mu \mathrm{m}$ 


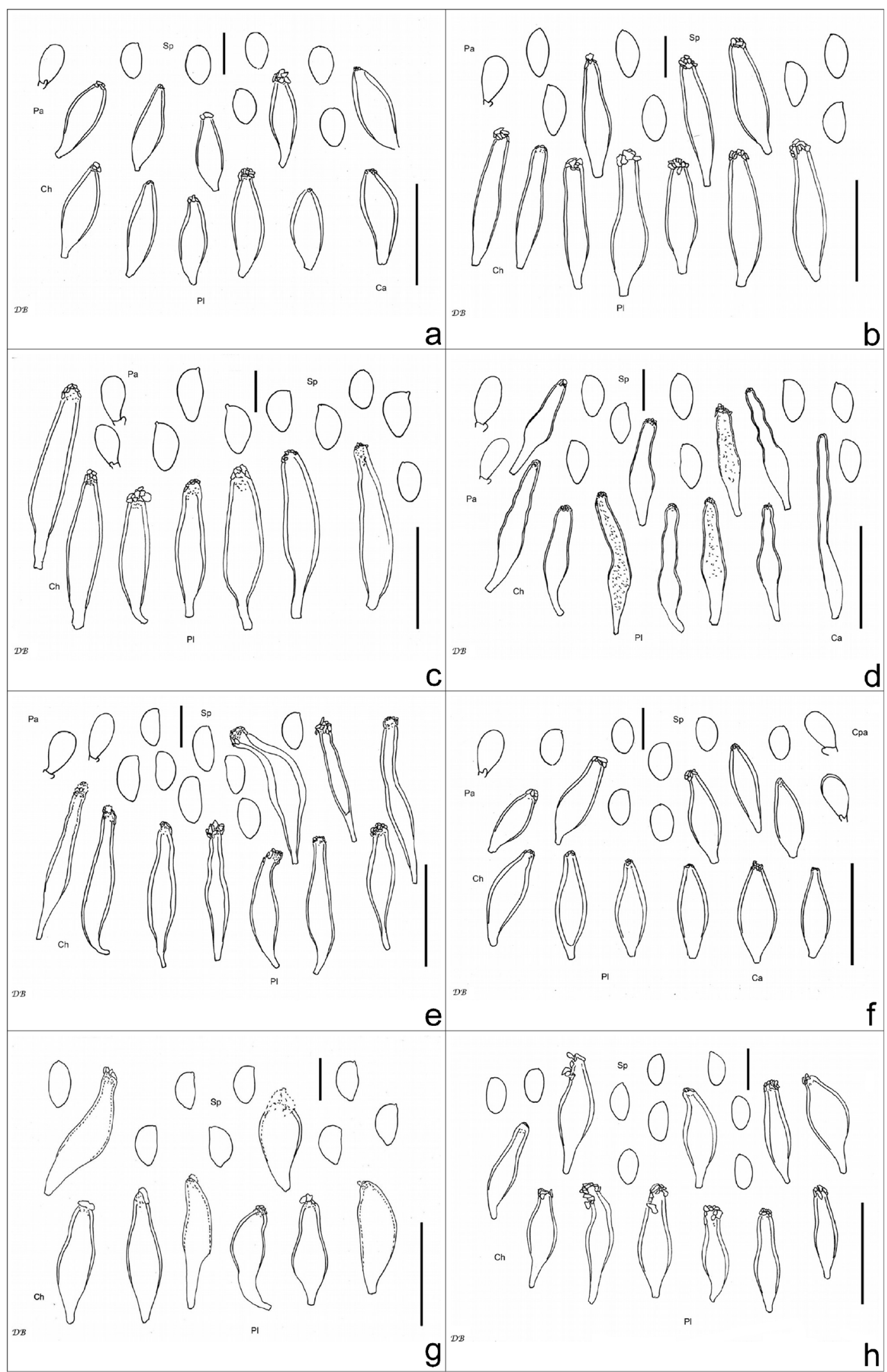

Fig. 27 Microscopic characters of type collections. a Inocybe subporospora. ((L-4370261). b I. subvirgata (PR1068). c I. tarda (G00058745). d I. tenuicystidiata (M_M-0281792). e I. tigrinella (XC2010-47). f I. tjallingiorum (L-0053540). g I. virgatula

(G00058741). h I. xantholeuca (L-4370262). Ca = Caulocystidia, Cpa = Cauloparacystidia, $\mathrm{Ch}=$ Cheilocystidia, $\mathrm{Pa}=$ Paracystidia, $\mathrm{Pl}=$ Pleurocystidia, $\mathrm{Sp}=$ Spores; scale bar spores: $10 \mu \mathrm{m}$, scale bar cystidia: $50 \mu \mathrm{m}$ 
1997). Inocybe beatifica is one of several species, such as I. furfurea (Bandini et al. 2019b), the stipes of which seem to be pruinose only in the upper part of the stipe but in fact are entirely pruinose, but only (very) sparely so in the lower half. These species should therefore be keyed out in both groups.

Acknowledgements We are grateful to the curators Philippe Clerc $(\mathrm{G})$, Michael Thalinger (IB/IBF), Angela Bond (K), Markus Scholler (KR), Nicolien Sol (L), Régis Courtecuisse (LIP), Dagmar Triebel (M), Raffaella Trabucco (MCVE), Caroline Loup (MPU), Ondřej Koukol (PRC), Jan Holec (PRM), Marco Floriani (TR) and Reinhardt Berndt (Z/ZT) for the loan of specimens in their keeping. We are particularly thankful to Holger Thüs (STU) for handling the numerous loans for us. We greatly appreciate the help of Konstanze Bensch with all kinds of questions around types and taxa. We would furthermore like to express our gratitude to Jukka Vauras and the herbarium TUR-A for the gift of several specimens, to Xavier Carteret and Patrick Reumaux for the gift of small pieces of several isotypes. We are also grateful to Thom Kuyper for information about a collection of $I$. bellidiana. We would furthermore like to express our gratitude to Giovanni Bandini, Inge Baas-Lenis Bejarano, Enrico Bizio, Zoltán Bratek, Rob Chrispijn, Josef Christan, Mihály Csizmár, Bálint Dima, Matthias Dondl, Fernando Esteve-Raventós, Bernd Fellmann, Reinhard Geiter, Bettina Haberl, Ellen and Henk Huijser, Peter Karasch, Lothar Krieglsteiner, Julia Kruse, Lutz Quecke, Jukka Vauras, Frank Venzlaff, Manuel Wallesch and Gerhard Wölfel for providing us with fresh collections or specimens or for other help. We thank Martin Bemmann for technical and other help. Many thanks also to the reviewers for their improvements of the manuscript. The German Barcode of Life (GBOL) project, supported by the German Federal Ministry of Education and Research (BMBF FKZ 01LI15011) as research for sustainable development (FONA; http://www.fona.de), contributed to the molecular work of U.E. We also appreciate the support of the Staatliches Museum für Naturkunde Stuttgart for molecular research on STU collections.

Author contribution D. B. and B. O. collected the great majority of the fresh collections treated here; D. B. did the morphological analyses and assembled the descriptions; U. E. did the molecular analyses; B. O. analysed relationships through BLAST searches; all authors contributed to the conception and writing of the manuscript.

Funding Open access funding enabled and organized by Projekt DEAL. Funding was provided by the German Barcode of Life (GBOL), by the Staatliches Museum of Naturkunde Stuttgart and privately by the authors.

Data Availability Sequence data are deposited in GenBank. The majority of the collections treated here has been deposited in public collections. Types have been deposited in public collections, with the exception of material (isotypes) supplied to the authors by collectors named below; in these cases, holotypes have normally been deposited in public collections at the time of publication of the respective names.

\section{Declarations}

Competing interests The authors declare no competing interests.

Open Access This article is licensed under a Creative Commons Attribution 4.0 International License, which permits use, sharing, adaptation, distribution and reproduction in any medium or format, as long as you give appropriate credit to the original author(s) and the source, provide a link to the Creative Commons licence, and indicate if changes were made. The images or other third party material in this article are included in the article's Creative Commons licence, unless indicated otherwise in a credit line to the material. If material is not included in the article's Creative Commons licence and your intended use is not permitted by statutory regulation or exceeds the permitted use, you will need to obtain permission directly from the copyright holder. To view a copy of this licence, visit http://creativecommons.org/licenses/by/4.0/.

\section{References}

Alessio CL (1989) Complemento allo studio del genere Inocybe, 10. contributo (con documenti e critiche bibliografiche). Micol Ital 18(2):3-20

Alessio CL (1997) Complemento allo studio del genere Inocybe, 20. contributo. Micol Ital 26(1):37-44

Altschul SF, Gish W, Miller W, Myers EW, Lipman DJ (1990) Basic local alignment search tool. J Mol Biol 215:403-410. https://doi. org/10.1016/S0022-2836(05)80360-2

Arraiano-Castilho R, Bidartondo MI, Niskanen T, Clarkson JJ, Brunner I, Zimmermann S, Senn-Irlet B, Frey B, Peintner U, Mrak T, Suz LM (2021) Habitat specialisation controls ectomycorrhizal fungi above the treeline in the European Alps. New Phytol 229:2901-2916. https://doi.org/10.1111/nph.17033

Atkinson GF (1918) Some new species of Inocybe. Am J Bot 5:210-218

Ayres DL, Darling A, Zwickl DJ, Beerli P, Holder MT, Lewis PO, Huelsenbeck JP, Ronquist F, Swofford DL, Cummings MP, Rambaut A, Suchard MA (2012) BEAGLE: an application programming interface for statistical phylogenetics. Syst Biol 61:170 173. https://doi.org/10.1093/sysbio/syr100

Bahram M, Polme S, Koljalg U, Zarre S, Tedersoo L (2012) Regional and local patterns of ectomycorrhizal fungal diversity and community structure along an altitudinal gradient in the Hyrcanian forests of northern Iran. New Phytol 193(2):465-473. https://doi.org/10. 1111/j.1469-8137.2011.03927.x

Bahram M, Koljalg U, Kohout P, Mirshahvaladi S, Tedersoo L (2013) Ectomycorrhizal fungi of exotic pine plantations in relation to native host trees in Iran: evidence of host range expansion by local symbionts to distantly related host taxa. Mycorrhiza 23(1):11-19. https:// doi.org/10.1007/s00572-012-0445-Z

Bandini D (2014) Zusammenfassung der Inocybe-Funde während der siebten Bayerischen Mykologischen Tagung. Mycol Bavar 15:3336

Bandini D, Huijser H (2017) Vezelkoppen (Inocybe) van Ameland, Inocybe griseotarda (Poirier). Coolia 60(4):243-247

Bandini D, Christan J, Eberhardt U, Ploch S, Tahir A, Oertel B, Thines M (2017) Inocybe sphagnophila sp. nov., eine neue Art der höckersporigen Untersektion Napipedinae der Gattung Inocybe (Agaricales). Mycol Bavar 18:11-34

Bandini D, Oertel B, Moreau P-A, Thines M, Ploch S (2019a) Three new hygrophilous species of Inocybe, subgenus Inocybe. Mycol Prog 18: 1101-1119

Bandini D, Oertel B, Ploch S, Ali T, Vauras J, Schneider A, Scholler M, Eberhardt U, Thines M (2019b) Revision of some central European species of Inocybe (Fr. : Fr.) Fr. subgenus Inocybe, with the description of five new species. Mycol Prog 18:247-294. https://doi.org/10. 1007/s11557-018-1439-9

Bandini D, Oertel B, Ploch S, Thines M (2019c) Inocybe heidelbergensis, eine neue Risspilz-Art der Untergattung Inocybe. Z Mykol 85(2): 195-213

Bandini D, Oertel B, Schüßler C, Eberhardt E (2020a) Noch mehr Risspilze: Fünfzehn neue und zwei wenig bekannte Arten der Gattung Inocybe. Mycol Bavar 20:13-101 
Bandini D, Sesli E, Oertel B, Krisai-Greilhuber I (2020b) Inocybe antoniniana, a new species of Inocybe section Marginatae with nodulose spores. Sydowia 72:95-106. https://doi.org/10.12905/ 0380.sydowia72-2020-0095

Bandini D, Vauras J, Weholt Ø, Oertel B, Eberhardt U (2020c) Inocybe woglindeana, a new species of the genus Inocybe, thriving in exposed habitats with calcareous sandy soil. Karstenia 58:41-56

Berkeley MJ, Broome CE (1873) Notices of British Fungi. Ann Mag Nat Hist (Ser 4) 11:339-349

Bizio E, Ferisin G, Dovana F (2016) Inocybe costinitii. A new species from the Istrian coast. Micol Veg Mediterr 31(2):95-102

Bizio E, Ferisin G, Dovana F (2017) Note sul campo di variabilità di Inocybe griseotarda. Riv di Micol 60(1):59-70

Bogar LM, Dickie IA, Kennedy PG (2015) Testing the co-invasion hypothesis: ectomycorrhizal fungal communities on Alnus glutinosa and Salix fragilis in New Zealand. Divers Distrib 21:268-278. https://doi.org/10.1111/ddi.12304

Bon M (1990) Flore mycologique du littoral - 05 - Inocybe. Doc Mycol 20(78):61-66

Bon M (1997) Clé monographique du genre Inocybe (Fr.) Fr. (2ème partie). Doc Mycol 27(108):1-77

Bon M (1998) Clé monographique du genre Inocybe (Fr.) Fr. (3ème partie). Doc Mycol 28(111):1-45

Braaten CC, Matheny PB, Viess DL, Wood MG, Williams JH, Bougher NL (2014) Two new species of Inocybe from Australia and North America that include novel secotioid forms. Botany 92:9-22

Branco S, Ree RH (2010) Serpentine soils do not limit mycorrhizal fungal diversity. PLoS One 5(7):E11757. https://doi.org/10.1371/journal. pone. 0011757

Breitenbach J, Kränzlin F (2000) Pilze der Schweiz 5 Mykologia Luzern

Bresadola G (1905) Hymenomycetes novi vel minus cogniti. Ann Mycol 3(2):159-164

Britzelmayr M (1891) Hymenomyceten aus Südbayern 10/VII. R. Friedländer \& Sohn Berlin

Bulliard P (1788-1792) Histoire des Champignons de la France. Paris

Buscardo E, Freitas H, Pereira JS, De Angelis P (2011) Common environmental factors explain both ectomycorrhizal species diversity and pine regeneration variability in a post-fire Mediterranean forest. Mycorrhiza 21(6):549-558. https://doi.org/10.1007/s00572-0110363-5

Carteret X, Reumaux P (2017) Miettes sur les Inocybes ( $8^{\mathrm{e}}$ série). Inocybes jaunes ou jaunâtres. Bull Soc mycol Fr 131(1-2):1-96

Carteret X, Reumaux P (2001) Briciole' sulle Inocybe. Boll Gr Micol G. Bresadola 44(3): 15-38

Carteret X, Reumaux P (2012) Miettes sur les Inocybes ( 6 e série). Étude de quelques nains de feuillus de la plaine, accompagnée d'une clé de détermination des taxons de la séction Lilacinae R. Heim. Bull Soc mycol Fr 127:1-53

Carteret X, Reumaux P (2013) Miettes sur les Inocybes ( $7^{\mathrm{e}}$ série). Variations sur le thème d'Inocybe geophylla et d'Inocybe phaeodisca. Cah FMBDS 2:1-59

Cripps C, Eberhardt U, Schütz N, Beker HJ, Evenson VS, Horak E (2019a) The genus Hebeloma in the Rocky Mountain alpine zone. MycoKeys 46:1-54

Cripps CL, Larsson E, Vauras J (2019b) Nodulose-spored Inocybe from the Rocky Mountain alpine zone molecularly linked to European and type specimens. Mycologia 112:133-153. https://doi.org/10. 1080/00275514.2019.1677419

Crous PW, Shivas RG, Quaedvlieg W, van der Bank M, Zhang Y, Summerell BA, Guarro J, Wingfield MJ, Wood AR, Alfenas AC, Braun U, Cano-Lira JF, García D, Marin-Felix Y, Alvarado P, Andrade JP, Armengol J, Assefa A, den Breeÿen A, Camele I, Cheewangkoon R, De Souza JT, Duong TA, Esteve-Raventós F, Fournier J, Frisullo S, García-Jiménez J, Gardiennet A, Gené J, Hernández-Restrepo M, Hirooka Y, Hospenthal DR, King A, Lechat C, Lombard L, Mang SM, Marbach PA, Marincowitz S,
Marin-Felix Y, Montaño-Mata NJ, Moreno G, Perez CA, Pérez Sierra AM, Robertson JL, Roux J, Rubio E, Schumacher RK, Stchigel AM, Sutton DA, Tan YP, Thompson EH, van der Linde E, Walker AK, Walker DM, Wickes BL, Wong PT, Groenewald JZ (2014) Fungal Planet description sheets: 214-280. Persoonia 32: 184-306. https://doi.org/10.3767/003158514X682395

Dovana F, Bizio E, Garbelotto M, Ferisin G (2021) Inocybe cervenianensis (Agaricales, Inocybaceae), a new species in the I. flavoalbida clade from Italy. Phytotaxa 484(2):227-236

Esteve-Raventós F, Moreno G, Bizio E, Alvarado P (2015) Inocybe flavobrunnescens, a new species in section Marginatae. Mycol Prog 14:1-12. https://doi.org/10.1007/s11557-015-1036-0

Esteve-Raventós F, Moreno G, Alvarado P, Olariaga I (2016) Unraveling the Inocybe praetervisa group through type studies and ITS data: Inocybe praetervisoides sp. nov. from the Mediterranean region. Mycologia 108:123-134

Esteve-Raventós F, Bandini D, Oertel B, González V, Moreno G, Olariaga I (2018) Advances in the knowledge of the Inocybe mixtilis group (Inocybaceae, Agaricomycetes), through molecular and morphological studies. Persoonia 41:213-236. https://doi.org/10.3767/ persoonia.2018.41.11

Fan Y, Bau T (2010) A revised checklist of the Genus Inocybe (Fr.) Fr. in China. J Fungal Res 8(4):189-193

Fan Y, Bau T (2013) Two striking Inocybe species from Yunnan Province, China. Mycotaxon 123(1):169-181

Fan Y, Bau T (2020) Two new smooth-spored species of Inocybe (Inocybaceae, Agaricales) from Gansu Province, northwestern China. Mycosystema 39(9):1694-1705

Fan Y, Wu RH, Bau T (2018) Two new species and eight newly recorded species of Inocybe subg. Inocybe from China. J Fungal Res 16(2): $70-83$

Favre J (1955) Les champignons supérieurs de la zone alpine du parc national Suisse. Ergebnisse der wissenschaftlichen Untersuchungen des schweizerischen Nationalparks NF 5:1-212

Favre J (1960) Catalogue descriptif des champignons supérieurs de la zone subalpine du parc national Suisse. Ergebnisse der wissenschaftlichen Untersuchungen des schweizerischen Nationalparks NF 6:323-610

Ferrari E (2006) Inocybe alpine e subalpine (Fungi non delineati 34/35/ 36). Candusso, Alassio

Ferrari E (2010) Inocybe dai litorali alla zona alpina (Fungi non delineati 54/55). Edizioni Candusso, Alassio

Franchi P, Marchetti M, Papetti C (2016) Inocybe tiliae, una nuova specie della Sezione Marginatae. Riv Micol 59(2):99-121

Furrer-Ziogas C (1952) Beitrag zur Inocybe-Bestimmung. Schweiz Z Pilzkd 30(11):173-180

Gardes M, Bruns TD (1993) ITS primers with enhanced specificity for Basidiomycetes - application to the identification of mycorrhizae and rusts. Mol Ecol 2:113-118. https://doi.org/10.1111/j.1365294X.1993.tb00005.x

Grund DW, Stuntz DE (1968) Nova Scotian Inocybes. I Mycologia 60: 406-425

Grund DW, Stuntz DE (1975) Nova Scotian Inocybes. III Mycologia 67: 19-31

Grund DW, Stuntz DE (1977) Nova Scotian Inocybes. IV Mycologia 69: 392-408

Grund DW, Stuntz DE (1981) Nova Scotian Inocybes. VI Mycologia 73: 655-674

Heim R (1931) Le genre Inocybe (Encyclopédie Mycologique). Lechevalier, Paris

Herink J (1954) Vláknice safránová - Inocybe crocifolia sp. n. Česká Mykol 8:121-124

Hoang DT, Chernomor O, von Haeseler A, Minh BQ, Vinh LS (2018) UFBoot2: improving the ultrafast bootstrap approximation. Mol Biol Evol 35:518-522. https://doi.org/10.1093/molbev/msx281 
Holmgren PK, Holmgren NH, Barnett LC (1990) Index Herbariorum, 8th edn. Botanic Garden, New York

Horak E (2018) The Fungi of Australia 6. Agaricales (Basidiomycota) of New Zealand 2. Brown Spored Genera. Westerdijk Biodiversity Series 16, Westerdijk Institute, Utrecht

Horak E, Stangl J (1980) Notizen zur Taxonomie und Verbreitung von Inocybe leptocystis. Sydowia 33:145-151

Horak E, Matheny PB, Desjardin DE, Soytong K (2015) The genus Inocybe (Inocybaceae, Agaricales, Basidiomycota) in Thailand and Malaysia. Phytotaxa 230:201-238

Iotti M, Marchetti M, Bonuso E, Zambonelli A (2005) Morphological and molecular characterization of the mycorrhizas of Inocybe rufuloides and I. splendens. Mycotaxon 94:75-84

Iotti M, Lancellotti E, Hall I, Zambonelli A (2010) The ectomycorrhizal community in natural Tuber borchii grounds. FEMS Microbiol Ecol 72:250-260. https://doi.org/10.1111/j.1574-6941.2010.00844.x

Kałucka I, Jagodziński A, Nowiński M (2016) Biodiversity of ectomycorrhizal fungi in surface mine spoil restoration stands in Poland - first time recorded, rare, and red-listed species. Acta Mycol 51(2):1-36. https://doi.org/10.5586/am.1080

Kalyaanamoorthy S, Minh BQ, Wong TKF, von Haeseler A, Jermiin LS (2017) ModelFinder: fast model selection for accurate phylogenetic estimates. Nat Methods 14:587-589. https://doi.org/10.1038/nmeth. 4285

Karsten PA (1879) Rysslands, Finlands och den Skandinaviska halföns Hattsvampar Förra Delen. Skifsvampar Bidrag till Kännedom av Finlands Natur och Folk 32:1-571

Karsten PA (1889) Kritisk öfverisgt af Finlands Basidsvampar (Basidiomycetes; Gastero- \& Hymenomycetes). Bidr Kännedom Finl Nat Folk 48:1-470

Katoh K, Kuma K, Toh H, Miyata T (2005) MAFFT version 5: improvement in accuracy of multiple sequence alignment. Nucleic Acids Res 33:511-518. https://doi.org/10.1093/nar/gki198

Katoh K, Rozewicki J, Yamada KD (2019) MAFFT online service: multiple sequence alignment, interactive sequence choice and visualization. Brief Bioinform 20:1160-1166. https://doi.org/10.1093/bib/ bbx 108

Kauffman CH (1924) Inocybe (Fries) Quél. North Am Flora 10(4):227260

Kjøller R (2006) Disproportionate abundance between ectomycorrhizal root tips and their associated mycelia. FEMS Microbiol Ecol 58(2): 214-224. https://doi.org/10.1111/j.1574-6941.2006.00166.x

Kokkonen K, Vauras J (2012) Eleven new boreal species of Inocybe with nodulose spores. Mycol Prog 11:299-341

Kõljalg U, Larsson K-H, Abarenkov K, Nilsson RH, Alexander IJ, Eberhardt U, Erland S, Høiland K, Kjøller R, Larsson E, Pennanen T, Sen R, Taylor AF, Tedersoo L, Vralstad T, Ursing BM (2005) UNITE: a database providing web-based methods for the molecular identification of ectomycorrhizal fungi. New Phytol 166:10631068. https://doi.org/10.1111/j.1469-8137.2005.01376.x

Kranabetter JM, Friesen J, Gamiet S, Kroeger P (2009) Epigeous fruiting bodies of ectomycorrhizal fungi as indicators of soil fertility and associated nitrogen status of boreal forests. Mycorrhiza 19(8):535548. https://doi.org/10.1007/s00572-009-0255-0

Kropp BR, Matheny PB, Nanagyulyan SG (2010) Phylogenetic taxonomy of the Inocybe splendens group and evolution of supersection "Marginatae". Mycologia 102:560-573

Kühner R (1955) Compléments a la "Flore analytique" V. Inocybes léiosporés cystidiés. Espèces nouvelles ou critiques. Bull Soc Nat Oyonnax 9:3-95

Kummer P (1871) Der Führer in die Pilzkunde. Anleitung zum methodischen, leichten und sichern Bestimmen der in Deutschland vorkommenden Pilze. Verlag von E. Luppe's Buchhandlung, Zerbst

Kuyper TW (1985) Studies in Inocybe. I Revision of the new taxa of Inocybe described by Velenovský Persoonia 12:375-400
Kuyper TW (1986) A revision of the genus Inocybe in Europe I Subgenus Inosperma and the smooth-spored species of subgenus Inocybe Persoonia Suppl:3

Kuyper TW (1989) Studien in Inocybe IV. Z Mykol 55:111-114

La Rosa A, Bizio E, Saitta A, Tedersoo L (2017) Inocybe castaneicolor (Agaricales, Basidiomycota), a new species in section Splendentes. Phytotaxa 316(1):79-87. https://doi.org/10.11646/phytotaxa.316.1.

Lainé P (2014) Quelques inocybes hors des sentiers battus II. Bull Soc mycol Fr 130(1-2):21-38

Lancellotti E, Franceschini A (2013) Studies on the ectomycorrhizal community in a declining Quercus suber L. stand. Mycorrhiza 23:533542. https://doi.org/10.1007/s00572-013-0493-z

Lange JE (1917) Studies in the Agarics of Denmark. III. Pluteus, Collybia, Inocybe. Dansk bot Ark 2(7):1-50

Larsson A (2014) AliView: a fast and lightweight alignment viewer and editor for large data sets. Bioinform 30:3276-3278. https://doi.org/ 10.1093/bioinformatics/btu531

Larsson E, Vauras J, Cripps CL (2014) Inocybe leiocephala, a species with an intercontinental distribution range - disentangling the I. leiocephala - subbrunnea - catalaunica morphological species complex. Karstenia 54:15-39

Larsson E, Vauras J, Cripps CL (2018a) Inocybe lemmi, a new species of section Marginatae from the alpine region of Sweden. Karstenia 57: $1-9$

Larsson E, Vauras J, Cripps CL (2018b) Inocybe praetervisa group - a clade of four closely related species with partly different geographical distribution ranges in Europe. Mycoscience 59(4):277-287. https://doi.org/10.1016/j.myc.2017.11.002

Latha KPD, Manimohan P (2017) Inocybe griseorubida, a new species of Pseudosperma clade from tropical India. Phytotaxa 221(2):166-174

Latha KPD, Manimohan P, Matheny PB (2016) A new species of Inocybe representing the Nothocybe lineage. Phytotaxa 267(1):40 50

LoBuglio KF, Rogers SO, Wang CJK (1991) Variation in ribosomal DNA among isolates of the mycorrhizal fungus Cenococcum geophilum. Can J Bot 69:2331-2343. https://doi.org/10.1139/b91294

Long D, Liu J, Han Q, Wang X, Huang J (2016) Ectomycorrhizal fungal communities associated with Populus simonii and Pinus tabuliformis in the hilly-gully region of the Loess Plateau, China. Sci Rep 6:24336. https://doi.org/10.1038/srep24336

Ludwig E (2017) Pilzkompendium 4 (parts 1 \& 2). Fungicon Berlin

Marchetti M, Franchi P, Consiglio G (2014) Tipificatione di alcune Inocybe di Britzelmayr. Riv Micol 57(2):127-178

Matheny B (2009) A phylogenetic classification of the Inocybaceae. McIlvainea 18:11-21

Matheny PB, Bougher NL (2017) Fungi of Australia, Inocybaceae. ABRS \& CSIRO Publishing Canberra \& Melbourne

Matheny PB, Kudzma LV (2019) New species of Inocybe (Inocybaceae) from eastern North America 1. J Torrey Bot Soc 146(3):213-235

Matheny PB, Swenie RA (2018) The Inocybe geophylla group in North America: a revision of the lilac species surrounding I. lilacina. Mycologia 110:618-634. https://doi.org/10.1080/00275514.2018. 1469880

Matheny PB, Liu YJ, Ammirati JF, Hall BD (2002) Using RPB1 sequences to improve phylogenetic inference among mushrooms (Inocybe, Agaricales). Am J Bot 89:688-698

Matheny PB, Aime MC, Bougher NL, Buyck B, Desjardin DE, Horak E, Kropp BR, Lodge DJ, Soytong K, Trappe JM, Hibbett DS (2009) Out of the Palaeotropics? Historical biogeography and diversification of the cosmopolitan ectomycorrhizal mushroom family Inocybaceae. J Biogeogr 36:577-592. https://doi.org/10.1111/j. 1365-2699.2008.02055.x 
Matheny PB, Hobbs AM, Esteve-Raventós F (2020) Genera of Inocybaceae: new skin for the old ceremony. Mycologia 112(1): 83-120. https://doi.org/10.1080/00275514.2019.1668906

Mešić A, Haelewaters D, Tkalčec Z, Liu J, Kušan IM, Aime MC, Pošta A (2021) Inocybe brijunica sp. nov., a new ectomycorrhizal fungus from Mediterranean Croatia revealed by morphology and multilocus phylogenetic analysis. J Fungi 7:199. https://doi.org/10.3390/ jof7030199

Miller MA, Pfeiffer W, Schwartz T (2010) Creating the CIPRES science gateway for inference of large phylogenetic trees. In: Xavier J (ed) 2010 Gateway Computing Environments Workshop (GCE). Proceedings of a meeting held 14 Nov 2010, New Orleans, Louisiana, USA. Institute of Electrical and Electronics Engineers (IEEE), Piscataway, New Jersey, US 1-8 https://doi.org/10.1109/ GCE.2010.5676129

Munsell O (2009) Soil Color Charts. X-Rite Grand Rapids MI

Napoli C, Mello A, Borra A, Vizzini A, Sourzat P, Bonfante P (2010) Tuber melanosporum, when dominant, affects fungal dynamics in truffle grounds. New Phytol 185(1):237-247

Nguyen LT, Schmidt HA, von Haeseler A, Minh BQ (2015) IQ-TREE: a fast and effective stochastic algorithm for estimating maximum likelihood phylogenies. Mol Biol Evol 32:268-274. https://doi.org/10. 1093/molbev/msu300

Orton PD (1960) New check list of British Agarics and Boleti, part III (keys to Crepidotus, Deconica, Flocculina, Hygrophorus, Naucoria, Pluteus and Volvaria). Trans Br Mycol Soc 43(2):159-439

Osmundson TW, Robert VA, Schoch CL, Baker LJ, Smith A, Robich G, Mizzan L, Garbelotto MM (2013) Filling gaps in biodiversity knowledge for macrofungi: contributions and assessment of an herbarium collection DNA barcode sequencing project. PLoS One 8(4): e62419. https://doi.org/10.1371/journal.pone.0062419

Peay KG, Garbelotto M, Bruns TD (2010) Evidence of dispersal limitation in soil microorganisms: isolation reduces species richness on mycorrhizal tree islands. Ecology 91:3631-3640. https://doi.org/10. $1890 / 09-2237.1$

Peck CH (1875) Report of the Botanist (1873). Annu Rep New York State Mus Nat Hist 27:73-116

Peck CH (1888) Report of the Botanist (1887). Annu Rep New York State Mus Nat Hist 41:51-122

Peck CH (1913) New species of fungi. Mycologia 5(2):67-71

Peintner U, Bougher NL, Castellano MA, Moncalvo JM, Moser MM, Trappe JM, Vilgalys R (2001) Multiple origins of sequestrate fungi related to Cortinarius (Cortinariaceae). Am J Bot 88(12):2168-2179

Poirier J (2002) Notes sur le genre Inocybe - 1. Doc Mycol 31(124):3-13

Poirier J (2012) Études dans le genre Inocybe - 2. Bull trimest fed mycol Dauphiné-Savoie 204-205:101-107

Poirier J (2016) Études dans le genre Inocybe - 3. Bull mycol bot Dauphiné-Savoie 223:53-63

Pozzi AC, Roy M, Nagati M, Schwob G, Manzi S, Gardes M, Moreau PA, Fernandez MP (2018) Patterns of diversity, endemism and specialization in the root symbiont communities of alder species on the island of Corsica. New Phytol 219:336-349. https://doi.org/10. 1111/nph.14996

Quélet L (1885) Quelques espèces critiques ou nouvelles de la Flore Mycologique de France. C r Assoc Fr Av Sci 13:277-286

Rambaut, A (2006-2018) FigTree. Tree figure drawing tool version 14.4, Institute of Evolutionary Biology, University of Edinburgh. Available from http://tree.bio.ed.ac.uk/ (accessed 20 Mar 2019)

Reumaux P (1986) Notes sur quatres Inocybes d'allure insignifiante - 1ère partie. Bull trimest fed mycol Dauphiné-Savoie 25(100):13-17

Reumaux P (2001) Miettes sur les Inocybes 4. Inocybes tigrés ou rimeux. Doc Mycol 31(121):3-21

Reumaux P, Poirier J, Moënne-Loccoz P (1988) Inocybe patibilis Reum. Bull Soc mycol Fr 103(4):Atlas no 248
Ricken A (1910-1915) Die Blätterpilze (Agaricaceae) Deutschlands und der angrenzenden Länder, besonders Österreichs und der Schweiz, 2 vols. Weigel, Leipzig

Ronquist F, Huelsenbeck JP, Teslenko M (2011) Draft MrBayes version 3.2 Manual: Tutorials and Model Summaries. http://mrbayes. sourceforge.net/mb3.2_manual.pdf (accessed 27 May 2019)

Ronquist F, Teslenko M, Van der Mark P, Ayres DL, Darling A, Höhna S, Larget B, Liu L, Sucharard MA, Huelsenbeck JP (2012) MrBayes 3.2: efficient Bayesian phylogenetic inference and model choice across a large model space. Syst Biol 61:539-542. https://doi.org/ 10.1093/sysbio/sys029

Ryberg M, Nilsson RH, Kristiansson E, Töpel M, Jacobsson S, Larsson E (2008) Mining metadata from unidentified ITS sequences in GenBank, a case study in Inocybe (Basidiomycota). BMC Evol Biol 8:50. https://doi.org/10.1186/1471-2148-8-50

Ryberg M, Larsson E, Jacobsson S (2010) An evolutionary perspective on morphological and ecological characters in the mushroom forming family Inocybaceae (Agaricomycotina, Fungi). Mol Phylogenet Evol 55:431-442

Saccardo PA (1887) Sylloge Hymenomycetum 1 Agaricineae. Sylloge Fungorum 5:1-1146

Saitta A, Anslan S, Bahram M, Brocca L, Tedersoo L (2018) Tree species identity and diversity drive fungal richness and community composition along an elevational gradient in a Mediterranean ecosystem. Mycorrhiza 28:39-47. https://doi.org/10.1007/s00572-017-0806-8

Schwöbel H, Stangl J (1982) Zwei neue Rißpilz-Arten, gefunden im Stadtgebiet von Karlsruhe. Carolinea 40:9-14

Singer R (1947) Champignons de la Catalogne. Espèces observées en 1934. Collect Bot 1(3):199-246

Stangl J (1983) Inocybe nitidiuscula (Britz.) Sacc., gültiger Name für Inocybe friesii Heim. Int J Mycol and Lichenol 1(2):161-168

Stangl J (1985) Inocybe xanthodisca Kühner 1955 ist Inocybe posterula (Britz. 1883) Saccardo 1887. Z Mykol 51:251-256

Stangl J (1989) Die Gattung Inocybe in Bayern. Hoppea 46:5-388

Stangl J, Glowinski H (1981) Zwei neue Arten der Gattung Inocybe aus dem Ostseeraum. Karstenia 21(1):26-30

Stangl J, Veselský J (1973) Zweiter Beitrag zur Kenntnis der selteneren Inocybe-Arten. Česká Mykol 27:11-25

Stangl J, Veselský J (1979) Inocybe metrodii sp. nov. Beiträge zur Kenntnis seltenerer Inocyben 16. Česká Mykol 33(4):220-224

Stangl J, Veselský J (1980) Inocybe lutescens Velenovský. Beiträge zur Kenntnis seltenerer Inocyben 18. Ceská Mykol 34(3):158-164

Suz LM, Barsoum N, Benham S, Dietrich H-P, Fetzer KD, Fischer R, García P, Gehrman J, Kristöfel F, Manninger M, Neagu S, Nicolas M, Oldenburger J, Raspe S, Sánchez G, Schröck HW, Schubert A, Verheyen K, Verstraeten A, Bidartondo MI (2014) Environmental drivers of ectomycorrhizal communities in Europe's temperate oak forests. Mol Ecol 23:5628-5644. https://doi.org/10.1111/mec. 12947

Suz LM, Kallow S, Reed K, Bidartondo MI, Barsoum N (2017) Pine mycorrhizal communities in pure and mixed pine-oak forests: abiotic environment trumps neighboring oak host effects. For Ecol and Management 406:370-380. https://doi.org/10.1016/j.foreco.2017. 09.030

Taschen E, Sauve M, Taudiere A, Parlade J, Selosse MA, Richard F (2015) Whose truffle is this? Distribution patterns of ectomycorrhizal fungal diversity in Tuber melanosporum brûlés developed in multi-host Mediterranean plant communities. Environ Microbiol 17(8):2747-2761. https://doi.org/10.1111/1462-2920. 12741

Tedersoo L, Suvi T, Larsson E, Kõljalg U (2006) Diversity and community structure of ectomycorrhizal fungi in a wooded meadow. Mycol Res 110(6):734-748. https://doi.org/10.1016/j.mycres.2006.04.007

Tedersoo L, Anslan S, Bahram M, Drenkhan R, Pritsch K, Buegger F, Padari A, Hagh-Doust N, Mikryukov V, Gohar D, Amiri R, Hiiesalu I, Lutter R, Rosenvald R, Rähn E, Adamson K, Drenkhan T, Tullus 
H, Jürimaa K, Sibul I, Otsing E, Põlme S, Metslaid M, Loit K, Agan A, Puusepp R, Varik I, Kõljalg U, Abarenkov K (2020) Regionalscale in-depth analysis of soil fungal diversity reveals strong $\mathrm{pH}$ and plant species effects in northern Europe. Front Microbiol 11:1953. https://doi.org/10.3389/fmicb.2020.01953

Timling I, Walker DA, Nusbaum C, Lennon NJ, Taylor DL (2014) Rich and cold: diversity, distribution and drivers of fungal communities in patterned-ground ecosystems of the North American Arctic. Mol Ecol 23:3258-3272. https://doi.org/10.1111/mec.12743

Trifinopoulos J, Nguyen L-T, von Haeseler A, Minh BQ (2016) W-IQTREE: a fast online phylogenetic tool for maximum likelihood analysis. Nucleic Acids Res 44(W1):W232-W235. https://doi.org/10. 1093/nar/gkw256

Vauras J, Larsson E (2016a) [2015] Inocybe caprimulgi and I. lacunarum, two new nodulose-spored species from Fennoscandia. Karstenia 55: $1-18$

Vauras J, Larsson E (2016b) Inocybe baltica and I. suecica, two new smooth-spored species from the Baltic Sea region. Karstenia 56: $13-26$

Vauras J, Larsson E (2020) First records of Inocybe melleiconica and I. pararubens for Northern Europe with a new variety from the alpine zone of the Scandinavian mountains. Karstenia 58(1):29-40. https:// doi.org/10.29204/ka.2020.487

Velenovský J (1920-1922) České Houby, Díl 1-5. České Botanické Společnosti, Praze

Vellinga EC (1988) Glossary. In: Bas C, Kuyper TW, Noordeloos, ME, Vellinga EC (eds), Flora Agaricina Neerlandica vol 1. A.A. Balkema, Rotterdam
Vilgalys R, Hester M (1990) Rapid genetic identification and mapping of enzymatically amplified ribosomal DNA from several Cryptococcus species. J Bacteriol 172:4238-4246. https://doi.org/10.1128/jb.172. 8.4238-4246.1990

Walbert K, Ramsfield TD, Ridgway HJ, Jones EE (2010) Ectomycorrhizal species associated with Pinus radiata in New Zealand including novel associations determined by molecular analysis. Mycorrhiza 20(3):209-215. https://doi.org/10.1007/s00572009-0277-7

White TJ, Bruns T, Lee S, Taylor J (1990) Amplification and direct sequencing of fungal ribosomal RNA genes for phylogenetics. In: Innis MA, Gelfand DH, Sninsky JJ, White TJ (eds) PCR Protocols: a guide to methods and applications. Academic Press, San Diego, CA 315-322

Wilson MJ, Certini G, Campbell CD, Anderson IC, Hillier S (2008) Does the preferential microbial colonisation of ferromagnesian minerals affect mineral weathering in soil? Naturwissenschaften 95(9):851858. https://doi.org/10.1007/s00114-008-0394-8

Wurzbacher C, Larsson E, Bengtsson-Palme J, Van den Wyngaert S, Svantesson S, Kristiansson E, Kagami M, Nilsson RH (2019) Introducing ribosomal tandem repeat barcoding for fungi. Mol Ecol Resour 19:118-127. https://doi.org/10.1111/1755-0998.12944

Yao QZ, Yan W, Zhao HY, Wei J (2017) Description and identification of Ostryopsis davidiana ectomycorrhizae in Inner Mongolia mountain forest of China. Österr Z Pilzk 26:17-25

Publisher's note Springer Nature remains neutral with regard to jurisdictional claims in published maps and institutional affiliations. 